\title{
Conversations from the Coalface: \\ Positive Asymmetry and the Culture of Silence that Surrounds the Pike River Mine Tragedy
}

\author{
by \\ Catriana Mulholland

\begin{abstract}
A thesis
submitted to the Victoria University of Wellington

in fulfilment of the requirements for the degree of

Doctor of Philosophy

in Social Policy
\end{abstract}

Victoria University of Wellington

2018 


\section{Abstract}

Charles Perrow (1999) once famously noted 'Where body counting replaces social and cultural values and excludes us from participating in decisions about the risks that a few have decided the many cannot do without, the issue is not risk, but power.' This dissertation explores positive asymmetry (Cerulo 2006) and the culture of silence that surrounds Pike River Mine disaster that killed 29 men on the West Coast of Aotearoa/New Zealand on 19 November 2010. This asymmetry involves habitual ways of thinking and behaving which increase the propensity to ignore an approaching worst case scenario in order to meet intended outcomes. Increasingly lauded in 'get rich quick' cultures, positive asymmetry can be lethal in mining and other hazardous workplaces where there is pressure to meet demands of the market that override pre-existing flaws in systems and culture, and it is often accompanied by practices of eclipsing (acts of banishing, physical seclusion, shunning) clouding (impressionism, shadowing) and recasting (rhetorical, prescriptive behaviours).

There is a culture of silence that accompanies this cognitive symmetry in relation to the case of Pike River Mine which existed from its early development and continues years after the fatalities in a culture of socially organised denial; which is one in which there is a collective distancing among individuals due to norms of emotion, conversation and attention (Norgaard 2011). What happened at Pike River Mine was not the result of an attention deficit model. There was plenty of information. The mine had some good safety systems. They were not utilised. So what was going on? 
In this thesis, I look to the James Reason Model of Accident Causation used before the Royal Commission of Inquiry into the disaster and argue that although this does well to describe risk and to illustrate accident causation as a failure of organizational systems, it cannot as a structural model possibly describe the cultural logic and power dynamics which lay beneath the competition driving decision-makers within these systems. Pike River Mine was a case of deliberate risk and hibernating beneath that risk was (and still can be) a base of unchecked power. It follows that any 'errortolerant' systems we design for safer workplaces will only work insofar as there is an 'error-intolerant culture' inside the industry. Pike River Mine was not an isolated incident and if we fail to look to the power that lay behind that deliberate risk taking, there will be more 'Pikes' to come. There exists a triple helix to this tragedy consisting of power, risk and asymmetry. In practising vigilance, we need to look to the junction of these three, for therein lies the perfect storm of conditions for future human tragedy and financial disaster in whichever industry chooses to practice it.

\section{Acknowledgements}

I am indebted to the many insights of my two inspiring supervisors, Dr Sandra Grey and Dr Benjamin Snyder; for their humour, wisdom, direction through the light and sometimes darker times of this academic and very human journey. It was a road less travelled. I definitely march to a different drum and your selfless time and care kept the flame going. Thank you. I wouldn't have lasted the marathon without you both.

I would also like to thank the staff of the School of Social and Cultural Studies at the Faculty of Humanities and Social Sciences, Victoria University of Wellington and especially for the calm and unwavering assistance of Suzanne Weaver who went out of her way to deal to any enquiry, often at a moment's notice. I would like to thank 
her colleagues and the new and welcoming Heather Day. Thank you to Dr Allison Kirkman and to La'Chelle Pretorius who welcomed me in on this journey and showed so much interest in what I was trying to do. Similarly, I would like to thank Linda Evans, Lynette Shum, Margaret Hurst of the Alexander Turnbull Library, Wellington and to the wonderful unnamed woman who spent so much time with me on the phone, January 2018 in relation to my enquiry to gain more reliable data relating to NZ workplace fatalities; only to find at the end of the call that she had lost her own two uncles within months of each other to workplace logging fatalities in 2017.

There are many wonderful people I wish to thank for their time, support and contribution to this dissertation. Your gift of moments or months of assistance, thought and opinion have been invaluable, Michael Alexander, Joel Allen, Dr Rod Alley, Hazel Armstrong, Chris Baker, Joy Baker, Peter Bayliss, Harry Bell, Paul Berry, Dr Lise Bird Chiborne, Hamish Bohannan, Greg Borichevsky, Dr Chris Bowden, Dr Kathleen Callaghan, Richard Carr, Mary Cordtz, Herman Cordtz, Nicholas Davidson, Dean Dunbar, Bobby Duncan, Peter Duncan, Tara Fisher, Tyne Gray, Geoff Infield, Alana Hamill, Noula Kazakos, Dr Allison Kirkman, Tony Kokshoorn, Harold Leask, Dr Rebbecca Lilley, Jim Luder, Tracey McCallum, Dr Chris McKeown, Bernie Monk, Kath Monk, Alan Monk, Olivia Monk, Valerie Mulholland, John Mulholland, Susan Mulholland, Tim Naylor, Jack O'Connor, Mandy O'Sullivan, Mark Parcell, Deb Potter, Lynne Provoost, Mary Pupich, Deb Richardson, Neville Rockhouse, John Saunders, Dr Charles Sedgwick, Richard Tacon, Dr Lizzie Towl, Maureen Truman. To the courage and bravery of Anna Osborne, Sonya Rockhouse, the Families and to the many people who contributed in so many ways and who chose to remain anonymous. You know who you are... Thank you for the many ways you breathed into life this growing Kete of Knowledge that we have all been weaving for so long, in the hope that,

Naku te rourou nau te rourou ka ora ai te iwi With your basket of knowledge and my basket of knowledge_ the people will live. 


\section{Table of Contents}

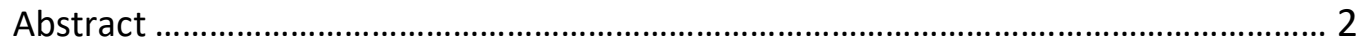

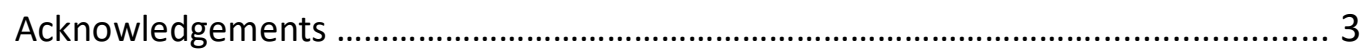

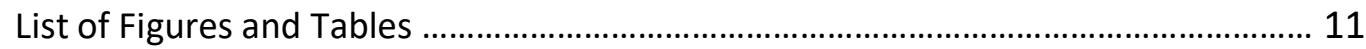

Positive Asymmetry: An introductory definition ...................................................... 12

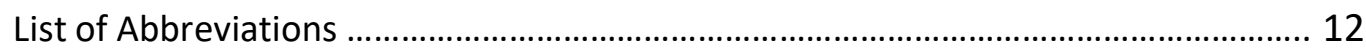

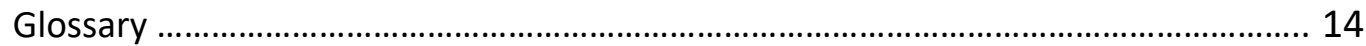

Chapter One: Introduction

(I) Introduction of Geographic and Historic Context ................................................ 22

(II) Snap Shot: Royal Commission of Inquiry on the Pike River Mine Tragedy 2012

Te Komihana a te Karauna mo te Parekura Ana Waor o te Awa O Pike, Vol.1 .......... 36

(III) Introduction to the Geology and Development of Pike River Mine .................... 38

Excerpts taken directly from the findings of the Royal Commission op. cit., include:

The Promise of Pike, Vol. 2, Chapter 3, pp. 32-33 and Overview: Vol. 1, pp. 16-22:

Conception, development, the company situation, Pike's vision, focus, governance of the board, management, the workforce, ventilation, methane management, electrical safety, hydro mining, the bonus system.

(IV) The tragedy: Photos of the 29 Men who died at Pike River Mine Royal Commission, Ibid, Vol. 1, P. 4-5; p.14

\section{Chapter Two: Literature Review}

(I) Disasters and the Social Construction of Risk - The Risk Society 53

(II) Neoliberalism - Risk and Power 
Historical Template of New Zealand Policy 66

(III) Positive Asymmetry and Risk (Karen Cerulo) 70

Eclipsing, Clouding, Recasting Practices 74

Eclipsing practices 74

Clouding practices 75
(a) Impressionism
(b) Shadowing

Recasting practices 77

(a) Rhetorical

(b) Prescriptive

(IV) An Introduction to Theorising Accident Causation 79

(V) Ontology, Epistemology, Methodology 85

Overview 95

Endnotes 98

\section{Chapter Three: Analysis (I)}

Extended Interpretation of the James Reason Model of Accident Causation ......... 111

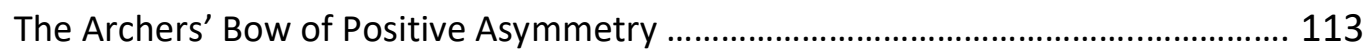

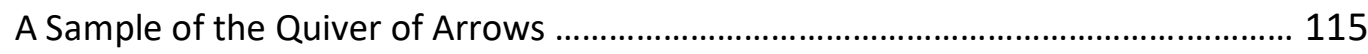

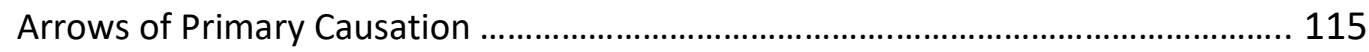

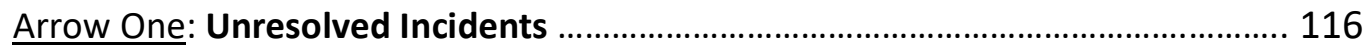


(i) Archer: CEO, board, management ................................................... 116

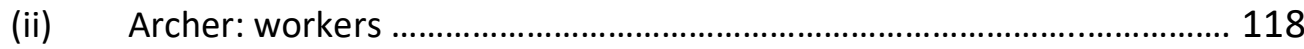

Arrow Two: New Technology and Hydro Mining ............................................... 122

(i) Archer: CEO, board, senior management ............................................ 123

Sample of Prior Warnings:

(a) Wishart Email (methane) ............................................................... 124

(b) Miles Brown (drainage) ................................................................. 127

(c) Masaoki Nishioka (hydro mining) .................................................... 128

(d) Van Rooyen (ventilation) ................................................................... 129

(e) Harry Bell (former Chief Inspector) ................................................ 131

The ‘Blame’ Culture at Pike: Acts of shunning, ignoring and shaming .................. 131

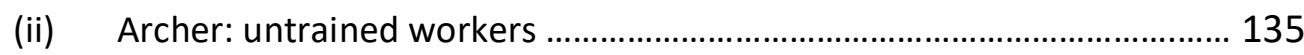

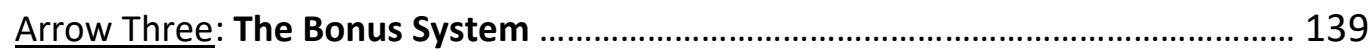

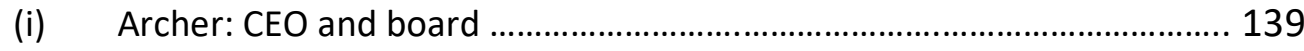

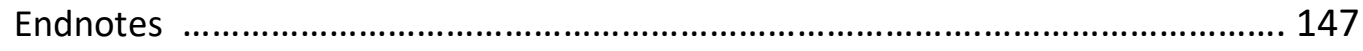

Chapter Four: Analysis (II)

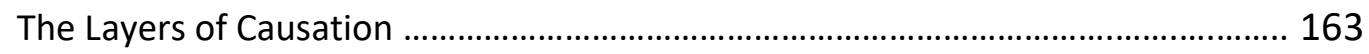

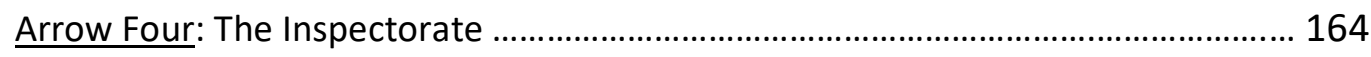

(i) Archer: The Department of Labour (DoL) ....................................... 167 
Chapter Five: Analysis (III)

Arrow Five: The Arrow of Production before Safety... 184

(i) Archer: The Board of Pike River Mine 185

(ii) Archer: The CEO and senior executives of Pike River Mine 193

Endnotes 202

Chapter Six: Discussion of Findings 212

Draft for Consultation Crimes (Corporate Manslaughter Act) Amendment Bill ...... 229

Revisiting the Model of Workplace Fatality Causation 235

Endnotes 245

Chapter Seven: Summary of Findings and Recommendations 258

For the Future

Cognitive Symmetry and those Directly Affected by Workplace Fatality 272

An Introduction to Recommendations 280

Recommendations 282

Endnotes 293 
(i) Photos of the Pike 29, Royal Commission of Inquiry on the Pike River Mine Tragedy NZ, Te Komihana a te Karauna mo te Parekura Ana Waro te Awa O Pike (2012), Vol.1 p. 4-5............................................................... 323

(ii) Location of the Mine Ibid, Vol.2, p. 31.................................................... 326

(iii) Original Map of Pike River Mine (Pike River Coal).................................. 327

(iv) Map of Pike River Mine op.cit., Vol.1 p. 10 (2012) ................................ 328

(v) Boundary restricted \& non-restricted zones Ibid, Vol.1 p.20 fig.2 ........ 329

(vi) Diagrammatic outline of hydro panel, Ibid, Vol.1, p.21, fig.3................ 329

(vii) Ventilation shaft \& alimak raise, ibid, Vol.2 p. 39, fig 3.7...................... 330

(viii) Typical elements of main ventilation shaft, ibid, Vol.2, p. 82, fig 8.1... 331

(ix) Orientation \& operation of underground fan, ibid, Vol.2, p. 93, 8.9.... 331

(x) Hydro panel \& cross-cut, ibid, Vol.2, p. 103, fig 8.16............................ 332

(xi) Location of the auxiliary fan, ibid, Vol.2, p. 105, fig 8.1..................... 332

(xii) Effects of roof fall on 30 October 2010, ibid, Vol. 2, p. 102, fig 8.15.... 333

(xiii) Last known position of men, Pike River Mine op. cit., Vol.2, p. 20....... 334

(xiv) Photo Map of mountains/portal from Atarau Family Memorial ........ 335

Appendix (II) Guidelines, Questions \& Consent Forms …………………..... 336

(i) Ethics: Sample Interview Questions/ Process............................................. 337 
(ii) Ethics: New Interview Information Form .................................................... 340

(iii) Ethics: Follow-Up Interview Information Form ........................................ 342

(iv) Ethics: New Interviewee Consent Form .................................................. 344

(v) Ethics: Prior Recorded Consent Form ....................................................... 346

(vi) Ethics: National Library NZ: Oral History Consent Form .............................. 348

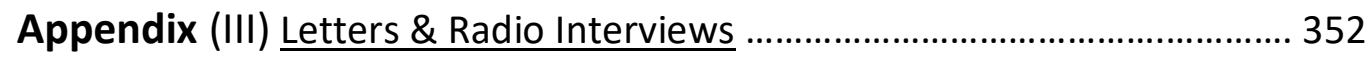

(i) Harry Bell, (former chief inspector of Mines), Letter to Minister of Energy, Max Bradford, 23 October 1997.................................................................... 353

(ii) M. Bradford, Former Minister of Energy, Reply to H. Bell 4 Nov, 1997......... 355

(iii) See M. Wilson interview Harry Bell, RNZ Checkpoint, 11 April 2013 ........... 356 https://www.radionz.co.nz/audio/player?audio id=2551745 $\left(2^{\text {nd }}\right.$ Item).

(iv) Nicholas Davidson QC, RNZ: K. Ryan Nine To Noon 11 April, 2013 ............ 356 https://www.radionz.co.nz/audio/player?audio id=2551702

Appendix (IV) Photo of Paul Berry, farmer, Grey District Councillor who donated some of his own farm land for the creation of a Family Memorial near Pike Mine. He did all the heavy lifting work, I later discovered, while awaiting open heart surgery. See Mulholland Interviews Paul Berry, 3 July 2012, Atarau 357

Appendix (V) A Scattering of Pike River Mine Photos 2011-2016 .................. 359 


\section{List of Figures and Tables}

Figure 1: Location of Pike River Mine, Royal Commission (2012) Vol.2, Fig 3.1 ....... 22

Figure 2: The James Reason (1990) Accident Causation Model 80

James Reason. (2004) 'Beyond the Organisational Accident: The Need for "Error

Wisdom" on the Frontline', Quality and Safety in Health Care, Vol.13, Suppl.2, p. 29.

Figure 3: James Reason 'Swiss Cheese' Model of Accident Causation

Royal Commission of Inquiry on the Pike River Mine Tragedy, Vol.2, 2:20: Fig.10.9.

Figure 4: Plea to stop overrides of safety circuits 120

Royal Commission of Inquiry op. cit., Vol.2, Fig.10.9: Plea to stop overrides of safety circuits; Pike River Coal Ltd, Incident/Accident Form, 2 Mar 2010, DAO.002.09871/2.

Figure 5: Email from Underviewer, Brian Wishart to Jimmy Cory ..... 125

Royal Commission of Inquiry op. cit., Vol.2, 9:63; Fig 9.6: Re: Methane Drainage.

Figure 6: Report of lack of gas detectors. 128

Royal Commission of Inquiry op. cit., Vol.2, Fig.10.10: Report of lack of gas detectors; Pike River Coal Ltd, Incident/Accident Form, 2 June 2010, DAO.001.00826/2.

Figure 7: Extracts from Dene Murphy's 21 Oct 2010 Deputies Report 136 Royal Commission of Inquiry op. cit., Vol.2, Fig. 8.19: Pike River Coal Mine, Extracts from Deane Murphy's, 21 Oct 2010 Deputies Production Report; DAO.001.02459/1.

Figure 8: Extract from Dene Murphy's June 2010 form. 137

Royal Commission of Inquiry op. cit., Vol.2, Fig. 8.11: Pike River Mine, Extract from Dene Murphy's 24 June 2010 Incident/ Accident Form; DAO.001.00749/2.

Figure 9: References to gas trips 19 November 2010 .137

Royal Commission of Inquiry op. cit., Vol.2, Fig. 10.8; Pike River Coal Mine, References to Gas Trips, 19 Nov 2010 Deputies Production Report: DAO.001.02568/1

Figure 10: Hydro Mining Bonus Table 140

Royal Commission of Inquiry Vol.2, 12:27; Fig. 12.8: Hydro-mining bonus table. 


\section{Positive Asymmetry}

\section{An introductory definition}

According to Cerulo (2006) positive asymmetry involves habitual ways of both thinking and behaving which increase our propensity to ignore an approaching worst case scenario in order to meet intended outcomes. Cultures of positive asymmetry might also encourage certain practices in the drive to reach targets which include:

Eclipsing Practices (acts of banishing, physical seclusion, shunning)

Clouding Practices (acts of impressionism, shadowing)

Recasting Practices (rhetorical, prescriptive behaviours)

These will be defined further in the course of the overall dissertation

Karen Cerulo (2006) Never Saw it Coming: Cultural Challenges to Envisioning the Worst, Chicago: The University of Chicago Press.

\section{List of Abbreviations}

CABA Compressed air breathing apparatus; may include fixed compressed air supply where units refilled while used or backpack system similar to scuba diving.

C-ALS A cavity auto scanning laser system that uses laser beams to create a threedimensional image of a void.

DAC Digital access carrier system. An underground communications system that operates like a party-line telephone system.

DOC Department of Conservation.

DoL Department of Labour. Now part of MBIE.

FAB (Fresh Air Base) Underground room-like sealed facility to maintain a respirable atmosphere in emergencies. 
FRAS Fire resistant anti-static. Can apply to brattice.

HSE Health and Safety in Employment Act 1992.

LHD or loader load haul dump machine; low-profile front-end loader.

MBIE Ministry of Business, Innovation and Employment.

MED Ministry of Economic Development. Now part of MBIE.

MinEX Health and Safety Council, the national health and safety organisation for the New Zealand minerals industry.

MRS New Zealand Mines Rescue Service, a specialist mines rescue service.

MRT New Zealand Mines Rescue Trust. It is a separate legal entity to the MRS and was incorporated pursuant to the Charitable Trusts Act 1957.

NOHSAC National Occupational Health and Safety Advisory Committee. Established in 2003 to provide independent advice to the minister of labour on major occupational health and safety issues. NOHSAC was abolished in 2009.

NZFS New Zealand Fire Service.

NZOG New Zealand Oil and Gas.

NZQA New Zealand Qualifications Authority.

SCADA Supervisory control and data acquisition is an industrial computer system that monitors and controls processes.

(SCSR) Self-contained self-rescuer. A temporary breathing system for use when the mine atmosphere becomes unbreathable. There are two possible systems: one with a simple filter (rarely used); the other, using potassium super peroxide, reacts with exhaled $\mathrm{CO} 2$ and water vapour and produces sufficient oxygen for approximately 30 to 60 minutes of use. Intended to allow the user to move from their current location to fresh air or another air source. 
(VSD) Variable speed drive. Equipment that regulates speed of an electric motor. (VCD) Ventilation control device Used to create a ventilation circuit. They consist of stoppings, overcasts or air crossings (which send air over a roadway) and other devices designed to direct or control the flow of air.

\section{Glossary}

These are also given definitions taken from Royal Commission of Inquiry (2012) report, Vol. 2, pp. 10-15. Many of these terms may prove useful not only in reading this dissertation but in revisiting quoted reports and evidence for future researchers.

Alimak shaft/raise/rise The Alimak bypassed the collapsed lower section of the main ventilation shaft; $2.5 \mathrm{~m}$ in diameter and was equipped with a $55 \mathrm{~m}$ vertical ladder.

Auxiliary fan Smaller fan used to ventilate dead-end roadways underground. Used in conjunction with ducting to force or extract air to or from the end of the road.

Booster fan Located underground in the main ventilation circuit to increase airflow.

Borehole/drillhole Hole created by drilling to gather geology information or for gas drainage. Can be done from the surface or underground.

Brattice Impervious plastic/fabric cloth used in the construction of ventilation control devices, e.g. stoppings.

Carbon dioxide (CO2) Formed underground by engine exhaust and/or oxidation of coal or fire and may be a coal seam gas. It is colourless but has an acidic odour at high concentrations.

Carbon monoxide (CO) Colourless, odourless gas formed by the incomplete combustion of carbon or a carbonaceous material e.g. diesel machines, mine fire, spontaneous combustion of coal. 
Cleanskin A worker with little or no underground mining experience.

Contraband Items that are prohibited underground, for example, cigarettes.

Core logging The drilling of holes in an extraction zone's roof and floor to take core samples for geotechnical logging.

Cross-cuts Underground roadways developed at regular intervals to join one or more main roadways.

Drift/drive/tunnel, an underground roadway.

Egress An exit from a mine

Emergency refuge An underground room-like sealed facility to maintain a respirable atmosphere in emergencies. It may have an air source that is independent of the main ventilation air.

Explosion panels Hinged doors/panels on the exhaust structure for the main fan that are forced open by the pressure generated by an explosion, to protect the evase from the force of the blast.

Explosive range Methane is flammable and explosive when mixed with oxygen between 5 to $15 \%$ methane in air by volume.

Flameproof Equipment enclosed in a special housing to ensure any ignition of methane is safely contained inside the enclosure.

Floxal A unit used to generate and pump nitrogen into a mine to make the atmosphere inert.

Flume system/slurry pipeline An open steel channel for transporting a coal and water slurry downhill from mining areas.

Forcing fan sends air along the intake towards the working faces of a mine. 
Free venting The practice of releasing methane from the drainage boreholes into the return of a mine's ventilation system.

Gas drainage Capturing and removing the naturally occurring gas in coal seams to prevent it entering mine airways. The gas can be drained in advance or after mining using different techniques. Often referred to as methane drainage if methane is the main gas component target to be captured.

Gassing out Coal mining term for an excessive amount of flammable gas in the general body of a mine's air.

Gassy mine A mine where tests on three successive days indicate the presence of flammable gas in an area, district, or main airway on the return or exhaust side.

Goaf The void created by coal extraction that is usually unsupported and susceptible to roof collapse.

Graben A block of strata between two faults that has moved downward.

Grizzly Feeder and sizer for the conveyor. Situated $2.1 \mathrm{~km}$ inbye of the portal.

Guzzler A machine located $18 \mathrm{~m}$ behind the hydro monitor used to collect and direct the slurry away from the mining areas.

Hydro mining/hydro monitor The use of a high-pressure water jet from a specialised hydro monitor machine to cut coal.

Hydrogen (H2) Colourless, tasteless and odourless gas. Highly flammable (4 to 74\%).

Hydrogen sulphide (H2S) Colourless gas with rotten egg odour. Highly toxic.

Improvement notice A notice issued by the health and safety regulator (a mining inspector) requiring a health and safety deficiency to be rectified.

Inbye The direction towards the coal face from any point of reference. 
Ingress An entry into a mine.

In-seam drainage Removal of coal seam gas with the use of in-seam drill holes and associated pipe work.

In-seam drilling of boreholes through the coal seam from an underground location.

Intake Underground roadway that has uncontaminated/fresh air moving through it.

Interburden An interval of sediments of varying depth that lies between two or more coal seams.

Jugernaut Type of loader (LHD).

Longwall mining A method of mining coal in long straight slices.

Main fan/primary fan Largest fan(s) that draws air into or pushes air through a mine.

Main ventilation shaft Vertical access with a primary purpose to exhaust air out of the mine.

Metalliferous mine Defined by regulation as including a surface or underground mine extracting, processing or crushing any mineral.

Methane ( $\mathrm{CH} 4)$ Highly flammable coal seam gas, which is tasteless and odourless. Highly flammable (5 to15\%).

Methane outburst The sudden ejection from the coal face into the mine workings of methane and carbon dioxide, generally including coal and rock.

Methane Spike An increase in the level of methane in a mine atmosphere.

Northern Lights Electronic system for tracking workers underground.

Outbye/backbye The direction away from the coal face from any point of reference.

Outcrop A segment of the coal seam or bedrock exposed to the atmosphere. 
Overcast A structure built in an underground roadway intersection to keep air paths separated, so that intake and return air can pass through the intersection.

Overpressure A pressure peak in a mine ventilation system caused by roof fall/fire/explosion/blast.

Panel mining area connected to the mains roadways consisting of access roads and extraction areas with a separate ventilation circuit.

Permit to mine weekly detailed plan of the forecast underground mining activities. Production and health and safety risks of the planned activities are identified and mitigation measures outlined.

Pike River Coal Ltd (in receivership from 13 December 2010). The company name was changed from Pike River Coal Company Ltd on 13 March 2006.

Pike Mine/Pike River The Pike River Coal Mine and/or surrounding the mine.

Pit bottom in coal An area of permanent roadways inbye of the main drift that housed water storage, pumping systems, electrical infrastructure and the main fan.

Pit bottom in stone A roadway area off the main drift containing underground services for coal collection, crushing and transport, water storage, high-pressure pumping systems and electrical infrastructure.

Portal surface entry point into a mine.

Prohibition notice A notice issued by the health and safety regulator (a mining inspector) requiring that an activity cease until such time as a health and safety deficiency has been rectified.

Range Refers to Pike's system of boreholes, pipes and other devices designed to capture and remove gas from coal seams to the surface. See gas drainage. 
Reflector sticks At Pike River these were pieces of PVC pipe about $1 \mathrm{~m}$ long wrapped with reflective tape intended to reflect light or be easily visible.

Rescue station (MRS) rescue station at Rapahoe on the West Coast providing logistical support, emergency equipment and 24 hour on-call rescue personnel.

Return Any underground roadway that has 'used' or contaminated air moving through it towards the surface after it has passed a mining area.

Rib The walls of a roadway or heading.

Rider seam The Brunner seam consists of the main seam and above it a narrower rider seam, separated by interburden of variable thickness.

Riser At Pike River the riser refers to a vertical 6" pipe through which methane-laden air was discharged to the surface. The riser was connected to the 4 "methane drainage pipe line running along the roof and ribs of the mine.

Robens Report The seminal 1972 United Kingdom report that resulted in widespread health and safety legislative change in a number of countries, including New Zealand.

Roof bolt/roof bolting techniques/cable bolts. Boreholes from 1 to $2.5 \mathrm{~m}$ long are drilled upward in the roof and bolts are inserted into the holes and anchored at the top by a chemical resin or mechanical device. Bolts may be inserted in a pattern. The purpose is to clamp together several roof beds to form a composite beam with strength considerably greater than the sum of the individual beds acting separately.

Safegas SIMTARS automated fire and explosive gas analysis system.

Slimline shaft Small diameter shaft from the mine to the surface connected to the pit bottom area of Pike River.

Smoke lines A series of rope lines and small cones hung along underground roadways to assist in guiding people through the mine to a point of safety in the event of an emergency and low visibility. 
Spaghetti Junction The intersection at the termination of the main drift, $2300 \mathrm{~m}$ from the portal, so named because of roadways and services that converged in this area.

Spontaneous combustion Coal reacts with oxygen to create heat. If the heat liberated during the process accumulates, the rate of the reaction increases and there is a further rise in temperature. When this temperature reaches the ignition temperature of coal, the coal starts to burn.

Standpipe A gland driven into the wall face and grouted into position as a permanent access point to a methane drainage borehole.

Steady state coal production The point at which a mine achieves a reliable coal extraction rate.

Stone dust Limestone dusted over the roof, ribs, face, and throughout a mine to render exposed coal dust inert.

Stopping A structure (temporary or permanent) built across a roadway to direct the air flow.

Stratigraphic (strata) complexity The structure of sedimentary rocks, which have recognisable parallel beds of considerable lateral extent. The beds deposited reflect the geological history (relative complexity) of a region.

Structural (faulting) complexity Fractures in the rocks that make up the Earth's crust, along which there has been relative displacement, i.e. rocks on either side have moved past each other.

Stub A small dead-end extension (2-5m) off main roadway. Stubs may be used for drilling, or locating plant and equipment, or to allow one vehicle to pass another.

Tag board system Tags for identifying who is underground are placed on a board before entering the mine usually at the portal, and are removed on departure. 
Telemetric (real-time) System where gas monitoring data is collected and analysed at an underground location and the result relayed electronically to another point (control room) for evaluation. Compare with Maihak system, where gas is pumped from underground but analysed on the surface.

Tool Box Talk Safety advisory notice produced by the Pike safety and training dept to notify underviewers of remedial action arising out of an incident at the mine.

Tube bundle monitoring system Bundle of tubes spread throughout underground workings to transport gas samples to the surface for Maihak (or other) analysis.

Underviewer Underviewers reported to the statutory mine manager and were responsible for coordinating and planning activities, managing employee attendance and issues, ensuring safety systems were implemented and maintained, and carrying out inspections and examinations.

Ventilation circuit Pathway that air follows through the mine or a section or a panel of the mine.

Ventilation fan A mechanical device used to create the air flow within the mine.

Ventilation system The whole of the system used to direct, control, push, or pull air throughout the mine. Way-finder beacon Escape routes out of mines can be marked with way-finder beacons which produce an audible signal and flashing lights to assist people to escape in low visibility.

Windblast The high velocity displacement of mine airways caused by a sudden strata failure. 


\section{Chapter 1 Introduction}

\section{(I) Geographic and Historic Context}

'All day it snowed. The slow sky slipped, past the children with their open mouths, their dancing fists. To settle at the place I could not find you. I could not find you. Ah, it shifts. It shifts, the old man later said. It drifts like heaps of petals, love. Today its teeth are razor sharp.' -'The Pass, Deception Valley, West Coast New Zealand (1)

When looking to the findings of the Royal Commission (2) the description of Pike is one of a remote mine located 'on the eastern side of the rugged Paparoa Range, 45 $\mathrm{km}$ north-east of Greymouth [whose] coal seam lies deep below the surface mainly within the Paparoa National Park. The coal seam dips in an easterly direction between a sheer escarpment to the west and the Hawera Fault to the east.'(3) The findings go on to describe some of the special physical characteristics of the coal field adding that Pike 'lies between Mount Hawera (1190m) to the North and Mount Anderson (1069m) to the south; The coalfield occupies an area of about $7 \mathrm{~km}^{\prime}$ (4) For some sense of the context of the West Coast and coal mining in New Zealand it is vital however, to provide here an introductory description not only of the location of Pike River Mine itself but some of the geographical features and history of the area.

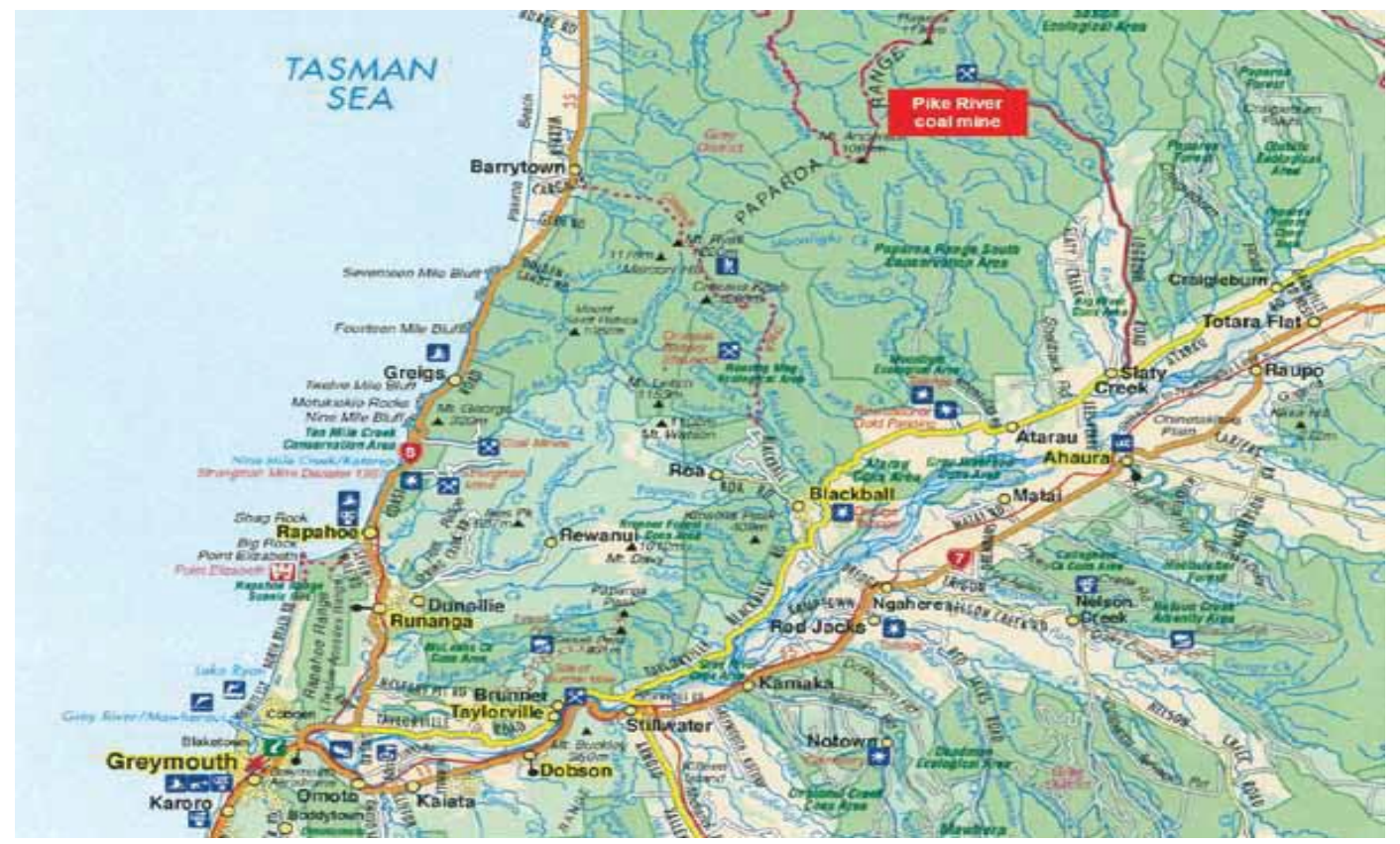

Figure 1: Location of the Pike River Coal Mine. (5) 
The West Coast of the South Island of New Zealand is well known for its remote and dramatically beautiful terrain. It is a combination of native bush, beaches, caves, deep lakes, limestone cliffs, pancake rocks, rare birds and native fauna; all battered to the west by the often dramatic Tasman Sea, with countless equally unpredictable inland rivers sheltered by the often snowy hazardous alpine frontier to the east.

It is said that explorers from Nelson first discovered coal in Grey Valley in 1840's (6) The remoteness of the West Coast and associated difficulties are well matched though, by the laughter and resilience of its stoic people who come from a proud and colourful past which not only led the country in the discovery of gold and the production of coal to fuel a country through its own shortages and two World Wars. The West Coast also led a quest for its own independence, while persistently giving of its time and resources to educate others outside the district in historic struggles for improved work conditions and standard of living in a new and developing nation.

Historian Len Richardson (1995) paints a vivid, detailed account of early migrant life on the West Coast with his examination of documents around the transportation of immigrants in the late 1870's from towns like Yorkshire and Sheffield who came with vast experience of British coalmines but who were often only reluctantly employed upon arrival for fear they might bring collectivist tendencies and unionise the mines. These were often seen as 'outsiders' and there were even incidences of the country refusing them entry at all (7). Earlier gold rushes to the towns of Hokitika. Kumara and Ross enticed many newcomers who often brought their own culture of politics over to the West Coast from Ireland, Scotland and Wales, (8) as did the later Australians; but 'few gold miners were willing to make the transition to highly disciplined form of coal labour and those who were proved [to be] indifferent workmen'. (9)There was also a disproportionate number of males among migrants but the British often came with families who were also skilled at working above ground in the British Coalmines.

Unlike the raw New Zealand mines, the pits of South Yorkshire had been sunk in areas where industry was well established. Sheffield and Rotherham were iron and steel centres. Barnsley and environs possessed a flourishing linen 
industry. The glass making and pottery trades were also prominent in the district... Miners in at least eight mining settlements were within half an hour's walking distance from Barnsley with 51,000 inhabitants....Rarely were miners' homes owned by their employers, and consequently they were free from the threat of eviction during strikes and lockouts.... Miners of Yorkshire had also carved out a role in public institutions in the larger towns, [as in] school boards, mechanics institutes, boards of health, town councils. (10)

Those who did work on the West Coast found the new life unexpectedly gruelling. There was certainly an abundance of rich bituminous coal seams to be worked but industry did not always follow. There were swollen rivers, no port of anchorage and isolation from other industrial workers. Migrants also often lived in ribbons of wind and rain swept huts perched precariously on bush slopes with very little sanitation.

An example of how austere life could be was the mining 'town' of Denniston, whose commercial operations started up in 1880 on its windswept plateau perched 2000 feet above a coastal plain to the far north of West Coast fields. Although Denniston was spoken of as 'a miracle of engineering' in the form of a counterweighted incline, the only way up (or down) the slope to the windswept mine settlement was via coal wagon on the cable haulage system; a journey so frightening there were cases of women who never came back down from the barren rock site in 20 years; other than to send the bodies of their sons to be buried at Waimangaroa, down by the sea. (11) The incidence of injury (12) and death on the West Coast and elsewhere in the New Zealand mining industry was also periodic as indicated in the following initial sample:

1879 Kaitangata, Otago (34 deaths)

1896 Brunner, West Coast (65 deaths)

1900 Westport-Cardiff, Mokihinhui*

1907 Nightcaps, Southland (3 deaths)

1914 Ralph's Colliery, Huntly (43 deaths)

1926 Dobson, West Coast (9 deaths)

1929 Linton, Ohai (3 deaths)

1939 Glen Afton, No.1 Mine, Huntly (11 deaths) 
1940 Kayes, Greymouth (5 deaths)

1955 Huntly, Waikato (1 death)

1958 Westhaven/Mangarakau, Collingwood (4 deaths)

1967 Strongman, West Coast (19 deaths)

1985 Boatmans No.4, Reefton (4 deaths)

1992 Huntly West, Waikato (no deaths but explosion heard for kms)

1998 Mount Davey, West Coast 1998 (2 deaths)

2006 Black Reef (Tiller), Greymouth (1 death)

2006 Roa, Blackball, West Coast (1 death)

2010 Pike River Mine, West Coast (29 deaths) (13)

From the beginning the West Coast rose up in the struggle to question and protest work conditions, industry and death in the workplace. There have in fact, been 12 Commissions of Inquiry set up to investigate New Zealand mining disasters (14) in the past 140 years and yet the work place deaths keep happening. This is puzzling given the amount of time and energy that West Coasters have personally put into unionising and fighting for the lives of their working families for well over that time.

From the times of the small operator working accessible coal seams, through to the introduction of the Union Steam Company which came to monopolise the major fields of Buller and Grey Valley coalfields, (15) workers stood to work independently against all sorts of odds. Women often stood up too, unafraid to make a stand.

Richardson (1995) makes reference to Ann Bromilow (1862-1939) who came to the West Coast in the early twentieth century from Staffordsheire and had worked from the age of 12 as a 'pit brow lass' in the Wigan collieries 'tipping and screening' and on the 'picking belts'. In Blackball she became the foundation member of the local branch of the Socialist Party. (16) The women of the West Coast made a huge contribution to the overall quality of life in many of the remote locations, setting up women's auxiliaries, anti-war leagues, school committees and socialist study groups. They were occasionally elected to borough councils. 'The involvement of women in community politics and the centrality of the family unit in mining added an important dimension to life on the coalfields. It also entrenched the closed nature of 
the pit communities.' (17) Neither were the women of New Zealand's coal mining world adverse to standing up for themselves when there was a point to be made.

Women were especially prominent in the early scuffles. They jostled the two miners who refused to join the union, stuffed hat-pins in their legs and burnt effigies of their wives. A visit to the town by the general manager of the company was the occasion of a 'monster demonstration' and ended with a scramble to get him safely out of town. (18)

Overall though, the major coalfields were gradually monopolised by absentee owners; many of which were shipping companies that had a minimal management presence on the coalfields. (19) The Westport Colliery Company even continued to do specific background checks on migrant miners in an effort not to have 'Methodists' or 'Unionists' (20) arriving in the country to destroy the 'work-hard/play-hard' culture they desired in the name of continued and profitable production; but even these attempts failed to stop the formation of the first miners' union in Denniston in 1884.

From the beginning, many West Coasters also made a concerted effort to unite locally when dealing with those from outside the district, even if internally their opinions might otherwise be diverse. They were not adverse either, to making it clear what would not be tolerated in their own environs. Typically seeing themselves as linked to the people of Christchurch over the Alps and to the far east of the Island, the West Coasters once fell out with the (WEA) Workers' Educational Association (1915) when its university-trained tutors tried to establish themselves in Greymouth.

Many miners insisted they had no use for the (WEA); declaring they still had all their own books and ballads they had personally brought over from 'the Old Country'. (21) Neither did they appreciate the missionary work (WEA) brought to the Grey mines in 1921. So the West Coast miners declared (WEA) economics not only 'reformist' but 'reactionary' and forced (WEA) to abandon its classes in the coal towns.' (22) 
The next decades were just as difficult for the miners in trying to find a union format that would accommodate and cover the many diverse needs and situations of the coalfields. Richardson gives four examples of specific attempts to achieve this nationally and 'on each occasion the impetus came from the West Coast'. (23)

(1) The Amalgamated Miners' and Labourers' Association (AMALA) of 1880's. This was an extension of the Denniston Miners' Union which tried to bring miners and labourers together in the Grey and Buller areas.

(2) The Miners Federation emerged in 1908 in the aftermath of the Blackball Strike. This was stronger in the Grey District than the AMAL but it was later swept away by the aftermath the National Watersiders' and Miners' strike of 1913.

(3) There was a strong attempt to reorganise the Miners' Federation of 1915, but this collapsed when it failed a coherent response to wage cuts 1922-23.

(4) The United Mine Workers (1923) formed in Runanga (West Coast) and Huntly (Waikato). Councils often became an extension of union and school committees.(24) The (UMV) survived, recognising the need for autonomy, focus and community. When there was occasion to disagree, local worker/district interests came first and a 'united front' was presented to outsiders who came over to the Coast to interfere.

It is not within the scope of this introduction to describe all the intriguing twists and turns around involvement of the West Coast regarding the Maritime Strike (1890), the Great National Strike (1913) and that of the National Watersiders and Miners' Strike (1951) but these could all well serve as examples of the resilience of many West Coasters to navigate their own way locally and not only against the odds of the many mixed interests of mine owners, cooperatives, collectivist tendencies and tributism, but that of their own often divided unions too, right up to national levels.

Two decades after the 1913 Strike, for example, new pits opened up in Blackball, Runanga, and Millerton. Coal production trebled, but so did the troubles associated in the personal, cultural and political arenas. Fortunes and wages fell with the price of coal. Disputes played out over conditions, work hours, risk, injury, death and 
competition. West Coasters who fought national conscription in 1914 sometimes refused to fight in 'other peoples' wars in the name of better working conditions and the rights of workers in the mines; only to then become even more steadfast in their overall opposition to an 'imperialist war' as their mates returned with terrible injuries; or not at all. (25) Although the tone and method of argument often varied over the years - (many workers were more than happy to work in the mines as a way of contributing to the War effort in the fight against fascism in later years) - the primary objective was for fair and safe work conditions for all who worked in mines.

After the Second World War, miners wanted to retain what they had fought so hard for and gained from wartime industrial relations. They had gained a minimum wage clause, for example. A national agreement was in place and the nationalism of mines had begun. But in 1949 a Tory government came to power that was determined to curb the unions. As a result, the National Waterfront Dispute began in 1951 and a State of Emergency was called by the government. After a Lockout that lasted months with an often aggressive strategic militancy on the part of government that left many communities and families struggling, the 'Watersiders' was broken up into 26 separate port unions, leaving miners basically abandoned to economic forces.

Open-caste mining also began and expanded throughout New Zealand. This also broke the power of many underground hewers whose original skills and experience were no longer needed above ground. Some parts of the country could absorb a few of those left unemployed into forestry, farming and other industries. This was not so of the West Coast whose whole economy and livelihood often depended on mines whose locations and communities still existed in remote, inaccessible areas.

Although Nationalism was on its way, so too was a climate of developing proAmerican foreign policy and in 1951 the Labour Party decided to hold a referendum on compulsory military training. This, among other issues, was seen as another betrayal and a change in nature of labour values by many miners of the Coast.

In short, opposition to official union policy was building up around the twin pillars of coalfields radicalism: opposition to arbitration and to war. Labour 
was increasingly depicted as propping up the capitalist economy and furthering the interests of capitalist imperialism. (26)

There had already been serious tension growing between the Nation Council and districts, and among the contributing factors was the persuasion via the Union of Mine Workers' (UMW) of the Watersiders to moderate their actions in favour of a possible return of Labour Government. Such issues had the Grey Valley and Buller miners give increasing support instead to the Trade Union Congress TUC vs. UMW. When the West Coast was later advised from Wellington to pause before taking any further action, some were not prepared to wait any longer and Buller and the West Coast ran their own strike; a 20 week protest against the Emergency Regulations.

The ability to starve the miners into submission rested ultimately on (Regulation 8) of the Emergency Regulation by which individuals were liable to prosecution if they contributed to or solicited assistance for worker 'party to a declared strike'. (27)

This was to be a particularly tough time for the people of the West Coast who were effectively striking out on their own at considerable cost to themselves and their families for what they thought could only benefit the national cause. They did not have the resources of the North Island to see them through these weeks. And scenes on some parts of the Coast began to echo the destitution of earlier eras when as the Greymouth Evening Star reported for example that 'families were living off the meat thrown away by butchers in the slaughter yards on 'killing days'. (28) Such conditions did not seem to smother the resilience for long though, with the emergence of former defiance from many affected by these changes on the Coast:

The Mines Department began to receive complaints of 'petty acts of sabotage'.... Trucks careered down an incline after a safety block had been deliberately opened. (29) 'Ropeways had been damaged. There were complaints also of a defiant attitude to deputies, and talk of difficulties between shiftmen and truckers...' (30) 
The solidarity of strikers on parts of the West Coast even meant that for the opencast mines to operate the government thought to involve the armed forces. (31)

The task of shifting coal from the remote coal towns to the port of Westport fell to naval ratings. Their presence was resented and resisted. Removing coal from Stockton plateau offered plenty of scope to those who wished to frustrate the exercise. Coal had to be carried by truck for 10 miles across the plateau to Millerton, transferred to railways wagons and then lowered by rope nearly 1000 feet down the side of the plateau passing through a tunnel as it did so before it reached the railhead at Granity. Acts of petty sabotage abounded... Coal trucks were derailed in the tunnel; brass filings were placed in the oil sump of the bulldozer [and] wagons finished their journeys much lighter than when they arrived. (32)

Through the decades, West Coasters who sometimes found themselves cut off by geographical conditions and assistance, still often gave generous financial support to others across the country and to Australia, as they determined their own localised, regional strategy that they considered had brought them to power in the first place. This did not always put them in favour with the Unionists of Wellington, but once they saw injustice their focus was unstoppable, regardless of obstacles on their path.

In many matters the West Coast demonstrated to the rest of the country that 'collective action remained viable'; that it was possible to reverse the trend of the times' (33) Sadly though, for all it contributed culturally, politically, economically to the rest of country, the West Coast has had more than its share of tragedy in recent times including that of Strongman Mine (1967), Reefton (1985) Mount Davey Mine, (1998); Black Reef (Tiller) Roa, Blackball (2006), the loss of 29 men on 19 November 2010, and other disasters as with the deaths of 13 students with their guide at Cave Creek, north of Greymouth at Paparoa National Park in April 1995. (34)

These events also thread their way through many of the interviews I conducted in relation to my own research on Pike River Mine (2011-16) and they are an integral part of the tapestry of loss that still lives just beneath the surface of the independent 
fight of families to bring the bodies of their 29 men home from the mine; challenging not only the risk and human cost of this tragedy but the silence and power that still surrounds the continued workplace deaths of other industries of New Zealand.

'It was just like Cave Creek and Strongman [Mine] all over again,' said one school principal I interviewed in 2011. 'It just brought back memories. The helicopters flying back and forth. Yeah, it was Cave Creek all over again.' (35)

'All those sirens,' another community leader told me in 2012. 'The day of the first Pike explosion, a number of us reverted back to the Cave Creek tragedy because there were helicopters buzzing everywhere... The same thing happened with Pike... Helicopters going up and down all the time... You go immediately back. You revert back to - I've had this feeling before.' (36)

Dialogue and debate were once both a critical dynamic of not just surviving, but thriving on West Coast of Aotearoa/ New Zealand. There was once a rich but broken seam which ran northwards along the coastal ranges of Westport. Once there was flooding and the mouth of the Grey was often turbulent or obstructed by silt. There were shipping delays, costly coal pits and 'cracking' which extended to the surface, threatening the stability of the land above the coal seams. These problems still exist. There is one major problem however, that is often not publically discussed and I find it whenever I read Richardson (1995), Vaughan (1996) Perrow (1999), Freudenburg (2013) and copies of Maoriland Worker, an NZ miner's magazine (1911):

There is a need for reform in coal.... Through [these] pages, miners [can] see in the discrepancies between safety regulations and mining practice, the deeper contradiction between mine safety and the exigencies of profit. (37))

And there it is, over one hundred years ago, the constant problem in production of coal in New Zealand was not just unmitigated risk, but unchecked power. It still is. 


\section{Endnotes: (I) Geographic and Historic Context}

(1) The Pass, A poem by Catriana (Cathy) Mulholland; The Pass: 'Surviving the Otira' Deception Valley, 1991 in Mutes and Earthquakes: (1997) Bill Manhire, Victoria University Press. Note: The Deception River is East of Greymouth New Zealand. It is a tributary of the West Coast's Otira River, flowing generally north for 17 kilometres 11 miles - from its source on the slopes of Mount Franklin.

(2) Royal Commission of Inquiry on the Pike River Mine Tragedy NZ, (2012) Te Komihana a te Karauna mo te Parekura Ana Waor o te Awa O Pike/ Vol 1 \& 2.

(3) Ibid., Vol. 1, p. 16.

(4) Ibid., Vol. 2, p. 31.

(5) Figure 1, Ibid., Vol. 2, p. 31. figure 3.1: Location of Pike River Mine, Royal Commission. See also, Appendix (I) History and Maps (p. 323) of this dissertation.

(6) Richardson, Len. (1995) Coal, Class and Community: The United Mineworkers of New Zealand 1880-1960, NZ: Auckland University Press, p. 17.

(7) Ibid., p. 21 'Even as they sailed from Plymouth in the Opawa, the migrant miners became the subject of controversy. Their prospective employers - The Westport Colliery Company - clearly meant their earlier strictures against unionism to be taken seriously... They were scarcely at sea when A. J. Burn, managing director of the new company, got a whiff of unionism being born to Denniston by Methodist miners.... Such men were 'the very worst miners' whose 'practice did not accord with their profession'. They were not wanted in Denniston.' This ship was refused employment in Denniston and the migrants were scattered around other New Zealand coalfields.

(8) McGill, David. (1990) The Lion and the Wolfhound: The Irish Rebellion on the New Zealand Goldfields, New Zealand: Grantham House Publishing.

(9) Richardson, op. cit., p. 18. See also AJHR 1880, D4, p. 12. 
(10) Ibid., p. 20-21. See also Pat Spaven, 'Main gates of protest: contrast in rank and file of South Yorkshire Miners, 1858-1894' in Harrison, Independent Collier, p. 207-9.

(11) Richardson, op. cit., p. 18; Prospectus of the Westport Coal Company Limited; See also E.A Smallholme- Fraser, 'Evolution of the coal mining community', pp. 1-13; 22-36; Jenny Patrick's Denniston Rose (2003)Auckland, NZ: Random House.

(12) For an example of 'Injury' in the New Zealand Mining workplace, refer to the Notes of Len Richardson (1995) in his (1995) Coal, Class and Community: The United Mineworkers New Zealand, 1880-1960, NZ: Auckland University Press, p. 319:

'An accident at the Wallsend Mine on 25 April 1887 in which two men were injured. His [George Alfred Ancell] report issued on 4 August 1887 and published in the Grey River Angus, was critical of the procedures which were followed and some of the findings of the official report. It criticised the appointment of Greymouth's local Resident Magistrate, Jackson Kiddel, as a one-man mission of enquiry and stressed the need for such a commission to be composed of men with experience of mining.

It also displayed an awareness of earlier mining accidents both in New Zealand and Australia. The Wallsend disaster occurred only weeks after a major disaster at Bulli, near Wollongong in New South Wales, where on 23 March 1887, 81 miners were killed in an explosion. The Grey River Angus had noted the accident on 18 April 1887 For more on this case, see, Accident in Wallsend Coal-mine: (Report of the Commission Appointed to Enquire into the cause of), Government Printer, 1887.

(13) Royal Commission (2012) op. cit., Vol. 1, p. 15; Vol. 2 Chapter 20, pp. 258-261.

(14) Vol. 1, p. 3, para. 1.

(15) See Len Richardson. 'British Colliers and Colonial Capitalism...' pp. 59-75.

(16) Richardson, Len. (1995) Coal, Class and Community: The United Mineworkers of New Zealand 1880-1960, NZ: Auckland University Press, p. 3; See, also AJHR 1891. C3, pp. 16-17.

(17) Ibid., p. 4. 
(18) Ibid., p. 38. See also, Otago Workman, 5 Nov.1886; Clutha Leader, 24 June 1887.

(19) Richardson, op. cit., p. 5; AJHR 1922, C2, p. 34; 1926, C2, p. 35; 1928, C2, p. 34.

(20) ibid., p. 21.

(21) Richardson, Len (1995) op. cit., p.14-15. See also, E. Hunter, Ballads of the Track: Where Labour's Cause will win; The Road the Men Came Home; The Dream of Toil.

(22) Ibid., p. 210. See G. Manning to H. Belshaw, 21 June 1922, C2/1922, District Council Correspondence, WEA, UCA; T. Mann, Tom Mann's Memoirs, 1923.

See also, $A$ journey through Dennison: Stories and research from the Interpretation

Panel at Denniston Coalfields historic Area.

https://www.doc.govt.nz/Documents/conservation/historic/by-region/westcoast/denniston/iourney-through-denniston-part1.pdf

(23) Richardson, Len. (1984) 'The Denniston Miners' Union: a Centennial History 1884-1984', DMUC, Westport: NZ, pp. 10-21; See also, P.J Farrell, P.J (1955) 'The workers and Grey district politics, 1865-1913'; M.A thesis, University of Canterbury, New Zealand, pp. $183-216$.

(24) Richardson, Len (1995) op. cit, p. 5-9. See also. 'Class, Community and Conflict.' in Richardson and McIntyre (eds.) Provincial Perspectives, pp. 106-27; Also see, O'Farrell, The workers and Grey District Politics, pp. 220-245.

(25) Richardson, Len 'Politics and war coalminers and conscription', pp. 128-55.

(26) Richardson, Len. (1995) Coal, Class and Community, op. cit., p. 287.

(27) Ibid., p. 295.

(28) Ibid., p. 245. See also Greymouth Evening Star, 20 May 1932.

(29) MD N4/4/9, StrongmanBinnery, 7 June 1940.

(30) Richardson, Len. (1995) Coal, Class and Community, op. cit., p. 277. 
(31) Ibid., p. 292.

(32) Ibid., p. 292. See also, NZ Herald, 2 May 1951.

(33) Ibid., p. 207. See also, Rules \& Constitution of the UMWNZ, p. 1, ATL.

(34) The Cave Creek Tragedy of 28 April 1995, north of Greymouth at Paparoa National Park killed 14 people (13 students) and their guide when a viewing platform collapsed sending them 40 metres to the rocks below. There was wide criticism of the government and its policies towards funding/management of the conservation estate. An inquiry revealed serious systemic failures in the building of the unstable platform. NZ government departments are now held criminally liable for inadequate building practices, in the same way as non-government organisations. Yet even with all its proven practice, no such liability has been applied to the case of Pike Mine.

(35) Mulholland Interviews, July 2011 (15.7.11) 19:57.

(36) Mulholland Interviews, February 2012 (8.2.12) Pt.2, 3:13-3:28.

(37) Richardson op. cit., p. 119. See also, J. McCullough, Diaries, 28 Feb. 1911. 


\section{(II) Snapshot: Royal Commission of Inquiry on the Pike River Mine Tragedy (2012) Te Komihana a te Karauna mo te Parekura Ana Waor o te Awa O Pike/ Vol. 1, p. 12.}

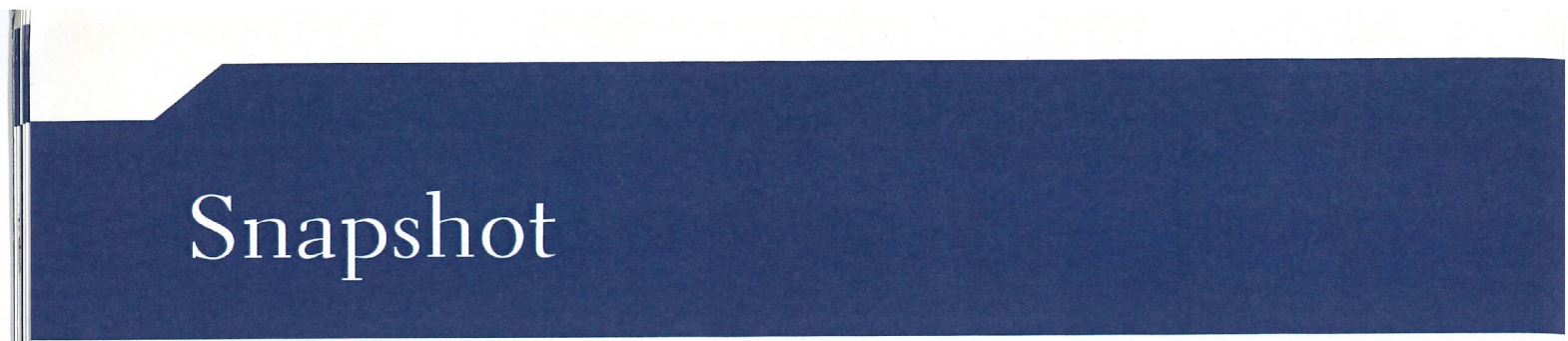

The Pike River underground coal mine lies high in the rugged Paparoa Range on the West Coast of the South Island. Access to the mine workings was through a single $2.3 \mathrm{~km}$ stone drift, or tunnel, which ran upwards through complex geological faulting to intersect the Brunner coal seam.

On Friday 19 November 2010, at 3:45 pm, the mine exploded. Twenty-nine men underground died immediately, or shortly afterwards, from the blast or from the toxic atmosphere. Two men in the stone drift, some distance from the mine workings, managed to escape.

Over the next nine days the mine exploded three more times before it was sealed. There is currently no access to the mine. The commission is satisfied that the immediate cause of the first explosion was the ignition of a substantial volume of methane gas. The commission's report identifies a number of possible explanations for the source of that accumulation of methane, and the circumstances in which it was ignited.

Methane gas, which is found naturally in coal, is explosive when it comprises 5 to $15 \%$ in volume of air. In that range it is easily ignited. Methane control is therefore a crucial requirement in all underground coal mines. Control is maintained by effective ventilation, draining methane from the coal seam before mining if necessary, and by constant monitoring of the mine's atmosphere.

The mine was new and the owner, Pike River Coal Ltd (Pike), had not completed the systems and infrastructure necessary to safely produce coal. Its health and safety systems were inadequate. Pike's ventilation and methane drainage systems could not cope with everything the company was trying to do: driving roadways through coal, drilling ahead into the coal seam and extracting coal by hydro mining, a method known to produce large quantities of methane.

There were numerous warnings of a potential catastrophe at Pike River. One source of these was the reports made by the underground deputies and workers. For months they had reported incidents of excess methane (and many other health and safety problems). In the last 48 days before the explosion there were 21 reports of methane levels reaching explosive volumes, and 27 reports of lesser, but potentially dangerous, volumes. The reports of excess methane continued up to the very morning of the tragedy. The warnings were not heeded.

The drive for coal production before the mine was ready created the circumstances within which the tragedy occurred. A drive for production is a normal feature of coal mining but Pike was in a particularly difficult situation. It had only one mine, which was its sole source of revenue. The company was continuing to borrow to keep operations going. Development of the mine had been difficult from the start and the company's original prediction that it would produce more than a million tonnes of coal a year by 2008 had proved illusory. The company had shipped only 42,000 tonnes of coal in total. It was having some success in extracting coal as it drove roadways but it was pinning its hopes on hydro mining as the main production method and revenue earner. Hydro mining started in September 2010 but was proving difficult to manage and output was poor.

It is the commission's view that even though the company was operating in a known high-hazard industry, the board of directors did not ensure that health and safety was being properly managed and the executive managers did not properly assess the health and safety risks that the workers were facing. In the drive towards coal production the directors and executive managers paid insufficient attention to health and safety and exposed the company's workers to unacceptable risks. Mining should have stopped until the risks could be properly managed.

The Department of Labour did not have the focus, capacity or strategies to ensure that Pike was meeting its legal responsibilities under health and safety laws. The department assumed that Pike was complying with the law, even though there was ample evidence to the contrary. The department should have prohibited Pike from operating the mine until its health and safety systems were adequate.

12 Volume 1

Royal Commission of Inquiry (2012) op. cit., Vol. 1, p. 12. 
After the explosion a major search and rescue effort was launched. There was no predictable window of opportunity within which the Mines Rescue Service (MRS) could have safely entered the mine. Pike had no system for sampling the mine atmosphere after an explosion and without that information it was impossible to assess the risks of entry. The placement of the main fan underground and the damage caused to the back-up fan on the surface meant that the mine could not be reventilated quickly.

The New Zealand Police led the emergency response and made the major decisions in Wellington. There had been no combined testing of an emergency response of this nature involving Pike, mining specialists, the MRS, the police and emergency services.

For the first few days the families were given an over optimistic view of their men's chances of survival, but this was inadvertent. When the second explosion occurred five days later any remaining hope disappeared.

The new owner of the mine, Solid Energy New Zealand Ltd, has agreed that it will take all reasonable steps to recover the bodies provided this 'can be achieved safely, is technically feasible and is financially credible!? Any recovery will hinge on a resumption of commercial mining operations.

The mine is sealed and its atmosphere is inert. Solid Energy is ensuring the safety of the mine, including physical security, monitoring of the underground atmosphere, checking of seals and contingency planning.

New Zealand has a poor health and safety record compared with other advanced countries. The government has set up an independent ministerial task force to determine if New Zealand's health and safety system is fit for purpose. The task force will no doubt examine on a broader scale some of the matters that the commission has considered.

To reduce the risks of future tragedies, the commission makes 16 principal recommendations, set out at the end of this volume. Some recommendations have implications beyond the underground coal mining industry.

The commission recommends that there should be a new regulator with a sole focus on health and safety. The new regulator should be a Crown entity with an expert board accountable to the minister and working closely with the Ministry of Business, Innovation and Employment, employers and workers.

Based on the commission's inquiries, the Health and Safety in Employment Act 1992 is generally fit for purpose but many changes are required to update the mining regulations. The commission recommends that the changes be progressed by an expert mining task force separate from the ministerial task force. The Queensland and New South Wales regulations provide good precedents.

More worker participation in managing health and safety is needed and will require legislative change and guidance from the regulator.

Major improvements to emergency management are required. The first step should be a joint review by the organisations that responded at Pike River, then amendments to the co-ordinated incident management system and finally a programme of testing and simulation of emergencies to iron out any problems.

The statutory responsibilities of directors for health and safety should be reviewed to reflect their governance responsibilities, including their responsibility to hold management to account.

Leaving aside regulatory change, the commission recommends that directors should rigorously review their organisation's compliance with health and safety laws and assure themselves that risks are being properly managed. Managers should access the best practice guidance available on leading health and safety in the workplace.

The changes recommended by the commission rest firmly on the principle that health and safety in New Zealand can be improved only by the combined efforts of government, employers and workers.

Royal Commission of Inquiry (2012) op. cit., Vol. 1, p. 13. 


\section{(III) An introduction to Geology and Development of Pike River Mine}

The following excerpts are taken directly from the findings of the Royal Commission. For more detail, see Royal Commission of Inquiry on the Pike River Mine Tragedy NZ, Te Komihana a te Karauna mo te Parekura Ana Waro te Awa O Pike (2012), Vol.1-2.

The Promise of Pike, Royal Commission (2012) op. cit., Vol. 2, Chapter 3, pp. 32-33:

\section{Geology}

(6) The geology of the coal field is complex, as can be seen from the simplified crosssectional figure below. There are two coal measures, the Brunner seam, which was mined and, approximately $200 \mathrm{~m}$ below it, much older Paparoa seams. The Brunner seam consists of the main seam and above it a narrower rider seam, separated by interburden of variable thickness. The seams outcrop on the western escarpment. The Hawera Fault not only marks the eastern margin of the coal field, but has also deformed the seam upwards adjacent to the fault line.

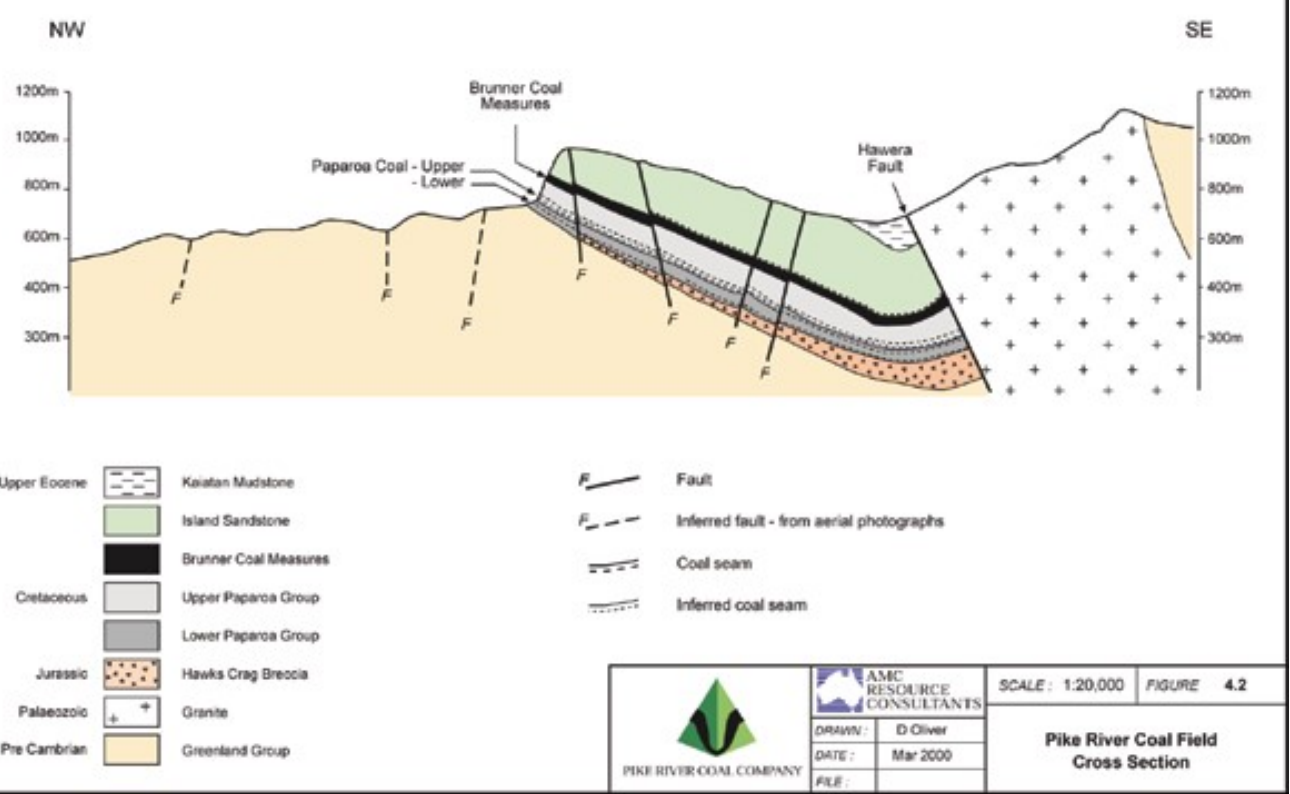

Figure 3.2: Pike River coal field cross-section 
Royal Commission of Inquiry (2012) op. cit., Vol. 2, p. 32.

(7) Other faults intersect the Brunner seam, which dips at a gradient of between $10^{\circ}$ and $20^{\circ}$. Island sandstone of varying depths overlies the coal field depending upon the surface contours. As can be seen in the simplified diagram of the west to east cross-section below, the surface contour is highly variable, this being rugged country intersected by gullies and streams.

(8) The Paparoa Range forms a barrier to the dominant westerly air flow from the Tasman Sea. As a result the coal field area has rainfall of up to $6 \mathrm{~m}$ per annum. The altitude of the area makes it prone to snowfalls in winter; cloud and rain are the predominant climatic features for most of the year.

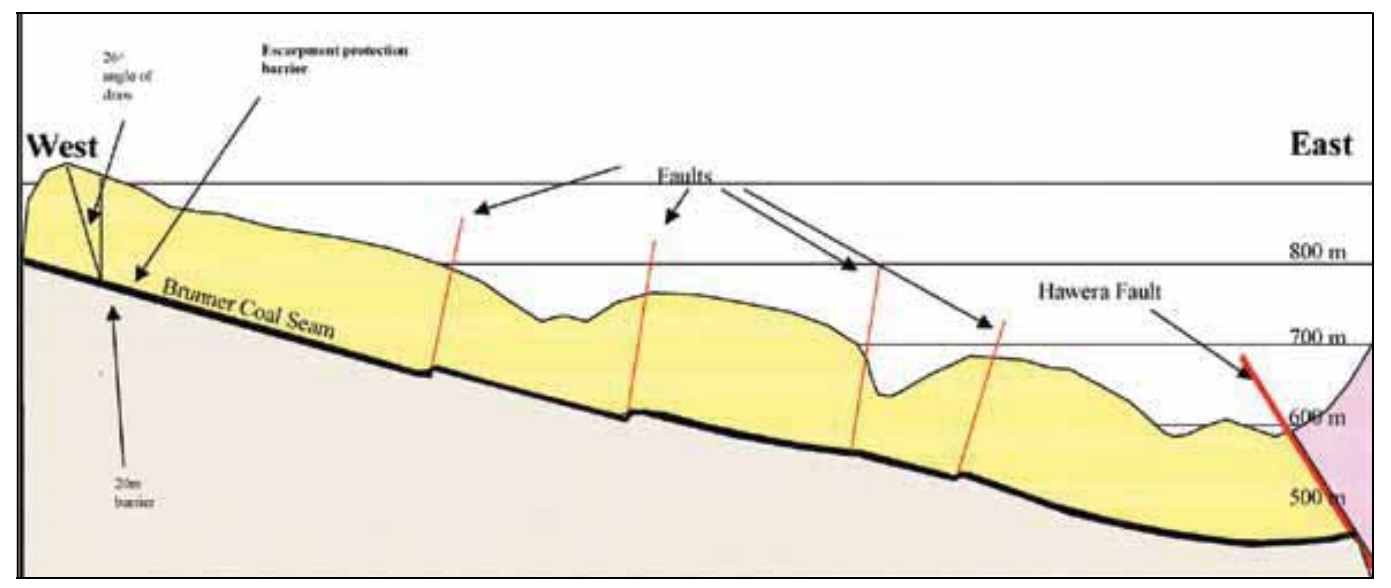

Figure 3.3: Pike River coal field west-east cross-section

Royal Commission of Inquiry (2012) op. cit., Vol. 2, p. 33.

\section{The following excerpts are also taken directly from the Royal Commission (2012)}

For further detail, see Royal Commission of Inquiry on the Pike River Mine Tragedy (2012); Vol. 1, pp. 14-28; See also, Vol 2. pp 31-44. 
Overview: Royal Commission of Inquiry (2012) op. cit., Vol. 1, pp. 16-22:

\section{The Pike River mine}

\section{Conception}

Pike River Coal Company Ltd (Pike) was formed in 1982 and acquired by New Zealand Oil \& Gas Ltd (NZOG) in 1998. Over a 13-year period Pike explored and then acquired the necessary authorisations for the mine, including a mining permit, an access arrangement and resource consents. Initial exploration indicated a recoverable coal reserve of 19 million tonnes of high-quality hard coking coal.

In 2005 the Pike board decided to proceed with development of the mine. In May 2007 Pike offered shares in the company for public subscription and allotted 85 million one-dollar shares to over 5000 new investors. NZOG remained the major shareholder, but no longer held a controlling interest. Development costs were estimated at $\$ 124$ million, with annual coal production of more than a million tonnes projected by 2008. Pike River was developed as an underground mine, because open cast mining was not economic owing to the depth of the Brunner coal seam.

\section{Development}

The construction of an access road began in September 2006, followed by a $2.3 \mathrm{~km}$ tunnel (drift) driven through stone to access the eastern side of the coal seam. In November 2008 the mine was officially opened.

The coal seam was intersected to the west of the Hawera Fault and development of the pit bottom area began in early 2009. By November 2010 the extent of underground development was as shown in the mine plan below.

Royal Commission of Inquiry (2012) op. cit., Vol. 1, p. 16. 


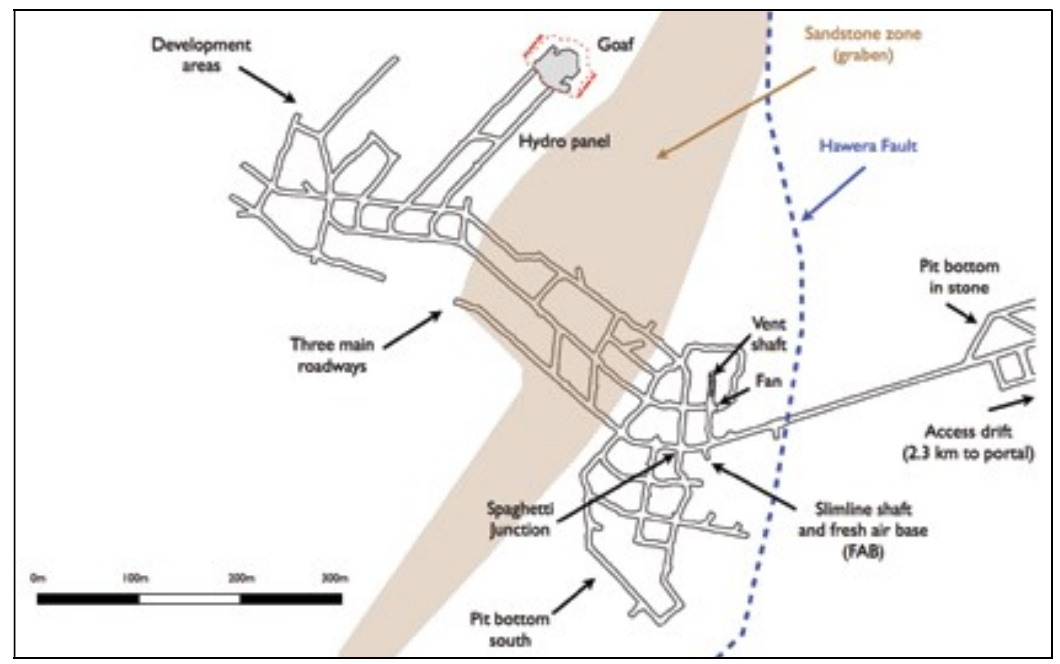

The mine plan as at November 2010

There were two mine infrastructure areas (pit bottom in stone and pit bottom south), three main roadways, the hydro mining panel and further development areas to the north-west. Spaghetti Junction was the meeting point of the drift and pit bottom, with two surface-to-mine shafts nearby- the main ventilation shaft, and the slimline shaft, at the bottom of which was a so-called fresh air base (FAB). Pike River was a small mine, still at an early stage of development.

\section{The company situation}

Pike's knowledge of the geology and the extent and location of the coal seam was based on an initial 14-borehole exploration programme, supplemented by a similar number of boreholes drilled subsequently. These provided insufficient geological information, which led to adverse unexpected ground conditions hindering mine development.

Construction of the drift took much longer than anticipated, as did mine roadway development. Delays were caused by a downthrust between faults, called a graben, which created a zone of sandstone instead of coal, and the collapse of the bottom section of the ventilation shaft during construction. The collapse meant that a bypass had to be built to reconnect to the upper part of the shaft about $50 \mathrm{~m}$ above pit bottom. The first coal sales, totalling 42,000 tonnes, were delayed until 2010 .

Royal Commission of Inquiry (2012) op. cit., Vol. 1, p. 16-17. 
Development costs escalated over the \$143 million figure projected in 2007.

Pike required capital and during 2010 it raised $\$ 140$ million from shareholders, and was seeking another $\$ 70$ million as at 19 November and also borrowed \$66 million from NZOG. [New Zealand Oil and Gas].

In September 2010 the Pike chief executive, Gordon Ward, resigned and was subsequently replaced by Peter Whittall. The board demanded 'better forecasting from management, as Pike had over-promised and under delivered'.

In November 2010 Pike was still in start-up mode and considerably behind its development schedule. Market credibility, capital raising, higher coal production, increased ventilation capacity, methane management and up-skilling the workforce were significant challenges facing the company.

History demonstrates that problems of this kind may be the precursors to a major process safety accident. Whether an accident occurs depends on how the company responds to the challenges and the quality of its health and safety programme.

\section{Pike River Coal Ltd}

\section{Pike's vision}

Pike River Coal Ltd (renamed from Pike River Coal Company Ltd in March 2006) set out to develop a safe, world-class coal mine. The company was also very committed to good environmental management, as was acknowledged by conservation leaders. Underground coal mining is both hazardous and complex at the best of times. Pike faced added challenges as it developed a new mine in a mountainous area where difficult geological conditions required some innovative solutions.

Pike recruited some well-qualified managers, many from overseas, including, for instance, Douglas White in early 2010, who was a former deputy chief inspector of mines in Australia. Over several months he tried to introduce some health and safety initiatives at the mine.

Royal Commission of Inquiry (2012) op. cit., Vol. 1, p. 17. 
Pike also obtained advice from New Zealand and Australian consultants throughout the various stages of the mine's development. The commission's attention was drawn to the number, 36 , and qualifications and experience of these consultants. They provided advice across a range of disciplines, including geotechnical engineering, ventilation, strata control, electrical safety, methane managementto mention a few.

These aspects are acknowledged at the outset partly because the commission's analysis of Pike River's operation and systems in 2010 is necessarily concerned with aspects, often negative, of likely relevance to the cause of the explosion.

This does not mean that the commission has overlooked the company's aim to develop a productive and safe mine. Unfortunately Pike lost sight of that aim as its drive for production intensified.

\section{A short-term focus}

Pike's long-term mine plan had been to develop roadways to the north-west corner of the mine, establish a second intake and begin hydro mining in that area, and for mining to retreat back to pit bottom over the life of the mine, approximately 19 years. However, development delays and the consequent need for cash flow led to the need for a quick solution.

In September 2010 Pike started mining in the hydro panel close to pit bottom. The second intake, had it been developed, would have doubled as a walkout egress from the mine and also improved the efficiency of the ventilation system.

\section{Governance by the board}

The Pike board of directors was required to set the strategic direction of the company and delegate its implementation to management. The directors then had to ensure that appropriate systems were in place, including risk management, internal reporting and legal compliance systems, and also monitor the performance of management. A two-man health, safety and environment committee was to lead this process and report to the board. It could commission external reports and audit.

Royal Commission of Inquiry (2012) op. cit., Vol. 1, p.18. 
The board received a monthly report containing a health and safety section. Although this was helpful, it did not cover the hazards relevant to a catastrophic event such as an explosion. The board did not assess critical design and health and safety issues, including, for example, the location of the main fan underground at pit bottom. An insurance risk survey received in July $\mathbf{2 0 1 0}$ identified serious concerns about the hazards posed by hydro mining, windblast and a gas explosion, and urged the need for a comprehensive risk assessment of the mining operation. Neither the board nor its committee saw the report.

The mine manager attended a board meeting four days before the explosion and told the directors that gas management was 'more a nuisance and daily operational consideration than a significant problem or barrier to operations'. The board was not well placed to assess this assurance.

The board did not verify that effective systems were in place and that risk management was effective. Nor did it properly hold management to account, but instead assumed that managers would draw the board's attention to any major operational problems. The board did not provide effective health and safety leadership and protect the workforce from harm. It was distracted by the financial and production pressures that confronted the company.

\section{Management}

At the time of the explosion the management team at Pike River comprised Peter Whittall, chief executive officer; Douglas White, site general manager; Stephen Ellis, production manager; and seven department managers. However, there was constant management change over the years. There were six mine managers in the 26 months before the explosion. Mr Ellis was to become the next mine manager as soon as he acquired the required New Zealand qualification. In the meantime $\mathrm{Mr}$ White was the mine manager on top of his other duties. Gordon Ward was the chief executive until succeeded by Mr Whittall in October 2010.

Royal Commission of Inquiry (2012) op. cit., Vol. 1, p.18. 
There was also significant change in other management positions. Throughout 2010 the management team faced planning changes and operational challenges, including improving coal production, establishing the hydro panel, commissioning the new main underground fan, upgrading the methane drainage system and resolving problems with mining machinery. These coincided with the drive to achieve coal production. Pike's mine management plans and procedures needed considerable attention. The health and safety management plan was largely in draft, partly while awaiting technical input from other managers. The ventilation management plan was deficient, and Mr White assumed responsibility for ventilation in the absence of a ventilation engineer when his workload was already formidable.

\section{The workforce}

Pike recognised the need for good training programmes, given the inexperience and diversity of much of its workforce. Miners received comprehensive induction training and continuing training was introduced in 2010 but deferred as the push for production gathered momentum. Numerous contractors were engaged on a longterm basis. Contractor health and safety management was less effective. The induction and underground supervision of the smaller contractors in particular was lax. This was recognised and was about to be addressed when the explosion intervened.

Underground, difficulties arose because of a shortage of underviewers and deputies, a high ratio of inexperienced to experienced miners and the presence of overseas miners unused to New Zealand mining conditions. A serious problem was the workers' practice of bypassing safety devices on mining machinery so work could continue regardless of the presence of methane. This was reckless behaviour. There were also reports of other conduct and incidents caused by inexperience, inadequate training and failures to follow procedures.

Royal Commission of Inquiry (2012) op. cit., Vol. 1, p.19. 


\section{Ventilation}

A mine ventilation system must provide fresh air throughout the workings, and take return (foul) air out of the mine. At Pike River the intake of fresh air was from the portal, and return air was expelled to the surface up the ventilation shaft. The main fan and movable auxiliary fans circulated the air, with the assistance of ventilation control devices that guided air flow and stopped the mixing of intake and return air.

The original mine plan specified two main fans located on the mountainside next to a ventilation shaft. Two planning changes were made. Pike decided to relocate the fans underground in stone at the bottom of a ventilation shaft. In 2007 the site of the ventilation shaft was moved to its eventual location north of Spaghetti Junction. Placing a main fan underground in a gassy coal mine was a world first. The decision was neither adequately risk assessed nor did it receive adequate board consideration. A ventilation consultant and some Pike staff voiced opposition, but the decision was not reviewed. Putting the fan underground was a major error.

The fan significantly increased Pike's ventilation capacity, at least in the short term. After the explosion, however, the joint investigation expert panel used computer modelling to establish the ventilation sufficiency at the time of the explosion and found air supply to the inbye (further into the mine) areas of the mine would have been fragile, particularly in an emergency. Ventilation consultants advised Pike on an as required basis, but no one at the mine had dedicated responsibility for ventilation management.

The main fan failed in the explosion. It was not explosion protected. A back-up fan at the top of the ventilation shaft was damaged in the explosion and did not automatically start as planned. The ventilation system shut down.

Royal Commission of Inquiry (2012) op. cit., Vol. 1, p. 19. 


\section{Methane management}

To provide safe working conditions in a gassy coal mine effective methane management is essential. Methane levels at Pike River were managed through the ventilation system and some pre-drainage of the coal seam from in-seam boreholes.

The in-seam boreholes were primarily to map the limits of the coal seam and were not designed for pre-drainage. Some pre-drainage still occurred, requiring Pike to install a gas pipeline to vent methane to the surface. By April 2010 the pipeline could not cope and an underviewer emailed management, stating: 'History has shown us in the mining industry that methane when given the write [sic] environment will show us no mercy. It is my opinion that it is time we took our methane drainage ... more seriously and redesigned our entire system.'

Gas consultants were engaged and advised that the pipeline required urgent upgrading. As a stopgap measure methane was 'free vented into the mine's return airway to be handled by the ventilation system. The upgrade of the drainage pipeline was put on hold and free venting of large volumes of methane continued up to the time of the explosion. Free venting is no longer recognised as normal practice in modern underground coal mines.

Continuous monitoring of methane levels is essential to understanding the underground atmosphere and trends. Pike installed fixed sensors that reported to the control room, but at the time of the explosion there were too few and they were not well sited. There were only four fixed sensors in return air. One in the hydro panel reported to the operator of the water jet, another was not functional.

Sensors were also located at the bottom and near the top of the ventilation shaft. The bottom one was broken for 11 weeks before the explosion and the other was unreliable and could not read above $2.96 \%$ methane. There were no fixed sensors reporting to the surface from the working areas of the mine inbye of the main fan.

Royal Commission of Inquiry (2012) op. cit., Vol. 1, p.19-20. 
Gas readings were also taken throughout the mine using hand-held detectors and readings were noted in shift reports. Methane sensors attached to machinery were generally well maintained and calibrated to trip power at a set methane level. There was constant tripping on some machines, which led to the bypassing of sensors by some workers. Despite its limitations, the monitoring system showed there was a serious methane management problem. After hydro mining began, high readings many dangerously high - were recorded most days. This information was not properly assessed and response to warning signs of an explosion risk not inadequate.

\section{Electrical safety}

Considerable electrical equipment was located underground at Pike River. Highvoltage cables through the drift supplied power to underground. At Spaghetti Junction cables were intertwined with utility services, including drainage pipes carrying methane, creating a hazard.

Regulations require a gassy mine to have a restricted zone where all electrical equipment must be incapable of sparking an explosion. The dividing line at Pike River is shown below.

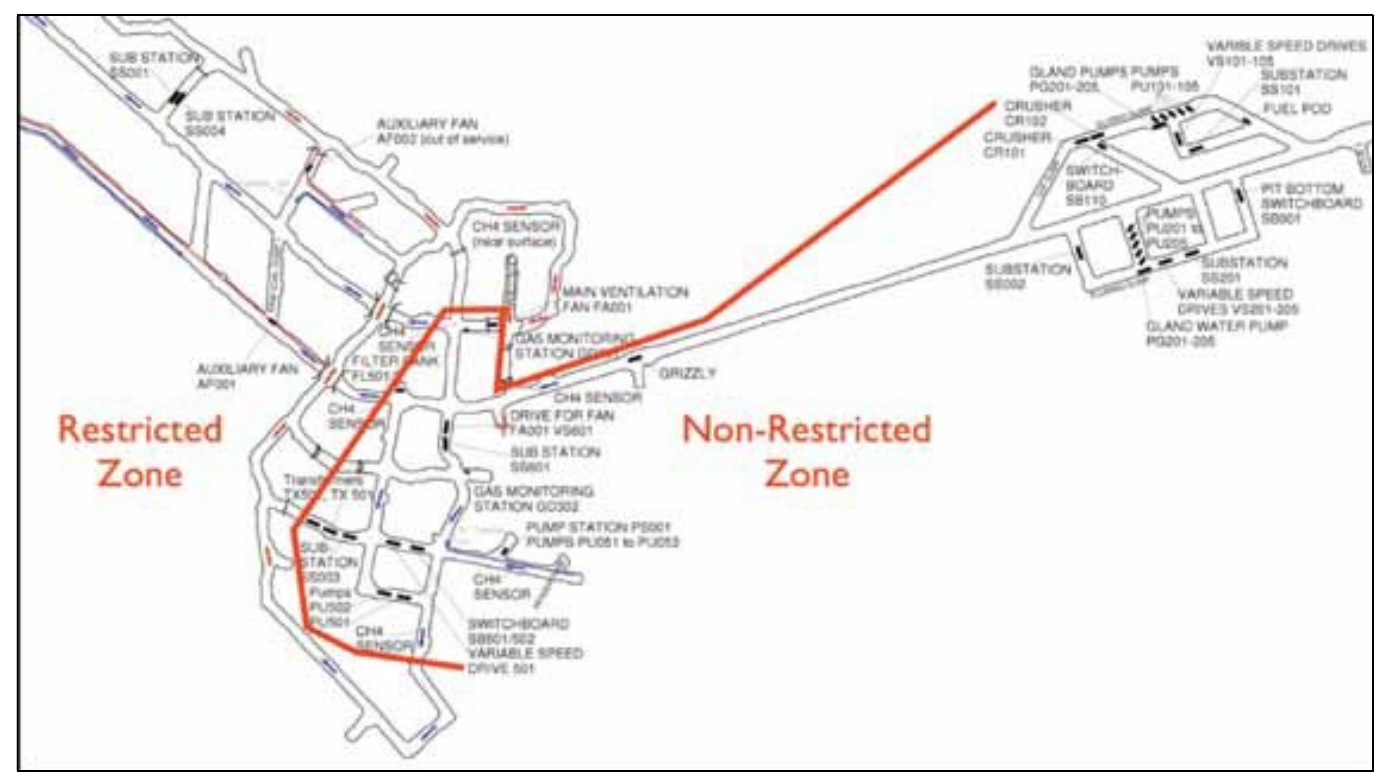

Figure 2: Boundary between the restricted and non-restricted zones

Royal Commission of Inquiry (2012) op. cit., Vol. 1, p. 20. 
The non-restricted zone, as drawn, allowed unprotected electrical equipment to be located on the right-hand side of the line in most of pit bottom south. The zone was fixed without a risk assessment, after electrical equipment was already installed and after the location of the main fan motor had been determined.

A number of variable speed drives (VSDs) were located underground. VSDs controlled power supply to the fan and water pumps. There were problems with the VSDs, one of which was replaced and a number of which were removed for repair. The extent of these problems underlined the need for a comprehensive risk assessment of the electrical installations underground at Pike River.

Mine documents suggested the appointment of a senior electrical engineer to oversee electrical safety in the mine. An appointment was made but he had not started at the time of the explosion. DOL did not have the capacity to inspect Pike's electrical systems following the major underground installations.

Investigations are continuing to establish whether an electrical cause could have initiated the explosion, but answers will depend on gaining entry into the mine.

\section{Hydro mining}

Hydro mining started at Pike River in September 2010. This is an uncommon and specialised mining technique that uses a water jet to cut the coal face and requires expert design of the mining panel and equipment. Operators must be trained to follow a set cutting sequence and to direct the water jet to avoid the undue disturbance and release of methane. The hydro panel was developed (see Fig 3).

The water jet was mounted on the monitor, with an operator stationed at the guzzler. The goaf was unsupported and roof falls were expected.

The intake of fresh air is represented by the blue arrows, the outflow of return air by the red arrows. When hydro mining began the workers had the incentive of a $\$ \mathbf{1 3 , 0 0 0}$ bonus if they met production targets by late September, after which the payment would decrease from week to week. 
Royal Commission of Inquiry (2012) op. cit., Vol. 1, p. 20-21.

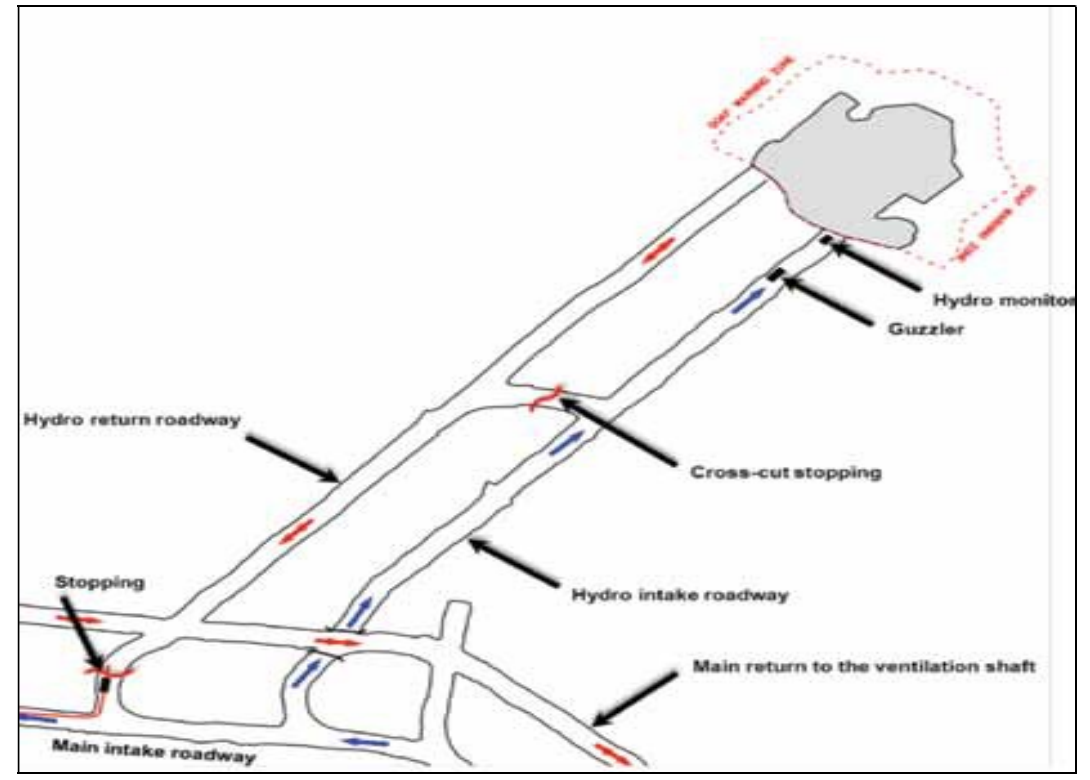

Figure 3: Diagrammatic outline of hydro panel

Despite a number of set-up problems the targets were met towards the end of the month. After the new fan was commissioned, ventilation to the hydro panel improved and during October 2010 hydro mining became a two-shift, 24-hour operation.

In October the width of the extraction area was increased from $30 \mathrm{~m}$ to $45 \mathrm{~m}$, although a consultant geotechnical engineer had indicated the risk of a major roof collapse in the goaf could not be excluded.

On 30 October a significant roof fall did occur, causing a pressure wave that took out the stopping in the hydro cross-cut intended to separate intake and return air. Methane readings were high, but there was no explosion.

Hydro mining continued into November without reassessment of the risk of further roof falls in the goaf. Production levels did not improve, and spikes in the methane levels continued to be recorded in the weeks leading up to the explosion.

Royal Commission of Inquiry (2012), op. cit., Vol. 1, P. 21-22: 


\section{The Pike River Mine tragedy}

On Friday 19 November 2010 at 3:45pm

there was an underground explosion at the Pike River coal mine.

Twenty-nine men lost their lives.

Their bodies have not been recovered.

Two men survived the explosion.

They were in the stone access tunnel (drift), a distance from the pit bottom area where the main workplaces were located. Although initially overcome, Daniel Rockhouse rescued himself and colleague Russell Smith.

The New Zealand Police led the emergency response that involved emergency services, and mines rescue crews from New Zealand, New South Wales and Queensland. Despite strenuous efforts by everyone involved, a lack of information concerning the conditions underground prevented a rescue attempt.

A second explosion on Wednesday 24 November extinguished any hope of the men's survival. The emergency focus changed to recovery of the bodies.*

Royal Commission of Inquiry (2012) op. cit., P. 14.

* The bodies of the 29 men have still have not been recovered as of March 2018. 
(IV) The tragedy: Photos of the 29 Men who died at Pike River Mine Royal Commission of Inquiry (2012) op. cit, Vol. 1, P. 4-5.

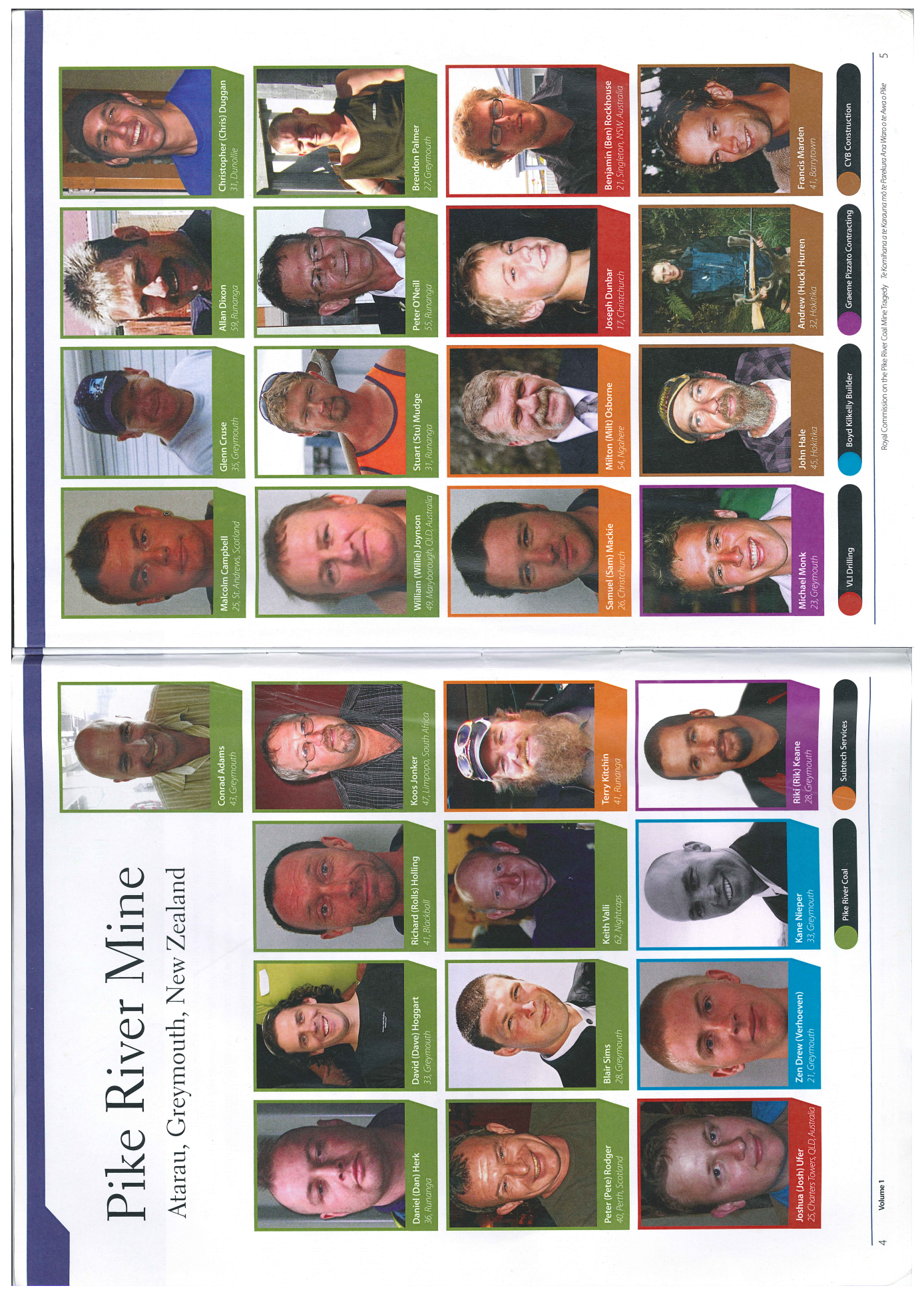




\section{Chapter 2 Literature Review}

\section{(I) Disasters and the Social Construction of Risk - The Risk Society}

We are living in a 'runaway world' stippled by ominous dangers, military conflicts and environmental hazards... Increasing portions of our everyday lives are spent negotiating change, dealing with uncertainty and assessing personal impacts of situations that appear to be out of our control. In one way or another, the defining markers of modern society are all associated with the phenomenon of risk. - Mythen (2004) Ulrich Beck: A Critical Introduction to the Risk Society. UK: Pluto Press.

In looking to the social construction of risk I will introduce the perspectives of Ulrich Beck $(1992,2000)$ and Anthony Giddens $(1990,2003)$ who for many years worked independently of each other as theorists in Germany and Britain, but whose ideas began to coincide (with variations) regarding the social construction of risk and the 'risk society' which often demarcates the pervasive effects of risk in every day life.

In defining risk I also include reference to sociologist, Gabe Mythen (2004) who, as the director of (ESRC) North West Doctoral Training Centre, School of Law and Social Justice in the United Kingdom, looks to the impacts of risk and uncertainty across a wide range of domains including predicting criminal behaviour, counter-terrorism regulation, mapping of labour market trends, ecological and environmental impacts.

In contemporary western culture it could be said that 'risk' has become increasingly complex to define when looking to the evolution of social institutions, welfare and economy alongside expansion of scientific, technical, medical knowledge and the continued need for more effective risk calculation, assessment and management.

In an era of advanced modernity and globalisation there are many risks around economic convergence, political fluctuation, national insecurity, ecological issues, climate change, genetic engineering, biological and chemical trials; all developments underscored by risk, right down to the misappropriation of anthrax, ricin, Sarin and more recently Novichok (meaning Russian for 'newcomer'). It seems we live in an 
epoch of flux before we can even get to analysis of risk society in the workplace; with the nature of risk often seeming overwhelming, ambiguous and indeterminate.

Layered over the top of longstanding every day hazards, current anxieties about the threat of terrorism have added to a general feeling of public unease... Just as a century ago, the idea of 'progress' helped to name an optimistic era. So today risk, by its very pervasiveness, seems to be the defining marker of a less sanguine moment. (1)

In order to circumnavigate the many sources, the varied approaches and expert analysis of risk it is important to look to four paradigms which evolved within social sciences as a means of conceptualising risk. In doing so, I specifically cite here Mythen (2004) in the hope that this very fundamental listing of approaches (the four paradigms) might guide future researchers in their areas of interest and speciality (2)

(a) Anthropological approaches: involving differences in risk perception, accounted for through world-views, patterns of cultural values; see pioneering work of Mary Douglas (1966, 1982, 1985, 1992); Caplan (2000); Bujra (2000); Nugent (2000). (3a)

(b) Social psychology, psychometric: individual cognition of risk, Paul Slovic (1987, 1992, 2000); heuristics/biases commonly affect individual perceptions of risk (3b)

(c) Governmentality: approach to risk e.g many theorists deploying Michel Foucault's writing on disciplinary effect of discourse (Foucault, 1978, 1991) e.g Castel (1991), O'Malley (2001), Dean (1999); look to role of social institutions in constructing understandings of risk which restrict and regiment human behaviour (3c)

(d) Risk Society: looking to perspectives of Beck (1992), Giddens $(1998,1999)$ with regard to advanced modernity, risk society and the social construction of risk. (3d) Although I will later also focus on links between individual cognition of risk when referring to the work of Karen Cerulo (2006) and Kari Marie Norgaard (2011), it is specifically the perspective of Becks (1992) and Giddens (1998) and their analysis of Risk Society that I will refer to now, with regard to the social construction of risk. 
There is also much debate around Beck's defining of three specific 'epochs' of risk, but I will refer to them here as a guide to his initial theorising around pre-industrial (traditional) society, industrial society, and the second modernity or 'risk society'.

Beck differentiates between 'natural hazards' and 'manufactured risks' arguing that in the age of industrial modernity risk was regulated to a certain extent via a small store of knowledge relating to reasonably definable human-made risks and 'natural' disaster. This is again open to debate, but Beck fundamentally emphasises that there were changes to the composition of risk accompanying each of the major structural transformations from pre-industrial to industrial modernity, through to risk society; that defining and dealing with risk has became more complex in advanced modernity with risk now transcending many more traditional boundaries of time and space.

Beck looks to macro-social processes which catalyse the risk society and although his language can seem slightly hyperbolic at times, his 'three pillars of risk' (4) are a good introduction for reflexive dialogue. He defines the first pillar of risk as that of the transformations in relationship between time and space. The second is the catastrophic nature of risk, and the third is the breakdown of social insurance.

Beck also refers to 'three icons of destruction', which he defines as nuclear power, environmental despoliation and genetic technology. He analyses risk in his work on Chernobyl (1986) right through to the BP oil spill in the Gulf of Mexico (2010); encouraging critical reflection of ongoing potential of low-probability but high consequence disasters. In looking to the transformation of relationships between time, risk and space, he argues disasters like Chernobyl redefine the geographical boundaries of risk in surpassing spatial limits, whose results cannot be temporarily limited; stating 'the injured of Chernobyl are today, years after the catastrophe, not even born yet'. (5) Beck also looks to 'seriality of manufactured risks' that cannot always be attributed to solitary sources, such as cancer or VCJD. He argues that in advanced modernity, risk can not be seen as local and/or global but intertwined. 
According to Beck, the changing nature of risk is intrinsically wedded to the broader process of reflexive modernisation. (6) And the scope of his work does seem vast at times, but he speaks well to how the unmanageable quality of manufactured risk has adversely impacted on social institutions charged with maintain health and safety.

In looking to the disenchantment caused by the many developments within risk society, Ulrich Becks and Anthony Giddens both refer to Reflexive Modernisation Theory (RTM) to help address questions about societal risk with regard to social order, risk knowledge and institutional and political responses. Becks looks to the concept of 'Boomerang Effects' which he initially argues transcend boundaries of class in the 'risk society' given that 'radiation offers no privilege to any social grouping'. (7) Beck later revisits and amends some of his earlier comments on class and the ambiguity of risk though, as he looks to later global and workplace issues.

Giddens, on the other hand, argues that modernity represents a discontinuous break from past 'epoch'/eras. Central to his argument is the manufactured uncertainty and pervasive nature of risk that have led to institutionalisation of risk environments, including those of financial markets. (8) He looks to distinctive characteristics of institutions and argues three factors explaining the dynamism of modernity.

As with Beck, Giddens looks to separation of both time and space, but he also analyses the shifting of social systems via the mechanisms of symbolic tokens (money) and expert systems (science). He looks to the reflexive ordering and reordering of social, political and economic relations (e.g reflexivity in knowledge and reflexivity in action) (9) and suggests that factors producing erratic nature of modernity include 'unintended consequences' (aggravated systems complexity) and reflexivity or circularity of new knowledge, which alters the nature of the world. (10).

Giddens argues we are experiencing the modernisation of modernity itself and that 'Industry, science and technology - the very institutions that have reduced premodern threats such as famines and that have produced many benefits for humankind - are paradoxically the genesis of this manufactured uncertainty.' (11) 
It is Anthony Giddens (1990) who first describes risk society as a juggernaut in a 'runaway world' (2003) that seems increasingly out of control,(12) as institutions increasingly come up against their own limits. Giddens reiterates that much of the risk we are now experiencing in high modernity is human-created; that 'natural catastrophes or external threats are now trumped' (no pun intended) in the modern era in 'frequency, magnitude, spread and catastrophic potential' (13) and that 'the increased degree of manufactured uncertainty and the pervasive spread of risk have lead to the institutionalisation of risk environments.' i.e that these are systems constituted through risk, rather than risk just being incidental to them. (14)

Giddens suggests that in late modernity (which he also refers to as 'radicalised modernity') there are specific aspects of institutionalised risk that need highlighting. The first is that all of us are exposed to risk, regardless of outcome or benefit; even if we did not want to be part of it in the first place i.e it is also increasingly complex to opt out. The second aspect of institutional risk is that, given intersecting cultures of low-probability, high consequence risk, these institutionalised risk environments carry the possibility of extreme disaster e.g global change, or a Great Recession as in the near collapse of the world financial economy (2008). This can be equally true of our workplace culture 'the more calamitous the hazards invoked 'the less' we have any real experience of what we risk: for if things go wrong, it is already too late.' (15)

It is not all doom and gloom though. Becks and Giddens do introduce us to Reflexive Modernisation Theory (RMT) with its emphasis on 'self-transformation of modern society' (Beck 2009) as a way of looking to issues of emerging social conflict and rapid technological and social change. (16) RMT sometimes has a lack of sensitivity to some historical questions though, and even Becks came to acknowledge that it can be a bit Eurocentric at times; but Beck also theorizes that the source of institutional influence in individual actions is carried out through systems of subpolitics and both he and Giddens look to macro-structural and mirco-agency risk awareness that might lead to shifts in governance structure and management strategies. (17) To follow are charts compiled by Eugene Rosa, (et al) depicting Key Characteristics of the Risk Society (2014) and Comparing Beck and Giddens on Risk Theory Insight (2014). 


\section{Key Characteristics of the Risk Society}

As represented in the work of Rosa, E.A. Renn, O. and McCright, A., eds. (2014) The Risk Society Revisited: Social Theory and Governance, USA: Temple University Press, p. 75

\begin{tabular}{|c|c|c|}
\hline & Modern Industrial Society & Risk Society \\
\hline Origin of mega-risks & $\begin{array}{l}\text { Earthquakes and floods } \\
\text { caused by nature or God }\end{array}$ & $\begin{array}{l}\text { Climate change is caused } \\
\text { by human decision making }\end{array}$ \\
\hline Modernization process & $\begin{array}{l}\text { Simple modernization } \\
\text { from agrarian to industrial } \\
\text { society (modernization of } \\
\text { tradition) }\end{array}$ & $\begin{array}{l}\text { Reflexive modernization } \\
\text { from industrial to risk } \\
\text { society (radicalization of } \\
\text { modernization and } \\
\text { rationalization of } \\
\text { rationalization) }\end{array}$ \\
\hline $\begin{array}{l}\text { Prevailing type of } \\
\text { differentiation }\end{array}$ & $\begin{array}{l}\text { Class positions } \\
\text { (rich vs. poor) from } \\
\text { distribution of goods }\end{array}$ & $\begin{array}{l}\text { Risk positions (different } \\
\text { grades of 'affected') from } \\
\text { distribution of bads. }\end{array}$ \\
\hline $\begin{array}{l}\text { Transformation of human } \\
\text { actors }\end{array}$ & $\begin{array}{l}\text { Detraditionalization and } \\
\text { early individualization }\end{array}$ & Heightened individualism \\
\hline $\begin{array}{l}\text { Human perception } \\
\text { of risks }\end{array}$ & $\begin{array}{l}\text { Retention of cognitive } \\
\text { sovereignty }\end{array}$ & $\begin{array}{l}\text { Loss of cognitive } \\
\text { sovereignty (dependence } \\
\text { on science to tell us how } \\
\text { badly we are in trouble) }\end{array}$ \\
\hline Emerging mode of science & Primary scientization & Reflexive scientizaton \\
\hline Main line of conflict & Relations of production & Relations of definition \\
\hline $\begin{array}{l}\text { Preeminent political } \\
\text { paradigm }\end{array}$ & $\begin{array}{l}\text { Retention of national } \\
\text { sovereignty }\end{array}$ & $\begin{array}{l}\text { Emergence of } \\
\text { cosmopolitanism }\end{array}$ \\
\hline Management of risks & $\begin{array}{l}\text { Attempts are appropriate } \\
\text { to the magnitude and } \\
\text { scope of risks }\end{array}$ & $\begin{array}{l}\text { Magnitude and scope of } \\
\text { risks outpace conventional } \\
\text { attempts to manage them }\end{array}$ \\
\hline
\end{tabular}




\section{Comparing Beck and Giddens on Risk Theory Insight}

As represented in the work of Rosa, E.A. Renn, O. and McCright, A., eds. (2014)

The Risk Society Revisited: Social Theory and Governance, USA: Temple University Press, p. 96

\begin{tabular}{|c|c|c|}
\hline Key Characteristics & Ulrich Beck & Anthony Giddens \\
\hline $\begin{array}{l}\text { Theoretical emphasis on } \\
\text { order/stasis or } \\
\text { conflict/change }\end{array}$ & $\begin{array}{l}\text { Emphasises } \\
\text { conflict and change }\end{array}$ & $\begin{array}{l}\text { Emphasises } \\
\text { conflict and change }\end{array}$ \\
\hline $\begin{array}{l}\text { Continuity or } \\
\text { discontinuity with the } \\
\text { past }\end{array}$ & $\begin{array}{l}\text { Magnitude and scope of } \\
\text { risks bring } \\
\text { discontinuity with the past }\end{array}$ & $\begin{array}{l}\text { Institutionalised risk } \\
\text { environments of global } \\
\text { scale force discontinuity } \\
\text { with the past }\end{array}$ \\
\hline Structure or agency & $\begin{array}{l}\text { Structural changes } \\
\text { create new opportunities } \\
\text { for agency in non- } \\
\text { institutional locations }\end{array}$ & $\begin{array}{l}\text { Structuration is synergy } \\
\text { between actor agent and } \\
\text { social structure }\end{array}$ \\
\hline Descriptive or prescriptive & Descriptive or prescriptive & $\begin{array}{l}\text { Mostly descriptive, but a } \\
\text { little prescriptive }\end{array}$ \\
\hline $\begin{array}{l}\text { Ontology and } \\
\text { epistemology of risk }\end{array}$ & $\begin{array}{l}\text { Realist ontology; } \\
\text { opposes naïve realist } \\
\text { epistemology; } \\
\text { expresses partially social } \\
\text { constructionist ideas } \\
\end{array}$ & $\begin{array}{l}\text { Realist ontology; } \\
\text { critical realist } \\
\text { epistemology; }\end{array}$ \\
\hline $\begin{array}{l}\text { Prevailing } \\
\text { characterisation of risk }\end{array}$ & $\begin{array}{l}\text { Risk as master frame; } \\
\text { defining characteristic } \\
\text { of advanced modernity; } \\
\text { risk exposes paradoxes of } \\
\text { advanced modernity }\end{array}$ & $\begin{array}{l}\text { Risk manufactured } \\
\text { uncertainty is emblematic } \\
\text { of modernity }\end{array}$ \\
\hline $\begin{array}{l}\text { Emphasis on which social } \\
\text { actors as risk agents }\end{array}$ & $\begin{array}{l}\text { Individuals and } \\
\text { institutions; largely ignores } \\
\text { organisations }\end{array}$ & $\begin{array}{l}\text { Individuals and } \\
\text { institutions; largely ignores } \\
\text { organisations }\end{array}$ \\
\hline
\end{tabular}




\begin{tabular}{|l|l|l|}
\hline $\begin{array}{l}\text { Are we creating risks } \\
\text { more rapidly than we can } \\
\text { understand and manage } \\
\text { them? }\end{array}$ & Yes & Probably \\
\hline Tone & $\begin{array}{l}\text { Wants to be optimistic but } \\
\text { is actually quite pessimistic }\end{array}$ & Is mostly optimistic \\
\hline $\begin{array}{l}\text { What is the way out of } \\
\text { our predicament? }\end{array}$ & $\begin{array}{l}\text { Radicalisation of } \\
\text { modernisation }\end{array}$ & $\begin{array}{l}\text { Modernisation of } \\
\text { modernisation }\end{array}$ \\
\hline
\end{tabular}

Overall, Giddens seems to present a slightly more optimistic outlook for the future. He suggests ways to reflexively mobilise collectively with potential to drive key concepts of life politics. He theorizes the source of influence is 'collectivised individuals who are prepared to join social movements about unacceptable risks, about systems to govern them or about societal management of them'; (18) that this is possible by the humanising of technology, the use of the internet, global networks and systems of governance to further 'democratize democracy'.

I would argue that we now have a few more slightly Orwellian issues to deal with in an age of Trumpism, but the work of Becks and Giddens remain an effective foundation template from which to begin an introduction to our journey through the construction of risk in order to find more effective strategies to bridge dialogue and democracy that confront and deals to risk society of our present day working lives. 


\section{(II) Neoliberalism - Risk and Power}

'The advocacy of neoliberalism by business and the Treasury is highly significant, because business interest groups are able to exert disproportionate influence over state policy formulation and Treasury is strategically located within the machinery of government to exert more influence over Cabinet than any other state agency'. - Roper (2005) Prosperity for All? Economic, Social and Political Change in New Zealand since 1935, NZ: Dumore Press, (xxi)

With all that is implied in much of the media and related networks both nationally and globally it would be easy to sometimes feel confused by neoliberalism and all its associated phraseology of prolonged economic liberalisation reform, privatisation, deregulation, lifting and/or applying of tariffs, free trade, austerity, reductions in government spending (particularly in welfare, education and health); all to increase the role of the private sector in the name of a mythical trickle-down economy.

Late twentieth/twenty-first century neoliberalism is in fact a resurgence of concepts associated with the neoclassical tradition (or laissez faire economic liberalism) of the nineteenth century. And central to neoclassicism is the belief that the economy is self-adjusting; that it always tends towards a market-clearing general equilibrium in which all resources are fully employed and everything that is produced, is sold' (19) .

In both traditions of neoliberalism and neoclassicism, the government plays a limited role in redistributing income through taxation and welfare. In fact, in pursuit of its balance of payments equilibrium, the government tries not to interfere in dealings of private enterprise too much at all. Reduction of expenditure can become a process that then continues over decades, right alongside increased taxation (of all, but the upper percent) as successive governments liberalise regulatory control over markets.

As is often the case, there might initially seem to be a higher rate of employment (20) generated by some of these changes in the medium term, which feeds back into the myth of some 'spontaneously' generated 'trickle down' economy; but in reality the majority of profit does not often trickle down to the workers but instead, tends to 
gush right back up to private companies who are sometimes only temporarily located in order to accomplish their tight schedules and profit margins, and who also tend to often employ 'short cuts' and/or practices not typically allowed in their own place of origin, as the role and vigilance of government shifts in this paradigm.

In this thesis I hope to begin a much needed conversation around neoliberalism and issues related to power, and risk in the Aotearoa/ New Zealand workplace; as in fact, neoliberalism revives many of the central assumptions of neoclassicism and is most accurately viewed as a contemporary variant of it.'(21) For now though, it is important to describe more of the political context from which neoliberalism sprang.

I write, for example, from the view that neoclassicism operated (pre-1936) in this country and that neoliberalism occurred from late 1970 s onwards. I would also argue that as of (2016) we are on the cusp of not only late neoliberalism, but that of a potentially new political era globally; the shape of which we probably have not seen in decades (but which has visited us before). It is a space in time we should also have anticipated, but failed to see (and still refuse to see). This, ironically enough, could now also follow some of the lines of denial I introduce here at the mirco-level of the workplace. For the purposes of this dissertation however, I keep the discussion within the last years of neoliberalism and the era of 29 deaths at Pike River Mine.

In my introduction to geographic and historic context I described certain social and developments in industrial relations on the West Coast and larger New Zealand (22) and I will now return to the post-World War (II) era in which this country also developed upon a social democratic Keynesianism paradigm for policy making. (23)

Unlike neoclassicism and neoliberalism, the Keynesian view point argues that market economies are not self-adjusting and are therefore incapable of translating poverty into 'potential plenty' without some guidance and direction. (24) In a New Zealand context, this would mean that government practises vigilance and responsibility as Kiatiaki (25) and be prepared to intervene if required for the wellbeing of all society; for as has already been proven in times of recession (and specifically of the Great Depression) the economic system is 'capable of remaining in a chronic condition of 
subnormal activity for a considerable period without any market tendency either towards recovery or total collapse'. The Keynesianism viewpoint also emphasises that in such cases government needs to intervene as 'market economies tend to distribute income and wealth in a highly unequal manner, and state has a legitimate role to play in redistributing income in order to ameliorate social inequality.' (26)

So with regard to major turning points, there was a big shift from neoclassicism to Keynesianism in 1935 when the first Labour Government of New Zealand developed a social democratic Keynesian policy which underlay developing policy through the Great Depression and World Wars and into to the mid-1970s. Via Keynesianism, the Social Security Act of 1938, established, for example, benefits for all New Zealanders including superannuation, the widows, family, invalid, sickness and unemployment benefits (among many others) right through to the introduction of the domestic purposes benefit (1973); the establishment of the Waitangi Tribunal under the Treaty of Waitangi Act (1975) and the introduction of New Zealand Superannuation Act (1974) which was a universal superannuation scheme for all New Zealanders. A change to neoliberalism however, was about to embed itself for the next decades.

The monetarist and new classical schools of thought successfully overturned Keynesianism and created a new monetarist orthodoxy which prevailed from the late 1970's until the late 1990's. In the process it revived many of the central theoretical precepts of the neoclassical orthodoxy that had prevailed prior to the Great Depression. (27)

The benefit of Keynesianism continued for a while, of course, into this new era but was increasingly undermined around issues of economic stagnation in a fading post war boom, issues of unemployment and unrest, common to the rest of the world.

The next defining shift for Keynesian macroeconomics in New Zealand could be said to be in 1984 with the election of the fourth Labour government and its rapid implementation of neoliberal policies from 1984-1990. This followed from the Third (Muldoon) National Government (1975-81) with its 'Think Big' policies, wage price freeze, social unrest, and the tax avoidance, continued via subsequent governments. 
The political instability, abandonment of social democratic Keynesianism, and adoption of neoliberalism that had characterised parliamentary politics since the mid-1970s can be interpreted as crisis management by governments wrestling with economic forces over which they have limited, but still significant control. (28)

There were also splits among many traditional supporters of Labour post-1984 as they witnessed neoliberal policies pursued over the next years deregulate the economy, dismantle the welfare state and introduce 'user pays'; a process that was readily continued with the election of the next National Government in 1990 and which became known to many internationally as the 'New Zealand Experiment' (29)

Other governments around the world were watching for the outcome of this switch to neoliberalism on our economy, with Britain to take up our template of change as New Zealand was lauded by some as 'an international model for economic reform' (30); the most thorough-going economic reform in the OCED'; (31) 'out-Thatchering Mrs Thatcher' (32) with its 'trail-blazing economic reforms' (33) and a 'paradise for free-marketeers - if not for New Zealanders, who have lost their jobs'. (34)

Unemployment and poverty became structural features of New Zealand life. The Labour government had been responsible for the early decline, with rising unemployment, failure to keep benefits and family assistance in line with inflation, and the favourable tax treatment of the rich at the expense of the poor. Its National successor had further fuelled unemployment and deregulated the labour market to force wages and penal rates down. It had slashed benefit levels, tightened eligibility criteria, imposed user charges and suspended inflation-indexing for family assistance and income support. (35)

Alongside all these changes came the restructuring of primary, secondary and tertiary education; the privatisation of many aspects of public health; the introduction of student loans and an increased culture of risk tolerant regulation. (36) 
The one consistency in the next decades seems to have been the associated rhetoric used and which often confused those at the receiving end of all these social changes.

The use of the term 'Third Way' to describe an era of subsequent change in social and economic development both here and in Britain is, for example, notoriously hard to define. It could be argued the term was used in later years to imply there was some sort of difference between it and neoliberalism when, in fact, it was often used to 'soften' concepts of the neoliberal policy regime; (37) as in presenting the continued neoliberal micromanagement (with its increase state involvement in all these areas and infrastructure of the economy) as something a little more palatable for the general populace who had to live with the consequences of its social reforms.

Jane Kelsey (2015) whose speciality is in the critique of law and policy under neoliberalism, speaks to this more recently in her work 'the Fire Economy' (38) with specific reference to her original analysis of 'the New Zealand Experiment' (1995) and uses the metaphor of the Fire Economy to describe the shift in global capitalism since the 1970s and more specifically to recent times, arguing as follows:

While a lot has been written about the causes of and responses to the Global Financial Crisis (GFC) there is a real gap in the literature on the dependence of the Fire Economy (Finance, Insurance, Real Estate) on neoliberalism. In New Zealand the need to address that relationship is particularly acute, because our unique brand of neoliberalism was designed to be very hard to change.... My original goal was to write a sequel to the New Zealand Experiment (1995) to show how New Zealand's neoliberalism has become embedded over three decades and what barriers that poses to a post-neoliberal transformation. The fallout from the GFC and our own troubles: finance company collapses, post-earthquake insurance, urban and rural property bubbles, and massive national and household debt - refocused my priority on the co-dependence of neo-liberalism and FIRE economy. (39)

I will refer back to this as this thesis proceeds. In the meantime, to follow is an introductory historical overview to the development of policy in New Zealand: 


\section{An Historical overview of policy in New Zealand $(40)$}

As is represented in the work of Maidment, J and Beddoe, L. (2016) Social Policy for Social Work and Human Services in Aotearoa New Zealand: Diverse Perspectives, N.: University of Canterbury, p. 61.

\section{0: The beginning of colonisation}

The Treaty of Waitangi is signed and a Eurocentric approach to social policy emerges.

\section{0s: Liberal views of state}

Welfare is delivered through the English Poor Law 1601, premised on the idea of deserving and undeserving poor. Welfare is primarily delivered by churches and benevolent societies. Specific policy examples include world firsts that promoted individual rights and freedom:

- 1893 Women's Franchise - Women are granted the right to vote in parliamentary elections

- 1898 Old-Age Pension Act - Provision of a means-tested retirement scheme

- 1881: The Adoption Act.

\section{0s: Social democracy}

Established in 1938, the welfare state embodied many of the principles of social democracy. The 'cradle-to-the-grave' provision of welfare was manifested in universal benefits, state housing and free education. Two examples are:

- 1933: Labour's Elizabeth McCombs is elected as first woman member of parliament

- 1938: Social Security Act establishes benefits including superannuation, the widows' family, invalid, sickness and unemployment benefits, among others. 


\section{0s: Rights-based social policy}

The social policy approach of the 1970s focused on rights as citizens. It included the emergence of feminist discourse through the women's liberation movement and development if a Maori rights movement. Policies included:

- 1973: introduction of the Domestic Purposes Benefit

- 1975: establishment of Waitangi Tribunal under the Treaty of Waitangi Act

- 1974: accident compensation - universal no-fault compensation for personal injury

- 1974: New Zealand Superannuation Act - a universal superannuation scheme for all New Zealanders.

\section{0s and 1990s: Neoliberalism - Scaling back the state}

There are numerous examples of neoliberal social policy adopted in New Zealand during the 1980s and 1990s. Following the election in 1984 the government began a consistent approach of deregulating the economy and dismantling the welfare state, alongside the introduction of 'user pays' for tertiary education and healthcare. Policy examples include:

- 1984 Rogernomics: market structuring deregulation and privatisation

- 1986 the State Owned Enterprises Act - the establishment of governmentowned companies in areas including transport, electricity and communications to increase competition and improve profitability of the public sector (many of these companies were subsequently sold)

- 1991 the Employment Contracts Act, which was based on the idea that employment negotiations should occur between employer and employee directly, thereby removing the power of the unions

- 1991: the 'Mother of all Budgets' (Ruthanasisa), entrenched government spending, cut benefits and introduced market rents for state housing 
- 1992: Occupational Safety and Health (OSH) Act.

- 1993: the Health and Disability Services Act - established health providers as for-profit enterprises

- 1998: introduction of the community wage - a 'work for the dole' scheme.

2000s: Social Development

Elected in December 1999 - the fifth Labour government spent the first years in power undoing many of the neoliberal policies of 1990s. They then began a process of reform premised on social development. Policy examples include:

- 2000: the Housing Restructuring Amendment Bill, which reinstated incomerelated rent for state housing

- 2000: the abolition of interest on student loans

- 2001: Social Security Amendment Act - disestablished the community wage

- 2001: the release of the policy document, Pathways to Opportunity

- 2003: the Prostitution Reform Act, which decriminalised prostitution

- 2004: Working for Families - tax credits for families

- 2004: The Civil Union Act - which recognised gay, lesbian and heterosexual couples relationships

- 2006: Kiwisaver- A state subsidised retirement scheme

- 2007: the Crimes (Substituted Section 59) Amendment Act, which removed the defence of reasonable force in the discipline of children.

\section{8: The New Right}

A National-led coalition government was elected in November 2008. The policy agenda reflected a neo-conservative agenda, premised on getting tough on law and order, reducing the role of the state and reforming welfare. Policy examples include: 
- 2008: tax cuts - the top personal tax rate was reduced from $39 \%$ to $33 \%$

- 2008: the Employment Relations Amendment Act which allowed staff to be dismissed without reason, within 90 days of starting a new job

- 2010: the Sentencing and Parole Reform Act, (three strikes policy)

- 2010: the creation of the Auckland super city

- 2012: the Public Finance (Mixed Ownership Model) Amendment Act relating to asset sales

- 2012: welfare reform - three new benefit categories were introduced, alongside a youth payment card, sanctions and social obligations for beneficiaries

- 2014: changes to social houses.

It is in looking to this foundation of political change and following the threads that wove themselves through successive governments of this country in terms of economic, social and industrial reform that we finally have a context in which to look to the injury and death rate in the New Zealand workplace of later years, and to what may have happened at Pike River Mine (2010) and which did not end there.

With regard to related policy, there were major pieces of positive legislation later developed in New Zealand in response to the case of Pike River Mine despite the political climate of the times and the many obstacles on the way to accomplishing any of it. There was for example, Andrew Little's Crimes (Corporate Manslaughter) Worksafe New Zealand Amendment Bill 2012 which was written to deter and respond to events like the Pike River explosion(s). (41) It was not passed; a fact that should not be overlooked in light of all that has just been discussed but other acts soon followed it in direct response to the case of Pike River Mine; as in the Health and Safety in Employment Amendment Act (2013), the Worksafe New Zealand Act (2013), the Mines Rescue Act 2013. Some of Andrew Little's proposals were also implemented in the Health and Safety at Work Act (2015); all of which began life as 
the Health and Safety (Pike River Implementation) Bill, as was recently pointed out by criminologist Dr Sarah Monod de Froideville (42) of Victoria University, Wellington.

As of May (2018) Dr Stephen Blumenfeld, director of the Centre for Labour, Employment and Work at Victoria University also referenced that negligence is indeed missing in the Crimes Act Repeal and that 'an offence of corporate manslaughter is needed to hold organisation and executives at the highest level accountable for deaths resulting from management findings'. (43) In referencing this, he speaks to the deaths of 115 people in the collapse of the CTV building as a result of the 2011 Christchurch earthquake and to a number of other workplace disasters.

I also argue along with Roper (2005) and Kelsey (2015) that there is an urgent need to look directly to institutional factors too, as 'these are important in explaining why the neoliberal reform program was implemented more rapidly and comprehensively in New Zealand than in more other advanced capitalist countries.' (44)

\section{(III) Positive Asymmetry and Risk}

Following the argument of Cerulo (2006) (45) positive asymmetry could be described as our ability to distance 'the worst' in order to meet intended goals. It involves habitual ways of thinking and behaving which increase our propensity to ignore the reality of an approaching worst case scenario in the drive to meet these targets.

Positive asymmetry is increasingly lauded in 'get rich quick' and 'think positive/reap positive' cultures but it can be lethal in mining and other hazardous workplaces; particularly when there is pressure for positive outcomes to meet demands of the market which override pre-existing flaws in systems and culture. Positive asymmetry encourages an attitude of 'ongoing positivity' where a climate of negativity might otherwise prevail and affect and/or hinder goals and workplace outcomes.

Positive asymmetry might initially seem to favour the wellbeing and financial good of both the worker and the overall industry until it creates a blind spot which affects 
the vision to contemplate even the possibility of a worst case scenario; often putting workers and the community itself at risk of financial loss, accident or even death.

Cerulo (2006) states cultural practices integral to understanding positive asymmetry involve ways of thinking and behaving that have often become so routine as to be acted upon subconsciously. These include acts of eclipsing, clouding and recasting which Cerulo also defines with associated practices: 'Eclipsing' for example, includes acts of banishing, physical seclusion, shunning. 'Clouding' behaviours may also be coupled with acts of impressionism and shadowing. 'Recasting' involves rhetorical, prescriptive behaviours, all of which I will define further as the thesis proceeds. (46)

In a culture of positive asymmetry these practices are often communicated to a group in such a way that the practice itself becomes second nature; along with a blurred perceptual porthole for noting impending risk or an approaching worst case scenario. Positive asymmetry might, for example, aim to distance 'negative thinking' about an intended production target, in order to meet it. It encourages 'positive thinking' with a tendency to 'background the worst' in favour of embellishing the 'rewards', or simply 'bearing up for your mates'. It can become a perceptual pattern with a potential blind spot for acknowledging an approaching worst case scenario, in enough time to confront and avert it, while struggling to meet the specified goals. (47)

Positive asymmetry encourages not only emotional and financial rewards, it can often inadvertently foster a counter-culture of silence, isolation and even bullying; whereby routine acts (which might have started subconsciously) become so habitual as to translate into a conscious pattern of practices which over time, develop an alignment of systemic and cultural flaws within the fatality causation model itself. Unless intercepted, this can add to conditions of workplace tragedy. Cerulo states:

In identifying and exploring the practices that sustain positive asymmetry we learn something about the constitutive rules by which quality is defined. We learn something as well about the scope and consistency of culture's impact on cognition and resulting action. For the practices that support positive 
asymmetry, although not universal, remain strikingly consistent across social situations and equally recalcitrant through time. (48)

In her own study, Cerulo chose four historic events and examined the role that positive asymmetry played in each of them. (49)These included an examination of

(1) Challenger Space Shuttle (1986) disaster;

(2) Phoenix Memo/NYC Twin Towers (2001);

(3) Y2K (2000);

(4) SARS Outbreak (2002);

Cerulo analysed how, when all four scenarios had been presented with certain 'prior knowledge' the first two scenarios i.e The Challenger (1986) and the Twin Towers (2001) ended in calamity, while the latter two i.e Y2K and the SARS Outbreak (listed) were subsequently averted. She asked why this was so and looked to cognitive and cultural acts integral to positive asymmetry; analysing samples of associated behavioural practices. Cerulo noted that those industries fundamentally attuned to being consistently on the lookout for the worst case scenario also tended to be more likely to locate threatening scenarios and act ahead of time, averting disaster.

She noticed commonalities existing within the approaches of both the medical and ICT industries, for example, in relation to the efficient aversion of both Y2K and SARS threats. Cerulo noted the approaches of these industries tended to be autonomous, service oriented and dominated by 'formal knowledge'. She went on to describe these as often exhibiting porous community boundaries. These also often held explicit beliefs from highly articulated script for action and despite affiliation with organisations, maintained considerable ability to monitor and control themselves (50)

Cerulo cites computer operators, programmers, systems analysts (COPS) and medical practitioners (MPs) as examples of groups who actively practise positive asymmetry in reverse; that is, negative asymmetry. She found these specific industries tend to be dynamic, flexible and willing to communicate on multi-dimensional levels. Each generally worked via structural webs which encourage 'thinking outside the box', 
often breaking with cultural conventions to find not only satisfactory, but innovative solutions. (51) Cerulo emphasises when these characteristics 'occur in combination, they create a distinct type of social structure; an emancipating structure... Such a structure can free groups, communities from the constraints of perceptual conventions...Thus, beyond MPs, beyond COPS, any group or community structured in this way can leave positive asymmetry behind' (52) working to common goals, and achieving exceptional outcomes with less error and potential for tragedy.

When considering Cerulo's work and looking to the findings of the Royal Commission of Inquiry (53) it is easy to see that Pike River Mine was not such an emancipating structure. It was in fact, one which follows quite well Cerulo's (54) description of positive asymmetry, in that it seemed to have a repetitive blind spot for a developing worst case scenario, even when flags were raised, warning of impending tragedy.

There were numerous warnings of potential catastrophe at Pike River Mine. One source of these was the reports made by the underground deputies and workers. For months they had reported incidents of excess methane. In the last 48 days before the explosion, there were 21 reports of methane levels reaching explosive volumes; 27 reports of lesser but potentially dangerous volumes. Reports of excess methane continued up to the very morning of the tragedy. The warnings were not heeded. (55)

In fact, the Royal Commission of Inquiry found there were 1083 reported incidents leading up to the 2010 Pike River Mine tragedy. It summarised 436 of these in a schedule under the following headings: methane spikes, ventilation spikes, strata, bypassing of safety devices, equipment sparking. (56)

So what exactly was happening at Pike River Mine? The findings clearly show there were people working at all levels of the system who knew dangerous incidents were occurring at the mine that were not being resolved. These incidents were reported by workers and management. Why were these warnings not heeded? Why did this awareness not translate into preventative action? To understand this, there is a need 
to look into some of the practices inherent in positive asymmetry and how these might apply to the findings of the Inquiry into the Pike River Mine fatalities of 2010.

\section{Eclipsing, Clouding and Recasting Practices}

Elusiveness is neither natural nor accidental. Our inability to see or imagine 'the worst' stems from institutionalised cultural practices; practices that routinely eclipse, cloud or simply recast our conceptions of quality. With 'the worst' distanced from view so systematically, groups and communities are left with a brighter vantage point on the world, a place where [only] the best case scenario remains centred in gaze. (57)

As cited previously Cerulo (2006) groups cultural practices of positive asymmetry into three categories and their associated behaviours. (58) These are as follows:

Eclipsing Practices (acts of banishing, physical seclusion, shunning)

Clouding Practices (acts of impressionism, shadowing)

Recasting Practices (rhetorical, prescriptive behaviours)

\section{(i) Eclipsing Practices}

According to Cerulo (2006) (59) eclipsing practices include acts of banishing, physical seclusion and shunning. They are used to make the 'negative' aspects of a potentially unwanted scenario, functionally 'invisible'. (60) Added to these are behaviours which include shaming, blaming, ignoring; diverting the bearer of unwanted information. These practices are used to make the 'worst' invisible, in order to focus on the 'best' and to distract from any acknowledgement of an impending worst case scenario.

Many examples of eclipsing practices abound in the research of Cerulo (2006) and Vaughan (1996); as in reference to the Challenger disaster (1986) whereby 'those who practiced positive asymmetry overpowered group members who championed a worst case image' (61) of a pending problem (the 0-rings) but whose mission still 
continued on the trajectory to launch deadlines regardless; culminating in the death of all seven crew members in January 1986. Such practices are aspects of positive asymmetry and are equally the girders to a culture of socially organised denial. (62)

Cerulo further emphasises that eclipsing practices are not isolated acts. These are usually initiated in a moment of clear acknowledgement (63) whereby 'faults' might be eliminated, for example, by prioritizing the company's virtues. The worst case scenario might be 'ever-present', but seldom articulated and never scrutinized. (64) It follows that if there is ever any danger of 'collective acknowledgement' of the worst, then 'the worst' is swiftly 'removed'; (65) or at least, distanced by these eclipsing practices (66) in order to reach a predetermined goal without being deterred from it.

Cerulo cites another example of this 'failure to see' in referring to the US electronic communication now dubbed the 'Phoenix Memo' (67) As early as May 2001, concerns were actually voiced of a potential domestic terrorist event involving the use of planes to attack civilian targets internally in the United States.

'The intelligence community may have been more attuned to the worst case scenario than the White House and its Cabinet... but they were convinced attacks would target US interests overseas. Consequently the potential of a domestic incident was eclipsed as inconsistent with reasonable expectations.' (68)

\section{(ii) Clouding Practices}

According to Cerulo (2006) Clouding Practices are behaviours which keep the worst visible, but vaguely defined. (69) She cites two main categories of clouding practices underpinning positive asymmetry, that of (a) Impressionism and (b) Shadowing.

\section{(a) Impressionism}

The group or community is actively discouraged from pursing any correction that might bring the worst into focus. Cerulo compares this to the scenario of standing before the painting of an impressionist; a near sightedness might 
occur with the features seemingly blurred. There might even be a little doubt that what you are seeing is in fact, what others are actually seeing. (70)

\section{(b) Shadowing}

Images are presented to individuals/community in terms of the "best versus the worst' (71) Overpowering images of excellence might, for example, be used with amplification of information on the 'finest' scenario. Positives and highs are exaggerated in such a way they effectively shadow the 'lows'. (72)

Cerulo identifies governments as the most prolific agents of shadowing practices especially in times of chaos where victories are amplified to overshadow worst case scenarios like injuries and potential annihilation. When 'unforeseen' tragedy or 'financial fall-out' occurs, the facts, figures and events will abound with spin to reassure entire audiences that 'all was done' in the interests of the nation, the economy, or local business to determine the most 'positive outcomes' that we are all promised from some 'trickle down affect' when targets are reached in the future.

Awards are crucial to the shadowing process and are often bestowed in excess; (medals in war, tax cuts, bonuses, promotions in business) to feather a further culture of positive asymmetry where workers, community and investors are situated at a best case-porthole. (73) With acts of shadowing and impressionism, however, a certain 'looking out' for some affirmation from the 'experts' will often occur. Once affirmation is received from some 'higher' realm in workplace culture, for example, the employee might go back to stand before the same impressionist portrait (74) of the dilemma hung before them with the overall view not any clearer than it was before; but now there is new doubt in their own very real world experience and interpretation of it. I argue that when everyone is standing in the silence of positive asymmetry before this picture of 'risk and reward' the whole workplace culture may perform from a place of blurred denial; almost to the point at times, of re-enacting a contemporary version of the Emperor's New Clothes. Still waiting, and reinforced by a system of positive asymmetry, everyone is now resigned to think that when in doubt, it is best just to remain silent so as not to appear foolish. 
In cultures of positive asymmetry, Cerulo also cites acts of 'clouding' as not dissimilar to practices of 'eclipsing', in terms of hiding and blocking behaviours; the difference being, that clouding practices ensure that if there is ever any identification of the 'worst case' scenario then that 'voice' is 'brought to account' or swiftly removed. (75) I argue that in workplace culture, such a voice might even be subtly 'demoted' by not being 'promoted' at all over time. The image here, is still one of the 'blurring' of details and self esteem; not only of the individual but of the entire group who might now find it hard to focus on the 'worst' for long enough to ever actually confront it.

\section{(iii) Recasting Practices}

Cerulo states that recasting practices are used to help a group or community to reconstruct a tragedy in the best light; so the worst case scenario is redefined as an opportunity to 'see past' and/or glorify this obstacle or calamity. These practices are categorised as being either (a) rhetorical or (b) prescriptive. (76)

\section{(a) Rhetorical}

These are practices where the negative is reframed. Examples of this are often enacted following atrocities and 'natural' disasters. I found many examples of rhetorical framing following my own personal experience of the London July 7 bombings (2005) and later, the experience of friends in the Christchurch New Zealand Earthquake (2011) where in the weeks following these tragedies, trauma was often ironically recast as something that has been 'sent to test us'; to show 'how strong we are' in striving for 'better outcomes'. Following Cerulo (2006) this is often sugar-coated with ideals of the 'worst' somehow co-existing in some other 'noble' dimension. The tragedy might become inverted and decorated with phrases of grandeur; so that the worst case scenario might now (even more ironically) be refashioned as something momentous and important to individual or group development. 


\section{(b) Prescriptive}

These are practices which describe a negative outcome as an opportunity; never an obstacle; always a 'lesson to learn from'; always a 'chance to reconstruct'. Cerulo would argue 'prescriptive' practices have many characteristics of 'rhetorical' recasting, but they do not come sugar-coated with a more 'noble dimension'. Prescriptive recasting is often utilised with demands and certain judgements attached. There is usually a call to 'harden up', to 'move beyond negativity' and to view, for example, the introduction of the new, untested technology of hydro mining at Pike RiverMine in 2010 (right alongside that of the newly introduced and competitive bonus system to reward production targets) as something to benefit all; regardless of the potential for signs of risk to now be completely ignored in the drive to meet company targets. Prescriptive recasting might also be used post-disaster or tragedy, to have an audience or even a nation believe there is something wrong with those still found to be protesting, angry and/or grieving at all.

As this thesis proceeds I will expand these definitions and give examples of positive asymmetry as it relates to Pike Mine using my own data and findings of the Royal Commission to show how eclipsing, clouding and recasting practices underpinned the culture of production that lead to the deaths of 29 men at the mine in 2010.

Other than links to be made between risk and cognition (Cerulo 2006, Norgaard 2011), there is also literal, interpretive implicatory denial (Cohen 2001) and often repetitive organisational risk taking (Vaughan 1996) to be considered in any analysis. Added to this, the interconnected issues of power (Perrow, 1999) and recreancy (Freudenburg 2013) making it clear just how difficult it might be to find a voice in the risk society (Beck, Giddens 1992) let alone a collective one in a climate of power and asymmetry supported by deregulation where even experts are no longer listened to. 


\section{And Introduction to Theorising Accident Causation}

Within the literature of theorising accidents there is also an examination of the Accident Causation Model developed by psychologist, James Reason (77) who argues that workplace tragedy can be traced to four potential layers of failure at levels of

(1) organisation

(2) supervision

(3) preconditions

(4) unsafe acts.

At the Royal Commission of Inquiry (78) Dr Kathleen Callaghan, director of the Human Factors Group, School of Medicine, at the University of Auckland, presented the James Reason 'Swiss Cheese' Model of Accident Causation (79) and contributed to it her own very good interpretation of human science factors. Callaghan extended this model, referring to James Reason who argues that steps to prevent accidents can be viewed as barriers which are much like layers of cheese; that there are holes (flaws) in each of the four slices of this 'cheese' which represent weaknesses in layers of organisation, supervision, preconditions and unsafe acts. Most of these are usually manageable but given that some are often less so, there will always be a need for these to be closely monitored and managed for safety in the overall workplace. (80)

Callaghan uses this model to show that, should flaws or 'holes in the cheese' in any of the four levels of protection between hazards align and their safety systems fail, the overall severity of the 'accident' will be determined by the specific alignment and by the initial and ongoing reaction to it. She suggests a workplace model of potential accident causation should ideally represent 'Cheddar' vs. 'Swiss' cheese and that the fewer 'holes' or flaws at each level of the model, the better, for all concerned.

In order to prevent alignments of such flaws a deeper understanding of human factors science connected to the accident causation model is required. (81) Callaghan brings to the James Reason Model the need for consideration of inter-related health and safety factors to do with the (a) job (b) individual and (c) organisation. She 
argues the way human factors inter-relate must be actively evaluated and acted upon; but given that we do not live in a perfect world, human error must be taken into account with greater vigilance in creating safer workplace environments.

As a speaker at the Business Leaders' Health \& Safety Forum for ZeroHarm Workplaces in Christchurch, New Zealand (2013). (82) Callaghan argued that whether these holes in the safety defence slices of this model do align to cause an accident is often a matter of Sod's Law. She reiterates that no matter how good the system and processes are, people will always have the propensity to 'stuff up' i.e Sod's Law, and that a change of focus therefore is needed to create error-tolerant systems.

Realistically, the scientific evidence shows us, there is not much we can do to stop people from 'stuffing up'. There is a growing realisation that systems, therefore, must be designed to be error tolerant... Good workplace safety requires constant vigilance. Management and directors must make a personal commitment to eliminate any holes in their safety defences. (83)

Kathleen Callaghan states leaders who are under constant attack from 'Sod's Law' need to be extra vigilant and focus on the areas they can control, these often being:

(a) organisational factors that contribute to accidents

(b) quality of supervision

Figure 2: The James Reason (1990) Accident Causation Model (84)

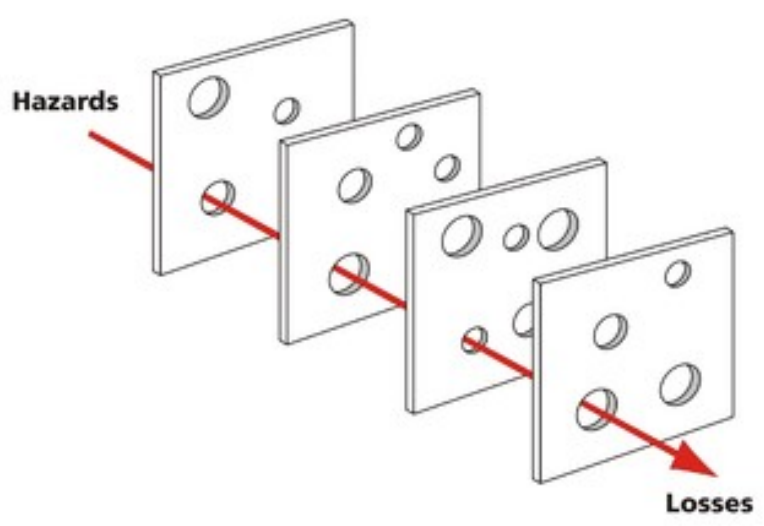


In her own analysis Dr Callaghan states that there are, of course, flaws at the level of 'Unsafe Acts' (85) in most industries as these directly relate to the actions and decisions of people in any company and that with humans being fallible there is a limit to what can be done to stop people making mistakes. Callaghan emphasises that this does not mean that we allow our 'Cheddar Model' to turn into one of the 'Swiss Cheese' variety. She urges business leaders to be more vigilant and to

(a) focus on areas where they have most control at levels (1) and (2)

(b) gain the commitment of CEOs/directors to minimize these flaws so the model resembles Cheddar as opposed to 'Swiss Cheese' and

(c) practise vigilance, never forgetting that 'Sod's Law' never rests (86)

Kathleen Callaghan adds to our understanding of what happened at Pike River Mine and her continued contribution to the accident causation model includes her positivity and dedication in educating business leaders, post-Pike on being vigilant. This includes encouraging leaders to recognise their own agency in creating a shift within their own processes and systems of organisation and supervision to create safer and, as a direct consequence, more productive workplace environments.

Callaghan and a 'Zero-Harm' (87) team of experts continued to run the seminars for business leaders in several main centres of New Zealand in the months following the publication of the findings of the Royal Commission (2012). But it is time others played their part. All the work that was initiated in the first years following the Pike River Mine tragedy cannot end there. There was too much left unresolved. The model of accident causation also needs to be examined in a New Zealand context. The British model was a good start but, as I will show in examining primary data, this model cannot fully describe what happened at Pike River Mine systemically.

I argue the findings of the Royal Commission show that the flaws in all four 'safety defence' levels of Pike River Mine were in fact, so numerous and 'riddled with holes' there was virtually no 'cheese' left to any line of defence. The work begun by Dr Callaghan was an excellent start and there needs to be further investigation. 
Looking to the findings of the Royal Commission I would also agree that the case of Pike River Mine would need to add to each of these four 'cheese' levels of the James Reason Model of Accident Causation the following findings for further consideration:

At the levels of (1) organisational (2) supervision

(a) lack of standard operating procedures

(b) rapid turnover of senior executives

(c) supervisors failing to enforce rules and

(d) even violating the standard operating procedures themselves

At the level (3) Preconditions

(a) decisions made around a new mine, located in a challenging, geographically faulted [gassier than usual] environment

(b) dynamics of employment when worker experience was available

(c) goaf/roof collapses, slips, deadlines, company cash flow problems

At the level (4) Unsafe Acts (88)

(a) it appears no one on the board had experience of local underground coal mining

(b) no qualified ventilation engineer was employed at the mine

(c) no secondary means of egress

(d) installation and positioning of underground fan

(e) inadequate Fresh Air Base (FAB); limited) O2 masks; faulty phone

(f) introduction of technology and vehicles unsuited to NZ conditions

(g) many major unattended faults i.e methane, drainage, ventilation

(h) introduction of hydro mining (July 2010) and a competitive bonus system to meet the December (2010) coal production targets

(i) repetitive failure to listen to warnings; to question and/or check for advice (at all levels of the system, from the top-down). 
At the level of 'Unsafe Acts' the Royal Commission of Inquiry found the failings at Pike River Mine to be numerous. In fact, I found these to be so numerous it became impossible to list them all within the confines of this dissertation. The case of Pike River Mine is one in which there were so many arrows of causation driven through the many pre-existing and developing holes (flaws) of all four levels of the James Reason Model of Causation that this 'Swiss Cheese' Model might be better described as 'Feta' as there was so little left of its levels of defence at Pike by November 2010.

This suggests a need to look at other theorists who might also add to our knowledge of the cultural logic and power (Perrow, 1999) and which possibly lay beneath levels of risk at Pike River Mine and perhaps the fatalities of other New Zealand industries.

In this dissertation I will build on the work of Kathleen Callaghan by drawing on insights from the sociology of organisational disasters and begin with the concept of 'positive asymmetry' as explored by sociologist Karen Cerulo.(89) As previously cited, positive asymmetry involves habitual ways of thinking and acting which have us fail to acknowledge an approaching worst case scenario in the drive to meet specified goals. It is often accompanied by eclipsing, clouding and recasting practices that come with dynamics of power which, unless addressed, add to the culture of silence and denial around recognising, acknowledging and diverting potential fatality. I will present evidence of practices at Pike River Mine which appear to have occurred with a number of blind spots for the potential of a developing worst case scenario.

I will also look to Charles Perrow (1999) who analyses risky technologies and argues that most high-risks systems have certain special characteristics 'beyond their toxic or explosive or generic dangers which court a certain inevitable danger' if equally special attention is not applied to, for example, their interactive complexity and tight couplings. (90) Perrow looks, for example, to the way systems are tied together, how failures interact. He emphasises when 'error-tolerant' systems are designed, these will work insofar as there is an 'error-intolerant culture' within the industry. (91)

Perrow introduces a certain underlying dynamics of power to the discussion, along with the interactive complexity of systems and 'gaps in knowledge' which all add to 
my argument that the James Reason Model of Causation can not possibly describe nor engage in questions around drive for profit, political economy or accountability. 'Neither can it address deregulation, the lack of mine inspectors, the veneration of audit (as opposed to direct inspection) culture, the swift approval of mine permits over safety concerns; which all point to the seemingly unassailable priority of profit'. (92) Neither can this model describe cultural logic and power dynamics hibernating behind so many threads of risk taking; nor the competition driving competitive decision-makers as evidenced before the Royal Commission, and which indicate a continued lack of willingness to acknowledge an approaching worst case scenario.

Drawing on Kari Marie Norgaard (2011) I will also look to aspects of socially organised denial. (93) In her own study, Norgaard examined how people experienced and reacted to disturbing information in their direct environment and then failed to react, even when it deeply affected them physically, culturally and economically. She discovered that this was not a result of some kind of information deficit. The community had plenty of information. So why were they not acting proactively in defense of the repetition of loss? Norgaard makes links between emotion and cognition; asking whether emotions are part of the matrix of 'ignoring' and if so, why this 'awareness' might not translate into social action. She discovered there were not just isolated acts of 'ignoring' but collective distancing among individuals due to norms of emotion, conversation and attention within a developing culture of denial.

I also look to William Freudenburg (2013) in this thesis; his focus on organisation of hazards and recreancy (the failure of institutional players, experts and organisations to perform their roles responsibly and to the expected standards of proficiency) (94) and how this may have affected outcomes in relation to the case of Pike River Mine.

With regard to the social construction of risk I will continue to look to Ulrich Beck and Anthony Giddens of Risk Society: Towards a New Modernity '( 1992); (95) and to Eugene Rosa, Ortwin Renn, Aaron McCright, The Risk Society Revisited. (2015) (96) There are also further links to be made between risk and cognition in the theorising of Mary Douglas and Aaron Wildavsky. (97) Stanley Cohen's (2001) states of denial (98) and Kathleen Tierney's excellent (2014) analysis of The Social Roots of Risk. (99) Daniel 
Kahan's (Yale) The Culture and Cognition Project, (2017) which I discovered late in my study but recommend as invaluable analysis on cognition and heuristics. (100)

This dissertation uses the theorising of Diane Vaughan (1996) and her analysis of the social organisation of mistake, technical deviation and the perception of 'acceptable risk'. (101) Vaughan adds to our knowledge regarding the misconduct of organisations vs. organisational misconduct and looks to macro-micro connections; to issues of satisficing vs. optimising and to how macro structural forces affect decision making. Vaughan speaks to the Amoral Calculator Hypothesis. (102) She looks to structural secrecy and how the normalisation of deviance becomes institutionalised. Vaughan supplements cognition with organizational and environmental interactions. This adds understanding to repetitive risk and to my argument that Pike River Mine was a case of deliberate risk and hibernating beneath that risk was a case of unchecked power.

\section{Ontology, Epistemology and Methodology}

I have sometimes been asked whether I conduct my research as an activist, academic or a journalist involved in action research. My reply is that I have needed to be all of these in looking to the 'black box' of what really happened at Pike River Mine (2010).

In relation to this specific piece of research I have, of course, needed to approach data with particular ontological and epistemological commitments. I also know that it is relatively rare to simply state that a piece of research is conducted (in my case) from within a subjective ontology which is interpretivist in its epistemology and qualitative in methodology. Much of this will already be reflected in what I have already written in these first two chapters and in the sample of the many authors I have read over the years of this dissertation, and so far referred to in this review. I would like though to unpack a little more of my specific approach and process here.

From an epistemological point of view and coming from an interpretivist position I look, for example, for the meaning that actions have for agents and in so doing I am well aware of the double hermeneutic of a world interpreted by actors who may be interpreted again by the agents observing them. That is why I bring to this study an 
active reflexivity in which I have also constantly examined and reflected upon my own part in the process; using a variety of ethnographic techniques as in use of dialogue, interviews, transcription and the analysis of documents, while attending High Court and journaling my own observations for over five years of this process.

It has been challenging, for example, to evaluate the work of the Royal Commission when the first-person evidence gathered by the commission has been embargoed for the next 100 years. In a perfect world I would have gathered primary evidence from the Royal Commission itself and reanalysed this data from a cultural and sociological (rather than a structural risk management) perspective; but the data is now not publically available for a century. So I have attempted to do the next best thing which is to gather my own interviews and place them alongside the findings of the Royal Commission's report. This is a beginning, but it is by no means ideal.

Perhaps the Commission will reconsider the releasing of this data (redacted if necessary) to help everyone (at the very least) to come to terms with what really happened at Pike River Mine. Re-entry of the drift to this mine for retrieval of the 29 men and any latent forensic evidence must also occur. These are issues I shall revisit in the recommendations section once I have looked to positive asymmetry and the culture of silence that existed at Pike River Mine and which I argue, still exists in the multiplicity of single workplace deaths in many other New Zealand industries.

In this thesis I also utilise the heuristic tool advocated by Carol Bacchi (2009) (103) who focuses on the effects of 'problematisation' with her (WPR) 'What's the Problem Represented to be?' policy approach to analysis. Bacchi emphasises the need to ask probing, insightful questions regarding issues, behaviours and systems, encouraging us to 'problem-question' in order to construct more effective long term solutions.

Bacchi's theoretic framework (WPR) approach also encourages active self-reflection not unlike that of Paulo Freire (104) who confronted the culture of silence and powerlessness in his own Brazilian community by encouraging dialogue, actionreflection praxis and a shift away from 'banking concepts of education' towards a more positive climate of creative problem solving for change. Bacchi's approach is, 
on the other hand, Foucauldian (105) grounded in post-structuralist theory and discourse analysis. She looks to policy and systems that react to pre-existing problems with 'quick fixes' and challenges this, encouraging 'problematising'; asking probing questions to interrogate the role play in governing, investigative processes.

Bacchi's post-structural approach to analysis (WPR) asks us to consider 'What's the problem really represented to be?' In so doing she shifts the focus initially from 'problem solving' to 'problem questioning'. This creates potential to gather voice, encourage dialogue, reflection and revisit issues, looking to the ways we think about and represent these problems in order to solve them more effectively. (106) Bacchi encourages us, for example, to dig deep beneath conceptual premises and presumptions so that we might challenge boundaries (both social and political) across space and time for solutions that move us away from repetitive mistakes.

It is Carole Bacchi's (2009) framework for social policy (WPR) that I will now weave through the following chapters and it includes the following questions (107)

1. What is the problem represented to be in a specific policy? (WPR) (108)

2. What presuppositions or assumptions underlie this representation of the problem?

3. How has this representation of the problem come about? Analysing policy: What is the problem represented to be?

4. What is left unproblematic in this problem representation? Where are the silences? Can the problem be thought about differently?

5.What effects are produced by this representation of the problem?

6. How/Where has this representation of the problem been produced, disseminated and defended? How could it be questioned, disrupted, replaced? 
(Qn 1) identifies what the problem is represented to be (WPR)

(Qn 2) analyses the cultural underpinnings

(Qn 3) examines the origins, history and mechanisms

(Qn 4) reflects on gaps and silences in designated represented problems

I aim to use of Bacchi's framework in this thesis in the hope it will add to the analysis of 'what the problem was represented to be' regarding the case of Pike River Mine. I argue that the Royal Commission did an excellent job of 'problematising' risk; but it chose not to problematise 'power' and it definitely did not problematise the concept of 'positive asymmetry' and issues of 'doing the same things over and over again, expecting a different result' with all the potential for risk, injury and even death in the workplace in the name of reaching production targets. It is time to ask the right questions in order to problem solve or we will keep making the same fatal mistakes.

My own involvement in this dissertation process came via an unanticipated trajectory which set me off on an equally unexpected journey. When I first began my work on Pike Mine in July (2011) I was a teacher and journalist who had returned to New Zealand from a permanent teaching position in a London (UK) school after the London July 7 bombings which had killed 52, and injured more than 700 people back in 2005. Having got our children through the trauma of proximity to Kings Cross and the aftermath of the months that followed, I became interested in how schools such as ours coped while continuing to teach deeply affected children, post tragedy.

I began my work on Pike River Mine (July 2011) here in New Zealand, initially to investigate links of resilience in the aftermath of that tragedy and hoped to archive the voices of community leaders affected both by the Pike tragedy of 2010 and those of the Christchurch Earthquake (February 2011). I had no idea that my project would change to the extent that it did, as people across the mining community became interested in what I was doing and inevitably lead me to findings on a secondary trajectory which would not only change the initial project, but the course of my life. 
My approach requires the use of dialogue, narration, interviews, and document analysis in order to get beneath the story and take it apart for a wider systemic analysis. My theorising around silence, denial and cultures of positive asymmetry stems (as already cited) from the research of Kari Marie Norgaard (109) Karen Cerulo (110), Diane Vaughan (111) with theory of behavioural practices ready to be woven into a developing kete, leaving room to discuss primary arrows of causation and change.

I also follow an action-reflection praxis which allows participants autonomy in narrating the direction(s) of their own dialogue. This lessens the chance of missing new findings; which had potential to occur if I had conducted interviews on a predirected course which may have become clouded with unexpected, unintended prior assumptions. It is obvious that the very presence of a researcher can also affect the course of the interview too. That is why I planned this process as carefully as I could, trying to be as 'small' a presence as I could be in all interviews. All participants had agency over the direction of their interviews. They determined how long they spoke for and they all knew they could pause or stop the interviews at any stage.

At the end of this process, I transcribed the interviews and participants were given opportunity to add or edit anything before returning the final draft. This interpretive process allowed me to incorporate new, developing understandings and was, in itself, part of my epistemological approach. This may have created a much longer process overall, but it also encouraged further dialogue with new participants who may not have otherwise chosen to speak out at all; let alone enter the actionreflective praxis. The whole approach also encouraged me to regularly reflect upon my own position in the process, as much as I reflected upon theirs.

I offer my results as an interpretation of the relationship between actors, agents and observers at Pike River Mine in the hope it might challenge cultural logic and power dynamics that were in operation in this case and which may still be affecting other workplace fatalities in other industries of this country. I add my findings to the quantitative results of the Royal Commission of Inquiry. (112) I argue that we all do have the potential to be reflexive agents. We do have the ability to interpret and 
constructively challenge systems to improve them and that there must be further investigation and unpacking of what really happened at Pike River Mine.

I argue that the original unpacking of knowledge in the case of Pike River Mine (2011-2012) was set up with certain frames and ideas which meant that we were only ever going to come up with certain conclusions. What was inevitably produced was a valuable narrative to that time and space, but we need a 'reopening' of that.

I argue that Pike River Mine was a case of deliberate risk, and hibernating beneath that risk was (and still can be) a case of unchecked power. There is a need to further investigate the case of power that lay under that risk and the Triple Helix of this case. Added to this, is also a triple helix of audience I have designed this thesis around to be sure it is accessible to academics, policy makers and community, alike.

In continuing this study I conducted 35 interviews in Greymouth, Hari Hari, Hokitika, Runanga, Rapahoe, Barrytown, Moana, Nelson, Motueka, Christchurch and Wellington (2011-2016). Each interview lasted anything from 20 minutes to two hours, with the timing determined by each participant, as was the course of the interview itself. Most participants were sent an email pre-interview with my initial questions. This was to allow them to determine the course that each of their interviews took in terms of time and theme. On three occasions I was encouraged after talking to school principals, for example, to make time to interview another later in the day who knew I was in Greymouth and who also wanted to speak to me. In these cases I took the questions with me, knowing that the person who referred me had also talked with their colleague to explain the process before I arrived.

Some participants used these questions, while others referred to them only as a starting point and had their own lines of dialogue they wished to follow. I really wanted to encourage this in order to leave as much room as possible for new narratives to surface. It gave participants more sense of control and agency to decide their own course to introduce themes I may not have otherwise thought of. 
Ultimately I wanted the voice and experience of the people to come through with their own stories, opinions and interpretations. I also wanted interviewees to know that they could pause or stop the interview at any stage and this was done in a number of interviews on various occasions, as directed by the participant, usually to catch breath, sometimes to cry and at other times, just to reassess what they wished to say next. In none of the interviews did I record any time-out needed for tears or related trauma. The appearance of printed pauses in any of the transcriptions is simply to make sense of conversational flow and is used to signify that a participant had requested a break for any number of reasons, including unexpected phone calls or family interruptions.

As previously cited, at the end of the transcription process, all interviewees were also presented with the opportunity to read over and edit their own interviews a few weeks later; with only two of the entire sample ever choosing to withdraw their interview completely. This was particularly disappointing as these participants had a very important contribution to make to the overall study; but such a sudden retraction (even very late in the research process) was a price I knew I might have to pay from the start of the project. It was important to respect the withdrawal of significant information, no matter how frustrating, not only ethically but in the hope that these interviewees might have enough trust in me if they ever wished to bring the information forward again later, then this will always be possible. The fact this happened at all, is perhaps an indication that clouding, eclipsing and recasting practices were still being experienced by those who had been so closely associated with the Pike River Mine tragedy as late as (2015) and reconfirmed how powerful the culture of denial and positive asymmetry continues to be, post-Pike tragedy.

Two additional participants also asked for deletions to specific paragraphs in their own individual transcripts which was done and returned for further verification from those interviewees; all of whom otherwise, agreed to still partake in this research and to eventually have their complete interviews placed at the National Archives of New Zealand. Participants also had the choice of adding an embargo on their transcripts if required. The few participants who did opt for embargoes to be placed 
on their interviews at the National Archives, still signed that they agreed with my own use of their transcripts if needed for my own research. By placing the approved interviews at the National Archives I also hope that these interviews might one day be useful (if and when indicated by each participant) for any future investigation into this history which could have been averted (but which was not); in the hope of future vigilance and examination of silence, denial and positive asymmetry to more effectively challenge the culture of the invisible hand of our New Zealand economy.

Throughout this thesis, I also look to George Lakoff (2014), the cognitive linguist and philosopher who asks us to question our use of language in the framing of debate. Lakoff states, for example that 'frames are mental structures that shape the way we see the world. As a result they shape the goals we seek, the plans we make, the way we act and what counts as a good or bad outcome of our actions. In politics our frames shape our social policies and the institutions we form to carry our policies. To change our frames, is to change all of this. Reframing is social change.' (113)

I further use Lakoff's theorising in this dissertation to argue that we must refrain from using language to frame the rate of deaths in the New Zealand workplace as 'accidents' when in fact with all the prior knowledge, expertise and resources now available to us, these need to be called out for what they are: 'workplace fatalities'. In this thesis I also refer to 'accident causation' in this country as 'fatality causation'. Similarly, no matter how uncomfortable it may make certain parties feel - with all evidence now available to us - Pike was never on a trajectory to triumph in coal production for December 2010, but rather on a foreseeable trajectory to tragedy.

Other examples of the misuse of language in reframing the Pike debate are abundant in media reports which incorrectly use language around 're-entry of the mine', when it is in fact the 'drift of the mine' the families wish to re-enter; whose safety has long been proven by international experts. Such misuse of language by both media and politicians serves to alienate potential support for the families and other interested parties who need any possible latent forensic evidence the Royal Commission was denied in the mine post-explosions and/or to provide at the vey least, some closure for the families eight years after the deaths of their 29 men. 
The 'framing' of knowledge and language still needs to be addressed because findings suggest that what happened at Pike River Mine was a foreseeable fatality emerging from a culture of organised denial and one which appears to have been more concerned with meeting production and financial targets than the safety. (114) The Royal Commission (2012) found that there was a 'culture of production before safety' at Pike RiverMine. (115) I argue that there is also a culture of silence and denial that continues to exist today around workplace fatalities in Aotearoa/New Zealand.

The concept of the Triple Helix of Fatality I introduce, with its three strands of risk, power and positive asymmetry could be a useful tool to add to analysis of fatality causation in the workplace. It is important to look to the junction of risk, power and positive asymmetry; for there lies the perfect storm of conditions for future fatalities in whichever industry chooses to practices it. It is time to reframe the debate.

This is not intended to be a comparative study. This dissertation is rather, an indepth case study in relation to cited theorists and directed also to a triple helix of audience (academics, policy makers, community) in the hope these will stand to speak truth to power for improvement of workplace culture in an Aotearoa/ New Zealand context.

It is always a huge risk in itself, to conduct inductive research and for many reasons. The process can take years. Transcripts can be withdrawn (which must be allowed ethically). Interested parties can also slip away and unanticipated twists can occur which can potentially thwart the whole academic processes, such as the 100 year embargo placed on interviews the commission conducted in relation to Pike Mine.

The research process definitely becomes a solitary one. Misunderstandings can arise over why you turn down other writing work in favour of what some may define as one workplace tragedy over another. But I still insist it will never be alright in New Zealand for 29 men go to work one day in November 2010, never come home again and to be left entombed in their workplace eight years later. That is not alright anywhere. So I continued in hope that others might eventually contribute their own voice and expertise in both challenging this and the high rate of workplace fatality in 
an Aotearoa context. I continue in memory of all who have died (and are still) dying in industries driven by deregulated production that favours profit ahead of safety.

I encourage others to add to my interpretation, as much as I have tried to add to those before me. For surely it is in the interest of everyone to run both a safe and profitable workplace. To have significant change to occur it is important though, that we no longer work in isolation. Our many separate strands of experience and knowledge are much too valuable for that. We cannot allow what happened at Pike River Mine to fade into history as some might prefer, when so much of this case has been left unchallenged. We still have agency to come together with voice to weave our findings and experience, strength and hope into our own harakeke of change.

\section{Whaowhia te Kete matauranga}

\section{Ehara taku toa te toa Takitahi engari he toa Takimano}

So with this Whakatauki in mind and of spirit, I will begin by telling this story in three main parts. I will call these the Three Acts of Narration. They include the use of documents, dialogue and action reflection praxis to both inform and encourage others to ask further probing insightful questions in order to build safer workplace environments in this country. It is important to reiterate here that this is just one narrative of thread to be woven into a much wider and diverse Kowhaiwhai of our workplace fabric as New Zealanders. It is only in coming together that this harakeke of many strands of narration will interweave to link the kete of our peoples who are still too often disempowered by systems of silence, denial and positive asymmetry.

This dissertation starts with what happened at Pike River Mine and examines the existing model of causation, asking why we continue to have such high workplace fatality in this country. I will evaluate and add to the model a sample of systemic arrows of causation which must be examined to further challenge what happened at Pike River Mine and continues to happen looking to cultures of silence and denial. 
This small academic contribution is only a beginning thread which I hope will soon encourage others out of isolation to add their own experience to create the required shift in all our systems of denial and indifference for safer work place futures in an Aotearoa/ New Zealand context. We need to come together though if we really want an interwoven harakeke of change. We need to come out of silence, find our voices and build this action-reflection praxis together if we are to breathe to life this Kete of Knowledge we have been weaving for so long in the hope that Naku te rourou nau te rourou ka ora ai te iwi_With your basket and my basket_the people will live.

\section{Overview}

My study will introduce a sample of five arrows of fatality causation. I argue that these arrows (representing decisions guided by a specific cultural logic) were all fired from an archery bow (to denote the driven power) of a culture of positive asymmetry (in which there was a failure to acknowledge a looming worst case scenario in the drive to meet intended financial targets) and which caused the Pike River Mine Tragedy. I argue that there are connections to be made with other industries operating in this country and their workplace fatalities to this day.

My inquiry also asks how does our history influence that moment of the disaster, working back through other tragedies, past and present. I ask why it is, given all findings of the Royal Commission (116) we can still be calling the high rate of deaths in the New Zealand workplace 'accidents' at all; suggesting with such knowledge, we need to shift now from a study of 'accident causation' to one of 'fatality causation'.

I will illustrate some of the early warning signs in our systems, to the really loud warning signs apparent for so long at Pike River Mine, to the even louder realities of the actual disaster. I will use the findings of the Royal Commission of Inquiry and document analysis alongside my own interviews to allow the many threads of human and voiced experience of affected lives to come through. The voice will appear gradually, so that those unfamiliar with the Pike River Mine tragedy can get an introduction to the findings surrounding the build up and aftermath of that. Then a 
sample of some of the many voices of the case will filter through and 'take over' giving wider slices of their own lived experience of Pike until they almost fall back to whisper at the chapter of the findings, as if waiting for you to finally hear what they have to say in the recommendations, as one crescendo of voice calling for change.

I am hoping my method will reframe a discussion of Pike River Mine around fatality causation and to examine what exactly intersects at the junction of risk; making connections with the continued multiplicity of single workplace fatalities still occurring in other industries around New Zealand in the hope more people will find voice to emerge from systems of silence and denial to constructively confront the culture of their own workplaces with a new model of empowerment and change.

Systems matter just as much as how we define and talk about the world matters and I want to present this dissertation in a way that it might be accessible to academics, policy makers, workers and families. Busy people may only be interested in dipping into certain sections of this thesis to find what they are looking for. So the way I narrate my findings is very important. If people do not have time to read the whole thesis they will need to understand why the recommendations flow as they do.

I have begun this process by narrating my findings in three Acts which I hope will make the overall work accessible to all. Each of these 'Acts' will begin with its own introduction to explain 'Why this is important.' There will also be a need to spiral back occasionally to repeat certain themes so that readers can 'come into the story' understanding where they are in the narration and 'leave again' if they need to relay back to their own spheres. That is how story telling works. In my own Irish tradition the narration of events is valued. Seanachie (117) as with many of Maori and Pasifica cultures, choose not to narrate in a linear fashion when the story, in all reality, is of three (or more) dimensions. The spiral retelling of the themes is used, therefore, to refresh the memory of the reader so that information is ready to be acted upon.

The use of a syncretic linear narrative does not work in the case of Pike River Mine. It might tell part of the story, but it does not explain the multi-faceted nature of what really happened to cause the deaths of 29 men in November, 2010. Neither does it 
explain why, with all the international proof that it is now safe to enter the drift of that mine to retrieve the bodies and any latent evidence, that this has still not been done (2018). It certainly does not tell the story of why we continue to have the high rate of deaths occurring in the Aotearoa/New Zealand workplace, post Pike Tragedy.

The findings of the Royal Commission of Inquiry (118) are as far as we got. They were very good findings. But even the commissioners of the time admitted there was only so far they could go on certain lines of inquiry as there was no access to the mine.

Because it has not been possible to access the underground parts of the mine in which significant electrical equipment is located, its installation and functioning, and its potential contribution to the explosion, cannot be determined.... the commission is compelled to limit its analysis (119)

The story of Pike River Mine has also been told in certain ways, by different parties. But as yet, it has no ending as many issues related to the tragedy remain unresolved.

Mr Reczek acknowledged...the non-availability of information following forensic analysis of failed resistors... described his report as 'incomplete' because it involved 'drawing conclusions or inferences, based on information... which isn't conclusive'. (120)

The story is also not fully told or we would not continue to have as many workplace accidents as we still do have in this country. (121) It follows that we are missing something essential in the narration. Is it a failure to learn? Or is there something more to tell? I am sometimes even asked what is there to learn from delving further into the story of Pike River Mine at all. How does that change the model of accident causation? In an Aotearoa/New Zealand context it begins by telling us the model is incomplete. We can certainly add to the model and need to ignite a conversation around it, as was originally begun at the Royal Commission and carried forward by all those who tried to instigate change in the years following the tragedy. We can reevaluate, educate and learn. But we can also constructively challenge the model too. 
The idea that this model can really prevent a future Pike River Mine like disaster from recurring is questionable when the dynamics of power that created the culture of Pike River Mine in the first place, still exist in the multiplicity of single workplace fatalities in New Zealand, post-tragedy. This will require the waking up of systems from a culture of silence and denial around the use of many behavioural practices that are part of the untold story of Pike River Mine and which still exist in the New Zealand workplace. These will be defined in further detail as this doctorate proceeds.

In the meantime, the story of Pike River Mine remains a hard truth to tell. The evidence is unsettling because it does not fit the very model we are supposed to believe in; which means it has continued to be eclipsed, clouded and recast in the years, post-Pike, as much as the tragedy itself originally was. It seems that many were shocked by what occurred at Pike, gave generously for a few weeks and then moved on to the next thing with a colloquial 'She'll be right', as if waiting for the whole memory of it to go away; but we cannot afford to let that happen and we will not let that happen, because 'she' was not 'all right' in New Zealand to begin with.

\section{Endnotes: Chapter 2}

\section{(I) Disasters and the Social Construction of Risk}

(1) Mythen, Gabe (2004) Ulrich Beck: A Critical Introduction to the Risk Society. UK:

Pluto Press, p. 2; see also (Jasanoff, 1999; 136).

(2) Mythen (2004) op. cit, p. 4.

(3) Ibid., p. 5.

(4) Ibid., p. 17.

(5) (Beck 1996: 31). See also: Beck, Ulrich and Giddens, Anthony (1992) Risk Society:

Towards a New Modernity (Theory Culture and Society) $1^{\text {st }}$ ed. SAGE Publications.

(6) Mythen (2004) Ibid, p. 6; see also (Beck, 1998a: 20). 
(7) Rosa, E.A. Renn, O. and McCright, A., eds. (2014) The Risk Society Revisited: Social Theory and Governance, USA: Temple University Press, p. 76.

(8) Ibid., p. 88.

(9) Ibid., p. 85.

(10) Ibid., p. 86.

(11) Ibid., p. 87.

(12) Ibid., p. 86.

(13) Ibid., p. 87.

(14) Ibid., p. 88.

(15) Ibid., p. 89.

(16) Ibid., p. 95.

(17) Ibid., p. 93.

(18) Ibid., p. 94.

\section{(II) Neoliberalism and Risk}

(19) Roper, Brian (2005) Prosperity for All? Economic, Social and Political Change in New Zealand since 1935, NZ: Dumore Press, (xvii); also, (Whitwell, 1986, pp. 26-52).

(20) Ibid., 'Moreover, the evidence indicates that full, or even approximately full, employment is of rare and short lived occurrence'. (Whitwell, 1986 pp. 38-9).

The state has an active, interventionist role in managing the economy in order to maintain full employment and stimulate economic growth'.

(21) Ibid., (xviii).

(22) See Chapter I (i) of this thesis.

(23) Roper (2005) op. cit., (xix). 
(24) Ibid., (xxvii).

(25) Kaitiaki: New Zealand Maori (and much more than a noun) meaning 'guardian' and as a trustee, a minder, a keeper or spiritual custodian, steward of the people and their well being. It includes aspects of Ako (a culturally inherent teaching/learning relationship) for afterall, 'Koia rā te take hei ārai atu i tēnei tū mate, i whakaarohia nuitia, kia hangaia e te Pāremata tētahi ritenga hou, kia āhei ai te whiu i ngā kaitiaki e mahi hē ana' (TM 23/4/1881:2)... it was carefully considered by Parliament to create a new procedure to enable the prosecution of trustees who transgress.

(26) Roper (2005) op. cit., (xvii).

(27) Ibid., (xviii).

(28) Ibid., (xix).

(29) Kelsey, Jane (1995) The New Zealand Experiment: a world model for structural adjustment? Auckland, N.Z: Auckland University Press; Bridget Williams Books.

(30) Ibid., p. 8. See, N, Haworth, 'Neo-Liberalism, Economic Internationalisation and the Contemporary State of New Zealand' in A. Sharp (ed). Leap into the Dark: the Changing Role of the State in New Zealand Since 1984, AUP, Auckland, 1994, p. 19. See also Economist, 13 November 1993, p. 155.

(31) Kelsey, Jane (1995) op. cit., p. 8. See also, Economist, 10 July 1993, p. 75.

(32) Economist, 15 June 1991, p. 72.

(33) Ibid., p. 8. See also, Economist, 13 November 1993, p. 155.

(34) Economist, 13 October 1993, p. 128.

(35) Kelsey, Jane (1995) The New Zealand Experiment: a world model for structural adjustment? Auckland, N.Z: Auckland University Press; Bridget Williams Books, p. 10.

(36) Kelsey, Jane. (2015) The Fire Economy: New Zealand's Reckoning. Wellington, New Zealand: Bridget Williams Books with the New Zealand Law Foundation, P. 150. 
See also risk-tolerant regulation in relation, pp. 150-178. And for a more detailed discussion on embedded neoliberalism, see pp. 121-235.

(37) Roper (2005) op. cit., p. 229.

(38) Kelsey, Jane, op. cit., (2015); also, The New Zealand Experiment op. cit., (1995).

(39) Ibid., p. 7.

\section{An Historical Template of New Zealand Policy}

(40) As is represented in the work of Maidment, J and Beddoe, L. (2016) Social Policy for Social Work and Human Services in Aotearoa New Zealand: Diverse Perspectives, NZ: University of Canterbury, p. 61.

(41) Andrew Little has been a Labour Member of Parliament since 2011. He was Leader of the NZ Labour Party and Leader of the Opposition from 18 November 2014 to 1 August 2017. He has assumed several portfolios since October 2017 including Minister of Justice, Minister of Courts; Minister for Treaty of Waitangi Negotiations, Minister Responsible for the Government Communications Security Bureau and the NZ Intelligence Service, and Minister Responsible for The Pike River Mine Re-entry.

(42) Dr Sarah Monod de Froideville is a criminologist at the School of Social and Cultural Studies, Victoria University of Wellington, New Zealand.

(43) Dr Stephen Blumenfeld, Director of Victoria University of Wellington's Centre for Labour, Employment and Work.

https://www.victoria.ac.nz/news/2018/05/negligence-missing-in-crimes-act-repeal

(44) Roper (2005) op. cit., (xxi).

\section{(III) Introducing Positive Asymmetry}

(45) Cerulo, Karen. opt., cit. (2006)

(46) Ibid., p. 73.

(47) Ibid., p. 234. 
(48) Ibid., p. 121.

(49) Ibid., p. 235.

(50) Ibid., pp. 187-192.

(51) Ibid., p. 235.

(52) Ibid., p. 193.

(53) Royal Commission of Inquiry on the Pike River Mine Tragedy NZ, Te Komihana a te Karauna mo te Parekura Ana Waro te Awa O Pike, (2012) Vol.1; Vol.2.

(54) Cerulo, op. cit., (2006).

(55) Royal Commission of Inquiry (2012); op. cit., Vol.1, p. 12. para. 6.

(56) Ibid., Vol.2, 7:54.

\section{Eclipsing, Clouding and Recasting Practices}

(57) Cerulo, op. cit., p. 121.

(58) Ibid., pp. 72-121.

(59) Ibid., (2006).

(60) Ibid., p. 73.

(61) Ibid., p. 193.

(62) Norgaard, op. cit., (2011).

(63) Cerulo, op. cit., p. 72-73.

(64) Ibid., p. 76.

(65) Ibid., p. 126. 
(66) Examples of 'eclipsing' practices can be found in the four previously cited case studies of (Cerulo, 2006); which included the (1) US Challenger Space Shuttle (1986) disaster; (2) Phoenix Memo/NYC Twin Towers (2001); (3) Y2K 2000; (4) SARS 2002 Outbreak. See also, Karen Cerulo (2006) Never Saw it Coming: Cultural Challenges to Envisioning the Worst, Chicago: The University of Chicago Press, p. 235.

(67) Cerulo, op. cit., p. 206.

(68) Ibid., p. 275.

(69) Ibid., p. 95.

(70) Ibid., p. 96.

(71) Ibid., p. 107.

(72) Ibid., p. 111.

(73) Ibid., p. 112.

(74) Ibid., p. 96.

(75) Ibid., p. 107.

(76) Ibid., p. 114.

\section{Theorising Accidents}

(77) Reason, James. (1997) Managing Risks of Organizational Accidents, London: Routledge.

(78) Royal Commission of Inquiry (2012) op. cit., Vol.1, Vol.2.

(79) Ibid., Vol.2, 2:20, fig.2.1.

(80) Ibid., Vol.2, 2:1-23. Also, Callaghan, Kathleen. (April 2013) ‘Pike River: Lessons for Directors and Senior Business Leaders Conference Health \& Safety Forum. www.zeroharm.org.nz/leadership/case-studies/pike- river 
(81) Callaghan, Kathleen op. cit., (2013).

(82) Ibid., www.zeroharm.org.nz/leadership/case-studies/pike- river

(83) Ibid., (2:36).

(84) Reason, James. (2004) 'Beyond the Organisational Accident: The Need for "Error Wisdom" on the Frontline', Quality and Safety in Health Care, Vol.13, Suppl.2, p. 29.

(85) Many unsafe acts of Pike Mine are listed in Royal Commission of Inquiry on the Pike River Mine Tragedy NZ, Te Komihana a te Karauna mo te Parekura Ana Waro te Awa O Pike (2012); Vol.1, Vol.2.

(86) Pike River: Lessons for Directors and Senior Business Leaders Conference Health \& Safety Forum, Christchurch (2013) Lessons of the Past we've Forgotten: Three things to Remember; also, Royal Commission of Inquiry (2012) op. cit., Vol.1, p. 19.

(87) Dr Kathleen Callaghan, op. cit., (2013) Keynote speaker/experts, included:

- Dr. Kathleen Callaghan; 'an expert witness on human science factors for the Commission, used what happened at Pike River to highlight common failures by directors and senior managers in relation to workplace safety'.

- Nicholas Davidson, QC 'represented families at the Pike River Royal Commission. He gave his opinion on how Pike's board, managers and workers 'never saw it coming' because they failed to ask the right questions, recognise the risks and respond appropriately to warnings'.

- Ralph Chivers, 'Former Institute of Directors CEO Ralph Chivers outlined the board's role in safety and new guidelines to help directors fulfill their duties'.

(a) 'It appears no one on the board had experience in the local underground coal mining industry. The business was new with the mine still under development, as were its systems, including health and safety'. Vol.2, 5:19. 
(b) The ventilation management plan was incomplete, largely ignored in practice and required the appointment of a ventilation engineer to be responsible for the ventilation system. No one was appointed to the role and the mine manager became the de facto ventilation engineer, without the time or resources to carry out the role adequately.' Vol.2, 8: 152.

(c) Morale and absenteeism were a concern. The company relied heavily on contractors and consultants. It had purchased equipment unsuitable for the difficult strata conditions encountered. There was no second egress for use by workers in an emergency. Vol.2, 5:20.

(d) Mr Stewart's review identified serious problems with safety critical systems. The instrumentation of the main fan was not compliant with regulations; there was no remote gas monitoring systems in the mine connected with the control room; the ventilation structures (stoppings and doors) were inadequate and training on construction was needed; the stoppings needed protection from blast damage caused by shot-firing; there was a lack of information on ventilation air-flow; there were obstructions and debris in the main returns leading to the Alimak ventilation shaft; There were no stone dust barriers; The ventilation shaft was impractical as a second egress; Intershift reports by mine deputies were inadequate; the methane gas drainage line alongside the main access road in Spaghetti Junction was at risk of damage from mobile equipment. Vol.2, 5:35.

(e) At Pike River, the drive to produce coal in 2010 led to a view that management of some hazards could await the implementation of a long-term solution, when for example, suitable second egress and a usable fresh air base (FAB) should have been high-priority safety requirements. Vol.2, 7:16.

A proper FAB was not completed by the end of June (2010) There was only a pull-down brattice stopping to isolate the slimline shaft stub. This was in interim measure while the $F A B$ was designed and ventilation surveys undertaken. Vol.2, 7:46. The interim safeguard of a proper FAB had not 
eventuated either. A fundamental concern of the workforce remained unaddressed - eight months after it was first raised. Vol.2, 7:49.

There was insufficient training on emergency preparedness at Pike. Training on the use of self-rescuers was inadequate. Many of the workers at the mine in November 2010 had not been involved in a mock underground evacuation, the last one having taken place in October 2009. There had been no training to test the practical implementation for the mine's emergency response management plane, which had not been reviewed since Feb 2009. Vol.2, 6:57.

The lower FAB was installed by McConnell Dowell during the development of the drift. Located in a stone stub, it was a converted container with sealable double doors. At the time of the explosion it had been decommissioned and was no longer supplied with compressed air. The telephone connection to the surface was not working and replacement self-rescuers, first aid equipment and fire-fighting equipment had been removed. Vol.2, 16:131.

(f) It had purchased equipment unsuitable for the difficult strata conditions encountered. Vol. 2, 5:20... There were major problems with the advent of hydro mining, the company's main production method Vol.2, 5:18. The mine's health and safety management systems, including vital systems such as ventilation management, methane drainage, gas monitoring and hydro mining, were still under development at 19 November 2010, as discussed in Vol.1, 5:43. See also Vol. 2, Chapters (7-12) of the Royal Commission findings.

(g) Ventilation, Vol.2, Ch.8; Methane, Vol.2, Ch.9; Drainage, Vol.2, Ch.10; Gas Monitoring, Vol.2 10; Electrical Safety, Vol.2, Ch.11.

(h) The Hydro Mining and Competitive Bonus System were both introduced. Hydro Mining, Vol.2, Ch.12; Hydro Bonus System Vol.2, 12:27 In response to the increasing delays, in July 2010 the Pike board authorised payment of a hydro-production bonus to staff when hydro extraction began.

The bonus started at $\$ \mathbf{1 3 , 0 0 0}$ if hydro production was achieved, together with 
$630 \mathrm{~m}$ of roadway development by September 2010. After that date the amount of the bonus reduced each week. Vol.2, 12:27.

(i) See a sample of warnings given in Chapter Three of this dissertation:

\section{Sample of Prior Warnings:}

(a) Brian Wishart Email (methane)

(b) Miles Brown (drainage)

(c) Masaoki Nishioka (hydro mining)

(d) Pieter Van Rooyen (ventilation)

(e) Harry Bell (former Chief Inspector of Mines)

(89) Cerulo, Karen. (2006) Never Saw it Coming: Cultural Challenges to Envisioning the Worst, Chicago: University of Chicago Press.

(90) Perrow, Charles. (1999) Normal Accidents: Living with High-Risk Technologies, New Jersey: Princeton University Press.

(91) Ibid., p.11.

(92) Matthewman, Steve. (2018) Associate Professor, University of Auckland, Social theory, technology studies, the sociology of accidents and disasters; author of Technology and Social Theory (2011) Auckland, New Zealand, Palgrave. Comments to C. Mulholland 29 May 2018.

(93) Norgaard, Kari Marie. (2011) Living in Denial: Climate Change, Emotions and Everyday Life. Cambridge, Massachusetts: MIT Press.

(94) William R. Freudenburg, W. R. (2013) A Life in Social Research: 21; Research in Social Problems and Public Policy ed. Susan Maret, UK: Emerald Group Publishing.

(95) Ulrich Beck and Anthony Giddens (1992) Risk Society: Towards a New Modernity (Theory Culture and Society) $1^{\text {st }}$ ed. SAGE Publications. 
(96) Eugene Rosa, Ortwin Renn, and Aaron McCright (eds.) The Risk Society Revisited: Social Theory and Governance: Volume 34, Issue 12, December 2014: An Official Publication of the Society of Risk Analysis.

(97) Douglas, Mary; Wildavsky, Aaron. (1983) Risk Culture, University California Press

(98) Stanley Cohen (2001) States of Denial: Knowing about Atrocities and Suffering. Cambridge: Polity Press.

(99) Kathleen Tierney (2014) The Social Roots of Risk, Producing Disasters, Promoting Resilience, Stanford University Press.

(100) See: Dan M. Kahan, (1999/2017) Elizabeth K. Dollard Professor of Law \& Professor of Psychology, 'The Culture and Cognition Project'; Yale Law School http://www.culturalcognition.net/kahan/

(101) Vaughan, Diane. (1996) The Challenger Launch Decision. Chicago: University of Chicago Press.

(102) Ibid., p. 47, regarding the launch decisions of The Challenger (1986): 'The basic assumptions underlying the amoral calculator hypothesis_that the launch was a cost/safety trade-off intended to sustain the Shuttle Program's economic viability did not make sense'.

See also: Diane Vaughn's Abstract, Re: Rational Choice, Situation in Action and the Social Control of Organisations. Law and Society Review 32, 1 June 1998: 23-61. 'Management decisions in the business world that value competitive and economic success more highly than the well-being of workers, consumers, or the general public so often have come to public attention that today's most widely accepted model of corporate criminality portrays managers of profit-seeking organizations as 'amoral calculators' whose illegal actions are motivated by rational calculation of costs and opportunities" (Kagan and Scholz, 1984).

(103) Bacchi, Carol. (2009) Analysing Policy: What's the Problem Represented to be? Australia: Pearson. 
(104) Freire, Paulo. (1972) Pedagogy of the Oppressed, UK: Penguin Books; Cultural Action for Freedom, UK: Penguin Books (1972); Education for Critical Consciousness. USA: Bloomsbury (1974); The Politics of Education South Hadley, Mass. (1985).

(105) Foucault, Michel, (2001) Power: Essential Works of Foucault, 1954-1984, (ed James D. Faubion) The New Press. See also Magnus Hornqvist (2010) Risk, Power and State: After Foucault, UK: Abingdon: Routledge.

(106) Bacchi, Carol. (2009) op. cit., (xxi).

(107) Ibid., p. 2

(108) Ibid., p. 7, 12.

(109) Norgaard, Kari Marie. (2011) Living in Denial: Climate Change, Emotions and Everyday Life, Cambridge, Massachusetts: MIT Press.

(110) Cerulo, Karen. (2006) Never Saw it Coming: Cultural Challenges to Envisioning the Worst, Chicago: University of Chicago Press.

(111) Vaughan, Diane. (1996) The Challenger Launch Decision: Risky Technology, Culture and Deviance at NASA, USA: The University of Chicago Press.

(112) Royal Commission of Inquiry on the Pike River Mine Tragedy NZ; Te Komihana a te Karauna mo te Parekura Ana Waro te Awa O Pike (2012), Vol.1 and Vol.2.

(113) Lakoff, G. (2014) Don't Think of an Elephant: Know Your Values and Frame your Debate, USA: Chelsea Green Publishing, (xii); see also his Metaphors We Live By, (1980) USA: University Chicago Press.

(114) Royal Commission of Inquiry (2012) op. cit., Vol. 2:5

'The Health and Safety in Employment (HSE) committee was to meet every six months, but by the time of the explosion had not met for 13 months; with the exception of the board meeting of 15 November when it questioned the general manager on health and safety [It was] said that was because the board as a whole 
was taking more interest in health and safety. No meeting for the HSE committee had been scheduled for 2011, in contrast to meeting of the board'. Vol. 2, 5:35

'Focused on production targets, the executive management pressed ahead when health and safety systems and risk assessment processes were inadequate. Because it did not follow good management principles and industry best practice, Pike's workers were exposed to health and safety risks'. Vol. 2, 5:47

(115) Royal Commission of Inquiry (2012) op. cit., Vol. 1, p. 19, para.2 'There was a culture of production before safety at Pike River Mine'.

\section{Overview}

(116) Royal Commission, op. cit., (2012).

(117) For more information on 'Seanachie' [Irish] or 'Seanachai' [Scottish] see Bryne, Sean, Economic Assistance and the Northern Ireland Peace Process: Building the Peace Dividend, US: Fairleigh Dickinson University Press, 2009; Also Chamberlain, Mary. (2004) Transnational Families: Memories and Narrative, UK: Oxford Brookes University, Oxford, 18 June; Some Irish Women Storytellers and Reflections on the Role of Women in the Storytelling Tradition, Clodagh Brennan Harvey Western Folklore Vol. 48, No. 2 (Apr., 1989), pp. 109-128; Falaky Nagy, Joseph, Observations on the Ossianesque in Medieval Irish Literature, Journal of (JAF) Vol 114, No. 454, 2001, pp 436-446.

(118) Royal Commission of Inquiry, op. cit., (2012).

(119) Ibid., Vol.2, 11:3.

(120) Ibid., Vol.2, 14:59.

(121) John Gibb, Otago Daily Times, New Zealand workplace death rate 'appalling', 16 June 2016. 


\section{Chapter 3 Analysis (I)}

\section{An Extended Interpretation of James Reason Model of Causation}

On 19 November 2010, there was an explosion at Pike River Mine on the West Coast of Aotearoa/New Zealand (1) which killed 29 men. Two men working some distance from the other miners and contractors managed to escape. Over the next nine days there were three more explosions before the mine was finally sealed. As of (2018) there have been no prosecutions and the bodies of all 29 men remain entombed. (2)

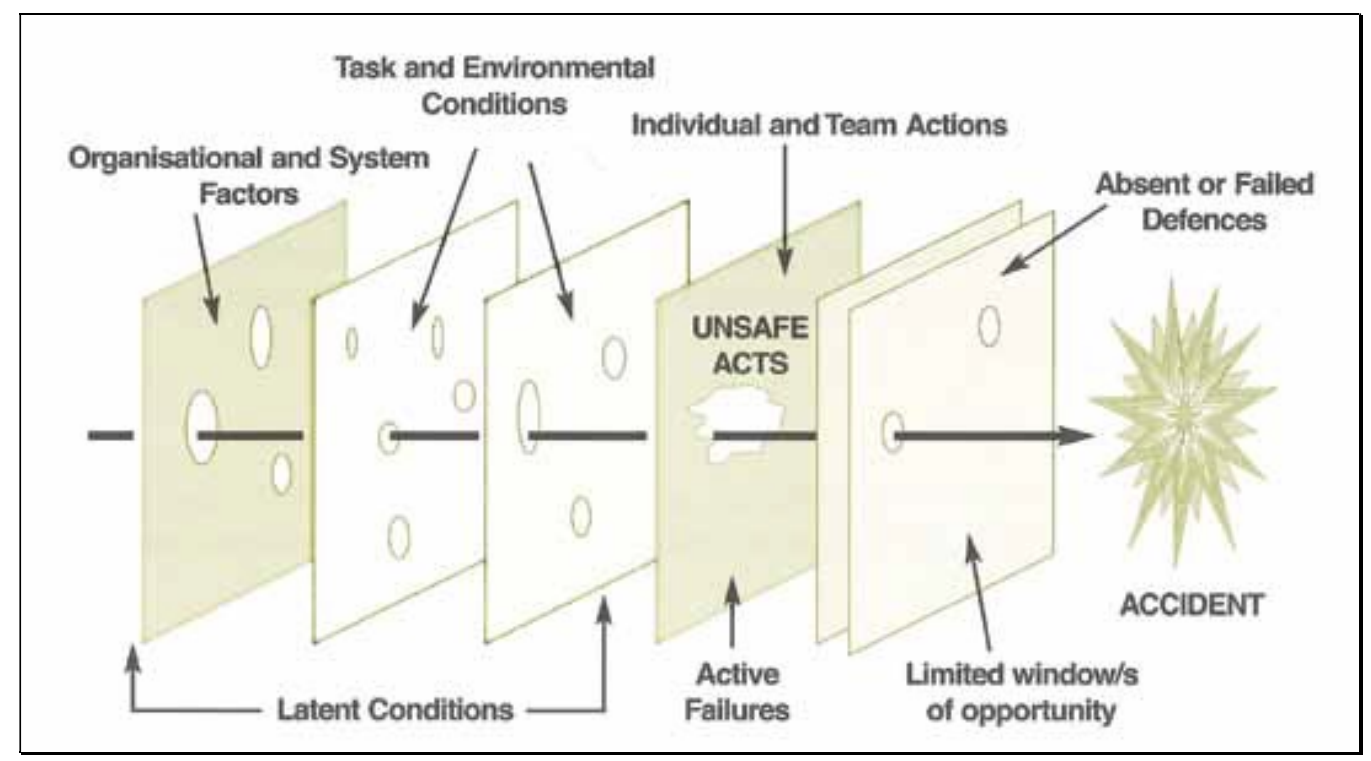

Figure 3: James Reason 'Swiss Cheese' Model of Accident Causation (3)

This doctorate will challenge and extend the James Reason Model of Accident Causation used by the Royal Commission of Inquiry (2012) to describe the case of Pike River Mine. Although a good start it was impossible for this model to explain the cultural logic and power dynamics which lay behind the deliberate risk taking and competition driving decision-makers within these systems. This model does map some of the organisational failures but it cannot tackle the very logics that produced vulnerability at Pike River Mine. The commission did not look to issues of power. It follows that any policy designed to prevent workplace fatalities based on the James Reason Model will be incomplete. I add the Triple Helix of risk, power and positive asymmetry to the discussion in the hope future workplace fatalities will be averted. 
I argue that although flaws in all four levels of the James Reason Model of Accident Causation did eventually align to cause the deaths of Pike River Mine (2010) it is the actual path of arrows travelling through these aligned gaps that must be examined.

I have developed the use of a certain 'Arrow and Archery' metaphor throughout this doctorate to frame the argument because I want it to be clearly understood that what occurred at Pike River Mine was not a process by which 'things' just suddenly happened. Pike River Mine was a case of deliberate risk and hibernating underneath that risk was (and still can be) a case of unchecked power.

My use of the archery metaphor illustrates the form and trajectory that certain 'arrows' took and the points from which they were actually propelled into a much larger model of fatality causation. The 'arrows' are the repeated pathways of decisions made, which were often not single but repetitive ones of dysfunction. What did these 'arrows' actually consist of? What was their trajectory and how were they propelled? Who or what were the archers and why was the trajectory to tragedy so repetitively ignored by those in power and at all levels of the system?

The findings of the Royal Commission of Inquiry (4) prove that many faulty decisions were made at Pike River Mine right up to the day of the first fatal explosion. When faults and misuse of systems were voiced by individuals their concerns were often shunned, diverted or ignored. The post-Pike conversation has often centred around important issues like 'a failure to learn' or 'improved practices for workplace safety' but I argue we are missing something much more fundamental than that.

Pike River Mine was never simply a case of one single shot, nor even a series of shots accidentally passing through a chance alignment of holes in the original causation model. Pike River Mine was a case of production targets being deliberately pushed through the pre-existing flaws in a system with a definite blindness for a developing worst case scenario. I ask what was happening that so many people could continue to envision the positive while dismissing the reality around fatal risk even when numerous red flags were regularly raised, warning of a pending workplace disaster. 
At Pike River Mine for example, these arrows (representing decisions guided by a specific cultural logic) were fired constantly from a culture of positive asymmetry. which as cited, is one in which there is a failure to acknowledge a looming worst case scenario (Cerulo 2006) in the drive to meet (in this case) intended financial targets. In the case of Pike River Mine, decisions of dysfunction were repeatedly fired out at dangerous trajectories into all levels of this 'accident' causation model and I ask why the mining operation was not halted at least temporarily, as would have been required of a mine in Australia. The arrows of production at this mine zig-zagged and were often redirected by deliberate actions which inevitably ended in tragedy.

The James Reason Model of Accident Causation cannot describe fully what really happened at Pike River Mine. British in origin, this structural model introduces, but cannot explain what occurred systemically in an Aotearoa, New Zealand context; nor can it describe why it is that post-Pike tragedy, our workplaces continue to be 'unsafe when compared to workplaces in UK, Australia and many other OECD nations'. (5)

In revisiting this, I argue that we can continue to have all the best workplace safety systems the world has to offer but if we fail to address what these arrows (the decisions guided by cultural/systemic logic) and the course of their trajectories actually consisted of, then tragedies as extreme as Pike Mine will happen again and are in fact, already occurring in the continued multiplicity of single workplace fatalities in logging and many other hazardous industries in this country.

\section{The Archers' Bow of Positive Asymmetry}

The extended version of the causation model for Pike River Mine must include the Bow of Positive Asymmetry from which the quiver of arrows was shot. I return here, to my original 'archery' metaphor which I first introduced earlier to demonstrate that Pike River Mine was not just a case of risk, but one of unchecked power.

I specifically use the metaphor of the Archers' Bow to make it very clear that there was a pattern of repetitive and deliberate action powering this bow (this culture). 
In the findings of the Royal Commission and in my own interview data, there are many examples of both workers and experts who tried to warn of potential disaster but who were often shunned, diverted and/or ignored by the CEO, some of senior management and a number of systems operating in a culture of positive asymmetry with its failure to sometimes even recognise, let alone acknowledge an approaching worst case scenario in favour of (in this case) the drive to meet financial targets.

As also previously mentioned, my use of an archery metaphor serves to illustrate the form and trajectory that certain 'arrows' (representing decisions guided by a set of cultural practices) took in this drive for production, and the points from which they were propelled into the model of fatality causation. These 'arrows' often followed pathways of decisions which were not single, but repetitive ones of dysfunction.

So, in following Cerulo's (6) argument that positive asymmetry involves ways of thinking and behaving which become so routine as to be acted upon subconsciously, and which mask perceptual portholes to a developing worst case scenario, (7) I argue that the bow (or culture) of positive asymmetry operating at Pike River Mine had its own cultural and systemic archers which fired specific arrows out on a trajectory of 'production before safety' (8) into the already beleaguered and deeply faulted mine.

The continued acts of the archers at the bow, along with the systems and a culture that actively supported it (via action and sometimes lack of it) stoked an almost perfect storm of conditions which drove the arrows repetitively through the preexisting imperfections of the original model in the name of meeting financial goals and production deadlines. This created flaws so gaping and numerous that by 2010 there was little left to any levels of safety defence at the mine. The findings of the Royal Commission are very clear that there were many red flags predicting potential tragedy at Pike River Mine. There were individuals who challenged the archers at the bow and even the culture of the bow itself. Others tried to deflect the alignment of arrows and flaws through which they passed, but the culture of denial and positive asymmetry was so prevalent at Pike River Mine, that a workplace tragedy became inevitable unless there an was immediate regulatory intervention. This did not occur. 


\section{A Sample from the Quiver of Arrows}

There is evidence of many arrows flying into the accident causation model of Pike River Mine with date and ownership tags created at least two decades prior to the disaster of 2010. These often travelled with warnings attached the entire course of their trajectory. Many of these 'arrows' are in the findings of the Royal Commission of Inquiry and given that this is not a case of a single arrow of causation flying into Pike River Mine, but an entire quiver full of them, it would be impossible to anaylse each separately within the confines of this dissertation. It is possible however, to analyse a sample of primary arrows of causation. I will choose five of these arrows. This will create a platform for analysis, as once these arrows are identified it will be a easier to examine aspects of power that set off other similarly dangerous arrows along the way, further affecting all levels of defence in the original causation model. I will analyse the shape of these primary arrows in particular, the course they took and how a 'perfect storm' of conditions was created for disaster at Pike River Mine.

\section{Arrows of Primary Causation}

Arrow One: Unresolved Incidents

Archers: CEO, board, management

Archers: workers

Arrow Two: The New Technology of Hydro Mining

Archers: CEO, board, senior management

Archers: untrained Workers

Arrow Three: The Bonus System

Archers: CEO

Archers: The board

Arrow Four: The Inspectorate

Archers: Department of Labour (DoL)

Archers: Ministry of Economic Development (MED) 
Arrow Five: Culture of Production before Safety

Archers: The board of Pike River Mine

Archers: The CEO, the board and senior executives

\section{The Arrow of Unresolved Incidents}

\section{Uncomfortable Truth No. 1}

In the last 48 days before the explosion [at Pike Mine] there were 21 reports of methane levels reaching explosive volumes, and 27 reports of lesser, but potentially dangerous volumes. The reports of excess methane continued up to the very morning of the tragedy. The warnings were not heeded. (9)

Arrow One: The Arrow of Unresolved Incidents

Archer: CEO, Board, Management

Among the primary arrows to fly into the Causation Model of Pike River Mine was that of Unresolved Incidents. Any attempt to deflect this arrow was eclipsed and recast in the name of 'production before safety' (10) at the mine. The Archers at the Bow of Positive Asymmetry had developed habitual ways of both thinking and acting which clouded or ignored any evidence of a worst case scenario occurring in the workplace. These ways of thinking and behaving had become so routine as to be acted upon both deliberately and subconsciously, but with such repetition that the Arrow of Unresolved Incidents flew a direct and determined course through all levels of the accident causation of the mine, perpetuating a climate of denial which accompanied the push to reach financial deadlines right up to the day of explosion.

\section{(i) Archer: CEO, Board, Management}

The findings of the Royal Commission of Inquiry show that prior to the tragedy of November 2010 there were numerous safety incidents reported by both workers 
and management at the mine; but that many of these had not been acted upon and with an increasing number of them not being disclosed at all. Workers reported, for example, significant methane management problems but found that there was no effective system to respond to this'.(11) There is also evidence to suggest that some people working at the mine no longer reported potentially dangerous situations, with many of the former complaints not having been dealt with at all.

There were problems with the investigation process. Many reports were assigned to an investigator, but no investigation was completed. This was evident from the report forms filed with the Commission. Some departments would have only a handful of investigations outstanding, while the engineering and production departments sometimes had up to seventy uncompleted investigations and some were over a year old. Measures to deal with the backlog were unsuccessful. When the backlog was discussed with [the mine manager] in October 2010 he decided that they should be cleared and a fresh start made 'with a new management and new mine manager'. This meant many reports were never properly investigated. (12)

Following Cerulo's (13) analysis of positive asymmetry and of worst case scenarios not being 'seen' in enough time to avert them, I also found there to be a continued culture of eclipsing, clouding and recasting practices occurring at Pike River Mine in the many months and even weeks leading up to the November 2010 disaster. Findings suggest that when there was a chance of any collective acknowledgement of 'the worst' at the mine 'the worst' was removed, as in the earlier example of the decision to delete a entire backlog of health and safety complaints that had not been dealt with in October 2010, in the name of a 'new start' just one month before the tragedy. (14) This is evidence of a recasting practice.

An effort was also made to foster positive asymmetry whereby the 'best' (a changeover in management) was recast to distract from any acknowledgement of the 'worst' (workplace safety concerns) with negative aspects of any unwanted scenario (a likely explosion) made (inadvertently or otherwise) functionally invisible. 
This could only have encouraged a further culture of silence and denial at the mine, in which making further complaints might seem pointless. 'The emergency response management plan essentially discounted the risk of an explosion. The plan and the responses by the witnesses indicate a lack of appreciation of the explosion risk'. (15)

So, given all the difficulties of a particularly gassy mine, (16) let alone one with as many problems as Pike, how could the executive and senior management still fail to 'see' the potential for an explosion? It is true Pike was experiencing financial pressure. (17) There was also had a 'rapid turnover' of statutory mine managers and middle managers. Many workers were inexperienced. Morale and absenteeism was of concern. The company relied heavily on contractors and consultants. (18) There was also a lack of communication between senior executives and the board of the mine. Sometimes essential information was not presented to the board at all; but neither did the board always ask for it; as was clearly shown in the findings of the Royal Commission. (19) There also continued to be a number of issues at the mine needing to be addressed around ventilation, electrical safety and the new practice of hydro mining; (20) but by 2010 Pike River Mine operated from a climate of socially organised denial, positive asymmetry, and the arrow of unresolved incidents continued on its trajectory through the culture of 'production before safety' at Pike River Mine (21) where overall, the risk of explosion was denied and not responded to.

\section{(ii) Archer: Workers}

With so many employees having witnessed unsafe incidents at the mine on a regular basis, it is difficult to argue that the ignoring of 'at-risk' behaviours was a 'failure to learn' stemming from a 'lack of knowledge'; but rather, one of a growing sense of powerlessness on the part of employees. Beneath this 'failure to learn' was a certain 'willingness to deny' which existed to systemic levels; with practices which may have once been considered 'deviant' becoming little more than hushed acts of conformity. Take for example, the following findings from the Royal Commission of Inquiry. (22) 
Analysis of the incident/accident reports exposed incidents of deliberate bypassing of safety systems and tampering with safety locks or covers, rendering them unoperable... A worker admitted briefly taping a plastic bag over a methane monitor on the morning 19 November 2010. (23)

When this incident is analysed further, it is obvious that even when the potential for impending danger was witnessed by a supervisor, it also became eclipsed. The worst case scenario (though ever-present) was left unscrutinised in favour of targets and the pressure of a system with a coal and cash flow deadline. At the Commission of Inquiry, the former employee admitted (without intentional irony) that he ignored this incident, to 'save the boys' legs [save time]; another example of avoiding the 'worst' in the name of focusing on the 'best' under the guise of time management.

One worker admitted he covered a gas sensor with a plastic bag. He did [it] 'to save it tripping and having to wait around for an electrician... and to save the boys' legs ... He had heard of gas detectors being covered on other machines, including loaders. He thought every miner knew how to do it. (24)

Here is further evidence of a culture where it had become increasingly acceptable to practice unsafe acts with a collective blind spot for the development of a worst case scenario because now 'everybody else is doing it'. Such practices were no longer isolated acts; but often initiated visibly in moments of clear acknowledgement. It is also further indication of a sort of cultural osmosis; a developing pervasive culture of denial which had moved from upper management all the way down to the coal face with seemingly little consequence and a growing tendency not to see any potential for the developing worst case scenario, in favour of reaching production deadlines.

Another miner saw compressed air being blown onto gas sensors to keep the machine cutting, and miners using metal clips to override machine-mounted sensors... In fact, he saw machines overridden following gas trips 'quite a few times illegally' (25)

In fact, these instances 'happened so often' a worker would come on shift to find the previous shift had continued a faulty practice, because...'a lot of people did it'. 
Workers might sometimes 'bypass gas detectors 'out of frustration' because of the poor standard of equipment at Pike River and 'the need to get the job done'. (26)

Following Vaughan (1996) findings around the social organisation of mistake (27), I also argue that Pike Mine was 'built on a series of faulty decision making sequences, which when repeated without much consequence gradually become a trusted paradigm' (28) and in a culture of positive asymmetry which had workers continuously doubting their own perceptions right up to the day of the November 2010 tragedy.

Workers often felt powerless to make any significant change to faulty practices, as the mine did not seem to have systems developed enough to identify, let alone respond, for example, to the bypassing of sensors. Faulty practice did not always go unchallenged, but efforts to report these were often eclipsed and bypassed.

One worker told Investigators that written reports of sensors being bypassed would just 'disappear' without any response from management. (29)

This growing sense of powerlessness and frustration among workers is also indicated by evidence of report slips written and sent directly to the mine manger about the faulty systems demanding that practices at Pike be urgently addressed. In March 2010, after 14 reports of gas sensors bypassed, one frustrated employee wrote the following, in an urgent attempt to 'stop people from overriding safety circuits' (30)

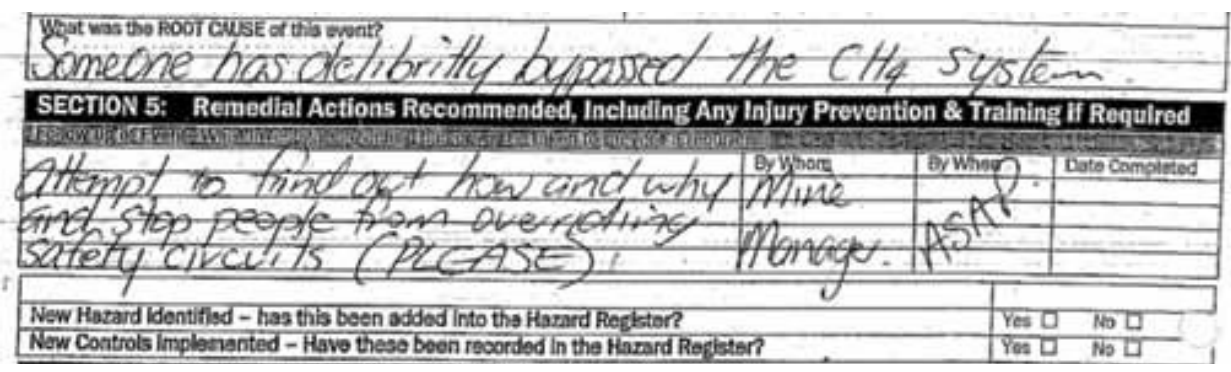

Figure 4: Plea to stop overrides of safety circuits (31)

Yet the findings of the commission indicate that even when reported incidents were addressed, there was often no formal management sign-off to say so; or employees were informed they should speak to deputies or under managers; or issue a 'tool box talk'. (32) There had developed a culture in which it had become routine to reduce the details of reports as they made their way up (and down) the hierarchy. (33) 
Processes were not just eclipsed at Pike River Mine they were also clouded and recast. The bearer of unwanted information (no matter where they appeared in the system) was often diverted via shaming, shunning, shadowing behaviours. (34) The mine had become a culture of production where 'bureaucrats failed to see potential disasters situated in their own choices' and were working at a level of interpretative denial. This mirrors the research of positive asymmetry introduced by Cerulo (35) and of Norgaard (36) into cultures of developing secrecy and socially organised denial.

In sharp contrast to psychological approaches to denial, the notion of socially organised denial emphasises that 'ignoring' occurs in response to social circumstances and is carried out through a process of social interaction... It is a process by which individuals collectively distance themselves from information because of norms of emotion and conversation. (37)

At Pike River Mine there were people at all levels of the system now ignoring 'at-risk' acts and working at the mine without even fully realising the extent of their own denial and possibly that of others, because these 'at-risk behaviours' had become 'normalised' from the 'top-down'. When a worker doubted their own interpretation of what was a safe practice, and had the initial courage to mention their concern, they were silenced by clouding and shadowing processes modelled all around them. This in turn, continued to justify risky behaviours, with a developing 'blind spot' for impending danger and often in the name of deadlines and a production schedule which was reinforced by a competitive bonus system to meet targets. (38)

There were, however, also a number of individuals who stood out from the culture of systemic silence and tried to draw attention to problems at the Pike River Mine; but their efforts to confront the culture of denial surrounding concerns and their attempts to warn in order to avert a worst case scenario in the workplace, were often eclipsed to such a point that they felt belittled or bullied and then began to doubt their own experience, judgement, and interpretation of risk. (39) Acts of prescriptive recasting were also apparent when one manager tried to voice his concerns to colleague and was told to 'take a concrete pill' and 'harden up.' (40) 


\section{The Arrow of New Technology and Hydro Mining}

\section{Uncomfortable Truth No. 2}

It appears no one on the board had experience in the local underground coal mining industry. The business was new with the mine still under development, as were its systems, including health and safety. (41) The reports of excess methane continued up to the morning of the tragedy. The warnings were not heeded. (42) ...The mine's health and safety management vital systems: ventilation management, methane drainage, gas monitoring, hydro mining, were still under development 19 November 2010. (43)

Arrow Two: The Arrow of New Technology and Hydro Mining

Archers: CEO, Board, Senior Management

Archers: Untrained Workers

The next of the Primary Arrows to repetitively pierce the causation model of Pike River Mine was that of newly introduced and often untested technology. (44) There was no qualified ventilation engineer at the mine. (45) There were constant problems with methane drainage, ventilation and electrical systems, even before the introduction of hydro mining and the installation of an underground fan (46) to 'help with ventilation' in the very gassy mine; (47) which added further to issues of faulty terrain and untested technology, with all the potential to cause an explosion. (48)

There was also the issue of another collapsed goaf in October 2010. (49) Collapses like these were known to leak excess methane measuring 'off the charts' on the already faulty measuring equipment; (50) but none of this was amended by November 2010. Added to the new technology of hydro mining (51) a competitive bonus system (52) was suddenly introduced at Pike the same month (July 2010) to ensure targets were reached to meet financial and production deadlines expected of December 2010. 
(i) Archer: CEO, Board, Senior Management

The Royal Commission of Inquiry into the tragedy of 29 November 2010 states that Pike had 'purchased equipment unsuitable for the difficult [NZ] strata conditions encountered. Some key equipment and systems were unproven when production began. There was no suitable second egress for use by workers in an emergency.' (53)

'The one drift. There was only one drift,' said a father I interviewed in 2011 who lost his son to the subsequent Pike disaster. 'There was only one ventilation thing. And that was their means of getting out if there was an explosion... My son [who died] said to me one day. He said to me 'Dad, if you and I were working down the mine together,' he said to me 'I'm going to beat you to that freegen ladder because you'll be too big and bloody tired to get up that ladder.'.... A 150 bloody metre walk up the bloody ladder; to get out with massive amount of bloody methane and you're supposed to be trying to use the rescue gear and trying to go up 150 metre ladder. You've got to be a fit man to do that... [pause] And here they are, saying they can't even walk on a bloody flat area down 500 metres to put their bloody recovery system in. And look how pedantic they've been about that.' (54)

Similarly, a sibling spoke of the death of his younger brother in July 2011. 'He always talked about the Walk Out of the mine....Like, if they walked [out the $2.3 \mathrm{~km}$ drift]. And he says to me 'I wouldn't take it'. I remember the day he once did it, he says 'It took 2-3 hours to [walk out],' So, you sort of didn't really know, if he was doing the Walk Out at that time [of the explosion].' (55)

Added to this is also the evidence that there was no suitable Fresh Air Base (FAB) at the mine. (56) There were not enough self-rescuer masks, and only one barely workable phone, as was proven on the day of the explosion with the initial failed attempts of the only two survivors to make contact with rescuers above ground. (57)

This is not to say that there were not brave individuals who tried to act as deflectors to these arrows of causation before the tragedy occurred. Individuals did speak up but they were not heard. Complaints were made, but they invariably became subject 
to the silencing practices of positive asymmetry and denial later evidenced in the documented in the findings of the Royal Commission. (58) What lies undefined, however, was the culture of Pike River Mine. This culture encouraged certain ways of thinking and behaving that became 'normalised' over time in the drive to reach increasingly demanding production targets; which seemed to consistently mask perceptual portholes for recognising an approaching worst case scenario, and this did not only occur at the coalface but across entire systems of denial and inaction. It is essential to analyse these practices to understand the case of Pike River Mine, and to prevent high rates of workplace tragedies in other New Zealand industries.

Example One: Brian Wishart Email (methane)

Brian Wishart, an experienced miner, tried to draw attention to his concerns about the methane drainage system at Pike River Mine in 2010 via email. [See figure 4] (59) This was not a new complaint. Many similar concerns had been made by others at the mine but they had mostly been diverted or ignored. In April 2010 however, this particular email of Wishart drew some initial response, possibly because it brought to mind the recent news (5 April 2010) of a coal dust explosion at Upper Big Branch Coal mine, West Virginia, US which had just killed 29, leaving two others injured.

The 'American pit' that Wishart refers to in his 11 April 210 email (below) as having 'recently exploded' around issues of 'inadequate methane drainage system' is Upper Big Branch Mine, and the deaths referred to, had occurred just six days earlier. (60)

There had already been at least eight prior statutory reports completed by Pike deputies, in the month preceding Wishart's email; all of which noted exactly these concerns with over pressurised gas drainage system. (61) But complaints had become normalised via the culture of positive asymmetry operating at Pike River Mine. 
Attention Jimmy Cory

General Concerns Methane drainage system PRCL. 11/4/2010

I would like to bring to your attention again the inadequacy of our Methane Drainage system.

1 - The running of a gas drainage system in intake airways is of concern to me as any trouble that we have with water traps, which is very regularly causes methane to vent into our intake roadways this scenario would not happen in NSW or QLD as this kind of arrangement would not get past a risk assessment process and would not be allowed, we should also not allow this practice.

$2-$ The positioning of this system in $3 \mathrm{ct}$ also leaves it venerable to damage from jugos ect.

3- We now also have a fresh air base with a methane riser in the middle of it.

4-Over the weekend we had to reposition a water trap at the FAB as it was installed in such a way that the FAB door could not be dropped down in an emergency?

5- On numerous occasions I have found methane free venting in the old drill stub, while we are drilling there is so much pressure in the line that this stub does not actually discharge any methane into the system.

6 - Water traps are continuously filling with water at a rate faster that they can be drained.

7-The first trap in the line is that inundated with water while drilling that the trap tube is by bull hose draining straight into the flumes which also surges gas into the return.

8 - "There is a definite problem when we are pushing water up the riser".

9-This is all due to the line being too small for the sheer volume of methane we are trying to force downhill then up the riser.

$10-$ My list goes on... but by now I'm sure you get the picture.

It is my opinion that the VLW drill program should be suspended until the line is renewed with larger pipes installed out of the intake. I am well aware of the pressures we are under as a company but this should not be the pressure that possibly one day causes us a serious incident.

Last night the surges in the system were so violent that I was concerned it could blow of the rubber pipe which connects to the trap in the $3 / B$ intake position. This would be very dangerous, if this happened with nobody in the vicinity to close the valve at macdow cribo which is not easily accessible we would have full flow methane directly into the intake and in turn across macdow headings I'm sure with that flow the methane would be in the 5-15\% range with plenty of Oxy not a nice scenario.

Just to bring to your attention the suspected findings of the American pit that recently exploded was centered around an inadequate methane drainage system.

History has shown us in the mining industry that methane when given the write environment will show us no mercy. It is my opinion that it is time we took our methane drainage here at PRCL more seriously and redesigned our entire system.

Regards

Brian Wishart

Figure 5: Email from Underviewer, B. Wishart to J. Cory: RE: Methane Drainage (62)

The findings of the Royal Commission state: 'Some issues with the system [at Pike] were already known, but this email provoked an immediate response.

Mr Cory showed it to Pieter van Rooyen who took it to the next production meeting where 'various actions' were discussed. 'Short-term remedies' were implemented, and Pike engaged an Australian gas drainage consultant, Miles Brown of Drive

Mining Pty Ltd.' (63) 
In drawing attention to the recent tragedy of a comparable overseas mine, Wishart's email had, in fact, temporarily forced the hazardous problem of the gas drainage system (64) into some kind of 'collective acknowledgement' of a looming worst case scenario at the mine, albeit temporarily. His complaint was definitely brought up at the next Pike Mine production meeting but clouding practices occurred; a sample of which appear below in (examples 2-3) whereby the identification of a worst case scenario was blurred again from view in favour of 'short term' remedies.

Some issues relating to the inadequacy of methane drainage were, for example, already known (65) as in the running of a gas drainage system in the intake airway and the building of a methane riser in the middle of the Fresh Air Base (FAB); the door of which could not be dropped in an emergency. There were water traps continuously filling with water at a faster rate than they could be drained and the sheer volume of methane being forced uphill and into the riser. (66) Yet according to the later findings of the Royal Commission of Inquiry 'short term remedies were implemented' which were known at the time to be inadequate but which were the 'easiest' to start with.

At the time it [the methane drainage system] was installed, Mr Whittall [who had directed the mine's development since 2005] fully expected the 4" pipeline would eventually become inadequate, but the small diameter pipeline was chosen because 'it was easiest to start with'. (67)

Indeed the whole situation was already 'clouded' in the form and location of pipe work and gas riser; only to be eclipsed, yet again, in terms of the total lack of close monitoring of gas concentrations, pressure and flow. 'Yet no manual measurement or monitoring processes were established when the system was installed. (68) And neither were the sensors. Many of the issues brought up at the production meeting had not been fully addressed, let alone implemented by the time of the explosion.

During a risk assessment into the operation of the ventilation fans held on 14 October 2010, an action plan recorded the need to move the methane drainage lines into a better area away from the methane sensor at the main fan motor. This had not occurred by 19 November 2010. (69) 
Such practices were not isolated acts at Pike Mine. They seemed to be initiated in moments of clear acknowledgement as indicated by the findings of the Commission. Short term remedies also tend to highlight 'the best' of a situation in a climate of positive asymmetry, creating a consistent shift of focus (whether that be inadvertent or otherwise) from the 'negative' in the drive to meet intended goals and deadlines.

In further following the argument of Cerulo (2006) a concerned person might find themselves for example, in such an environment subject to acts of 'shadowing' (70) and 'impressionism' (71) in which they begin to doubt their own perception and start to wonder if their initial concerns (of what they thought they saw occurring in the workplace) was in fact, what other people saw at all. (72) Many of the workers were new to Pike River Mine. Some were contractors from other industries. Then, with the introduction of a bonus system and the need for 'group focus', 'team spirit' and the overall outcomes of production, a certain 'looking out' for affirmation of 'mates' and from 'experts' might sometimes occur, with the concerned individual finally deciding that when in doubt it might be best just to remain silent, so as not to feel foolish. (73)

Example Two: Miles Brown Consultation (drainage)

In direct response to Mr Wishart's email, Australian gas consultant, Mr Miles Brown conducted three site visits to Pike River Mine to advise on the gas Drainage System. He inspected and consulted with staff from the Pike Services Department and he gave Mr Cory [addressed in Mr Wishart's email] 'training including on gas flow measurement, and provided lengthy technical reports supplemented by email advice when required'. (74) Unfortunately, these expert warnings were clouded and eclipsed:

When Mr Brown requested information on Pike's gas reservoir, before arriving in New Zealand, there was no gas content data available as 'up until then, Pike had not taken any core samples during its in-seam drilling programme.'(75) 'A lack of data' meant he was unable to properly design a gas drainage system and had to make assumptions about the gas reservoir. (76) 
Mr Brown however, provided a gas drainage schedule for the mine and Pike accepted his recommendations. (77) But these also seemed to have been ignored. The outburst threshold level for the Brunner seam was still unknown at the time of the November 2010 explosion. (78) The professional concerns of Mr Brown were eclipsed and later clouded when he returned to Pike River Mine. On June 2010 Mr Brown stated that 'any [starting of] hydro extraction before the underground fan was commissioned would increase methane levels in the return, and would have a negative effect on the available ventilation'. He also doubted the desired extraction rates were achievable without and ungraded gas drainage line.' (79)

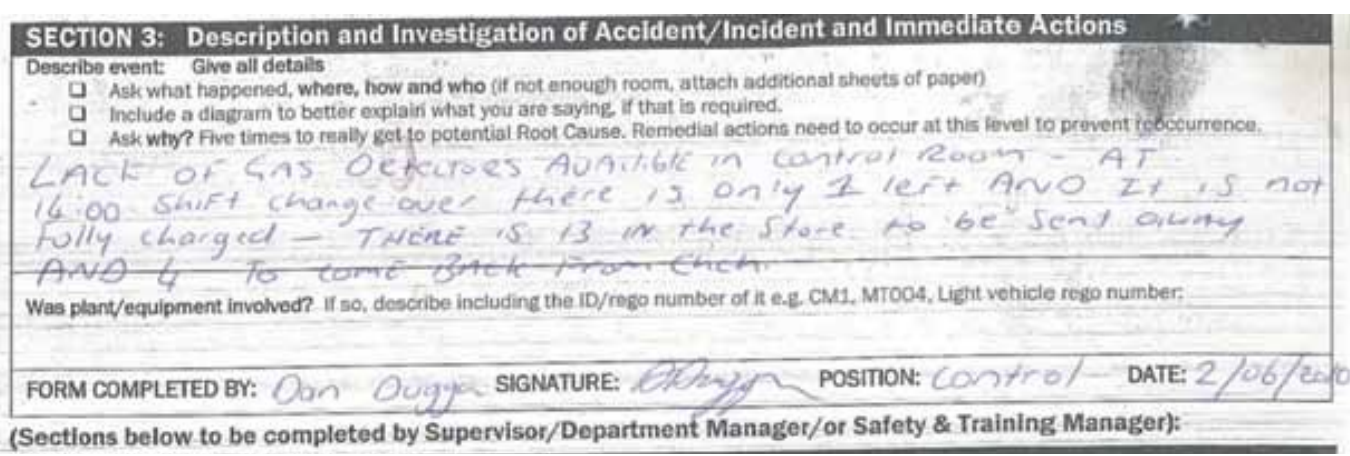

Figure 6: Report of lack of gas detectors (80)

When Mr Brown returned to Pike River Mine, September 2010, [Pike] was about to begin hydro extraction, regardless. His warnings went unheeded as 'there had been no upgrade to the gas drainage infrastructure; the underground fan had not been commissioned and free venting was still occurring.' (81)

Example Three: Masaoki Nishioka Advice (hydro mining)

Complaints (82) from all levels of the mine continued to be recast, as seen in the evidence of Masaoki Nishioka, who had come to Pike with years of experience in hydraulic mining in Japan, Canada and New Zealand mines. 'Mr Nishioka left Pike River Mine in October 2010, one month prior to the tragedy, concluding that the mine was unsafe due to high methane levels, inadequate ventilation, poor methane drainage from the coal, and the lack of a second means of egress.' (83) Nishioka also warned several staff members, including middle managers Pieter van Rooyen and Terry Moynihan, that the mine could explode at any time. (84) 
Example Four: Pieter van Rooyen Requests (Ventilation)

A number of people had also raised the need for a ventilation engineer at the mine. Pieter van Rooyen, the technical services manager at Pike, later told the Royal Commission that 'when appointed in February 2009 he assumed there would be a ventilation officer at the mine. He thought one was needed; particularly since he had very little ventilation experience. He [later] suggested to [the CEO] that Pike should send one of its engineers to New South Wales to complete a ventilation officer qualification.' (85) But he was told that it was not necessary as Pike was a 'small mine' and that a ventilation officer was not required by New Zealand law. He raised this issue again with the general site manager but his concern was again eclipsed.

Mr Whittall said a ventilation officer was not required under New Zealand legislation, and not necessary owing to the size of the mine. Mr van Rooyen also raised this matter with Mr White. (86)

The matter was not resolved by 19 November 2010. This suggests a level of dysfunction operating at company and management level at the Pike River Mine which repeatedly ignored consistent warnings, from both workers and experts and fostered a culture which (inadvertently or otherwise) encouraged a 'blind spot' at the perceptual porthole of recognising an approaching worst case scenario. It also suggests that the way the mine was operating continued to be endorsed by systems which possibly stood to profit from reaching these risky production deadlines.

'Now ah, the Australian...approach to it was,' said another senior mining executive I interviewed in 2014 'Well, in Australia we just put in men and machinery - or mostly machinery - and we produce more tonnes. Well, it's not possible here [in New Zealand]. But you couldn't have that discussion, with them. So there was a construct. The whole thing was built - It was a house of cards built on - with no foundation.' (87) 
Mr van Rooyen worked a 70-110 hour week as technical services manager at Pike, and often on crisis management (88) $\mathrm{He}$ had been in a position to sign the permit to the mine, but the mining operation continued without his signature anyway. (89)

'The company focus, as conveyed to me by Gordon Ward and Peter Whittall, was on the need to produce coal as soon as possible,' Mr van Rooyen later told the Royal Commission... 'There was no way the company would delay coal production.' He also disagreed with the location of the fresh air base which was too close to methane drainage lines. (90)

Mr van Rooyen resigned from Pike just weeks before the mine exploded. And this by no means an isolated case. Another example of eclipsing/recasting practice can be seen in Pike's introduction and use of an underground fan 'to improve ventilation'. Legislation in other countries either expressly bans main underground fans in coal mines, or assumes they are installed on the surface; that only booster and auxiliary fans are installed underground. The International Labour organisation (ILO) code of practice issued in 2006, assumes main ventilation fans are stored on the surface. New Zealand Law does not specifically prohibit the installation of main fans underground and there is no mention of the location of main fans in the guidelines issued by the national health and safety council for the NZ minerals industry (MinEx) in October 2009.(91)

The culture of Pike River Mine was found to be dysfunctional. The fundamental need for a ventilation officer (and other requirements) in a gassy mine seems to have also been overshadowed by the apparent 'positives' [of running a small New Zealand mine] and that 'if [it] is not required by law, 'it must be okay then'.

'New Zealand legislation at the time, didn't specifically not allow it,' one mining executive told me in 2014. 'So that might have been the rational for putting the fan underground. 'It doesn't say we can't do it. So that must mean we can do it.' (92) 
Example Four: Harry Bell, former chief inspector (warnings from 1980's onwards)

As with the case of Masaoki Nishioka, Mr van Rooyen also mentioned a number of concerns before he left the mine. (93) He recalled that in $2009 \mathrm{Mr}$ Rennie, an Australian ventilation consultant engaged by the mine, had 'expressed, concerns about the placement of the main fans underground'. Mr van Rooyen spoke to $\mathrm{Mr}$ Whittall, who said 'the decision had already been made, and one fan was already in New Zealand and the other partially constructed but on hold.' (94)

It seems that suggestions were often ignored by the CEO and there was a culture of blame at the mine. When the Royal Commission of Inquiry into the subsequent tragedy of November 2010 asked about the management style at the mine, Mr van Rooyen stated that he had at times found that frustrating; 'Mr Whittall did on occasion make it clear his decisions were final. When errors were made, [he] often blamed them on others;' and 'there was a culture of blame at Pike River Mine.' (95)

\section{The 'Blame' Culture at Pike - Acts of Shunning, Ignoring and Shaming}

When a former mine manager of Pike gave evidence at the Commission of Inquiry it became apparent that practices of eclipsing at the mine included acts of 'shunning'. Mr White had been the sixth general manager in two years (96) 'There was a blame culture when I arrived [at Pike],' said Mr White 'It was always someone else's fault.' He went on to describe Mr Whittall's style as dictatorial, overbearing and at times, it was not uncommon for the CEO to publically berate managers in front of their peers; a practice that he found 'disgusting'. Mr White stated there had been no love lost between Mr Whittall and senior managers; that 'it had been hard to work for some one who had made or overseen so many stuff ups and blames everyone else.' (97)

Mr Neville Rockhouse, the Health and Safety manager at Pike also described a culture of blame at the mine. (98) His younger son Ben, 21, was killed in the tragedy. His father died of a heart attack the same night and his elder son, Daniel 24, was knocked out by the initial blast, but stumbled along the $2.3 \mathrm{~km}$ mine drift, dragging 
his unconscious friend, Russell Smith, 50, to safety. They were the only two survivors that day. When I interviewed Mr Rockhouse in Christchurch, July 2012 he said:

'In the early part of the Inquiry it became apparent very, very quickly that it appeared to be presented as me against Peter Whittall... And the lawyers started to try and put that slant on it: 'this is an employee who has issues with his boss' etc, but it wasn't the case. I was telling the truth. At the time of explosion I came out publically and said No, we had very robust safety management systems. We had everything in place. You know, it was a safe mine. But then gradually, very gradually...I started to find out the truth. And the truth was there were a few guys in that organisation at a higher level than myself that deliberately decided that they needed coal on a boat. And that they would take all steps; whatever they were, whatever they needed to do, to fulfil that objective of getting coal on a boat by Christmas 2010'. (99)

The evidence of a 'blame culture' at Pike River Mine is also a recurring theme in my own interviews. The commission found Pike had some safety systems but that they were not utilised. (100) It stated that the professional support had been lacking for $\mathrm{Mr}$ Rockhouse as Health and Safety Officer at Pike and that when he raised his professional concerns about the safety of the mine, these were often not addressed.

The commission is satisfied that Mr Rockhouse needed significant support and guidance in developing Pike's health and safety management system, and direction on priorities. And when Mr Rockhouse was vocal in raising safety concerns, for example, in the absence of a second means of egress and the need for a refuge chamber, his concerns were not addressed. Generally his department struggled for credibility alongside the more productionfocused departments. (101).

Mr Rockhouse gave evidence of how senior managers were at times humiliated in front of their peers by the CEO. He tried to develop workplace safety documents (102) but had no power to implement them. He had no oversight over other departments. 
Mr Rockhouse had a heavy workload, sometimes working 60-80 hours per week. He sought more staff for his department but was largely unsuccessful. He found it difficult to get co-operation from other managers. (103)

The Royal Commission stated 'Although Mr Rockhouse was the architect of most of the health and safety documents, he depended on technical input from managers or staff of other departments. He had no authority over the managers and staff and there was no central oversight of the way departments managed health and safety other than Mr Rockhouse who was 'chasing them constantly to get stuff done'. (104)

This is further evidence of clouding practice in operation at the mine. Mr Rockhouse repeatedly asked for more safety staff. His requests were ignored. His efforts continued to be eclipsed and recast. On occasion, when he tried to oversee progress, he was told off. He was berated, shunned and bullied. Mr Rockhouse later said 'On one occasion, [Mr Whittall] caught me helping one of the managers do some of the stuff and he sort of turned around and said 'Keep your bloody nose out of it'.' (105)

At the Inquiry Mr Rockhouse also mentioned feeling humiliated by the CEO who had pointed out minor errors in his presentation in front of senior managers at a meeting. He was so affected by these practices he decided to resign; a fact he confided to a manager who replied 'Take some concrete pills and harden up'. (106) This is an example of prescriptive recasting and demonstrates how entrenched the culture of positive asymmetry had become at the mine. The Commission concluded:

The executive management team did not always prioritise safety matters. $\mathrm{Mr}$ Rockhouse, without a strong mandate, found it difficult to influence and involve others. The safety and training department at Pike appears to have been marginalised. (107)

The Royal Commission also found that Mr Borichevsky, the technical services coordinator attempted to monitor and present his concerns, only to have them recast. 
[Mr Borichevsky] monitored gas levels and trends and reported these to the daily production meeting until the new production manager, Mr Ellis, took over running the meetings around mid-September 2010. (108)

Mr Borichevsky said at one stage he reported on methane spikes to morning production meetings. To do so, he obtained printouts of methane records, made a note of any spikes, reviewed the deputies' reports and other documents to try to establish the cause, and discussed the spikes in the meetings. However, Mr Borichevsky maintains that when Mr Ellis took over the morning meetings the agenda changed to focus on production, and $\mathrm{Mr}$ Ellis was not interested in methane spikes. (109)

Mr Ellis rejected Mr Borichevsky's comments and said that although he did not recall Mr Borichevsky discussing gas levels at the production meetings, there was nothing to prevent him from doing so. What is clear is that methane spikes were no longer discussed at production meetings from late 2010. Coal extraction from the hydro panel had started and there was an increased need to discuss and resolve methane levels. (110)

The findings state that Borichevsky and Ellis gave conflicting evidence about the change of focus in the production meetings, but the daily review and reconciliation of gas levels and trends did not occur from that point on. (111)

In presenting his daily scientific results, it seems the efforts of Mr Borichevsky were at first clouded and then gradually eclipsed, to the point that he too was diverted as a 'bearer of unwanted information' from illuminating risk in the face of mounting production deadlines; deterred from presenting his own concerns. The findings of the commission also state 'The location of a fan in an underground coal mine was for example, considered 'unique in the world', (112) 'never seen in an underground coal mine' (113) 'largely untested and unusual', (114) and associated with three main risks:

First, it is more difficult to re-establish ventilation after an explosion, which could compromise the survival chances of anyone underground. Second, an underground fan is more likely to be damaged by an explosion. Third, an 
underground fan is closer to explosive material such as methane and coal dust; a malfunction of the fan or its motor can be a source of ignition. (115)

As late as October $2010 \mathrm{Mr}$ Borichevsky was still trying to address the development of a second form of egress. (116) But the proposals of Mr Rockhouse, Mr Borichevsky and a number of other experts were all invariably ignored or diverted. The unsafe practices continued knowingly at Pike River Mine, and the ventilation shaft remained the unofficial designated 'second form of egress' (117) giving 29 men, no means of escape on the day of the first explosion at the mine on 19 November 2010.

\section{(ii) Archer: Untrained Workers}

The managers were not alone in feeling eclipsed at Pike River Mine, as can be seen in the following documents. There is evidence that employees at the mine still tried to improve issues like ventilation by bringing up the monitoring and focus of it in production meetings. Examples of how frustrated and possibly powerless some people may have felt can be seen in the professional recording of complaints in the last months and weeks leading up to the November 2010 tragedy at Pike River Mine.

Official written complaints are now screaming in all caps. They are desperate commands 'GET THE DAM VENTILATION SORTED OUT... THIS ISSUE HAS DRAGGED ON FOR $2 \frac{1}{2}$ YEARS!!!' followed by triple exclamation marks. There are also similar complaints in the form of questions i.e 'WHO IS THE VENTILATION ENGINEER???' followed by triple question marks and often peppered with curses 'bloody' 'shit'. People were still trying to get their point across on 21 October 2010 (fig 6). And it is clear from the way forms are filled in that employees perceived no one is listening. 


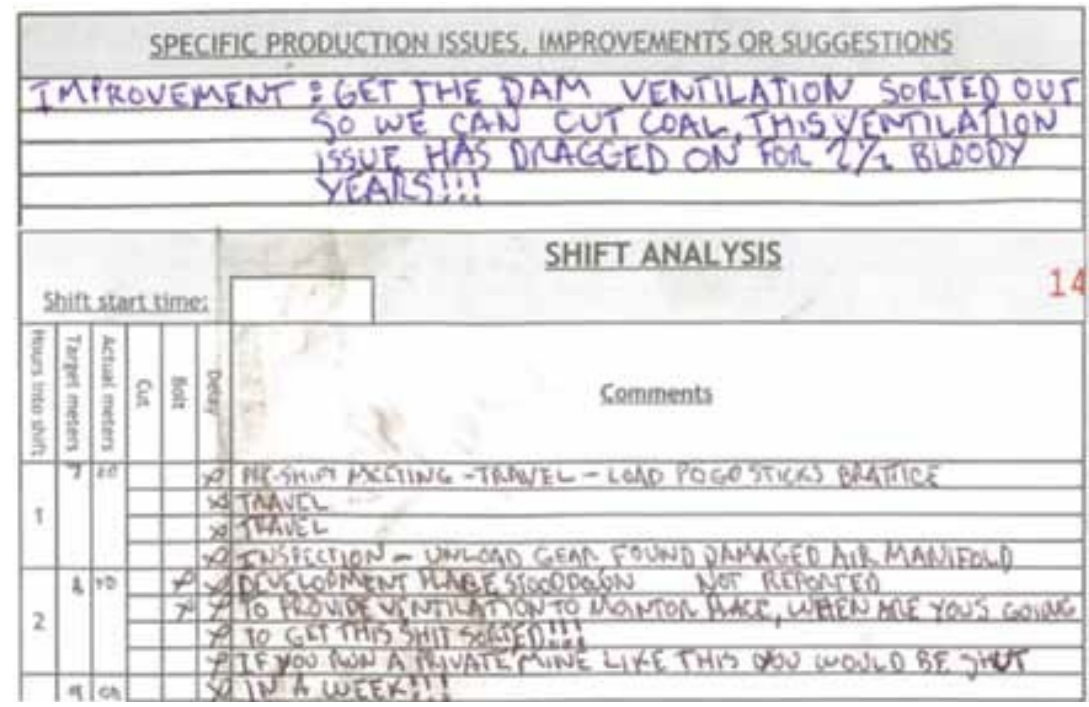

Figure 7: Extracts from Dene Murphy’s 21 October 2010 Deputies Production Report (118)

The major collapse of the ventilation shaft in February 2009 had also severely limited mine ventilation, which ironically enough was still considered the 'secondary means of egress'. (119)The Royal Commission of Inquiry into the tragedy at the mine later concluded that using the ventilation shaft as an 'escapeway' was a 'fundamentally flawed concept; as it was very physically demanding to climb the $105 \mathrm{~m}$ ladder system in normal conditions; and wearing a self-rescuer would have been even more difficult and probably impossible'; which was proven when the explosion of 2010, 'caused the vent shaft to become a chimney for flame and noxious gases.' (120)

There was also an assumption that the self-rescuers and the Fresh Air Base [FAB] were functional at the mine and working. The Royal Commission of Inquiry later found that none of the improvements to the Fresh Air Base, which were meant to be completed by June 2010, had been seen to by the time of the explosion (121) and 'There was insufficient training in emergency preparedness at Pike... Search, rescue and recovery training on the use of self-rescuers was inadequate'. Many of the workers at the mine in November 2010 had never been involved in even a mock underground evacuation; the last drill having occurred in October 2009. There had also been no training to test the practical implementation of the mine's emergency response management plan, which had not been reviewed since February 2009 (122) 


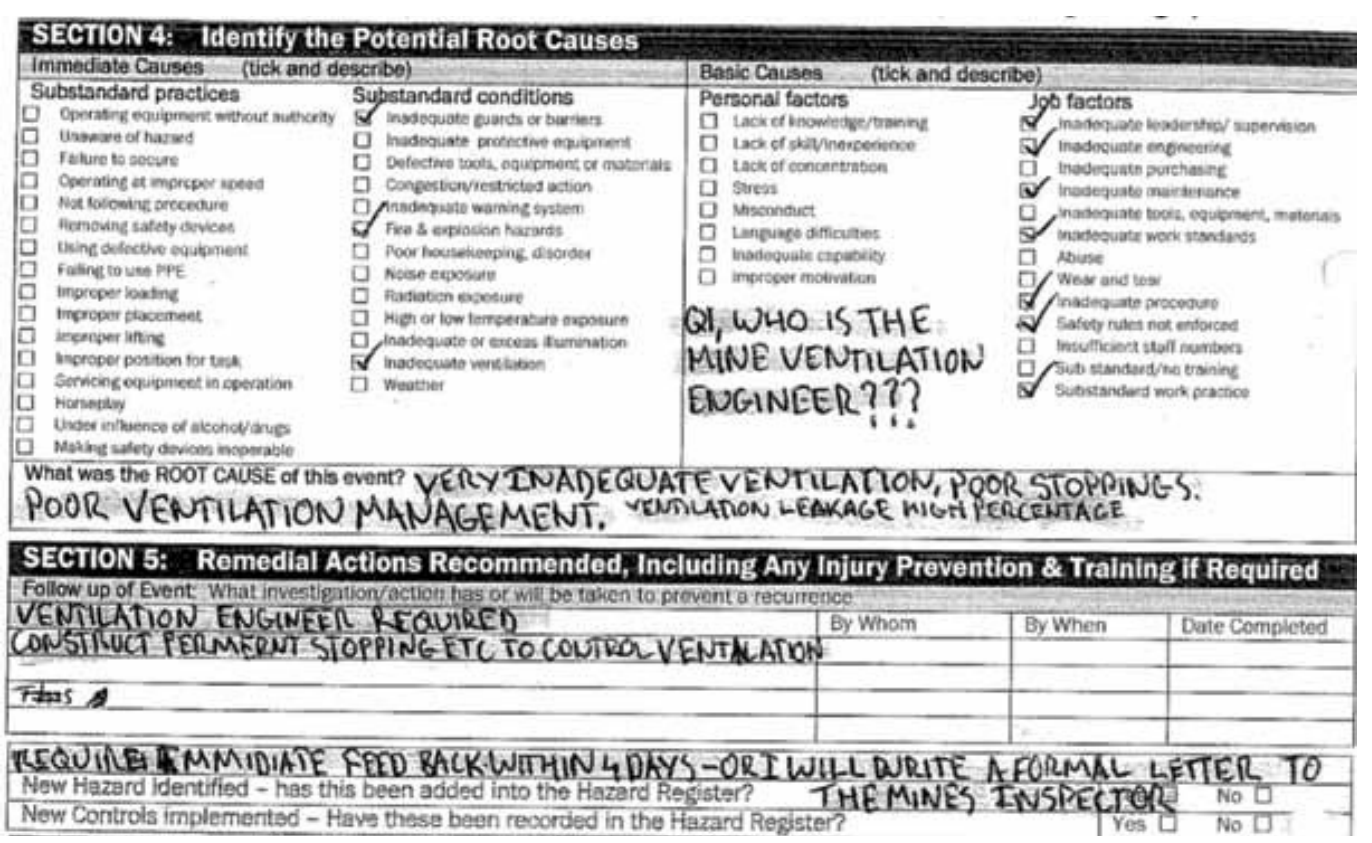

Figure 8: Extract from Dene Murphy's 24 June 2010 Incident/Accident Form (123)

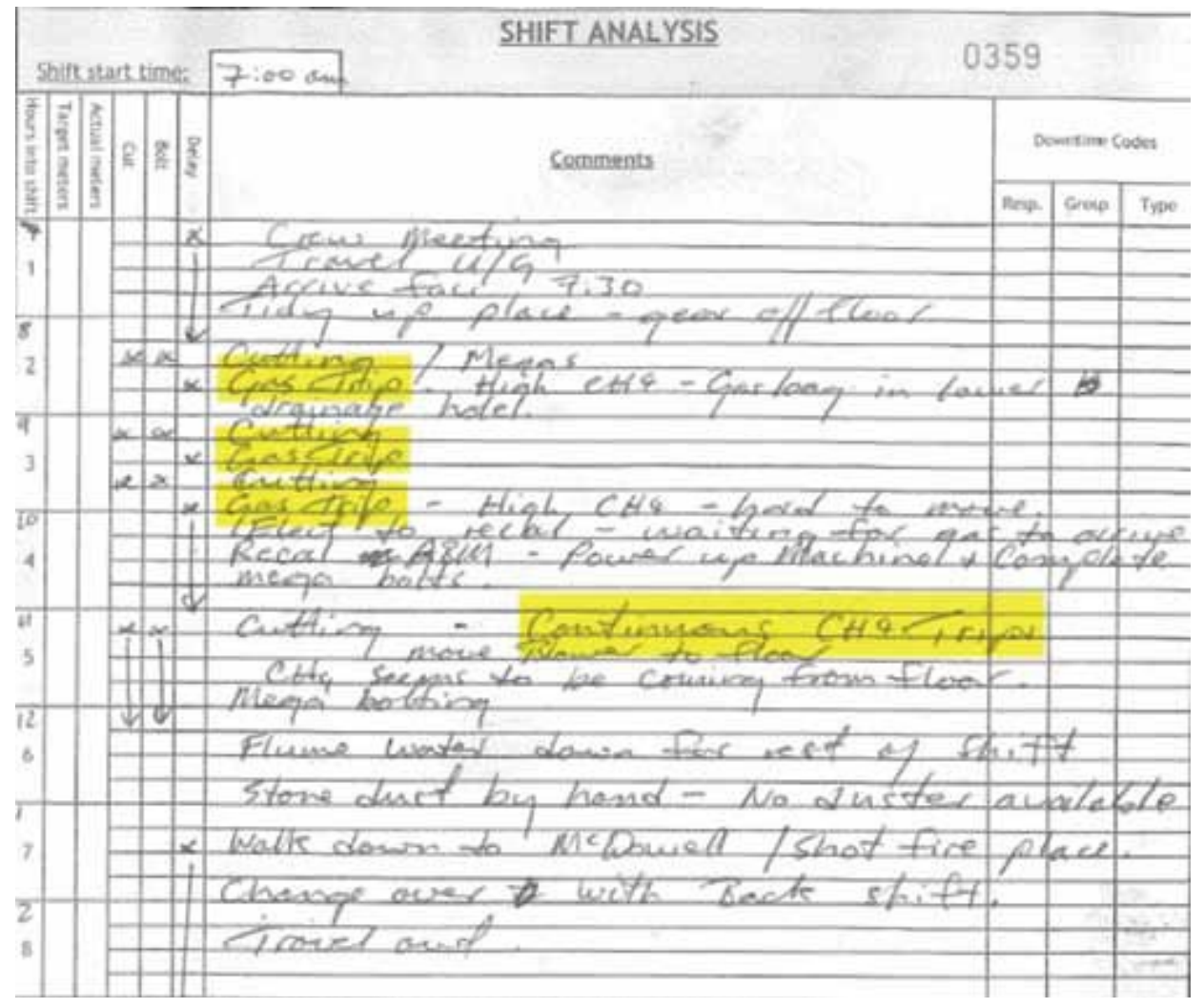

Figure 9: References to gas trips 19 November 2010 (124) 
There are many further examples of eclipsing and clouding practices occurring at the mine, which refer to gas trips, lack of gas detectors along with urgent requests in the months leading up to the tragedy to get the ventilation of the mine sorted out.

As well as information from the site, health and safety committee, numerous records and reports provided information about problems at the mine. Deputies and underviewers completed reports every shift. Control operators prepared shift, daily and even reports. Engineers, electricians and machine operators regularly inspected and reported on diesel engines, fans, pumps, sensors and electrical equipment. (125)

There was also no formal investigation into the rockfall which occurred at the mine on $\mathbf{3 0}$ October 2010 just three weeks before the 19 November tragedy. In this, part of the roof in the panel one goaf collapsed. 'The resulting rush of air was strong enough to knock over the stopping in the hydro panel cross-cut, and resulted in an explosive accumulation of methane'. (126) There had also been several different views on whether the roof collapse had extended further; and whether it would interfere with operations. (127) But this was not considered any more of a 'show stopper' (128) than it had been when the mine manger was presented with the September (2010) risk assessment in which a number of actions needing to be urgently addressed were indicated. None of these were even assigned to be dealt with until 16 September 2010, which was three days before hydro extraction was to begin. These included:

- specification of construction requirements [ventilation devices]

- ensuring that the [gas] monitors were installed to standard

- determining the capabilities of real time monitoring

- training the control room operators to be trained in SafeGas; and

- ensuring regular auditing of ventilation systems. (129)

The Commission reconfirms that many of these requirements had still not been attended to before the explosion on 19 November 2010. 'Most revealing of all is that in emailing this list to key personnel, the mine manager had stated None of these issues are show stoppers and some will take time to implement'. The Royal 
Commission later stated 'It is a revealing insight into the thinking at the mine that such fundamental requirements were not seen to be show stoppers.' (130)

Few metaphors illustrate so well, the level of denial and dysfunction that must have been operating at Pike River Mine than this; to have the general manager of mines stand up and declare 'the show must go on, regardless'. In the weeks leading up to the explosion, many 'obstacles' on the path to production seemed to be increasingly ignored or recast in the name of reaching production targets for the company; for Christmas, for your family, for your mates. The 'show stoppers' all seemed to have been temporarily recast as opportunities 'to test us' to show 'how versatile we are'; 'how capable we are under such pressure'. (131) Danger in a risky climate is now assigned to co-exist to a workplace culture of silence and positive asymmetry.

\section{The Arrow of the Bonus System}

\section{Uncomfortable Truth No. 3}

Although production bonuses are common in the coal mining industry, the hydro bonus at Pike created particular risks. Pike offered the bonus when there were known problems with equipment, ventilation, staff inexperience, a lack of effective monitoring systems. (132) The board initiated a staff bonus scheme based on reaching a coal production target promptly, with the bonus then reducing week to week. (133)

Arrow Three: The Bonus System

Archers: The CEO

Archers: The Board

Added to all these unresolved issues around hydro mining and new, untested technology unsuited to New Zealand terrain, was the introduction of a new competitive bonus system to make sure the Christmas (2010) deadline was met. The findings of the Royal Commission of Inquiry state that 'coal production was two years behind schedule at Pike River Mine' by 2010; that the 'the previous estimate of production capacity had to be severely reduced' and that 'lack of revenue was 
driving the company to seek further funding'. (134) There continued to be numerous problems in the workplace with many left unresolved, and in response to the specific difficulties around new technology and hydro mining, a bonus system was set up. This was also an attempt to eclipse absenteeism which had become a costly issue on top of the many geological and technological troubles of the working environment.

The causes of absenteeism at Pike River Mine were never made clear to the Board. (135) But once again, neither did the Board enquire. Many miners and contractors were by 2010, experiencing headaches, nausea and, in some cases, even nightmares with regard to unresolved issues at the mine. (136) When the bonus system was introduced in July (2010) it was initially used to cut absenteeism, retain staff and meet targets. Instead this bonus system was in effect, to become a primary arrow of causation on its own trajectory to tragedy at the Pike River Mine.

In July 2010 the hydro-mining bonus start-up was instituted, although the cause of the absenteeism problem was not clear to the board. The bonus was reduced by $\$ 200$ for each non-attendance, defined as every day or shift on which an employee was rostered but did not work for any reason, including sickness or lateness. By November 2010, the Pike considered that the bonus scheme had led to a 'reduction in sick leave usage'. (137)

\section{Hydro Mining Bonus Table}

- In the event that hydro is achieved earlier than 24 September this rate will increase and in the event that we do not achieve it until after 24 September, the amount will decrease as set out in the table below:

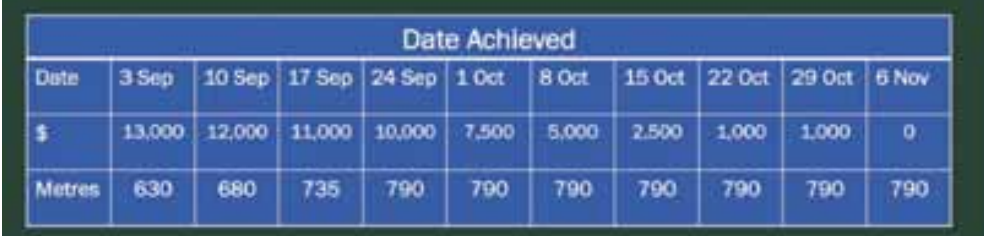

- The scheduled date for hydro start-up is 3 September 2010.

Figure 10: Hydro mining bonus table (138) 
In reality, this Bonus Arrow of causation was shot from the Bow of Positive Asymmetry on a flight of clouding practices. The many acts accompanying it had graduated from acts of eclipsing to practices of shadowing and impressionism; (139) but as the year progressed, the course of this arrow was no longer blurred. Those employed at all levels of Pike were aware that targets needed to be reached and that individual bonuses could be lost for entire teams, if they weren't achieved on time.

The path of this arrow was clear but its purpose was shadowed by practices which diverted acknowledgement of a developing worst case scenario. A system of rewards to achieve company targets was set; the most immediate seeming to have been to get a predetermined load of coal out of Pike River Mine by Christmas 2010. (140)

This 'Christmas' production deadline is referred to in a number of the interviews I conducted (2011-2106) and often with the mention of 'needing to get a boatload of coal out by Christmas'. In some cases this may have been something interviewees associated with the work pressure and the potential for a happier, more affluent Christmas; that they might all 'reap' this festive reward. In reality, however:

The board and executive management faced serious financial challenges, some of which had been apparent for years. The company had a history of not delivering on its promises. Coal production was years behind schedule and previous estimates of production capacity had to be severely reduced. Lack of revenue was driving the company to seek further funding. There were major problems with the advent of hydro mining, the company's main production method. (141)

The positive asymmetry of presenting the risky pressure of deadlines alongside increased financial reward for achieving company deadlines was set to combat absenteeism, sickness and low morale. There were daily and weekly monetary gains to be had by employees for reaching specific hydro mining targets, regardless of their training (or lack of it) in a gassy, faulty mine with newly acquired technology and mining equipment often unsuited to New Zealand conditions. A culture of positive asymmetry was crucial to the deadline. Employees were encouraged to 
persevere to reach targets in a climate that kept complaints to a minimum. The knowledge of escalating reward (and the fear of potential escalating loss) were crucial to the competitive process, with acts of impressionism keeping everyone at what Cerulo (2006) might termed as a 'best case' or 'best- view-only' port-hole. (142)

Competitive pressure to meet targets has identification of a 'worst case scenario' kept at a distance and seldom focused on for long to be acknowledged, let alone corrected. The culture of positive asymmetry at Pike River Mine was now one in which 'team focus' on all things 'positive' was paramount. All attention was recast to avoid viewing from worst case portholes; possibly with the hope that with just three more months of these work conditions and hours, it would all be done by Christmas.

It is important to emphasise that acts of recasting in terms of 'awards' were by now not only those of financial, monetary gain, but part of a team driven process and directed en block to achieve targets 'for the good of all'. No matter how faulty the mine's equipment, or how new the technology, or how inexperienced, untrained or concerned an employee might be, there was by now, such a culture of positive asymmetry at the mine, that it is almost impossible to focus on any 'incident of complaint' for long enough, to confront it for fear of inhibiting production process.

With the introduction of the bonus system there was also a more subtle 'team' vs. 'the company' mentality which further clouded any acknowledgement of unsafe practices, and especially with the knowledge of earlier unsafe incidents having been left unresolved by higher management (143) there would possibly have been very little incentive left for an employee to think that complaining was going to change anything at all, before Christmas. Miners and contractors were increasingly encouraged to turn a blind eye for the sake of the team and for the overall bonus.

It also might by then be argued that pressure to achieve the company production target by Christmas was a 'one-off necessity' in the face of new technology which would be 'better understood' when fully installed at the mine. The Bonus Arrow had been set on course for personal/team targets regardless of how faulty systems, new technology or delays might be. Acceptance might be argued to be the answer to 'all 
our problems' for a limited period of time for the good of the team. The culture of positive asymmetry at the mine might even ring with a certain dangerous rationality.

In response to the increasing delays, in July 2010 the Pike board authorised payment of a hydro production bonus to staff when hydro extraction began. The bonus started at $\$ 13,000$ if hydro production (defined as 1000 tonnes of coal) was achieved, together with $630 \mathrm{~m}$ of roadway development, by Sept 2010. After that the amount of the bonus reduced each week. (144)

By October, 2010 repetitive recasting practices first described by Cerulo (145) in her separate study had almost become prescriptive at this mine. Recasting practices typically require a certain virtuous mythologizing, in that individuals are usually convinced that even in the face of dangerous practice, 'positive thinking' is all that is needed for the 'good of all' to meet the desired financial outcome; that the means of production might invariably be justified by the final payment in a win-win situation. Company teams meet the target; employees 'get' part of the profits. Such practice encourages the entire team to see the positive in any negative and any negative as an opportunity. Any 'obstacle' becomes something to overcome in an effort to increase productivity that will affect the next production target and the next reward. Prescriptive recasting in such a workplace culture might be used to 'reconstruct' as to 'be strong in the face of challenge and risk' in the name of the 'team'. Any 'worst case scenario' at the mine might still be the stuff of personal nightmares, but it is now blurred from the perceptual porthole of the working hours, as each shift forges on to meet individual targets and strive for 'better outcomes' in overall production.

The loss of personal financial reward for any production delay is now attached to the overall culture, with graduated cuts to the daily bonus and production deadline if you don't work closely with 'your mates' for that. In a climate of positive asymmetry 'mate-ship' is fostered and this is now of high importance to whole teams of individuals, in getting through the daily gruel and conditions of the mine. Afterall, it will all be over by Christmas and any concerns will be addressed in the New Year. 
The Board (however) failed to address the risk that the bonus would place undue focus on production at the expense of safety. Following the bonus, the mine pulled out 'all stops' to start the hydro mining as quickly as possible.

Mr Nishioka reported that workers made 'strenuous effort' to produce 1000 tonnes of coal by midnight on 24 September, the due date for the $\$ 10,000$ bonus, although the methane levels rose to explosive levels in the return twice in the days leading up to this deadline.

It was hazardous to continue extraction in those conditions and Mr Nishioka recommended the operation stop until the main fan became operational. This did not happen until the bonus had been achieved. (146)

Clouding and eclipsing practices also continued to weave their way through double shifts at the mine and in such a way that they could even cause doubt among workers, as to whether what was being felt, seen and smelt, i.e the reported the effects of methane in terms of 'smell' and 'headaches', was in fact, what others were actually experiencing at all. Many of the men were new to mining. (147) Some had not acquired health and safety training, and so their own frame of reference might now depend on how others reacted to scenarios in the workplace; which might in turn, be downplayed or normalised via the norms of conversation, emotion and attention (Norgaard 2011] at all levels of the workplace to protect that promised bonus rate.

Now risk was almost collectively distanced (Norgaard 2011) in a climate of positive asymmetry (Cerulo 2006) that immersed everyone in denial from the hierarchy of the board and inspectorate, all the way down to the coalface in a culture of production before safety at Pike River Mine. Practices of asymmetry and their pathways of dysfunctional practice to reach prescribed targets continued right up to the day of tragedy despite all the problems needing to be urgently addressed; (148) a fact established by the commission and repeated in many of my own interviews: 
'I think the biggest travesty,' said a community leader I interviewed, whose staff had been deeply affected by the subsequent deaths at Pike 'The biggest travesty is the fact that this was an issue of money and peer pressure.' (149)

'It was all about the money. They put money ahead of human life,' one head teacher told me, adding that a child had came running to her in the days following the fatalities exclaiming... 'Miss. Miss, they're still alive. You know, they're still alive. They're in a place where they can breathe. They're still alive.' I mean, she concluded 'What do you tell a seven year old kid?' (150)

This was also an example of recasting a practice, where mixed messages of positivity and deflection had been used by the mine and some authorities to suggest for several days after the fatal explosion, that the men were alive and could be saved. In reality, there was a lot already known about the conditions, but there was silence.

'The ventilation wasn't right,' said one senior mining executive I interviewed in November 2012. 'The fan should not have been underground. The bonus system was wrong.' (151)

The shock of what had been going on in the mine was a hard truth for anyone to swallow. Many remained bewildered for months by how this could possibly have happened in a New Zealand mine. There are countless references to this throughout the interviews I conducted (2011-2016) as we all tried to make sense of the culture that had continued to exist for so long at the mine, only to cause such loss of life.

'But are we so safety conscious,' said another head teacher of a school whose staff and children and been deeply affected by the November 2010 tragedy. 'And people are always saying that we are now 'risk averse'. We've wrapped everyone up in cotton wool. And yet, once again - 29 people can be killed when they go off to work in the morning.' (152)

This chapter serves to remind us that clearly Pike River Mine was not as 'risk adverse' as it portrayed itself to the country, or to the West Coast community that had placed so much trust in the company. The facts around faulty terrain, new equipment, 
methane levels and workplace practice were often clouded, by action and/or by lack of it; but the practices continued regardless. There was, for example, another major goaf [roof collapse] in the mine just three weeks before the tragedy at Pike.

On 30 October 2010 there was a large roof fall in the goaf in the hydro panel. The roof fall generated a pressure wave that knocked over the stopping at cross-cut one in the hydro panel. (153) ... The resulting rush of air was strong enough to knock over a stopping in the hydro panel cross cut, and result in an explosive accumulation of methane. (154) ...A roof fall in the hydro panel goaf expelled a large volume of methane and damaged a nearby stopping, but there was no adequate management review and response to this event. (155)

There was no formal investigation into this rockfall. Little was done about it in the spaghetti junction of pipes and pathways existing underground. Methane may have continued leaking into the mine from that point on, but acts of rhetorical and prescriptive recasting practices continued at Pike Mine right up to the day of the November 2010 explosion. The mine was under serious financial pressure to meet targets promised to investors. (156) Production continued at the mine and despite all the concerns raised by the Health and Safety committee at Pike (157) Mr Peter Whittall, the CEO of Pike Mine, still addressed its Board and Share Holders at the Annual General Meeting of 15 November 2010, as follows:

I am very pleased with the way progress has gone [at the mine] There have been no significant issues and the hydro system cuts and flows through the Coal Preparation Plan as it is supposed to. (158)

In the next chapter I will continue to explore how the disaster of Pike River Mine was (and is) not just a case of unmanaged risk but also one of unchecked power. 


\section{Endnotes: Chapter 3}

An Interpretation of the James Reason Model of Accident Causation

(1) Aotearoa is the Maori name for New Zealand. Both names are official and used interchangeably.

(2) See Chapter One for an introduction to background of the case of Pike Mine.

(3) 'Swiss Cheese' Model of Causation, in Royal Commission of Inquiry on the Pike River Mine Tragedy NZ, Te Komihana a te Karauna mo te Parekura Ana Waro te Awa O Pike (2012), Vol.2, 2:20, Fig.1.

(4) Royal Commission of Inquiry on the Pike River Mine Tragedy NZ, Te Komihana a te Karauna mo te Parekura Ana Waro te Awa O Pike (2012), Vol.1 and Vol.2.

(5) Statistics show New Zealand workplaces were 'unsafe when compared to workplaces in UK, Australia and many other OECD nations'; John Gibb, Otago Daily Time, 16 June 2016, NZ workplace death rate 'appalling'; an interview with Dr Rebbecca Lilley, Senior Research Fellow at the Injury Prevention Research Unit, Department of Preventive and Social Medicine, University of Otago, NZ.

Note also: Demelza Leslie, interviewing Gordon MacDonald, CEO NZ Worksafe, 2016. 'Mr Gordon MacDonald said that [better workplace practice] 'involved a widespread change in behaviour, systems and culture. We're talking about all of that coming from a particularly low base where New Zealand was, in some respects, twice as bad as Australia in terms of its stats and three times as bad as the UK'. Demelza Leslie, Senior Political Reporter, Safety law fails to curb workplace death rate, 23 Nov 2016. https://www.radionz.co.nz/news/national/318693/safety-law-fails-to-curb$\underline{\text { workplace-death-rate }}$

(6) Cerulo, Karen. (2006) Never Saw it Coming: Cultural Challenges to Envisioning the Worst, Chicago: University of Chicago Press.

(7) Ibid., p. 234. 
(8) 'There was a Culture of production before Safety at Pike River Mine', Royal Commission of Inquiry Pike River Mine Tragedy NZ, Te Komihana a te Karauna mo te Parekura Ana Waro te Awa O Pike (2012); Vol.1, p. 19; Vol.2, 13:10, 13:20.

\section{The Arrow of Unresolved Incidents}

(9) Royal Commission of Inquiry (2012) op. cit, Vol 1, p. 12, para.6.

(10) Ibid., Vol.1, p. 19; Vol.2, 13:10, 13:20.

(11) Ibid., Vol.2. 5:16, 'no effective framework for ensuring there was a systematic assessment of risk throughout the organisation. Vol.2, 10:67 See also: Vol.2, 7:67, 9:123; $10: 39 ; 10: 59 ; 10: 67$. Note 'There were 1083 reported incidents leading up to the November 19, 2010 Pike River Mine tragedy. The Royal Commission summarised 436 of these reported incidents under the following headings: methane spikes, ventilation spikes, strata, bypassing of safety devices, equipment sparking'... (7:54).

(12) Ibid., Vol.2, 7:55. 'There were problems with the investigation process. Many reports were assigned to an investigator but no investigation was completed...'

(13) Cerulo, op. cit., (2006).

(14) See Note (12) 'When the backlog was discussed with [the mine manager] in October 2010 he decided that they [the reported incidents] should be cleared and a fresh start made 'with a new management and new mine manager'. This meant many reports were never properly investigated.' Vol.2, 7:55.

(15) Ibid., Vol.2, 13:32. 'In fact the emergency response management plan essentially discounted the risk of explosion. The plan and the responses by witnesses indicate a lack of appreciation of the explosion risk at Pike River, despite the history of methane explosions in mining and methane issues at Pike River.'

(16) Pike was a particularly gassy mine. 'In all coal mines, methane, occurs naturally in seam sand and is released by mining activity, being explosive in the range of 5$15 \%$ methane in air. There were numerous occasions where methane levels far 
exceeded these levels at Pike, without the men being evacuated... There was the collapse of the inner goaf [weeks before] with the potential for coal dust to initiate an explosion and many other difficulties at the mine. Methane was the expected fuel source as soon at the explosion occurred' RCPRI: Vol. 2 fig 14.2, fig 14.3, pp. 183-84; chapter 3:60; 7:62; 8:116-19; 8:121; 8:127; 8:129; Pike River Coal Ltd, Incident/ Accident Form, 29 October 2010, Panel 1 Goaf Fall 29/10/10, DAO.001.00436/23.

(17) Ibid., Vol.2, 12:26.

(18) Ibid., Vol.2, 5:20.

(19) Ibid., Vol.1, p. 18, para. 2. 'The board received a monthly report containing a health and safety section. Although this was helpful, it did not cover the hazards relevant to a catastrophic event such as an explosion. The board did not assess critical design and health and safety issues, including, for example, the location of the main fan underground at pit bottom. An insurance risk survey received in July 2010 identified serious concerns about the hazards posed by hydro mining, windblast and a gas explosion, and urged the need for a comprehensive risk assessment of the mining operation. Neither the board nor its committee saw the report'.

(20) Royal Commission of Inquiry, op. cit., Vol 1, pp. 16-21; electrical safety p. 20, hydro mining p. 21.

(21) Ibid., Vol.1, p. 19. See also Vol.2, 13:10, 13:20.

(22) Royal Commission of Inquiry op. cit., (2012).

(23) Ibid., Vol.2, 6:61.

(24) Ibid., Vol.2, 10:54. See Police/DoL Interview 8 April, 2011. INV.03.7556/16-17.

(25) Ibid., Vol.2, 10:54; 6:61. See also Police/DoL Interview 29 April, 2011.

INV.03.20794/3. The Commission decided by majority to withhold the name of the worker concerned. Commissioner B Dissented. See INV.03.20794/7; INV.03.20794/8

(26) Police/DoL Interview 29 April, 2011, op. cit., INV.03.20794/8; INV.03.20794/10. 
(27) Vaughan, Diane. (1996) The Challenger Launch Decision: Risky Technology, Culture and Deviance at NASA, USA: The University of Chicago Press.

(28) Ibid., p. 11, 61, 75; 'structural secrecy' p. 398; also: Cerulo (2006) op cit., p. 60.

(29) Royal Commission of Inquiry (2012), op. cit., Vol.2, 10:55; See also Police/DoL Interview 29 April, 2011, op. cit., INV.03.20794/4.

(30) Ibid., Vol.2 10:56; Also Royal Commission on the Pike River Coal Mine Tragedy (Katherine Ivory), Summary of the Reports of Certain Incidents at Pike River Coal Mine, Nov 2011, CACO 114/20-24.

(31) Ibid., Vol.2, p. 142, Fig.10.9: Plea to stop overrides of safety circuits; Pike River Coal Ltd, Incident/Accident Form, 2 March 2010, DAO.002.09871/2.

(32) Ibid., Vol.2, 10:57; 6:60.

(33) Cerulo, op. cit., p. 215.

(34) Ibid., p. 73-95.

(35) Cerulo, op. cit., (2006).

(36) Norgaard, Kari Marie. (2011) Living in Denial: Climate Change, Emotions and Everyday Life, Cambridge, Massachusetts: MIT Press, 2011.

(37) Ibid., p. 9.

(38) Royal Commission of Inquiry (2012), op. cit., Vol.2, 12:27.

(39) Cerulo, Karen op. cit., p. 72-121. See also: Chapter 4 of this thesis, where some of the agents of change who tried to alert management and government systems are discussed in more detail.

(40) Rachel Morton (2011) Phase 3 of the 'Royal Commission of Inquiry' Neville Rockhouse http://www.3news.co.nz/nznews/rockhouse-slams-former-pike-river-ceo 


\section{The Arrow of New Technology}

(41) Royal Commission of Inquiry (2012), op. cit., Vol.2, 5:19.

(42) Ibid., Vol 1, p. 12, para.6.

(43) Ibid., Vol.2, 5:43. See also, Chapters 7-12.

(44) Ibid., Vol.2, Chapter 12; See also 'Haste to see Hydro Extraction'; 12:34; Strata Control in the Hydro Panel 12:57.

(45) Ibid., Vol. 2 8:96-97.

(46) Ibid., Vol.2, 12:79 'On 30 October 2010, part of the roof in the roof panel 1 goaf collapsed. The resulting rush of air was strong enough to knock over a stopping in the hydro panel cross cut, and result in an explosive accumulation of methane.' See also: Vol.2, 8:13 The Unique placement of fan underground: 'Pike ultimately decided to install its fans underground, with a back-up fan on the surface. That situation is unique. Although underground booster fans are common in many countries, there is no evidence of any other coal mine in the world with a main fan underground.'

(47) See Note (16).

(48) 'In terms of checking to make sure the human elements are under control,' a senior executive told me in November 2014 'You're actually engineering out the things that are going to hurt you. Then you're going to learn something. But that's what Pike didn't do. Putting the fan underground wasn't engineering out a problem. It was engineering to get the mine up and running. And it produced more issues than you can poke a stick at.' Mulholland Interviews, January 2015, W (30.1.15) 28:55.

(49) Royal Commission Inquiry (2012), op. cit., Vol.2, 12:88 '30 October a roof fall in the hydro panel goaf expelled a large volume of methane and damaged a nearby stopping. There was no adequate management review and response to this event'.

(50) Ibid., Vol.2, 9:66; 9:67; See also Vol.2, 10:67 'There was only one working fixed methane sensor reporting to the control room that measured contaminated air in 
the ventilation return. This was not capable of showing a methane level above $2.96 \%$ and did not report to the main Safegas system'.

(51) Ibid., Vol.2 12:33, Hydro Mining begun (July 2010).

(52) Ibid., Vol.2, 12:27, Competitive Bonus system begun (July 2010).

(53) Ibid., Vol.2, 5:20; Egress: 'There was [also] a rapid turnover of statutory mine managers and middle managers. Many workers were inexperienced. Morale and absenteeism were of concern. The company relied heavily on contractors and consultants. It had purchased equipment unsuitable for the difficult strata conditions encountered. Some key equipment and systems were unproven when production began. There was no suitable second egress for use by workers in an emergency'.

(54) Mulholland Interviews, July 2011, BM (17.7.11) 27:06; 26:24- 27:06.

(55) Ibid, July 2011, AM (17.7.11) 8:45.

(56) Royal Commission Inquiry (2012), op. cit., Vol.1, p. 11; The Fresh Air Base (FAB) is 'an underground room-like sealed facility to maintain a respirable atmosphere in emergencies.' See also, Vol.2, 7:16, 7:55, 16:118-123.

Also, Vol.2, 10: 64; Many eclipsing practices on the part of workers/management (cultural, systemic) continued right up to the day of the explosion [19 November 2010] and will be analysed in subsequent chapters. One illustration of this is as follows: 'Miners are required by law to withdraw from the mine if flammable gas reaches $2 \%$ or more in the general body of air. One miner encountered methane over $2 \%$ 'quite a lot', and more than $5 \%$ on two occasions; one occasion, involved over $5 \%$ - approximately two weeks before 19 November - after the commissioning of the fan. He informed the deputy who said 'We'll be right. Just quickly get through [get the job done]'. They remained working in the explosive atmosphere for at least ten minutes. 'There was no investigation because I never reported it.' He said there were times when they continued working in $2 \%$ methane, contrary to regulations'. 
(57) Ibid., Vol.2, 16:131. Fresh Air Base (FAB) 'Located in a stone stub, it was a converted container with sealable double doors. At the time of the explosion it had been decommissioned and was no longer supplied with compressed air. The phone connection to the surface was not working and replacement self-rescuers, first aid equipment and fire-fighting had been removed'. See also [Witness of survivor 19 November 2010] 'On reaching the FAB, Daniel Rockhouse propped Mr Smith up in a sitting position against the rib and said, 'I'll be back in a sec.' The FAB was a shipping container converted to include a two-door sealable entrance. Survivor, Daniel Rockhouse thought it would provide a fresh air source, a telephone and spare selfrescuers. In fact, he found it had been decommissioned'. Vol. 2, 1:45.

(58) Ibid., (2012) Vol. 1, Vol. 2.

(59) Royal Commission of Inquiry (2012), op. cit., Vol.2, 9:63; (fig 9.6) Email, Brian Wishart to Jimmy Cory, 11 April 2010, DAO.025.32975/1.

(60) In 2015 I interviewed a senior mining executive who had been working in Kentucky at the time of the Upper Branch Mine Explosion in April 2010 who recalls when he later heard of the Pike Tragedy: 'It was shocking. As I said, we'd had the tragedy just up the road in Kentucky [US] where we were [months before] at Upper Branch. And spookily, it was the same number of people [killed]... I can remember we were at lunch. We'd just had a board meeting. We were quite excited about where we were going. And that [news of Pike] just totally - It was quite shocking. We were all just stunned." Mulholland Interviews, Jan 2015, HB (30.1.15) 6:16.

Note: The Upper Branch Mine tragedy, in Raleigh County, West Virginia, US, on 5 April, 2010. It was the result of a coal dust explosion 300m underground killing 29 of the 31 men on site. And In the case of Upper Branch The Mine Safety and Health Administration (MSHA) released its final report on December 6, 2011, concluding that flagrant safety violations contributed to the explosion.

(61) bid., Vol.2, 7:55; 9:62; 9:67; See also Adrian Couchman transcript, pp. 3803-04.

(62) Ibid., Vol.2, 9:63; Fig 9.6: Email, B. Wishart to J. Cory, RE: Methane Drainage. 
(63) Ibid., Vol.2, 9:64.

(64) Ibid., Vol. 2, 9:70. 'The pipeline was installed primarily in the return airways leading from connected boreholes outbye to the riser but it also ran for about $100 \mathrm{~m}$ in the intake airway from the overcast near the underground fan through Spaghetti Junction before turning left and then right to the gas riser located at the entrance to the slimline shaft/Fresh Airbase. This created a significant hazard.'

(65) Ibid., Vol. 2, 9:64.

(66) Ibid., Vol. 2, 9:63.

(67) Ibid., Vol. 2, 9:65.

(68) Ibid., Vol. 2, 9:66.

(69) Ibid., Vol.2, 9:71.

(70) Cerulo, Karen (2006) op. cit., p. 107.

(71) Ibid., p. 96.

(72) Ibid., p. 95.

(73) Ibid., p. 159.

(74) Royal Commission of Inquiry (2012), op. cit., Vol.2, 9:80.

(75) Ibid., Vol.2, 9:81.

(76) Ibid., Vol.2, 9:83.

(77) Ibid., Vol.2, 9:87.

(78) Ibid., Vol.2, 9:91.

(79) Ibid., Vol.2, 9:96.

(80) Ibid., Vol.2, p. 142, Fig.10.10: Report of lack of gas detectors; Pike River Coal Ltd, Incident/Accident Form, 2 June 2010, DAO.001.00826/2. 
(81) Ibid., Vol.2, 9:103. Note: 'Free venting' - The practice of releasing methane from the drainage boreholes into the return of a mine's ventilation system.

(82) Ibid., Vol.2, 9:125, 'Problems with management of the gas drainage system [also] continued with gas flow from the borehole GBH018 backing up and restricted by the 4" pipe. Ignored too, was underground superintendent, Les Tredinnick, who advised Pike staff in October 2010 of a 'whistling' standpipe and methane being emitted through the stone floor in ' $A$ ' heading in a pit bottom north'. Vol.2, 5:20; This had not been addressed by 19 November 2010'.

(83) Ibid., Vol.2, 5:20; 5:35; 'There was also no suitable second egress for use by workers in an emergency. The ventilation shaft was impractical as a second egress'; Vol.2, 7:16. 'At Pike River, the drive to produce coal in 2010 led to a view that management of some hazards could await the implementation of a long-term solution, when for example, suitable second egress and a usable fresh air base (FAB) should have been a high-priority safety requirements'. Vol.2, 7:16; 7:18; 7:21. Concerns about this were ignored, diverted; not addressed. Vol.2, 8:96; 7:41-43.

(84) Royal Commission Inquiry, op. cit.,Vol.2, 8:15, 141; Also (Vol.2, 11:31; 12:24-26, 31, 51-55) Note: Pieter van Rooyen, Handover Notes, 2 Nov 2010, PVR002.

(85) Ibid Vol.2, 8:96-97.

(86) Ibid., 8:96.

(87) Ibid., November 2014 U (19.11.14) (35:57).

See also: Royal Commission (2012) op. cit., Vol. 2, 3:32. 'Gordon Ward was an NZGO appointee who, in 1998, assumed responsibility for the Pike River Project. His background was in accountancy and auditing, not mining' He was a former general manager of Pike and CEO of the mine until October 2010. He did not return from Australia to attend the later Inquiry; and chose to make no further comment. (88) Pressure on Pike River mine to produce; Laura Mills of the Greymouth Star NZHerald.co.nz 16 Feb, 2012 https://www.nzherald.co.nz/business/news/article.cfm?c id=3\&objectid=10786019 
(89) See also: Rebecca Macfie 'Pike River: a tragedy that should never have happened', NZ Listener 5 November 2012. See also: Petrus (Pieter) van Rooyen, transcript, pp. 5181-83; Petrus (Pieter) van Rooyen, witness statement, 27 January 2012, PVR001/54-55, paragraphs 320-24.

(90) Pressure on Pike River mine to produce; op. cit., 16 Feb, 2012.

(91) Royal Commission (2012) op. cit., Vol.2, 8:15.

(92) Mulholland Interviews, October 2014, V (2.10.14) 1/02: 52:25.

(93) 'Pieter van Rooyen was the technical services manager from February 2009, but resigned effective from 3 November 2010. A new technical services manager had been recruited, but was not due to start at Pike until December 2010. In the meantime, the technical services coordinator, Gregory Borichevsky, an experienced mining engineer, was the most senior member of the technical services department. See, Royal Commission of Inquiry', op. cit., Vol.2, 4:26. Mr Borichevsky agreed to an interview with me in July 2011 which he later withdrew.

(94) Royal Commission of Inquiry (2012) op. cit., Vol.2, 8:33. See Notes 14, 42, 57, 77. (95) Rebecca Macfie (2012) Pike River Inquiry Phase 2: 'There was a Blame Culture' http://www.noted.co.nz/archive/listener-nz-2012/pike-river-inquiry-phase-3-therewas-a-blame-culture New Zealand Listener 17 February 2012.

The 'Blame' Culture at Pike - Acts of Shunning, Ignoring and Shaming

(96) Royal Commission of Inquiry, op. cit., Vol.2, 6:6 'From the time the mine was classified as a gassy coal mine in November 2008, Pike had six mine managers, two technical services managers and three engineering managers. In 2010 the mine had two production managers.' Note: It is important to emphasise that although media often referred to $\mathrm{Mr}$ Whittall as only having been CEO in the six weeks leading up to the tragedy, he had in fact directed the mine's development since 2005. 
(97) Douglas White, Submissions on Behalf of Doug White, 24 March 2012, WHI003 6; See also: Rebecca Macfie Pike River Inquiry Phase 2: 'There was a Blame Culture' NZ Listener 17 February 2012; Note: From 12 June 2010, Mr White was the statutory mine manager, which included supervising the health and safety of the underground operation. In the absence of a dedicated ventilation engineer, Mr White took on overall responsibility for managing the ventilation system'. Vol.2, 4:13.

(98) Neville Rockhouse http://www.3news.co.nz/nznews/rockhouse-slams-formerpike-river-ceo-2011120817\#axzz3Pb6plEet

(99) Mulholland Interviews, Neville Rockhouse, Christchurch, 8 July 2012, (3:57).

(100) Re: 'Egress' On '17 March 2010 Mr Rockhouse replied, noting that, following significant risk assessment, the Alimak section of the ventilation shaft would not be used as a second emergency egress if the drift was impassable. Instead a Fresh Air Base (FAB) was to be constructed in the slimline shaft stub. But a proper $F A B$ was not completed by the end of June. There was only a pull-down brattice stopping to isolate the slimline shaft stub. This was in interim measure while the FAB was designed and ventilation surveys undertaken'. Vol.2, 7:46.

'Mr Rockhouse again brought up of the issue of no second egress 13 September 2010 and then again on 11 October 2010. At the November 2010 meeting it was noted that Mr Ellis would report 'next month'. Vol.2, 7:47-48. By the date of the explosion little progress had been made. There was a plan to establish a walkout second egress, but its construction was at least 12 months off. The interim safeguard of a proper $F A B$ had not eventuated either. A fundamental concern of the workforce remained unaddressed, eight months after it was first raised'. Vol.2, 7:49.

(101) Royal Commission of Inquiry (2012), op. cit., Vol.2, 7:21.

(102) Ibid., Vol.2, 7:19-20.

(103) Ibid., Vol.2, 7:20-21.

(104) Ibid., Vol.2, 7:21-39. 
(105) Rachel Morton reporting (2011) on Phase 3 of the 'Royal Commission of Inquiry' Neville Rockhouse http://www.3news.co.nz/nznews/rockhouse-slamsformer-pike-river-ceo (1:55).

(106) Morton, op. cit (1:22).

(107) Royal Commission of Inquiry (2012) op. cit., Vol.2, 7:73.

(108) Ibid., Vol.2, 9:114.

(109) Ibid., Vol 2, 10:44.

(110) Ibid., Vol 2, 10:45.

(111) Ibid., Vol.2, 7:73. See also: See also : (1) Gregory Borichevsky, Police/DoL interview, 26 April 2011, INVO3.18954/7; (2) Gregory Borichevsky, witness statement, 26 June 2012, BOR0001/9, para. 57; (3) Gregory Borichevsky, Police/DoL Interview, 7 June 2011, INVO3.20410/73; (4) Gregory Borichevsky, witness statement, 26 June 2012, BOR0001/37p257.

(112) Royal Commission (2012), op. cit., Vol.2, 8:13 'Pike decided to install its fans underground, with a back-up fan on the surface. That situation is unique. Although underground booster fans are common in many countries, there is no evidence of any other coal mine in the world with a main fan underground.'

(113) Ibid., Vol.2, 15:24.

(114) Ibid., Vol.2, 11:47.

(115) Ibid., Vol.2, 8:14.

(116) Ibid., Vol.2, 16:142. 'On 29 October 2010 Gregory Borichevsky addressed the development of the second egress in a technical services memorandum to $\mathrm{Mr}$ White'. Vol.2, 8:5 'The proposed location of the egress was identified 250m northwest of the then most western margin of the workings. 'High level investigations' were required into numerous aspects, including flooding risk, slope stability, strata 
control, portal construction, as well as Department of Conservation (DoC) approval. Mr Borichevsky predicted the egress could be established by June to Sept 2011'.

(117) See also Vol.2, 9:53: In fact, 'a major collapse of the ventilation shaft on 2 February 2009, severely limited mine ventilation'.

(118) Ibid., Vol.2, p.105, Fig. 8.19: Pike River Coal Mine, Extracts from Deane Murphy's, 21 October 2010 Deputies Production Report; DAO.001.02459/1.

(119) Ibid., Vol.2, 9:53., 16:143.

(120) Ibid., Vol.2,16:143-145. See also Note (55) Mulholland Interviews, July 2011, BM (17.7.11) 27:06; 26:24-27:06; Mulholland Interviews, July 2011, AM (17.7.11) 8:45.

(121) Ibid., Vol.2, 16:132 Note 'The improvements were meant to have been completed by June 2010 but had not been done by the time of the explosion'.

(122) Ibid., Vol.2, 16:32 and 6:57.

(123) Ibid., Vol.2, p. 98, Fig. 8.11: Pike River Mine, Extract from Dene Murphy's 24 June 2010 Incident/ Accident Form; DAO.001.00749/2.

(124) Ibid, Vol.2, p. 141, Fig. 10.8; Pike River Coal Mine, References to Gas Trips, 19 November 2010 Deputies Production Report: DAO.001.02568/1.

(125) Ibid., Vol. 2 7:50; 7:54.

(126) Ibid., Vol.2, 12:79, 12:80.

(127) Ibid., Vol.2, 12:48.

(128) Ibid., Vol.2, 12:50. Most revealing of all is that in emailing this list to key personnel, the mine manager had stated 'None of these issues are show stoppers and some will take time to implement'. The Royal Commission later stated 'It is a revealing insight into the thinking at the mine that such fundamental requirements were not seen to be show stoppers.' 
(129) Ibid., Vol.2, 12:49.

(130) Ibid., Vol.2, 12:50. See also (123).

(131) Cerulo (2012) op. cit., p. 115.

\section{The Arrow of the Bonus System}

(132) Royal Commission of Inquiry (2012), op. cit., Vol.2, 12:32.

(133) Ibid., Vol.2, 12:88.

(134) Ibid., Vol.2, 5:18. See also: ' Mulholland Interviews, July 2012 S (3.7.12). 'It was just not on,' another executive told me in July 2012 'I mean, they didn't have enough dough. They were under capitalized by a country mile. And you know... Gordon Ward, and maybe one or two managers and that, but also the directors of New Zealand Oil and Gas. I mean, they weren't being responsible directors.

Mulholland Interviews, July 2012 Y (8.7.12) 68:05. 'He was ah, the money man,' a senior manager told me in July 2012. 'I tell you what. If you ever go into a capital venture and you need to raise money; to put something on the stock market, then Gordon Ward's your man. He's the money man. And he's bloody good at it... But to make this thing called Pike River actually work, he had to have someone who knew about mining. And he dropped all of his faith and all of his [pause] well, commitment into Peter Whittall - as being that expert.'

(135) Royal Commission of Inquiry (2012), op. cit., Vol.2, 5:22 'The statistical information provided to the board on health and safety comprised mainly of personal injury rates and time lost through accidents. Mr Dow was comfortable with the information provided to the board. [This] gave the board some insight but was not much help in assessing the risks of a catastrophic event faced by high-hazard industries. Pike had not developed more comprehensive measures which would have enabled the board and executive managers to measure what was being done to prevent catastrophes.' Vol.2, 5:22. [But neither did they ask for it] '...The nearest the board came to questioning management on such issues appears to have been on 15 
Nov 2010 when the general manager, Mr White, attended his first board meeting and was questioned about safety systems, Vol..2, 5:22. 'In describing his approach to governance, Mr Dow compared the difference between governance and management to the difference between 'church and state'. The Commission does not accept the analogy. Management operated under delegation from the board to hold management strictly and continually to account.' Vol. 2, 5:23.

(136) Mulholland Interviews, October 2011, BM (20.10.11) Pt.5, 10:32-42.

'...When [he] used to come home and say to me Dad, I've got massive headaches-' said a grieving father who lost his son to the Pike disaster 'And I didn't- I just thought, ah, you know, I didn't even think - Bloody gas in the Mine - Not knowing enough about it... And I tell you what, If my son was in that mine and I knew then, what I know now, they wouldn't have kept me out of that mine, going in-'

(137) Royal Commission of Inquiry (2012), op. cit., Vol .2, 6:20.

(138) Ibid., Vol.2, 12:27; p. 161, Fig. 12.8: Hydro-mining bonus table.

(139) Cerulo, op. cit., (2006).

(140) Mulholland Interviews, July 2011, February 2012, July 2012.

(141) Royal Commission of Inquiry (2012), op. cit., Vol.2, 5:18.

(142) Cerulo, (2006) op.cit, p. 234.

(143) Royal Commission of Inquiry (2012) op. cit., Vol.2, 7:55.

(144) Ibid., Vol.2, 12:27.

(145) Cerulo (2006) op. cit., pp. 114-121.

(146) Royal Commission of Inquiry (2012) op. cit. Vol.2, p. 12:31.

(147) Ibid., Vol.2, 6:16, 6:65, 6:70, 6:76.

(148) Ibid., Vol.2, 12:83-86. 
(149) Mulholland Interviews, February 2012, JL (14:17).

(150) Ibid., July 2011 NK (18.7.11) 23:51; 15:06. Note: There was also initially hope for rescue of the men, fed by the media, due to the televised rescue (just three months prior to the Pike tragedy) of 33 men trapped 2,300 feet underground for weeks in the San Jose gold mine near Copiago, Chile.

'No one knew what was going on,' said an interviewee in July 2011. 'And we still had that hope. So it wasn't [pause] so much - It was shock. But at that stage, tragedy hadn't set in. You know, it was that hope: We're gonna be like the Chilean Miners [They will all get out] - And that's what people were lead to believe... They were completely different mines, as we know now.' Mulholland Interviews, July 2011, K (18.7.11) 3:34.

(151) Ibid., November 2014, A (19.11.14) 42:02.

(152) Ibid, February 2012, MT (8.2.12) 15:19.

(153) Royal Commission of Inquiry (2012) op. cit., Vol.2, 8:116.

(154) Ibid., Vol.2, 12:79. [See Note 46]

(155) Ibid., Vol.2, 12:88 '...A roof fall in the hydro panel goaf expelled a large volume of methane and damaged a nearby stopping, but there was no adequate management review and response to this event'.

(156) Ibid., Vol.2, 3:71.

(157) Ibid., Vol.2, 7:44-45.

(158) Ibid., Vol.2, 12:87. 


\section{Chapter 4 Analysis (II)}

In the last chapter I focused mainly on the mine workers and management in the months and weeks leading up to the Pike River Mine tragedy of 19 November 2010. Now I will extend my analysis to view the wider organisational and legal structures that created the type of environment where a culture of positive asymmetry could not only grow but thrive, in the years before the tragedy at the mine occurred.

\section{The Layers of Causation}

'I think everyone was pretty focused on what the end goal was,' a mining executive told me in 2015. 'I mean, right from the [Pike] Board, through to the guy that was driving the guzzler, or whatever it's called at the Face. They were all focused on getting that first shipment [of coal] out by December.' (1)

The Royal Commission of Inquiry into the tragedy of 19 November 2010 concluded that there was a 'culture of production before safety' at Pike River Mine; (2) but the question remains, why did no one stop it? The 'unsafe acts' practised at this mine were so numerous it is impossible to map anything but a very small sample of these findings to the given 'slices' of the original model. (3) Furthermore, this model of causation cannot explain why the mine was allowed to continue to operate under the given conditions of each slice. It does not address the accumulation of years of numerous, gaping flaws in systemic, legislative and regulatory practices which left the actual 'accident' causation model of this mine so riddled with flaws that without adequate intervention, a workplace tragedy at the mine was virtually inevitable.

This model can not address the culture of silence and bullying that also existed at Pike River Mine, nor the continued use of risky technologies against all expert advice. It does not explain an almost continued silent systemic endorsement of a culture of 'production before safety' that operated the mine, and this model certainly cannot even begin to explain the sociological aspects of 'ignoring the warning signs' (4) 
'There was an approach to management [at Pike River Mine],' a senior executive told me in November 2014 'It was a culture that you would not want in any business, let alone in an underground coal mine where the potential for disaster is much greater than many other businesses.' (5)

Similarly, the James Reason Model of Causation does not explain how productivity was rated so highly above workplace safety that workers began to doubt themselves, their own experience, expertise and perceptions around risk at Pike River Mine. (6) It definitely cannot explain the underlying dynamics or issues of power at the mine. Neither can it show how this might translate to fatalities still occurring in other New Zealand Industries since the tragedy or even if links can be made with the past. (7)

'You know, I grew up [here] So I'm from a coal mining history,' the principal West Coast school told me in 2012 'I mean, I just didn't think in modern day, in New Zealand, we would have such a mining disaster. They have all these health and safety things. So it never entered my head this could possibly happen... especially you know, living on the Coast and you think people feel safe and secure going into the mines. And that the workplaces are safe.' (8)

\section{An Analysis of the Arrow of the Inspectorate}

\section{Uncomfortable Truth No. 4}

What happened at Pike River Mine was not an accident. The findings of the Royal Commission of Inquiry suggest the tragedy of November 2010 was preventable.

Arrow Four: The Inspectorate

Archers: The Department of Labour (DoL)

Archers: The Ministry of Economic Development (MED)

The first of many arrows (paths of repetitive decisions of dysfunction) to fly into the causation model of Pike River Mine, was that of the changing Inspectorate. At the time of the November 2010 tragedy there were only two inspectors employed by the 
Department of Labour (DoL) to inspect over 1000 coal, metalliferous mines, tunnels and quarries in New Zealand. (9) After a decade of deregulation, inspectors were no longer required to have expertise in the mining method used by the mines they inspected. They were not trained to audit mine systems. Neither was there a requirement for their ongoing professional development; although there is evidence to suggest that the inspectors asked for, and did attempt to update their skills. (10)

'Management's approach [at Pike Mine was like]... All you need is to check people's systems...' said Mr Firmin, one of two national inspectors in 2010. 'But I say I want ventilation, engineering training, geotechnical training. And they say it's not your responsibility. What do you need training, to that degree? ...Sometimes I say I am coming [to a mine] to do ventilation. So, show us all you have done. But I need qualifications to ask, is [the ventilation] adequate? ...You have to have continuous professional development... I need to be competent, up with the developments... I want to be current, go on courses, sit exams. It helps my credibility on site.' (11)

As an inspector, Mr Firmin felt he was not provided the level of training he required. There was no inspector based in the North Island, so his visits were arranged to the mines on a six month cycle. He was one of only two inspectors, nationally. They were both over worked and continued to have limited influence in the mines. 'They were not involved in granting qualifications or industry training, [but] both men continued to be concerned about the adequacy of mining qualifications and felt personally disadvantaged, seeing themselves as specialists within a generalist inspectorate which did not see the need to equip them with mining specific skills they needed'.

'About three years ago,' Mr Firmin said in his witness transcript for the later Royal Commission of Inquiry 'People at the Mining Steeling Group started to challenge, [us asking] 'Well, do you need to go to these places? How long do you need to go there?' And they weren't sort of trying to stop us; [they were] just saying 'Well, do you need to do this? There's less inspectors [now]. Why do you need to go to these places so often?' (13) 
Following the research of Cerulo, (14) this might be seen as an example of eclipsing practice whereby (intentionally or otherwise) 'negative' aspects of a potentially unwanted scenario, are made functionally invisible by diverting the "bearer of unwanted information' (in this case, the inspector admitting there is a gap in his expertise) requesting professional assistance (in the form of further training). He is eclipsed in a moment of clear acknowledgement and (in his case repeatedly), by not only being denied the additional training, but also by minimalising his need for it.

The drive for production at Pike where the inadequate ventilation was a potentially lethal issue, also created a climate whereby many hazards (though sometimes challenged) were often not attended to in a timely manner, and which left the only two national inspectors of all New Zealand's mines, tunnels and gullies feeling increasingly inadequate in front of the very real world of senior industrial mine management, when needing to question practices in the course of their inspection.

So ahead of risk we are also seeing here a recurring case of unchecked power which sometimes seems to favour the potential for industry to operate to goals and production deadlines without adequate consideration of a certain creeping risk involved in meeting those goals and production deadlines; with this being just one example of many, relating to years of deregulation in an Aotearoa/New Zealand.

In this case of Mr Firmin, there was also perhaps a certain 'shaming' implied here as well, that with only two inspectors employed to inspect all of New Zealand's mines, tunnels and gullies 'one of these' would even consider going on 'unnecessary courses' when it might add to the workload of his mate/colleague. Here too, we see another example of 'mates-man-ship' often fostered in a climate of positive asymmetry in the drive to meet deadlines. It does not matter that his colleague probably wanted the training too and perhaps had not yet been able to voice that.

Cultural practices like these are abundant when looking to decades of deregulation in which the former Department of Labour (DoL) operated; many of which are well documented in the findings of the Royal Commission of Inquiry in relation to the 
path to eventual tragedy of Pike River mine. Less apparent is how this moderating body, which oversaw workplaces nationally, ever got to this state in the first place. To unpack this further, I will trace back through the next arrow of primary causation; that of the Inspectorate and its Twin Archers, the former DoL and MED to try to show where they sprang from historically. This should provide an introduction to this fourth arrow, its pathway of decision making, the shape of its causation and how it came to be shot with such power from the Bow of Positive Asymmetry, to travel the entire course of its own trajectory undeterred to the tragedy of 19 November 2010.

\section{(i) Archer: The Department of Labour (DoL)}

In 1987 Coal Corp was created from the former government department, State Coal Mines. It was later renamed Solid Energy (1997), a state owned enterprise of the New Zealand Government and the largest coal mining company in the country. Overlooking the mining inspectorate was the Department of Labour (DoL).

The Department of Labour introduced the Occupational Safety and Health (OSH) Act in 1992. This did little to allay concerns though, that miners may not be as well trained as they had been under the original Coal Mines Act. Neither did it address the fact there might be a lack of experienced inspectors going into the mines. Concerns were heightened when DoL directed its new inspectors to 'do more audits and less inspections'; (15) contradicting all prior knowledge and experience which shows that consistent monitoring is not only required, but essential in gassy mines.

'They didn't have the experienced inspectors we had under the old Coal Mines Act,' former Chief Inspector of Mines, Harry Bell, told me in our April 2016 interview, 'One of the things they told us was that we were to do less inspection and more audits. Now [laugh] a gassy coal mine, you've got to inspect it. The more regularly you inspect it, the better. And I said 'No way, I've been an inspector since 1978. And I said I ain't changing. I'm an inspector of mines. And I will inspect them.' (16) 
The Department of Labour began to argue the salary of the original mines inspectors was much higher than that of their own governmental managers; (17) even though the new DoL inspectors often did not have the qualifications and experience of the original mining experts. Further cuts to the inspectorate ensued. The Board of Examiners was abolished and no approved code of conduct and practice for mining was ever put in place. (18) These changes did not go unchallenged, but were recast.

Mr Harry Bell, former Chief Inspector of Mines continued to emphasise throughout the 1980's that he and a number of colleagues did not support the Mine Inspection Group (MIG) shifting to the new inspectorate under the Department of Labour. There appeared to be attempts by DoL to use wages of the original mines inspectors as leverage to gain their own mangers higher salaries in the new inspectorate; even though many had never been miners, nor moved up through the required years of trade and training to become such. (19)

Mr Bell and others in the mining industry continued to act as guardians, however, as Kaitiaki (20) for the health and safety of miners. They fought the (1992) Act proposed by the Department of Labour, making it clear that if the salaries and training of mining personnel were cut, the calibre of skilled employees and inspectors would invariably be diminished and this would add to unsafe work practice and an increased risk in mines. (21) These voices continued to fight the Act right up to its final implementation in (1997); by which time, many skilled professionals had left the industry for better training, salary and conditions offered by Australian mines.

A number of mining experts had also retired by then; among them, the former chief inspector, Mr Harry Bell himself, who continued to warn that if the (1992) OSH Act were implemented it would not only compromise the safety of future miners and that 'past atrocities' would recur in the workplace. (22) Yet, even with the past workplace fatalities of Boatmans, Mount Davey, Black Reef, and Tiller Mines (23) the warnings were shunned or diverted and the former chief inspector was ignored.

I interviewed Mr Bell twice in April 2016 and it was evident that he continued to be deeply concerned about the state of health and safety in New Zealand mines. (24) The 
former chief inspector emphasised that there were others who had also been so concerned about the deteriorating state of the mining industry and inspectorate that they had approached him in his retirement, asking him to write a letter in 1997 to the then Minister of Energy, Max Bradford, to protest the final implementation of the 1992 Act. Mr Bell did this, (25) and added a description of the training once required of miners and inspectors; stating that if there were no improvements, a future mining tragedy was inevitable. But other than a letter of acknowledgement from the Minister of Energy, the warnings of Mr Bell continued to be ignored.

In 2013 Radio New Zealand revisited Mr Bell's (1997) correspondence to the then Minister of Energy. In this interview, Nicholas Davidson, QC refers to Mr Bell's letter of warning, written thirteen years prior to the Pike River Mine tragedy of 2010.

'And I think you have in front of you,' said Mr Davidson in his radio interview with Kathryn Ryan, on 11 April 2013 'a letter that was written by Harry Bell, former Chief Inspector of Mines to the Minister at the time, warning him [Mr Bradford] more or less, of exactly what happened here at Pike River Mine. It was written in the context of the inspectorate and where it would lie. But on the second page of the letter [there is] reference to 'the atrocities of the past' which lead to the mining legislation which had come down to avoid those atrocities ever occurring again... Harry Bell was warning,' said Mr Davidson 'that if the change in inspectorate system was introduced as the government proposed it to be introduced at the time - And it was introduced - Then there was a problem atrocities would occur again.' (26)

The 1997 submission of Mr Harry Bell (27) was an attempt to prevent further tragedy in mines, and the 'past atrocities' to which he refers are the many fatalities in New Zealand mining listed in the Royal Commission's findings. (28) Mr Bell uses the phrase 'past atrocities' in reference to his own personal experience of having gone into the Strongman Mine to retrieve many of the bodies from the 1967 tragedy. (29)

In writing his submission of 1997, he refers to the summing up of the magistrate at the Inquiry into Strongman disaster 'the mine manager is the paramount chief and 
all responsibilities fall on him'. (30) Yet, fifty years later, Mr Bell still argues the need for mining to be seen and considered a different industry from 'shops and factories'; that it should not have been pooled under the same (1992) Health and Safety Act' (31) Mr Bell continues to voice that, with the hazardous nature of mining it could 'no more fit under the umbrella of that Act, than marine and aviation industries could have done'; with mining being 'equally unique', in that 'the pilot of a plane or a captain of a ship has the same responsibilities as a mine manager'. (32)

In our first April 2016 interview, the former chief inspector of mines also reiterated how much had changed in the industry in the five years between the introduction of the Health \& Safety Act (1992) and its final implementation (1997).

'When we [went] underground,' Mr Bell told me in 2016 'we were put with all older men, whether we were shift men, truckers or miners or whatever. We were put with older men who taught us all the skills and all the hazards and what to look out for; how to do this and how to do that. But now if three 19 year old boys from high school want a job in the mine, they'd stick them in a portacom with a training officer for about three weeks. They would go through everything with them. But they wouldn't know how to work a roof bolter. They wouldn't know what he was [even] talking about.' (33)

To add to the lack of adequate training, many workers leading teams underground also felt suddenly swamped with a deluge of paperwork. When the (OSH) Act of 1997 was eventually implemented, many managers and experts who had previously spent a lot of time underground getting to know the teams and their systems, also began to feel deluged with audits which required them to work many more hours outside of the mines on their lap tops, than they had previously worked within them. They warned that it remained not only essential to inspect gassy coal mines more often; but that it would be catastrophic if they weren't able to do so, regularly.

'So I wrote this big letter to Max Bradford, the Minister of Energy,' Mr Bell told me in our April 2016 interview 'explaining all about what we [once] had to do to get our certificates. And [how] they changed all that. They did away 
with the Board of Examiners. You know, a mine manager [once had to] sit seven subjects. There was a 3-4 hour written paper and we had to get $60 \%$ to pass. If you passed, you went before the Board of Examiners to do an oral exam, because you get some bright lads who are very good at putting things down on paper. So you would get an experienced mine manager and an inspector of mines to verbally examine them [to] trip them up, test them.' (34)

This was clearly not happening decades after the tragedy of Strongman Mine, inspectors were feeling increasingly at odds with the fact that they no longer had the power to challenge or temporarily close a mining operation until audit requirements were met. (35) They felt they were no longer taken seriously. (36) They felt much of what had been gained from the legislation coming out of past mining disasters, was now being lost to the developing culture of production before safety in New Zealand mines. (37) So the more experienced miners began to 'vote with their feet'. They began to leave for the 'safer' mines developing in Australia and abroad.

'When the Labour Department (DoL) did take over in '97,' said Mr Bell 'the first thing they told our [former] inspectors was they were amazed that they were on higher salaries than their branch managers. They wanted to reduce their salaries. So what inspectors were left then said Ta. Ta. We're off,' he said 'And they were off, you know. And left... So what I'm saying is, they [the new inspectors] didn't get the background experience that's necessary to be able to make the decisions you've got to make and that of course,' he added 'was proven with Pike River Mine.' (38)

What this part of the narrative shows is that during a period of deregulation, training practices for mining recruits from ground level right up to the inspectorate were repackaged in such a way that the focus was placed on a newly perceived 'best' (that of short training courses based on time and funding efficiency) in exchange for the financial reward of meeting production deadlines. This is clearly no longer a simple a matter of risk, but of power; which was now being reinforced systemically. 
Instead of using all the expertise that was already available, the new inspectorate did not appear to value the rich experience of past mining experts and seemed to distance them; using their own salaries to create competitive leverage and a rift in communication, between the previously employed and the 'new experts'. To follow this, the 'older' worker experience was now short circuited to the extent that much of the home grown experience and talent began to leave New Zealand in the hope of opportunity and safer work conditions of Australian mines. Others simply retired.

The eclipsing was a gradual process (and does not only apply to the mining world, but equally to the professions of nursing and teaching in an age of neo-liberalism). A new crop of recruits is brought in who have few 'long term trade' mentors of experience left to remind them to ask questions. In a world where 'voice' is not valued, 'power' is the issue underlying 'risk' every time and this was very clearly demonstrated in the case of Pike River Mine. Although many trades were also affected by severe cut backs in an age of neo-liberalism the eclipsing process has a lot more potential for risk leading to death when attached to a hazardous industry.

Some people behind systems of power also like to reinvent the wheel and dress it up as innovation. There is not a lot of value placed, for example, on learning from past employees in an age of neoliberalism; or it is often eclipsed as something not innovative enough i.e There is often an 'out with the old' and 'in with the new' mentality fostered. Should a past 'voice of experience' interfere with its culture of positive asymmetry, then that voice is swiftly removed by a variety of shaming and distancing practices; especially if it this voice has potential of bringing a worst case scenario into view that might delay outcomes on the professional target deadline.

'Safe practices' are encouraged of course; but a culture of silence develops around 'how clever' we can be to 'manipulate these occasionally' for the 'good of all'; often with reference to reaching those prescribed goals. Sometimes a cultural and/or structural secrecy (Vaughan 1996) develops. I argue that, in this case, it also occurs 'among mates' to mirror the mates-man-ship working at higher levels, systemically. This equates with the 'hush-hush' of 'never letting on' that 'corners' are sometimes being cut with regard to aspects of safety; portrayed as for the 'good of the team'. 
This culture of positive asymmetry does not begin at ground level of the mines but is modelled by the hierarchy and reinforced as it travels all the way back down again through all the veins of organisation to the coal face. Positive asymmetry is about power and a certain machismo culture is often glorified, where risk is silently justified; almost raised to a kind of 'noble dimension' if it is 'done for the sake of your mates', the team; or in competition with others to achieve that 'greater' goal. Often added to this culture is the occasional clouding and recasting of information.

In a climate of positive asymmetry, astute leaders might for example, manipulate the workforce into believing 'Hey, we're all in this together-from workers to managers to executives - We are all 'equal' in striving to reach these production targets', and if not, be patient as you wait, for the benefits of your efforts - will 'trickle back down'. This concept of 'trickle' economy culture was tragic for the men of Pike River Mine.

'The expedience of exchanging lives for some quick cash is just something that doesn't go down well with us, here on the Coast,' said one West Coast community leader in our 2012 interview. 'And then what do our governments do? They got rid of the Mine Inspection Team. And have [two] mine inspectors nationally. Well, it's damn well not enough.' (39)

'So, I just find it ah, terribly confusing. And it just frustrates me,' said a family member in February 2012 'I mean, Number One is - How can you leave people in charge of doing a recovery, who caused the explosion?' (40)

In a culture of positive asymmetry the 'blurring' of borders in hierarchy occurs both culturally and systemically but with a gradual, subtle secrecy; often encouraged with a call for 'unity' at ground level, in the workplace. There is, for example, often an underlying 'carrot-before-the-horse' type focus of entrepreneurial effort at the coalface to get rewarded 'as a team'. You are instantly an 'enemy' if you should challenge the process in any way. And should the whole system collapse, there will be little accountability from the upper levels/echelon as the pyramid 'trickles down'. 
The power of reward is now also cast in such a way (as with the introduction of the Pike's Bonus System in July 2010 (41) that even when a worst case scenario might be 'ever-present', it is seldom articulated and never scrutinized because 'we're all in this together' and any 'negativity' is perceived as at odds with the welfare/good of the entire community. Another example of recasting practice is the honour bestowed upon Pike River Mine via the Department of Conservation (DOC). In this example, so much attention was placed on creating environmentally friendly roads and mining infrastructure that did not interfere with native flora and birdlife of the mining area, that Pike actually won an environmental award leading up to the year it blew up. (42)

Conversely, warnings like those of Harry Bell were so recast that thirteen years after his letter to the Department of Labour (DoL) warning of another potential tragedy in New Zealand mines, he found himself yet again, in November2010, standing before the mouth of another workplace tragedy - Pike Mine - knowing that among the 29 men, he had now lost his own nephew, Allan Dixon to another avoidable disaster.

(ii) Archer: The Ministry of Economic Development (MED)

Having identified another primary arrow as being that of the inspectorate, with an archer being that of the DoL it is important to now identify that there was of course a secondary archer to this primary arrow of causation, which played second fiddle to all this change. And that was the Ministry of Economic Development. (MED).

The MED was a public sector organisation, born out of the Ministry of Commerce in 2000 which was tasked with promoting development of the New Zealand economy. Some interesting changes transpired within weeks of the publication of the findings of the Royal Commission of Inquiry (2012) into the disaster of Pike River Mine.

Post-Pike, the 'Twin Archers' (or former ministries) of DoL + MED became the Ministry of Business Innovation and Development MBIE (July 2012). (43) When the findings of the Royal Commission of Inquiry into the Pike River Mine tragedy were finally made public, the MBIE launched its own 'independent' investigation, and in 
April 2013 it issued a formal apology, acknowledging Pike's mining permit had been handled by the MED in a 'light handed' and perfunctionary way'. (44)

In 2013, an independent report, following the findings of the Royal Commission of Inquiry and commissioned by the Ministry of Business Innovation and Employment. The CEO of MBIE apologised to the families in April of that year and said that Pike River Coal's initial mining permit had been 'handled by the MED in a light handed way'; that the policy at the time had been to process such applications as quickly as possible and that health and safety regulations had been specifically excluded. (45)

Having restructured, the MBIE would now 'shape the agenda by challenging the status quo and by generating, adopting new ideas, 'to bring those ideas to life'; albeit a slightly ironic turn of phrase, given that the 29 men could not be.

The MBIE will deliver on its purpose by working in the following ways. We shape the agenda by challenging the status quo, and by generating and adopting new ideas, to bring those ideas to life. (46)

This act of rhetorical recasting advertises a new ministry, with a brand new purpose. When the MBIE published its April 2013 report apologising to the families of those killed at Pike, it distanced itself from an organisation that no longer existed, stating:

The DoL was not firm enough with the Pike River Coal Company and in one case even failed to issue a Prohibition Notice when it should have. (47)

The reconstructed MBIE also states in the 2013 Report that the original Health and Safety Act (1992) was never backed up with regulation or detailed codes of practice. (48) Having a mining operation backed up with such regulation and detailed codes of practices could have prevented the tragedy of Pike River Mine in the first place; or at the very least, have the operation shut down temporarily; as would have occurred in a mining operation in Australia in similar circumstances, in order to address a number of repairs and at-risk concerns which would not be examined otherwise. 
Following the argument of Cerulo (2006) who looks to causes of catastrophe in her own research, I argue 'there also appears to have been a culture of production operating here, in which some bureaucrats failed to see potential disasters situated in their own choices; creating a structural secrecy.' (49)

The case of Pike River Mine was (and still is) not just simply one of risk but also one of power; an example of which can also be found in the action of Green Party MP Kevin Hague, who tried to prosecute the Department of Labour, for example, in 2011 over Pike River Mine, but found it became too difficult and too expensive to pursue. (50) Overall, however, the new MBIE and its investigation into an aspect of its former DoL + MED self was widely accepted by the New Zealand public, without question.

'The investigators concluded....' said David Smol, CEO of MBIE in 2013... 'Systemic failures in agencies meant that an employment investigation is not warranted. The investigators said DoL's performance as a health and safety regulator was dysfunctional and ineffectual. In relation to MED's assessment and monitoring of Pike's mining permit, the investigators found that such functions were handled in a 'light-handed and perfunctionary way.' (51)

Then, as if having been redeemed by publically apologising and denouncing threads or apparent aspects of its former self, came the complete reconstruction of a bureaucracy which had been part of the problem in the first place. This needed to happen, of course, but a certain silence behind issues of power, risk and positive asymmetry have still not been acknowledged, let alone identified and until they are, systems will continue to make the same fatal workplace mistakes.

In fact, Charles Perrow (1999) would remind us most high-risks systems 'have some special characteristics, beyond their toxic or explosive or generic dangers'; and that there is an interacting tendency which is 'characteristic of a system... an 'interactive complexity of a system' that is a tightly coupled process'. (52) I agree we must look to issues of power and to 'the way failures can interact and the way the system is tied together' ${ }^{(53)}$ if we are to effectively deal with high rate of fatality in the workplace. 
An interview conducted by Kathryn Ryan of Radio New Zealand in April 2013 also addresses the findings of the independent inquiry of the new MBIE and questions how such a 'light handed, perfunctionary way' could ever have been allowed by the MED in dealing with such a contemporary, hazardous industry in the first place. (54)

On being interviewed, Nicholas Davidson QC, one of the lawyers for the Pike River Mine families who had also lost his own nephew, Michael Monk to the tragedy, referred to not only the ineffectual and dysfunctional culture that was being perpetuated at Pike River Mine, but to the many red flags and warnings that had been ignored in the twenty years leading up to the November 2010 tragedy.

'Well, the process just meandered on,' Mr Davidson QC, said 'I mean, you identified a period of time, in 2008 when codes of practice were being looked at. It seems to have been treated in the most leisurely way. There was no urgency. And yet, there were very clear warnings out there about this; not just from Harry Bell, back in '97 letter. But in 2008 he was warning the inspectorate that by calling them and telling them gas had been encountered in the mine. There were small explosions taking place, or emissions were taking place while the tunnel was being drilled; matters of huge alarm. He [Harry Bell] contacted the manager of the mine and warned him of what he was learning from people who were working there.' (55)

'The process just meandered on'; 'There were very clear warnings about this'; 'It was dealt with in the most leisurely way'; 'There was no urgency'; 'There were so many red flags'; These were matters of 'huge alarm'. These were all phrases I also heard through my own interviews conducted (2011-2016) and those of media, regarding the Pike River Mine tragedy. So how and why were these warnings ignored? What was happening with DoL and MED to have a whole system behave in such a light handed' and 'perfunctionary' manner, with so much potential risk in the workplace? 
'There were flags up everywhere,' said Mr Davidson QC 'And that's the extraordinary thing. But none of this got through to the Department of Labour Inspectors. None of these things finally came to their attention or were acted on. So the notion that all this [Pike Mine] suddenly happened out of the blue is simply wrong. The warnings began 20 years ago.' (56)

The power behind the Bow of Positive Asymmetry from which the Arrow of the Inspectorate was sprung, via the Twin Archers of the DoL and the MED was backed by successive New Zealand governments. Here we have the very system supposedly set up to protect mines, and managers eclipsing inspectors with impossible conditions that blocked the potential to prevent risk; only to then recast the same inspectors out on the frontline when tragedy finally befalls a community.

'Now I can honestly tell you,' said Harry Bell, former chief inspector of mines 'None of the inspectors that I worked with would ever allow Pike Mine to be developed the way it was. They must've gone around with their eyes shut,' he told me in March 2016 'All those things that were going on at Pike River. And they didn't issue any prohibition notices or anything, you know. It just went on and on until it finally blew up.' (57)

\section{Endnotes: Chapter 4}

(1) Mulholland Interviews, January 2015, G (30.1.15) 18:08.

(2) Royal Commission of Inquiry on the Pike River Mine Tragedy NZ, Te Komihana a te Karauna mo te Parekura Ana Waro te Awa O Pike (2012); Vol.1, p. 19, para.2.

(3) See Theorising Accident Causation (Cbapter2) and related endnotes.

(4) Vaughan, Diane (1996) The Challenger Launch Decision: Risky Technology, Culture and Deviance at NASA, USA: The University of Chicago Press. See also Cerulo (2006) and Norgaard, (2011) for later discussion on socially organised denial.

(5) Mulholland Interviews, November, 2014, D (19.11.14) 12:33. 
(6) See Chapter 3 (Analysis I) of this dissertation.

(7) A sample of mining deaths in New Zealand since 1879:

1879 Kaitangata, Otago (34 deaths)

1896 Brunner, West Coast (65 deaths)

1900 Westport-Cardiff, Mokihinhui

1907 Nightcaps, Southland (3 deaths)

1914 Ralph's Colliery, Huntly (43 deaths)

1926 Dobson, West Coast (9 deaths)

1929 Linton, Ohai (3 deaths)

1939 Glen Afton, No.1 Mine, Huntly (11 deaths)

1940 Kayes, Greymouth (5 deaths)

1955 Huntly, Waikato (1 death)

1958 Westhaven/Mangarakau, Collingwood (4 deaths)

1967 Strongman, West Coast (19 deaths)

1985 Boatmans No.4, Reefton (4 deaths)

1992 Huntly West, Waikato

1998 Mount Davey, West Coast 1998 (2 deaths)

2006 Black Reef (Tiller), Greymouth (1 death)

2006 Roa, Blackball, West Coast (1 death)

2010 Pike River Mine, West Coast (29 deaths)

(8) Mulholland Interviews, February 2012, MP (9.2.12) 14:43, 15:15.

(9) Royal Commission of Inquiry (2012) op. cit., Vol.2., 22:28, 22:29; 22:50.

(10) Ibid., Vol.2 22:37; 22:40, 22:46, 22:50; 22:55.

(11) Ibid., Vol. 2, 22:40. Also: Neil Gunningham, David Neal, Review, DoL 0100010001/50, para.153.

(12) Ibid., Vol.2, 22:40-42. Note: Given that DoL was the moderator overlooking Health \& Safety of the inspectorate, it also seems a little incongruous that it would 
later be put in charge of leading the investigation and prosecution of others for the tragedy at Pike River Mine (2010).

(13) Ibid., Vol.2, 22:41; see also Michael Firmin, transcript, pp. 643-44.

(14) Cerulo, Karen. (2006) Never Saw it Coming: Cultural Challenges to Envisioning the Worst, Chicago: University of Chicago Press.

(15) Mulholland Interviews, Harry Bell, 24 April 2016.

(16) Ibid., 24.3.16, Pt.2 (2:12); 28.3.16 (43:56). (44:21).

(17) Ibid., 24.3.16, Pt.2 (3:16); 28.3 .16 (31:25).

(18) Ibid., 24.3.16, Pt.2 (1:03), (11:53), (17:14).

(19) Ibid., 24.3.16, Pt.2 (17:14); 28.3 .16 (31:55), (54:29), (55:51).

(20) Kaitiaki: New Zealand Maori meaning 'guardian' and as a trustee, a minder, a keeper or spiritual custodian, steward of the people and their well being. It includes aspects of Ako (a culturally inherent teaching/learning relationship).

(21) Harry Bell Letter to Max Bradford (1997), p.2, para.7; para.8; See also Mulholland Interviews, Harry Bell, (24.3.16) Pt.2, 10:45.

(22) Harry Bell Letter, op. cit., p. 2 para.8; See also, Mulholland Interviews, Harry Bell, 24.3.16, Pt.2, 8:53; 9:17); 9:29; 15:20.

(23) See also, Note (7). 1967 Strongman, West Coast (19 deaths); 1985 Boatmans No.4, Reefton (4 deaths); 1998 Mount Davey, West Coast 1998 (2 deaths) 2006 Black Reef (Tiller), Greymouth (1 death).

(24) Mulholland Interviews, Harry Bell, op. cit., 24 April and 28 April, 2016.

(25) See Appendices (III) Harry Bell's letter to the former Minister of Energy, Max Bradford 1997. 
(26) Mulholland/Harry Bell Interview (24.3.16) Pt.2, 8:53- 9:29. See also: Nicholas Davidson QC, RNZ: Kathryn Ryan Nine To Noon 11 April 2013 , https://www.radionz.co.nz/audio/player?audio id=2551702

(27) See Appendices (III) Letter from the Chief Inspector of Coal Mines to Minister of Energy (1997) Letter of Submission from Harry Bell, Former chief Inspector of Mines.

(28) Royal Commission of Inquiry (2012); op. cit. Vol. 2, Chapter 20.

(29) See also, Mulholland Interviews, Harry Bell (24.3.16), 6:34; 13:59; (28.3.16) 5:46, $6: 14,6: 21,7: 46,8: 49,19: 39,21: 40,25: 13,25: 26,26: 37,41: 51,64: 10$.

Note: The (1997) submission letter of Harry Bell was an effort to prevent further tragedy in New Zealand mines. His reference to 'past atrocities' is in direct reference to mining tragedies he was also directly affected by, as with Strongman Mine (1967) into which he had lead a rescue team to retrieve 17 of the 19 men killed there; only to later also lose his own nephew, Allan Dixon, to Pike River Mine in November 2010.

(30) Harry Bell Letter to MP, Max Bradford (1997) op. cit., para.9.

(31) Ibid., para.7.

(32) Ibid., para.8.

(33) Mulholland Interviews, Harry Bell, (28.3.16) 54:29.

(34) Ibid., Harry Bell, (24.3.16) 20:09.

(35) Ibid., (24.3.16) Pt. 2, 10:30; See, no ability to close down Vol.2. 22:46, 22:62.

(36) Royal Commission (2012) op. cit., Vol.2, 22:40, 22:46, 22:50, 22:59, 22:62.

(37) Mulholland Interviews, Harry Bell (24.3.16) Pt. 2, 9:17; 14:38; 15:20); 17:14.

(38) Ibid., (24.3.16) Pt .2, 3:10; 41:29.

See also Mary Wilson interview Harry Bell, RNZ Checkpoint, 11 April 2013

https://www.radionz.co.nz/audio/player?audio id=2551745 $\left(2^{\text {nd }}\right.$ Item). 
(39) Mulholland Interviews, February 2012, HL (8.2.12) Pt.2, 12:42; 13:05.

(40) Ibid., February 2012, BM (12.2.12) Pt.2, 37:35.

(41) Royal Commission of Inquiry, (2012) op. cit., Vol.2, 6:20.

(42) Ibid., Vol.2, 3:67. 'In September 2008 DOC recognised Pike River for 'the environmental consideration it had demonstrated in the establishment of [its] mining facilities'... Two months later, on a visit to the mine, Minister of Conservation Chris Carter added that it was a 'showcase development' which had set a new environmental standard for coal mining'. See also, Vol.2, 13:9.

(43) Website for NZ Ministry of Business Innovation and Employment (MBIE) 2016. http://www.mbie.govt.nz/about/who-we-are/our-character

(44) Smol, David CEO of the newly formed MBIE, April (2013)

http://www.business.govt.nz/worksafe/news/releases/2013/independentinvestigation-report-released

See also Shanks, D; Meares, Jane. (2013) Pike River Tragedy: Report of the Independent Investigation to the Chief Executive of the Ministry of Business, Innovation and Employment, (14 March 2013). http://www.mbie.govt.nz/infoservices/employment-skills/workplace-health-and-safety-reform/document-andimage-library/Pike-river-independent-investigation-report-mar-2013.pdf

(45) David Smol, op.cit. (2013).

(46) MBIE (2016) http://www.mbie.govt.nz/about/who-we-are/our-character (47) Shanks, D; Meares, Jane. op. cit., (2013); See also, Royal Commission of Inquiry, op. cit., (2012), Vol.2, 15: 80-82.

(48) Mulholland Interviews, Harry Bell, op. cit., (24.3.16) pt. 2, 1:03; 11:53; 17:14. See also, Note (45).

(49) Cerulo, Karen. (2006) op. cit., p. 215. See also the work of Vaughan (1996). 
(50) Mulholland Interviews, Harry Bell, op. cit., (24.3.16) pt. 2, 1:03 -124.

See RNZ, MPs first step to prosecute department over Pike disaster 25.11.11.

http://www.radionz.co.nz/news/pike-river-2010/92019/mp\%27s-first-step-to-

prosecute-department-over-pike-disaster

(51) http://www.business.govt.nz/worksafe/news/releases/2013/independent-

investigation-report-released from the new MBIE, April 2013. See also, Shanks, D. and Meares, Jane. op. cit., (2013). See also Note (42).

(52) Perrow, Charles. (1999) Normal Accidents: Living with High-Risk Technologies, New Jersey: Princeton University Press, 1999, p.3.

(53) Ibid., p.4

(54) Ibid., See Independent (MBIE) Report 14 March 2013, p. 2; See also Interview Mulholland/Harry Bell (24.3.16) pt. 2, 6:28. Note also RNZ: Kathryn Ryan interview Nicholas Davidson QC op. cit., 11 April 2013.

(55) Ibid., RNZ Kathryn Ryan interview (11.4.13). See also, Mulholland/Harry Bell Interview (24.3.16) pt. 2, 11:53.

(56) Ibid., 12:17-12:25.

(57) Mulholland interviews, Harry Bell, op. cit., 24 March 2016, pt.2, 4:21. 


\section{Chapter 5 Analysis (III)}

Having introduced the Arrow (pathway of decisions) of the Inspectorate and its Twin Archers, the former Department of Labour (DoL) and the Ministry of Economic Development (MED) it is time to look to another primary arrow of causation and this is the Arrow of 'Production before Safety' that permeated the entire culture of Pike River Mine. This arrow was set off on its own trajectory from the inception of the mine. But how could this have happened to a mine in cotemporary Aotearoa/New Zealand? Surely it would be in the interests of everyone to run a safe mine. What can be said of the cultural norms which allowed this trajectory to evolve in the first place?

\section{The Arrow of Production before Safety}

\section{Uncomfortable Truth No. 5}

At the executive management level there was a 'culture of production before safety' at Pike River Mine and as a result, signs of risk of an explosion were either not noticed or not responded to. (1)

Arrow Five: The Arrow of Production before Safety

Archers: The Board of Pike River Mine

Archers: The CEO and Senior Executives

Looking to all the findings, the performance of the Arrow of the Inspectorate and that of the first of its Archers, the former Department of Labour (DoL) as the health and safety regulator was in relation to Pike, 'dysfunctional and ineffectual'. (2) The newly established Ministry of Business, Innovation and Economic Development (MBIE) also concluded after the publication of the Royal Commission Report, 2012 that the former monitoring of Pike's permit via the former Ministry of Economic Development (MED) was 'discharged in a light-handed and perfunctionary way'. (3) But what was the actual role of Pike River Mine itself, in the months and weeks leading up to the tragedy of 2010 ? Why were so many of the warnings evidenced in the findings of the Royal Commission of Inquiry (4) and the later MBIE Report of 2013, 
so consistently ignored in relation to Pike by the Archers of the Secondary Arrow of Production? What was it about the cultural norms of Pike Mine that had the Archers of the mine's CEO and board so adamantly deflecting their own roles in the tragedy via pleas of 'we were not informed'; when it is well evidenced that the CEO had, at least been well informed, and similarly it is the job of any board to 'find out'.

\section{(i) Archer: The Board of Pike River Mine}

The findings of the Royal Commission show that 'executive management was so focused on hydro coal production, as was the board, that the 'associated risks were not properly assessed' (5) and that 'the way hydro mining was utilised also indicates a culture that put production before safety.'(6) 'It appears that no one on the board had experience in the local underground coal mining industry'. (7) The business was new. The mine was still under development, as were its systems, including health and safety. There seems to have been a lack of communication between senior executives and the Board of Pike and sometimes information was not presented to the board at all. (8) But it appears that neither did the board always ask for it either.

The board did not verify that effective systems were in place and that risk management was effective. Nor did it properly hold management to account, but instead assumed that managers would draw the board's attention to any major operational problems. The board did not provide effective health and safety leadership and protect the workforce from harm. It was distracted by the financial production pressures that confronted the company. (9)

My own interviews also speak to this culture of 'production before safety' that existed at Pike River Mine with constant references to the pressure workers and management felt to 'chase coal'; (10) 'needing so much coal by Christmas'; (11) 'pushing for coal'; (12) with 'huge pressure to bring the resource out'; (13) to 'take out coal as quick as they could'; (14) There was also reference to an apparent lack of concern on the part of management and the board; 'They didn't worry about it... They chased coal'. 'They didn't worry about making a second form of egress'; (15) 'Their only focus was on getting the first shipment out'. (16) 
Although many new workers at ground level may not have been aware Pike was in financial trouble (17) they would definitely have been aware there were production targets to be reached with the introduction of the competitive Bonus System in July 2010; alongside that of the brand new technology of hydro mining, the same month.

In 2010 the board and executive management faced serious challenges, some of which had been apparent for years. The company had a history of not delivering on its promises. Coal production was behind schedule and previous estimates of production capacity had to be severely reduced. Lack of revenue was driving the company to seek further funding. There were major problems with the advent of hydro mining, the company's main production method. (18)

There developed an urgency to combat absenteeism in order to meet both team and company targets, and to 'make that boat load of coal by Christmas'. This would appear to have been further reinforced by the board who 'initiated this staff bonus scheme based on reaching each production target promptly, with the bonus then reducing week by week.' (19) References to 'a few guys at the top' indicates a belief (or knowledge) on the part of some interviewed, that there were others at the 'very top' who not only knew of the debt the company was in, but of the focus taken to encourage everyone to strive for incentives from which they would all certainly gain.

'The truth is, there were a few guys in that organisation at a higher level than myself, who deliberately decided they needed coal on a boat,' said a senior manager I interviewed in 2012. 'And they would take all steps, whatever they were, whatever they needed to do, to fulfil that objective of getting that coal on the boat by Christmas.' (20)

Following the research of (Vaughan 1996) into repetitive organisational risk taking; and that of (Cohen 2001) into levels of literal, interpretive implicatory denial, it is possible to analyse all these in operation alongside a certain silence and socially organised denial (Norgaard 2011) at Pike River Mine, leading right up to disaster. 
In her own study looking to the catastrophic affect of change on a small Norwegian community (21) Kari Marie Norgaard (2011) looks, for example, to links between emotion and cognition with regard to the failure to react to warnings even when a worst case scenario was not only unfolding, but directly impacting upon businesses physically, culturally and economically. Norgaard discovered the subsequent collapse in this case, was not a result of any information deficit model. There had been plenty of information available. She found a collective distancing among individuals due to norms of emotion, conversation and attention within a developing culture of denial.

In the case of Pike, there was no lack of information either (as pointed out in my earlier analysis) with regard to the faults of the mine and its operations, but rather an almost collective distancing from the warning signs, further complicated by the introduction of a competitive bonus system in the drive to meet deadlines at the same time many were struggling to operate the new technology of hydro mining.

As previously cited, Charles Perrow (1999) argues in his own work on risk and power that 'most high-risks systems have certain special characteristics beyond their toxic or explosive or generic dangers which court a certain inevitable danger' if equally special attention is not applied to their interactive complexity and tight couplings. (22) Perrow looks for example, to the way failures interact and the way the system is tied together. He looks to interactive complexity of systems, to redundant pathways, to independent and 'tight interactive couplings' of factors which unless addressed, will lead to a domino effect of failures in a highly charged, increasingly hazardous unit.

Looking to all the data, the case of Pike River Mine was one in which risk continued to appear faster than the reduction of risk. (Perrow 1999) This seems to have been further clouded, eclipsed and recast in the short term in order to reach production deadlines just months away. This developing culture of positive asymmetry (Cerulo 2006) was further driven by systems of both cultural and economic power within the risk society (Beck, Giddens 1992). There was financial urgency coupled with a certain distancing from the facts, cultivated by developing norms of emotion, conversation and attention, or lack of it (Norgaard 2006). At Pike Mine, there was information and 'world class safety systems' available, but these were increasingly not utilised. (23) 
Here we have then, an example of an already hazardous industry (coal mining) which when monitored and functioning well, is still an industry of low-probability, high consequence risk. (Beck, Giddens 1992). So given the way failures interact and how a system is tied together (Perrow 1998) strategies should always be closely monitored, assessed and modelled from the top-down to avoid a potential worst case scenario.

This was clearly not happening at Pike River Mine. All the available data indicates that this particular coal mining operation on the West Coast of Aotearoa/New Zealand was failing on many levels; whose board seemed to be 'unaware' of these failures; whose company ethos seemed to be so driven to meet its operational targets and financial deadlines that Pike River Mine was in fact, very much a highprobability, high-consequence risk endeavour, possibly from its inception and whose potential for fatality was increasing by the day right up to the 29 fatalities of 2010 .

I argue that given there were already so many unattended and blatant violations of health and safety practice occurring at Pike River Mine (Chapters 3-4) this final 'coupling' (Perrow, 1999) of technology and competition: the introduction of hydro mining and a competitive bonus system in July 2010 had consequences which can no longer be viewed as an unforeseeable accident, but a recipe for inevitable fatality.

That is not so say an impending worst case scenario (Clarke, 2006; Sunstein, 2007) was not on the minds of workers and in some cases, very much so. There is evidence of headaches nausea and nightmares among the men. (24) But complaints were now potentially discouraged (via acts of positive asymmetry) in the name of 'being part of the team', 'not letting your mates down' and the drive to get coal out by December.

'You know, there should have been a cap. They didn't have one,' said one senior mining executive I interviewed in 2014. 'They had to go and implement something; which they did pretty quickly, but it's 101. If you've got a shaft that's a vent shaft - You need to be able to shut the doors.' (25) 
'So, why does a government let one of its departments buy a mine when they never had any money to buy it in the first place?' asked a grieving family member in February 2013. 'We don't run businesses like that. The man-onthe-street can't run a business like that.' (26)

'If there's one thing that stood out for me more than anything else at Pike River,' said Mr Davidson, QC, as he educated business leaders post-tragedy, while grieving the loss of his own nephew to the mine, 'It's the fact [Pike] had world class safety record systems. The trouble is, they weren't used.' (27)

These are all examples of risk, power and positive asymmetry intersecting in what I have come to call the triple helix of perfect storm conditions for impending disaster. Following the work of Diane Vaughan (1996) I also argue that this was often further fostered via the normalisation of deviance and a certain structural secrecy. (28)

In her awn analysis of the NASA (1986) Space Shuttle Challenger Disaster, Vaughan (1996) speaks to misconduct of organisations vs. organisational misconduct and the incremental descent into poor judgment, where pressures often not only became institutionalised, but 'where signals of potential danger become so normalised that action (or lack of it) also became aligned with organisational roles and the deviance in organisations is transformed into acceptable behaviour'. (29) With reference to her own research and analysis of this (1986) disaster, Vaughan says:

There [was] technical deviation... and predictions [were] redefined as an acceptable risk in official decisions. This sequence was repeated, becoming a pattern. Each time [there were] anomalies that were signals of potential danger, the risk was negotiated. Each time the outcome was to accept the risk. This pattern indicated the existence of a work group culture in which ...constructed beliefs and procedural responses became routinized. (30)

The findings of the Royal Commission (2012) indicate many such sequences being repeated and becoming an accepted pattern in order to reach production targets. By November 2010, some of the workers at ground level of Pike Mine may have had 
their own concerns about safety at the mine but with the triple helix of, risk, power and positive asymmetry fully in operation, anyone might decide to work one more day in collective denial (Norgaard 2011) to meet team production targets for the sake of your workmates, your family's Christmas and theirs. In the case of Pike River Mine, many would also have seen employees more experienced than themselves being shunned, diverted or ignored (Cerulo 2006) by management via a whole selection of eclipsing, clouding and recasting, practices (31) if they did choose to complain. Some would also have known of the hundreds of unsafe work practices reported that had never dealt with by management, and that all of them had been deleted in the name of a 'new start' with the promotion of a new manager. (32)

Many complaints had still not been dealt with by November 2010 but there was now a group culture of 'being positive', of 'doing it for your team' and 'what point would there be in complaining before Christmas now, anyway? It would be dealt with in the New Year'. Any chance of collective acknowledgement of danger was now blurred, rarely articulated and seldom scrutinized. Should someone now voice a concern, they and their complaint might be quickly distanced by rhetorical recasting practices relating to machismo or group 'strength' and 'give-us-a-hand-mate' positivity; only to be silenced in the drive of a bonuses to reach the team and company deadlines.

In looking to the findings of the Royal Commission (2012) and to the research of Vaughan (1996) with regard to the social organisation of mistake and structural secrecy leading to workplace disasters (33) it becomes very clear Pike River Mine had a culture in which it seemed to have become 'routine to reduce details of reports as they [made] their way up the management hierarchy' and which, with a 'repetitive faulty decision making sequence, increasingly likely to lead to fatalities'. (34)

There are many examples of this throughout the findings. The Pike board, for example 'appears to have received no information proving the effectiveness of crucial systems such as gas monitoring ventilation'. (35) 'The nearest the board came to questioning management on such issues appears to have been on 15 November 2010 (four days before the fatal explosion) when the general manager, Mr White, attended his first board meeting and was questioned about safety systems.' (36) 
The Royal Commission concluded 'The board did not verify that effective systems were in place and that risk management was effective. Nor did it properly hold management to account, but instead assumed that managers would draw the board's attention to any major operational problems. The board did not provide effective health and safety leadership and protect the workforce from harm. It was distracted by the financial production pressures that confronted the company.' (37)

The findings of the commission show the board of Pike Mine felt that 'things were under control, unless told otherwise'; (38) that there was no need for 'any more' information from other managers. i.e 'neither the board nor the committee felt it necessary to seek independent advice on health and safety;' and that 'if anyone wished to raise concerns, they had the opportunity to do so at company dinners or barbecues.' (39) I argue, however that with the culture of Pike, employees might find it difficult to raise concerns in a social setting in front of colleagues and bosses.

'There is a moral obligation that shareholders and receivers should take on board,' a community leader, who had lost a friend to the Pike Tragedy, told me in 2011. 'The government gets enormous taxes and revenue from the production that came out of that mine. So where's the responsibility?' (40)

This assumes of course, that the changing power dynamics of the risk society (Becks, Giddens 1992) now operating to levels of both interpretive and implicatory denial (Cohen 2001) in a culture of positive asymmetry (Cerulo 2006) at Pike River Mine would still encourage the practice of personal responsibility and active vigilance; looking for macro-micro connections and how those structural forces might affect decision making in order to prioritize safety over production (not vice versa) in the workplace vs. 'positive thinking' while checking the amoral calculator hypothesis.

The Royal Commission (2012) shows that Pike's 'Health and Safety (HSE) committee was to meet every six months but by the time of the [fatal] explosion it had not met for 13 months, with the exception of the board meeting of 15 November when it questioned the general manager on Health and Safety. (41) The chairman later told 
the commission 'this was because the board as a whole was taking more interest in health and safety'. [But] 'no meetings of the Health and Safety committee had been scheduled for 2011, in contrast to meetings of the board.' (42)

At Pike River Mine, 'the routine reduction of details' is evident as they continued up the management hierarchy. The mine manager attended the board meeting four days before the fatal 19 November 2010 explosion and told the directors that gas management was 'more a nuisance and daily operational consideration than a significant problem or barrier to operations [and] the board was not well placed to assess this assurance' (43) But 'neither did it verify effective systems were in place' (44) In fact, here again the earlier findings of the Royal Commission further emphasise:

In 2010 there were obvious warning signs that things were amiss. These included two third-party reviews that an alert chair and board would have found very revealing. (45)

The trouble is, inherent to this model of Pike River Mine was now a 'failure to ask the right questions', 'recognise the risks' or even 'respond appropriately to warnings'. (46) In reality, the board did not assess critical design, health and safety issues, including for example, the poor ventilation and the risks associated with putting the main fan underground at pit bottom in an effort to 'correct' ventilation. (47) The board also received a monthly report with a health and safety section, but this failed to cover issues related to hazards, like explosions for example, which have potential to occur in any mine; but particularly in a gassy, faulted mine like Pike. (48) Added to this, is the fact the board did not even get to see the comprehensive risk survey by Hawcroft Consulting International, commissioned by Pike's insurers; [nor] the second review of legislative compliance conducted by Minserv International Ltd (Minserv)’. (49)

'The board's role on safety is the same one as it plays across all areas of corporate governance,' said Mr Ralph Chivers, former Institute of Directors CEO speaking at the Business Leaders' Health \& Safety Forum for ZeroHarm Workplaces in Christchurch, New Zealand (2013) 'is to hold management to 
account...The board's [role] is to ask searching, probing, inciteful questions that come from a wealth of knowledge, experience, wisdom.' (50)

In outlining the role of a board in safety and the new guidelines to help directors fulfill their duties, Mr Chivers further added (2013) in response to the Commission's findings that no one on the Pike Board had underground coal mining experience (51)

'How could they possibly expect to interrogate management, to know what the warning signs are, to ask the questions?' It is not enough to turn up; sign off a few things, eat the cucumber sandwiches, and go home again,' said Mr Chivers. 'That is not the role of a director at all. An effective business culture and an effective health and safety culture starts with the board. Tone from the top is the expression we use.' (52)

'And they never saw it coming,' said Mr Nicholas Davison QC, with reference to the Board and management of the Pike River Mine disaster that would also claim the life of his own nephew 'And the reason they never saw it coming is they never made the enquiries the law, I think, requires them to make.' (53)

(ii) Archer: The CEO and Senior Executives of Pike River Mine

The Royal Commission found there had been six CEO's and a high turn over of senior executives in the two years leading up to the Pike River Mine fatalities (2010).

From the time the mine was classified as a gassy coal mine in November 2008 Pike had six mine managers, two technical services managers, three engineering managers. In 2010 the mine had two production managers. (54)

Although there was constant media spin, post-Pike that the last CEO, Peter Whittall had 'only been in the job for six weeks' leading up to the explosions, he had in fact 'joined the company from Australia in February 2005', was a 'mining engineer experienced in coal mine development and management' and had been the mine manager when he and Gordon Ward had presented the mine plan and financial 
model ('the joint report') to the Pike board in July 2005. (55) As general manager, and then CEO of the company, Mr Whittall had also for five years presided over the triple spearhead of poor ventilation; directed the use of a large fan in a gassy mine; (56) supported the much advised-against use of hydro mining in the geologically flawed workplace (57) and the introduction of a competitive bonus system the same month. (58) There was no official ventilation engineer and Mr Whittall had relocated to the North Island, paying mainly fortnightly visits to the mine in the South Island.

There was no secondary form of egress at the mine, which is a legal requirement for most contemporary mines, a fact often brought before the CEO and management. (59) There was also only one make-shift Fresh Air Base Facility (FAB) to escape to, which was virtually unusable. (60) There were limited self-rescuer masks and faulty phones. (61)There had also been only one evacuation drill and that was in October 2009 provided for a handful of staff with none of the many contractors present.

It was at this drill that some of the men joked of their real chances of escape up this proposed 'secondary means of egress'; a very steep, poorly angled shaft which in all potentiality might become a 'burning' mine chimney in an explosion; (62) all of which continues to demonstrate that at all levels of the system, including senior and executive management levels, there was an ongoing dysfunction in recognising a worst case scenario in favour of reaching financial targets and production deadlines.

The Chairman of Pike [on the appointment of Mr Whittall] commented in the board minutes [on 13 September 2010] that 'Pike River had in the past consistently overpromised and under delivered. This time it was important that we did a better job of forecasting the production schedule.' (63)

When Mr White, the site general manager; who was also mine manger and had the additional responsibility for ventilation, was asked by the Royal Commission about his perception of risk as in using the vent shaft as an escapeway and whether this was of concern, he replied 'I think it's fair to say that having never actually considered the possibility of the mine blowing up... It was not a matter that overly concerned me.' (64) 
Similarly, in his own witness account and on the perception of risk, Pike Mine Production Manager, Mr Ellis also said 'It was hectic. We don't expect an explosion of that magnitude at a mine site'. (65)

Mr Whittall had also been approached by a number of experts over the months; (including in the weeks leading to November 2010 tragedy) who were constantly warning him of the mine's poor ventilation, geological and associated faults. Mr Whittall, the executive managers, and the board, either through direct action (or lack of it) avoided these issues; remaining focused on production and earning revenue.

In 2010 the board and executive management faced serious challenges, some of which had been apparent for years. The company had a history of not delivering on its promises. Coal production was years behind schedule and previous estimates of production capacity had to be severely reduced. Lack of revenue was driving the company to seek further funding. There were major problems with the advent of hydro mining, the company's main production method. (66)

Again, what all the evidence illustrates is that the tragedy of Pike River Mine was a case of unchecked power. Risk management was undeveloped at the mine. Risk catastrophe was not identified by executive management. It was not reported to the board; (67) but neither did the board ask for it. The culture of silence at Pike River Mine was one in which the CEO and senior executives continued to shun, divert or ignore expert advice in the name of reaching the December production targets.

In May 2010 NZ Oil and Gas (NZOG) advanced the company US \$28.9 million (NZ\$41 million) upon the security of a convertible bond. This sum was required to pay a debt owed a Goldman Sachs entity (Liberty Harbour) after Pike River breached a production covenant contained in the loan agreement. In September NZOG also granted a short-term loan facility of \$25 million to meet a projected cash shortfall. In October Pike River drew down $\$ 13$ million. (68) 
On 18 November, the day before the explosion, the company was on the brink of raising a further $\$ 70$ million capital involving a share placement to ordinary shareholders of $\$ 25$ million and to institutional investors of $\$ 45$ million, fully underwritten by a major international investment bank. [It was] considered that this $\$ 70$ million would have carried the company through to the third quarter of 2011 when 'we expected to be in fully steady state hydro mining'. (69)

The findings of the Royal Commission show that Pike River Mine had consistently ignored the warning signs of an approaching worst case scenario and continued to operate under increasing financial pressure to meet its production targets. The reality of this was clouded and recast with deliberate actions, such as the earlier example of the CEO attending a board meeting four days before the fatal explosion at the mine to tell the directors that 'gas management' was 'more a nuisance and daily operational consideration than a significant problem or barrier to operations.' (70)

'There was complacency at that mine,' said a businessman I interviewed in February 2012, who had also lost friends in the Pike Mine tragedy. 'So at the end of the day, where was the Health and Safety meetings and the pecking order that you would have under any management regime? The managers of that business - which was Pike River Coal - should've taken a very serious view of that, especially in a methane filled mine. And they didn't.' (71)

'And I think the biggest thing is just the safety, the fact that there weren't the safety requirements there,' said another community leader in 2012. 'And when those things are taken away because of a need to just continue [production] then what accountability does a business have?' (72)

Among the findings, the Royal Commission states 'The board was not well placed to assess this assurance'; but once again neither did they seek to assess it. This also perpetuated complacency in averting a worst case scenario. Here, the ever aligning flaws of the accident/fatality causation model match up in the name of industry and production before safety, in order to meet company deadlines and financial targets. 
'That was my first thought,' said another leader who like many others of her community had witnessed past West Coast tragedies and had braced herself for the fallout of this for children and families needing help with this one. 'Look, I thought, here is another work place disaster for the West Coast, wrapped around the primary industry that we're involved in. How come this could happen again on this scale?' she asked me in 2012. 'Industrial accidents will always happen. I understand that. But how could it have happened again, in such a short time? - Because it's in our lifetime; since Strongman [mine tragedy] (73) How could this have happened again? ... It does seem to be avoidable... But here we are again, on the West Coast.' (74)

The findings show that the board, the CEO and senior executives of Pike River allowed (whether via action or inaction) a culture of production before safety to operate at Pike Mine in favour of meeting production targets. Similarly, they seemed to either cloud or recast issues raised by the Hawcroft (2009) Report, which repeated its recommendations for Pike in (2010). This asked the company to urgently develop a risk register to determine hazards. The Hawcroft Report had identified that a number of specific risk assessments were overdue on matters as vital as windblast, gas ventilation, hydro mining. This review recommended urgent action on these and other issues, and had rated the 'risk of a methane gas explosion' as possible. (75)

At Pike Mine, however the culture of denial and positive asymmetry (Cerulo 2006) seems to have been so pervasive that the former chairman of Pike River Mine told the Royal Commission in 2012 that he 'considered the matters raised would be appropriately dealt with by management at the mine. The Hawcroft report was not, in his view, something that would normally come to the board or its Health and Safety in Employment [HSE] committee'. (76) And as such, the issues brought up by the Hawcroft Report were still not addressed by 19 November 2010.

Added to what seems to be a lack of attention to recommendations, the decision making processes of senior management at Pike Mine then also seems to have become even more dysfunctional. It began to inadvertently manufacture more 
problems in trying to solve them. One example of this was adding an underground fan in a coal mine in the hope it would assist with ventilation (as there was no ventilation engineer). In so doing, even a hazardous industry (had it been well-run) on 'low-probability but high consequence risk' (Becks, Giddens 1992) had now simply manufactured more potential hazard and contributed further to an increasingly highprobability, high-consequence risk workplace culture, shifting ever closer to disaster.

'In terms of checking to make sure the human elements are under control,' another senior executive told me in November 2014 'You're actually engineering out the things that are going to hurt you. Then you're going to learn something. But that's what Pike didn't do. Putting the fan underground wasn't engineering out a problem. It was engineering to get the mine up and running. And it produced more issues than you can poke a stick at. ' (77)

Looking to the data of my own interviews also brings to mind the research of William Freudenburg (2013) (78) for here we are now not only looking to the many ways in which risk and a drive for production are repeated to the point that there is an almost 'acceptable' pattern of technical (Perrow, 1999) cultural (Norgaard 2011) and organisational dysfunction (Vaughan, 1996) often encouraged by positive asymmetry (Cerulo 2006) and a developing structural secrecy (Vaughan, 1996) but in the case of Pike River Mine there is now also a lot to demonstrate the organisation of hazards and recreancy, as in the failure of institutional players (experts and organisations) to perform their roles responsibly and to the expected standards of proficiency.

The evidence of recreancy in the case of Pike River Mine is to be found throughout the findings of the Royal Commission and I have referred to examples of this here and throughout this thesis. A prime example of recreancy requiring much further investigation however was this manufactured additional problem of the previously cited decision to place a fan (to improve ventilation) in and underground coalmine.

'Pike ultimately decided to install its fans underground, with a back-up fan on the surface. That situation is unique. Although underground booster fans are common in many countries, there is no evidence of any other coal mine in the world with a main 
fan underground'. (79) 'The abundance of evidence on just this one 'manufactured' and potentially explosive problem at Pike River Mine is very revealing. The location of a fan in an underground coal mine was considered 'unique in the world', (80) 'never seen in an underground coal mine' (81) 'largely untested and unusual', (82) and associated with three main risks: 'First, it is more difficult to re-establish ventilation after an explosion, which could compromise the survival chances of anyone underground. Second, an underground fan is more likely to be damaged by an explosion. Third, an underground fan is closer to explosive material such as methane and coal dust; a malfunction of the fan or its motor can be a source of ignition'. (83) So the question remains why was Pike allowed to put a fan in a contemporary mine?

'New Zealand legislation, at the time, didn't specifically not allow it,' said one senior executive trying to interpret the logic of those running Pike River Mine 'So that was their rational for putting it [the fan] down there anyway: It doesn't say we can't do it. So that must mean we can do it.' (84)

This act of rhetorical recasting (Cerulo 2006) in relation to recreancy (Freudenburg 2013) continued post-Pike tragedy. Gordon Ward, as former general manager of Pike who was CEO of the mine until October 2010, and whose background was in accountancy auditing (not mining) did not return from Australia to attend the Inquiry and chose to make no further comment and neither was he subpoenaed. (85) This was a matter of concern, repeatedly raised in many of my interviews (2011-2016); that this previous general mine manager and CEO had not been called back to New Zealand to stand before the Royal Commission into the November 2010 fatalities.

'I mean it was doomed from day one,' said a member of the Greymouth community in 2012 who had experience of mines in both New Zealand and Australia. 'Look, to a layperson like myself and most others, you wouldn't know that. But properly qualified people - engineers, management - people that were experienced like Gordon Ward and Peter Whittall, they should have known better. They would have known better. There's no question about that... They would have known that Queensland mine safety - and especially Peter Whittall who lived there - It was far different to New Zealand 
safety. And 'best practice' in Queensland dictated a lot of rules that management should have put in place here [in NZ] because it was self regulating to a degree; even though the Labour Department (DoL) were involved. The DoL only checked mines two, three, four times a year. That's hardly on a daily basis.' (86)

So, the risk of catastrophe was often not identified by executive management and it was not reported to the board (87) but neither did they ask for it. At Pike River Mine the board 'did not verify that effective systems were in place and that risk management was effective. (88) It remains perplexing that a board could possibly 'assume' anything in such a hazardous industry. Logically it would be in the best interests of any board of directors to seek out updated information to ascertain the running of a safe and profitable mine. The later argument that the board may have been presented with limited or 'faulty' information still does nothing to belie the fact that, as a board, it was their job to find out, to enquire, to request, to update, to test, to verify the information (or lack of it) in the successful running of a safe mine.

Recreancy (Freudenburg 2013) with its focus on organisation of hazards was not something that the model of accident causation presented to the Royal Commission 2012, could illustrate. How could it? What happened at Pike River Mine was a case of both risk and power affecting practice. The initial structural model describes accident causation as a failure of organisational systems but it could not possibly model the cultural practices and power dynamics driving decision making within those systems.

'And nobody listened,' said a teacher in February 2012 who had taught Joseph Dunbar, the youngest man to die in the tragedy, on his first day of work in the mine, just one day after his $17^{\text {th }}$ birthday. 'And that's the whole thing. Nobody listens [pause] because it's all about the money.' (89)

'They put money ahead of human life,' said another leader of the West Coast 'That's what they did. They put money ahead of human life.' (90) 
What my own findings show (despite the placement of the 100 year embargo on much of the data placed before the Royal Commission) is that many people affected by the Pike River Mine disaster had believed that they were living in an industrial society, when they were really living in the 'risk society' as first described by (Becks, Giddens 1998) where risks were, in fact, allocated them without their agreement. (91)

It is therefore essential to reemphasise here that in analysing what happened at Pike River Mine there is an urgent need to look to the triple helix of fatality causation operating in the New Zealand context of neoliberalism (92),structural secrecy (Kelsey, 1995, 2015; Vaughan 1998), the risk society (Beck, Giddens 1992), and positive asymmetry (Cerulo, 2006). Without an analysis of anticipatory governance (93) in the light of these strands, I argue that Pike River Mine will happen again and is, in fact, already happening in the multiplicity of single workplace fatalities in other industries.

When looking at the fatality causation model of Pike River Mine it is clear to see that this was never a case of a single shot, nor even a series of shots flying through an accidental alignment of holes in an accident causation model. In the case of Pike River Mine, the arrows of fatality zig-zagged and were often redirected by people taking certain deliberate actions with a stunning lack of accountability. There were archers at many levels of the system, redirecting or simply allowing the arrows of causation to continue on their route in the drive to meet financial goals and deadlines and all with an apparent blindness to the developing worst case scenario that favoured production before safety, over lives and families of Pike River Mine.

'Ah, it's a nightmare. It's just a nightmare,' one head teacher told me in February 2012. 'You're a teacher. You know what it's like. You're painting with the kids. Ah, it's just newspaper on the ground. It's just to protect the carpet. Then you have to think No! [It's photos again of the burning Mine]... These kids, they've had such a [pause] hugely traumatic experience.' (94)

'And those people up there in those mines were being paid extraordinarily big money for not looking after our men,' one grieving father told me in July 2012. 'And they murdered them. And that's all there is to it.' (95) 


\section{Endnotes: Chapter 5}

(1) Royal Commission of Inquiry (2012); op. cit., Overview Vol.1 p. 19, para.2. See also Vol.2 13:10, 13:20 'The findings of the Royal Commission show that Pike River Mine had 'a culture that put short-term production before safety'.

(2) 'Dysfunctional and ineffectual' (p. 2, para. 1) Shanks, D. and Meares, Jane. (2013) Pike River Tragedy: Report of the Independent Investigation to the Chief Executive of the Ministry of Business, Innovation and Employment, 14 March 2013.

http://www.mbie.govt.nz/info-services/employment-skills/workplace-health-andsafety-reform/document-and-image-library/Pike-river-independent-investigationreport-mar-2013.pdf An independent report Ministry of Business Innovation and Development (MBIE] admitted that systemic failures at the department of Labour may have contributed to the deaths of 29 men at the mine 2010.

(3) Ibid., re: the 'monitoring of Pike's permit was also proven to have been 'discharged in a light-handed and perfunctionary way. (р. 2, para. 2).

(4) Royal Commission of Inquiry (2012); op. cit., Vol.1 and Vol. 2.

(5) Ibid., Vol.1 p.19, para.2.

(6) Ibid., Vol.2, 13:10.

(7) Royal Commission (2012); op. cit., Vol.2, 5:19. See also John Dow, transcript, pp. 4120-22. Note: 'At the time of the explosion the board comprised John Dow (chairman), Raymond Meyer, Stuart Nattrass, Antony Radford, Dipak Agarwalla and Arun Jagatramka. Gordon Ward was an executive director from July 2006 until 1 October 2010. It appears that none of the directors had underground coal mining experience. Mr Dow's career was in metalliferous mining, Professor Meyer was a mechanical engineer, Mr Radford was the chairman of New Zealand Oil \& Gas (NZOG) and Messrs Agarwalla and Jagatramka were nominees of the Indian shareholder companies, both of which were coke producers. Vol.2, 4:3. 
(8) Ibid., Vol.2, 5:22-23. Note 'The statistical information provided to the board on health and safety comprised mainly of personal injury rates and 'time lost' through accidents... The information gave the board some insight but was not much help in assessing the risks of a catastrophic event faced by high-hazard industries. Pike had not developed more comprehensive measures which would have enabled the board and executive managers to measure what was being done to prevent catastrophes.'

(9) Ibid., Vol.1, p.18, para.6.

(10) Mulholland Interviews, October 2011 M (20.10.11) 6:27.

(11) bid., Oct 2011, February 2012 B (20.10.11) 6:58; (12.2.12 Pt.2) 6:46.

(12) Ibid., Feb 2012 M (12.2.12) Pt2, 15:03.

(13) Ibid., Feb 2012 L (8.2.12) 12:16.

(14) Ibid., July 2012 B (5.7.12) 9:06.

(15) Ibid., Feb 2012 M (12.2.12) Pt2, 6:46.

(16) Ibid., Jan 2015 R (30.1.15) 18:08.

(17) Royal Commission of Inquiry (2012); op. cit., Vol.2, 5:18.

(18) Ibid, Vol.2, 5:18-47. See also Vol.1, p. 17, para. 3: In fact.... Development costs escalated over the $\$ 143$ million figure projected in 2007. Pike required capital and during 2010 it raised $\$ 140$ million from shareholders, and was seeking another $\$ 70$ million as at 19 November and also borrowed $\$ 66$ million from NZOG.

(19) Ibid., Vol.2, 12:27.

(20) Ibid., July $2012 \times(5.7 .12)$ 3:57.

(21) Norgaard, Kari Marie. (2011) Living in Denial: Climate Change, Emotions and Everyday Life, Cambridge, Massachusetts: The MIT Press.

Note: Norgaard (2011) also refers here to Stanley Cohen (p.60) sociologist and criminologist, whose work and definition on types of denial include: 
(1) Literal where the assertion that something did not happen or is not true e.g global warming sceptics.

(2) Interpretive where the facts are not denied, but are instead given a different interpretation [euphemisms, technical jargon and word changing as used to dispute meaning of events e.g military collateral damage vs. killing civilians.

(3) Implicatory where information is not minimised but rather 'the psychological, political or moral implications that follow' $(2001,8)$

(22) Perrow, Charles. (1999) Normal Accidents: Living with High-Risk Technologies, New Jersey: Princeton University Press. p. 4.

(23) Vol. 2, 7:23, 7:46-49; 13:17-19.

(24) Mulholland Interviews, October 2011, BM (20.10.11) Pt.5, 10:32-42.

(25) Ibid., January 2015, Q (30.1.15) 20:46.

(26) Ibid., February 2013, M (14.2.13) 17:27.

(27) Nicholas Davidson, QC, (April 2013) op. cit., 'Pike River: Lessons for Directors and Senior Business Leaders Conference Health \& Safety Forum www.zeroharm.org.nz/leadership/case-studies/pike- river Note: Nicholas Davidson, QC 'represented families at the Pike River Royal Commission. He gave his opinion on how Pike 'never saw it coming' because they failed to ask the right questions, recognise the risks, respond appropriately to warnings'.

(28) Vaughan, D. (1996) The Challenger Launch Decision: Risky Technology, Culture and Deviance at NASA, USA: The University of Chicago Press.

(29) Ibid., (xiv).

(30) Ibid., p. 61.

(31) Chapters (2-4) of this thesis, re: Cerulo, Karen (2006) Never Saw it Coming: Cultural Challenges to Envisioning the Worst, Chicago: University of Chicago Press. 
(32) Royal Commission (2012); op. cit., Vol.2, 7:55. 'There were problems with the investigation process. Many reports were assigned to an investigator but no investigation was completed... Measures to deal with the backlog were unsuccessful. When the backlog was discussed with Mr White in October 2010 he decided that they should be cleared and a fresh start made 'with a new management and a new mine manager'. This meant that the incidents were never properly investigated'. See also Adrian Couchman, transcript pp.3803-04.

(33) Vaughan, D. (1996) op. cit., risk, work group culture and the normalisation of deviance, pp. 117-119; structural secrecy, pp.238-277.

(34) Ibid., p.14, p. 376, p.397.

(35) Royal Commission of Inquiry (2012); op. cit., Vol.2, 5:22.

(36) Ibid., Vol.2, 5:22-23.

(37) Ibid., Vol.1, p.18, para.6.

(38) Ibid., Vol.2, 5:46.

(39) Ibid., Vol.2, 5:26, 5:28.

(40) Mulholland Interviews, October 2011, T (19.10.11) 14:46; See (16:26) Oct, 2011.

(41) Royal Commission (2012) op. cit., Vol.2, 5:22.

(42) Ibid., Vol.2, 5:25.

(43) Ibid., Vol.1, p. 18; para.5.

(44) Ibid., para. 6.

(45) Ibid., Vol.2, 5:27.

(46) Ibid., Vol.1, p. 18; para.4.

(47) Ibid, Vol.2, 8:13. See also, 8:14, 11:47, 15:24.

(48) Ibid., Vo.1, p. 18, governance by the board; para. 2. See pp. 19-21; Vol 2, 14:21. 
(49) Ibid., Vol.2, 5:27... 'The first review was a comprehensive risk survey by Hawcroft Consulting International, commissioned by Pike's insurers. The second was a review of legislative compliance conducted by Minserv International Ltd (Minserv)....In its 2010 report on Pike, Hawcroft repeated its 2009 recommendations that a 'broad- brush' assessment of the operation was needed, in order to develop a risk register and determine core hazards. The report also identified that a number of specific risk assessments were outstanding on such vital matters as windblast, gas ventilation and hydro mining. Hawcroft rated the risk of a methane gas explosion 'possible'. The Hawcroft review also commented on the need for timely and effective action on incident reports'.

Ibid., Vol.2, 5:30-31, 'Mr Dow said that although the board was aware of the review, he had not read the report and the board had neither considered it nor been briefed on it...[Mr Dow] considered the [report] was not, in his view, something that would normally come to the board or its HSE committee. [He] added that the site managers were responsible for bringing the issues they considered important to the board's attention. These people were very competent and the board had every confidence in them. There were plenty of opportunities for site managers to bring safety concerns to his attention in both formal and informal situations and he was surprised that they had not done so.'

(50) Ralph Chivers, ‘Pike River: Lessons for Directors and Senior Business Leaders Conference Health \& Safety Forum, (Christchurch, New Zealand, April 2013). www.zeroharm.org.nz/leadership/case-studies/pike- river (3:25-4:22).

(51) Royal Commission of Inquiry (2012), op. cit., Vol.2, 5:19.

(52) Ralph Chivers, op. cit. 4:05-22.

(53) Nicholas Davidson QC, Kathryn Ryan Radio New Zealand Interview, Ryan (2:12). Nine To Noon (11.4.13) https://www.radionz.co.nz/audio/player?audio id=2551702

(54) Royal Commission of Inquiry (2012), op. cit., Vol.2, 6:6.

(55) Ibid., Vol.2, 3:32. 
(56) Ibid, Vol.2, 8:13. See Note (45) op. cit, Vol 2, 15:24; Vol 2, 11: 47.

(57) Ibid., Vol.2, 5:35, 5:43.

(58) The bonus system and new technology of hydro mining started up in July 2010.

(59) Ibid., Vol. 2, 5:20.

(60) Ibid., Vol.2, 7:16.

(61) Ibid., Vol.2, 10:9.

(62) Ibid, Vol.2, 6:57; 5:20; 7:16; 7:21; 7:46; 7:47; 7:48; 12:88; 15:43-56; 64-65; 82;

3:38 'A vertical ventilation shaft, over $100 \mathrm{~m}$ deep, provided return ventilation and a second means of egress. A second drive was to be established as the mine developed towards the north-west of the licence area'.

(63) Ibid., Vol.2, 3:73; See also Pike River Coal Ltd, Minutes of a Meeting of Directors, 13 September 2010, DAO.007.05996/9.

(64) Ibid., Vol.2, 13:29; See also Douglas White, transcript, p. 1259, 4945.

(65) Ibid., Vol.2, 13:30; S. Ellis, transcript, p, 2228. P. Whittall, transcript, p. 2791.

(66) Ibid., Vol.2, 5:18.

(67) Ibid., Vol.2, 5:42. See also Vol. 2, 5:14-17, 'The risk catastrophe was not identified by executive management and was not reported to the board. The warnings in the Hawcroft reports that risk management needed improvement were not heeded. Similarly, there was no comprehensive response to the Minserv legislative compliance audit. A number of other reports from consultants on safety critical issues, such as methane management and ventilation, were not properly addressed by the time of the tragedy'.

Ibid, Vol.2, 3:32, re: The final investment decision 'These were reflected in a mine plan and financial model ('the joint report') presented to the Pike board in July 2005 by Gordon Ward, the general manager, and Peter Whittall, the mine manager. Mr Ward was an NZOG appointee who, in 1998, assumed responsibility for the Pike 
River project. His background was in accountancy and auditing, not mining. $\mathrm{Mr}$ Whittall, who joined the company from Australia in February 2005, was a mining engineer and experienced in coal mine development and management.

(68) Royal Commission of Inquiry (2012) op. cit., Vol.2, 3:70. Note: David Salisbury witness statement, 25 May2011, NZOG0068/24, para, 95, 147, 151.

For more background to this, see Pike River Coal Ltd, Prospectus, DAO.012.02790/7

'In its 2007 prospectus Pike River anticipated that coal production would begin in the May 2008 quarter, with production of 243,000 tonnes for that calendar year, which would generate a cash flow of $\$ 38$ million at an average sale price of $\$ 157$ per tonne. The first two first two coal shipments were not until February and September 2010, when 20,000 and 22,000 tonnes respectively, were sold for around \$9 million. In October the company announced that its production forecast to June 2011 was downgraded from 620,000 to $320,000-360,000$ tonnes.' Vol. 2, 3:68.

Pike River Coal Ltd, Annual Review 2010, 22 September 2010, DAO.0008.05092/12.

'The company therefore had to raise funds to meet operational and capital costs in each of its last three years of operation. In February 2010 Pike River announced a $\$ 90$ million fundraising initiative. It raised $\$ 10$ million from a share placement in April and $\$ 40$ million from a rights issue in May. By October 2010 capital raised over the pervious three years had increased the number of ordinary shares on issue from 200 million on listing in 2007 to over 405 million'. Vol. 2, 3:69.

(69) Royal Commission of Inquiry (2012) op. cit., Vol.2, 3:71. See also: John Dow, transcript, pp. 3931-32.

(70) Ibid., Vol.1, p. 18, para.5, 6.

(71) Mulholland Interviews, February 2012, XY (7.2.12) 14:16; 14:34.

(72) Ibid., February 2012, JL (8.2.12) 20:51.

(73) The Strongman Mine disaster referred to here, occurred in Runanga, $7 \mathrm{~km}$ north of Greymouth, resulting in the deaths of 19 men in January 1967. 
(74) Mulholland Interviews, February 2012, MT (8.2.12) 20:53- 21:28.

(75) Royal Commission of Inquiry (2012), op. cit., Vol. 2, 5:29

'In its 2010 report on Pike, Hawcroft repeated its 2009 recommendations that a 'broad-brush' risk assessment of the operation was needed in order to develop a risk register and determine core hazards. The report also identified that a number of specific risk assessments were outstanding on such vital matters as windblast, gas ventilation and hydro mining. Hawcroft rated the risk of a methane gas explosion as possible'. The Hawcroft review also commented on the need for timely and effective action on incident reports'.

(76) Royal Commission (2012), op. cit., Vol. 2, 5:30. See also, Vol. 2, 5:31 'Mr Dow added that the site managers were responsible for bringing the issues they considered important to the board's attention. These people were very competent and the board had every confidence in them. There were plenty of opportunities for site managers to bring safety concerns to his attention in both formal and informal situations and he was surprised that they had not done so'.

(77) Mulholland Interviews, January 2015, W (30.1.15) 28:55. See Also Royal Commission (2012) op. cit. Vol.2, 5:30.

See also: Ibid, Vol.2, 3:72 'NZOG reviewed its investment in Pike during 2010...BDA noted that the impression (correct or otherwise) is that there does seem to be more of a focus on the market then the project, and there is a lot of effort being expended on presenting the project to the broking community.'

Vol.2, Ibid, 3:73 'The NZOG had lost confidence in both Pike's Chief Executive officer, Mr Ward and general manager, Mr Whittall, but Mr Dow only recalled the criticism as confined to Mr Ward. On 10 September Mr Ward's resignation was announced. Mr Dow commented on the board minutes that Pike River had in the past consistently overpromised and under delivered. This time it was important that we did a better job of forecasting the production schedule'.

(78) Freudenburg, William. R (2013). A Life in Social Research: 21; Research in Social Problems and Public Policy ed. Susan Maret, UK: Emerald Group Publishing. 
(79) Royal Commission of Inquiry (2012) op. cit. Vol.2, 8:13. See also, Vol.1, p. 19, para. 6. 'Placing a main fan underground in a gassy coal mine was a world first'.

(80) Ibid., Vol.2, 8:13. The Unique placement of fan underground: 'Pike ultimately decided to install its fan underground, with a back-up fan on the surface. That situation is unique. Although underground booster fans are common in many countries, there is no evidence of any other coal mine in the world with a main fan underground'.

(81) Ibid., Vol.2, 15:24. 'This proposal concerned Mr Firmin. He had experience of main fans located underground in hard rock tunnels, but never in an underground coal mine.'

(82) Ibid., Vol.2, 11:47.

(83) Ibid., Vol.2, 8:14

(84) Mulholland Interviews, October 2014, V (2.10.14) 1/02: 52:25.

See also Royal Commission of Inquiry (2012) Vol.2, 8:96-97 'Mr Whittall said a ventilation officer was not required under New Zealand legislation, and not necessary owing to the size of the mine. Mr van Rooyen also raised this matter with Mr White.' The matter was not resolved by 19 November 2001.

(85) Royal Commission (2012) op. cit. Vol.2, 5:3. 'Mr Dow provided the commission with written and oral evidence. [John Dow, transcript, p. 3900.] Antony Radford, a non-executive director, provided written evidence. [Ibid., pp. 3891-4156]. Gordon Ward, an executive director and chief executive, refused to provide written or oral evidence to the commission but had provided evidence to the joint investigation. [Gordon Ward, Police/DOL interview, 29 September 2011, INV.03.28891]. Note also, Mr Ward had been on the board since July 2006 and resigned in September 2010. He moved to Australia where he was effectively beyond the commission's reach.

(86) Mulholland Interviews, February 2012, P (7.2.12) 2:01; 2:24.

(87) Royal Commission of Inquiry (2012), op. cit., Vol. 2, 5:42. 
(88) Ibid., Vol.1, p.18, para.6.

(89) Mulholland Interviews February 2012, HL (8.2.12) Pt.2,12:31.

(90) Ibid, July 2011, NK (18.7.11) 23:51.

(91) This point was brought to my attention by Dr Daina Harvey, associate professor of sociology and anthropology (from Rutgers University, US) on reading this thesis.

(92) See Kelsey, Jane. (1995) The New Zealand Experiment: a world model for structural adjustment? Auckland, N.Z.: Auckland University Press; Bridget Williams Books; And her (2015)The Fire Economy: New Zealand's Reckoning. Wellington, New Zealand : Bridget Williams Books with the New Zealand Law Foundation.

(93) Boston, Jonathan (2017) Safeguarding the Future: Governing in an Uncertain World, Wellington, NZ: Bridget Williams Books Limited.

(94) Mulholland Interviews February, DR (12.2.12) Pt 2, 2:50.

(95) Ibid, July 2012, BM (5.7.12) Pt.5, 5:16. 


\section{Chapter 6 Discussion of Findings}

\section{Uncomfortable Truth No. 6}

Where body counting replaces social and cultural values and excludes us from participating in decisions about the risks that a few have decided the many cannot do without, the issue is not risk, but power. (1)

When we take a deeper look at what happened at Pike River Mine, we find that it was never simply a case of risk but a case of unchallenged power in relation to risk. Neither was this simply an issue of a failure to learn from past mistakes (although that is certainly a part of it); but a failure to see the way power can make us blind to risk, especially in the face of the seemingly unassailable priority of profit. In the last chapters I have discussed positive asymmetry, the culture of silence and denial that grew up around risk at Pike Mine and its climate of 'production before safety' which existed to meet company deadlines with a consistent blind spot for recognising an impending worse case scenario. This culminated in the deaths of 29 men at the mine in 2010 but it has not ended there because the structures of power that lead to this have never been fully confronted, nor its consequence. It is time to talk about that.

'It was quite shocking. We were all just stunned,' said a senior executive working on separate mining project in Australia in 2010. 'We knew about Pike... It was a deep mine. So when there was an explosion there, we already knew in our minds that this was serious. It wasn't going to be no trauma, you know. It was going to be a high trauma event.' (2)

'The stunned silence, you know, was like a hit in the guts,' said a sports leader in Greymouth speaking of his reaction to the news. 'We just stopped. [Then] that sick feeling. It stunned the whole community.' (3)

'Well, I went into more shock... We had seven children without fathers,' said one head teacher in 2012 'And we had ah, our Board Chair, now without his brother-in-law. And also uncles, [pause] brothers. We had three that I'd 
taught previously. And some of the names, an ex-student who used to be here, shifted up; another one of them. I was starting to think, oh my God. Runanga, we're a mining community. And some of ours used to work for Spring Creek were now out there. So, that's how quite a few of them were affected... And I was thinking, I know kids who've got fathers in some of these mines. [I need the names] I don't know which ones are where [to talk to their families]. Oh, it just went from nightmare to nightmare.' (4)

'And I had children whose parents were in management of Pike River,' said another head teacher I interviewed in July 2011. 'I had children whose parents were the miners. And I had children whose parents were (um) involved, the contractors around that. And I also had a number of children whose parents worked for other mines, but they were in the Mine's Rescue. So they were the kids that we were really concerned about too.' (5)

'Just the impact on - everybody,' said a community sports leader, in an earlier interview. 'Nobody was not touched in some way. From the very personal_ parents, brothers, wives, family_ To the next door neighbours; to the people who dealt with them in the shops, to ah_ And it's lingering.' (6)

'And why. And why are they withholding [information]?' one family member who had lost his brother in the tragedy asked me in July 2011. 'Shouldn't we all be on the same page trying to, you know? (7)

Pike River Mine was a case of deliberate risk and hibernating beneath that risk was (and still can be) a case of unchecked power. The issue to analyse in this frame is that 'problematisation' has been constructed and constrained by those in power. The James Reason Model of Accident Causation (8) was a good introduction to how accidents can occur in the workplace, but as previously cited, the evidence also indicates that the flaws in all four 'safety defence' levels of Pike River Mine were so numerous, gaping and 'riddled with holes' that in the end, this causation model was said to resemble 'Swiss Cheese' with virtually no defences left to the standing model. The work begun by Dr Callaghan (9) started a much needed conversation around the 
findings of the commission, which continues to be an invaluable contribution for the creation of safer workplace environments in New Zealand. But it cannot end there.

The problem is, seven years after the 2010 disaster we continue to focus on traditional risk prevention models; the very models that were willingly violated at Pike River Mine. Given the findings of the Royal Commission (10) we urgently need to move forward from just examining 'accident causation' and take a good look at 'fatality causation' instead. What was initially used to describe the tragedy of Pike was a good structural model at the time, but it does not take into account organised cultures, nor the power dynamics involved. The narrative needs to shift from 'risk' to 'power' in order to explain further what happened at the mine and how this might still contribute to workplace deaths in other hazardous industries in New Zealand.

At Pike River Mine there were many arrows (representing decisions guided by specific cultural practices) fired out constantly from the archers' bow (this culture of positive asymmetry). (11) Each was accompanied by a variety of eclipsing, clouding and recasting practices, and all driven on trajectories through flaws in the model of workplace risk and production in order to meet almost impossible financial targets.

Given these findings, a tragedy was inevitable unless the mine was closed and these 'arrows' diverted. This did not happen. In fact, in analysing a sample of these primary arrows (or pathways of dysfunctional decision) we see they were driven on separate but interconnected trajectories into the model of the mine. I argue that if any one of these arrows had been intersected in the months or even in the weeks leading up to November 2010, it is likely that the fatalities at the mine could have been averted, and if we continue to analyse workplace fatalities in terms of risk and never look at the dynamics of power, then there will be more 'Pikes' to come.

In my interviews (2011-2016) there was often reference to what was perceived by many as empty and broken promises in relation to Pike River Mine on the part of government and systems. In later years, I began to hear the occasional comment, spoken with a certain resignation from interviewees '-Just let it never happen again.' 
Many more participants, however, were quick to add that 'it is already happening again' in the refusal to allow re-entry of the Pike drift, i.e (the entry tunnel vs. the mine proper) - which has long been proven safe by international experts - to make just one attempt to bring the long entombed men 'back home' along with any latent forensic evidence; providing at the very least, some chance of closure for families.

This refusal to re-enter the drift of the mine is of course another example of eclipsing practice, as were those mentioned in earlier chapters of bullying at the mine or in that of the blatant refusal of a previous CEO to come back to New Zealand to testify before the Royal Commission at all. (12) Over the weeks and months that followed the 29 fatalities at the mine, interviewees began to express their frustration.

'Look, I've had enough of his experts,' a grieving father told me in 2012, on recounting his meeting with the then, prime minister, John Key. 'I stopped him in his tracks. And I said 'John, your experts blew the mine up another three times after the first explosion. So let's step away from your experts.' (13)

It is vital to make connections with available evidence of the Royal Commission that has not been embargoed for the next 100 years (14) (which was in itself, yet another recasting practice) and use the interviews we do have, alongside the original model of fatality causation in order to address the gaps or silences (Bacchi 2009) that it could not speak to, if we are ever going to learn from this and not repeat mistakes.

The Bacchi (WPR) approach to analysis (15) which I first introduced in (Chapter 2) of this thesis has been an invaluable tool in my own investigation in this respect, as it has helped 'direct attention to the ways in which particular representations play a central role in how these problems are also represented by those in power and how we are eventually governed'. (16) It is a loud silence and a crucial gap in any chance of coming up with authentic solutions because how the problem is constituted really does matter. 'This is because the way in which the 'problem' is represented carries all sorts of implications for how the issue is thought about and for how the people involved are treated, and are evoked to think about themselves.' (17) It also obviously 
matters in the creation of viable, long term solutions. Bacchi (2009) states, for example, that her (WPR) approach rests on three key propositions:

(1) We are governed by problematisations

(2) We need to study problematisations through analysing the problem representations they contain, rather than their problems

(3) We need to problematise (interrogate) the problem representations on offer, through scrutinising (18)

I argue as cited, that in problematising the Pike River Mine disaster the Royal Commission of Inquiry focused on what happened in terms of risk and not power. In chapters (3-5) I gave many examples of how it successfully proved that there was an inordinate amount of risk-taking at every tier of the system and concluded there was a 'culture of production before safety' at the mine (19). The Royal Commission did an excellent job of 'problematising' risk, but it chose not to problematise 'power' (Perrow 1999) or 'recreancy' (Freudenburg, 2013) and it definitely could not problematise the concept of 'positive asymmetry' (Cerulo 2006) nor related issues of doing [and not doing] the same things over and over again expecting a different result. (Vaughan, 1996; Norgaard, 2011). My argument is simple, if we fail to ask the right questions in problem solving, we will continue to make the same fatal mistakes.

One of the many silences with regard to 'gaps in knowledge' (Bacchi 2009) in relation to the case of Pike River Mine (post-tragedy) regards the aforementioned '100 year embargo' placed on many of the witness transcripts gathered up by the Royal Commission. This fact was revisited by Dr Felicity Lamm (20), the associate professor, co-director of the Centre for Occupational Health \& Safety Research, Auckland University of Technology (AUT) New Zealand when she said, in May 2017:

It is difficult, if not impossible to gain access to the thousands of documents gathered by the Royal Commission of Inquiry into the Tragedy. The reason for the one hundred year embargo is outlined in an email from the Department of Internal Affairs Te Tari Taiwhenua: 
Access restrictions of 100 years have been placed on submissions and evidence to protect personal privacy as well as to maintain implied and existing undertakings in relation to confidentiality.

'Families and friends of the deceased have reason to feel thwarted in their attempt to understand what really happened at Pike River Mine,' she said 'The Royal Commission answered a number, but not all the questions. The [omission] did not determine the 'immediate cause' of the first explosion primarily because they were unable to enter the mine. And yet now when the drift to the mine can be accessed, the owners are seeking to seal it.' (21)

This crucial detail of the 100 year embargo seems to have been so clouded and recast by the powers-that-be, that most New Zealanders seem to be unaware of it. Practices of silencing and eclipsing are also still occurring with regard to the need to re-enter the drift of Pike Mine and I argue we still continue to have workplace fatalities due to underlying dynamics of power in other New Zealand industries (22)

One example of this can be found in the writing of Te Aniwa Hurihanganui, Te Manu Korihi Reporter, who in noticing that five forestry workers had been killed JanuaryAugust 2017, decided to write about the most recent death of a young forestry worker who was the second in the family to die in that industry within the year, making 2017 the 'deadliest year' for workplace fatalities since 2013.

The death of a 23-year-old worker has brought the number of forestry fatalities to five, this year (2017) the deadliest year since 2013.

Te Oho Mauri Piripi Bartlett died in a forest in the Mangatokerau area in Gisborne last week. He is the second member of his family to have been killed at work in the forestry industry in a year. His relative, Niko BrookingHodgson, 24, died in August 2016.

Family spokesperson Willie Waitoa told media last week the whānau was in shock and the latest death was heartbreaking. Council of Trade Unions president, Richard Wagstaff said the government needed to address why 
safety standards were still not being met. He said the approved code of practice for safety and health in the industry had never been fit for purpose.

'It needs to be updated, made sense of, more practical, and needs to deal with the issue of fatigue. It doesn't. Why haven't we got improved codes of practice that we've been asking for ages? Why isn't there a greater presence of WorkSafe inspectors in the industry?'

He said more trees were expected to be felled in 2018. Employers and the industry were not ready to meet this demand. The Minister of Workplace Relations and Safety, Michael Woodhouse, said in a statement it was not possible for the approved code of practice to cover every possible scenario.' (23)

The 'approved code of practice' appears to be failing us. In following the analysis of [Norgaard 2011] I argue it seems that our own brand of socially organised denial in which individuals 'collectively distance themselves from information because of the norms of emotion, conversation and attention via existing strategies in process' (24), is killing us in the drive to meet production targets in the New Zealand workplace.

After the publication of the commission's findings, Dr Callaghan (25) and her team ran seminars around the country where they tried to educate leaders as to their need to be more vigilant about risk. But it cannot end there. Neither should it be the job of a few, to do the job of many. As New Zealanders, we all need to be an active part of challenging the culture of silence and denial when we see it occurring in industry, but this also presupposes that we all have the power of voice to do so on an equal basis in our workplaces, which often still operate on the edges of neoliberlism. (26)

The argument remains - how to make the right connection? Following (Bacchi, 2009) we might [again] start with the way we tend to 'problematise' things. (27) Due to all sorts of limitations, the Royal Commission of Inquiry problematised what happened at Pike Mine in a way that was only ever going to come up with certain conclusions. It is time to challenge that. With further analysis it seems that this 'model of risk' still operating post-Pike, within a New Zealand context does not work on three levels: 
It does not work at the level of government structures which have already proven in the New Zealand context that systems can simply 'move the picture about' posttragedy and 'morph' (Chapter 4) into a new organisation; encouraging re-structuring, redundancy, and then with a new name, apologise for that 'former' organisation's apparent past 'inconsistencies', thereby absolving all past responsibility. (28)

This, at systems level, is not much different from what a senior manager at Pike River Mine did at a cultural level when he wiped all former reports of unresolved incidents at the mine in the name of a 'new start'. (29) In both cases, this was not merely an act of eclipsing or clouding but an entire recasting practice, processed in the name of 'new beginnings'. It is an indication of just how entrenched the culture of denial and positive asymmetry (Cerulo 2006) can be in our workplaces, particularly when enhanced by recreancy (30) (Freudenburg 2013) and in a culture of neoliberalism.

Levels of denial (Cohen 2001) in a climate of action vs. inaction were also enhanced via continued eclipsing, clouding and recasting practices (31) (Cerulo 2006). These still wipe out a lot of potential to learn from past mistakes. There is a need to further analyse links between cognition and emotion (Norgaard 2011) in order to identify 'those processes by which individuals still collectively distance themselves from information via norms of emotion, conversation and attention' (32). We must look not only to the socially organised denial but to power and to the risk society (Beck, 1999), the interactive complexity of systems (33) (Perrow, 1999) to the normalisation of technical deviance (34) and to the social organisation of mistake (Vaughan, 1996).

The original model of risk does not work too well either, at the second level of industry. Given that capitalism is predicated on risk, it will often encourage the notion that risk is acceptable in deregulated systems, and to the point that some industries silently draw from actuarial models like that of the Ford Pinto Case; (35) whereby the potential for fatality is figured into some industry budgets in terms of potential post-death payouts vs. the profit of continued production i.e sometimes the 'continuation' of potentially hazardous production with the chance of the 'occasional fatality' is considered by some deregulated companies as 'worth the financial risk'.(36) 
As long as risk is defined by the parameters of this structural model, whole systems can get away with fatalities in the workplace. So this particular 'model of risk' does not work out too well either, at the third level of 'the worker'. There is, of course, a certain amount of risk built into any hazardous industry. (37) We live in a 'risk society'. (Beck, Giddens, 1992; Rosa, Renn, McCright, 2014). But the fact that Pike River Mine encouraged risk to the levels it did (as is documented by the Royal Commission) (38) in an industry already known to be hazardous, and then further encouraged competitive risk with the introduction of hydro mining and a bonus system in the drive to meet production deadlines (39) simply defies belief, no matter how entire systems in New Zealand try to rearrange the model to suit themselves, post-tragedy.

Certain systems were deeply invested in Pike River Mine from the beginning, networking to government levels. Yet there is no place to represent this adequately on the traditional model of 'accident' causation. In recruiting employees, Pike also implied it would have the latest methods, machinery and tool box talks; but there was no way for the average worker to verify these would not be well suited to the terrain and conditions of a very gassy, faulted mine. (40) The men went into the mine on trust that it would run to modern conditions; that they would come home safely. They trusted in what they thought was a contemporary industrial society, but what they worked in was, in fact, the 'risk society' (Beck, Giddens, 1992, 1998) in which the drive for profit, meant risks would be allocated to them without agreement. (41)

Surely it is in the interests of everyone to run a safe workplace, but the case of Pike is one in which, short-term profit seems to have been placed ahead of sustainable growth, and definitely well ahead of protecting the most essential part of that growth - the miners and contractors, themselves. There was no accountability for the loss of 29 lives on 19 November 2010 and as a result of that, I argue that the potential for continued 'structural secrecy' (Vaughan 1996) surrounding this case might also encourage other industries operating in this country to take 'short cuts' if they ever find themselves up against the financial wall that Pike River Mine did in a culture of positive asymmetry, recreancy, denial; all fostered in the drive for profit. 
Aspects of denial, recreancy and positive asymmetry are also visible, although often silenced (intentionally or otherwise) by lack of action at other tiers of the system. When looking to recent statistics of workplace fatalities, for example, Dr Rebecca Lilley of the University of Otago speaks to her own findings in June 2016:

Efforts to reduce New Zealand's 'appalling' death toll from workplace injuries are being handicapped by inadequate statistics.... The reported death rate from workplace injuries was 'appalling' and [have] to be addressed...

Shortcomings in current information on work-related fatal injuries are a significant barrier to reducing workplace death... Statistics showed New Zealand workplaces were unsafe when compared to workplaces in the UK, Australia and many other OECD nations.

'The reported death rate from workplace injuries is 'appalling' and had to be addressed,' she said. 'Every year, one in 10 workers was injured at work in New Zealand. Most recent estimates indicated more than 100,000 workers required time off work, 12,000 were permanently disabled and 105 were killed every year from work-related injuries'. (42)

Less than a year later Paloma Migone, Wellington Bureau Chief at Radio NZ, reported with reference to forestry, farming and construction industries and said in April 2017

Seven people have died in workplace accidents in the past fortnight, and Worksafe says a culture change is needed. There were just ten fatalities in the first three months of [this] year, but an average of about one a week for the past few years. Worksafe chief executive Nicole Rosie said the upward trend was 'really concerning and some families were now without a father, son or mother'. She said the deaths occurred in the high risk sectors: forestry, farming and construction... 'Yes, as a regulator we have new tools, but ultimately, it does require a culture change...' said Ms Rosie. (43)

I also argue that once national and international corporate cultures have witnessed a government shift whole systems completely around with no apparent consequence, 
post-Pike disaster, then the doors are flung wide open for other industries to also think that they too, can profit in deregulated system without much consequence and with less regard for a potential loss of lives in the course of their own production.

The drive for profit in a deregulated industry might also imply less urgency for well trained personnel in the workplace. Experts can be the pebble in the shoe of any deregulated industry, and so too can be any worker with a voice. In a culture of positive asymmetry (Cerulo 2006) and recreancy (Freudenburg, 2013) where risk is happening faster than the reduction of risk (Perrow 1999) and denied via the norms of culture, conversation and emotion (Norgaard, 1911) technical deviance occurs, then reoccurs until the power of structure and the structure of power coincide within the social organised mistake. (Vaughan, 1996) Anomalies are no longer questioned; sometimes not even identified (Vaughan 1996) and with increased couplings of interactive complexity (Perrow, 1999) any worker might now doubt their own perceptions of an approaching worst case scenario in confused silence.

'The voice of the workers...,' said one head teacher who had taught Joseph Dunbar, the youngest to be killed at Pike River, and who in having turned seventeen the night before, walked into the mine to die on his first day of work. 'The voice of the workers - If they had [allowed voice] in there, those miners who were concerned about safety issues with the mine, they would've been heard. And that would've been made loud and clear. The whole process would've stopped till these things were addressed.' (44)

On looking to issues of power in these primary systems it is not difficult to see that the original model of 'accident causation' does not work so well at the level of government structures, industry or worker. The problem once again is, as long as risk is defined within its parameters it allows everyone to slip away at the level of accountability which can only inevitably backfire on all three levels. An unintended consequence of this might be, the quiet confidence growing within the culture of other industries in this country to consider that a 'push for profit' might still be 'worth the gamble' of additional risk in the workplace on occasion to meet certain goals; given there were absolutely no prosecutions for the 29 fatalities at Pike Mine. 
This also allowed others to leave New Zealand with tickets and reputations intact to potentially go out and repeat the same mistakes in any other part of the world.

'And... what frustrates me is he [a senior manager] is heading to Canada,' said one family member in July 2012. 'People like him - Their [professional] tickets should be stripped off them forever.' (45)

'And the mine managers,' said a family member in 2013 'Why aren't they having a stand-down period? [But] what have they done? [One] has gone to Canada. He's gonna be the highfalutin manager in gold mining over there' 'We've got [another one back] running mines in Australia. We've probably got [another] going back to run things over there. So, why aren't they [stopped]? Look, let's face it. I'm a hotelier_If I drove down the road and killed somebody, my days as a hotelier would be over.' (46)

So when looking to 'problematisation' (Bacchi 2009) it might be of value to dig a little deeper to unpack the investigation of cause and ask why it was, that while so many were 'problem solving' in the case of production at Pike, so many were doing so little of the 'problem questioning' regarding human risk vs. power and cultures of silence. There remain many unanswered questions. Why, for example, was the mine not closed down, while the incidents were investigated, as would have happened in an Australian mine? Why was a mine allowed to continue to operate in such a state that it was precariously struggling for finances up to the day before the mine exploded (47)

Why also, was the evidence of others, among them Mr Greg Borichevsky; (48) a mining engineer and the most senior member of the technical services department, silenced from the Inquiry? (49) It is not within the scope of this dissertation to answer all these questions but it is to enquire why so few of these were not asked in the first place.

Right from the start the problem of what happened at Pike Mine was constructed in a certain way, which meant we were only ever going to get certain solutions. But if we were to construct it in another way, what conclusions would we then reach? 
'I think it's very clear what we need to have come out of the Inquiry,' one head teacher told me in Greymouth in 2012 'And that is for this not to happen again ...I'm old enough to remember the Strongman Mine Disaster (50) And I taught a child who lost his father in Strongman. So this is the second time round...There have been several other [disasters here] (51) And it's so amazing, when we're such a high tech society,' she said 'And when we have to go through so many hoops to take our children on a field trip because of safety, which I never complain about ... But we are so safety conscious. And people are saying we are now Risk Averse. We've wrapped everyone up in cotton wool. And yet, once again, 29 people can be killed when they go off to work in the morning. And it just happened again. (52)

This serves to illustrate the recognition that beneath all the analysis of repetitive risk are some questions that urgently need to be asked again about power. Here we have a traumatised community struggling to come to terms with both the loss of their men, and betrayal. They thought they had been living in an industrial society, when in fact, they had been living in the 'risk society' (Beck, Giddens 1992) where risk had been allocated to them without agreement. (53) And not for the first time. (54)

It could also be argued that aspects of denial (Norgaard 2011), structural secrecy (Vaughan 1996) and positive asymmetry (Cerulo 2006) still continue post-Pike, with regard to workplace fatalities that some industries are not directly reporting as such. When interviewed by the Otago Daily Times in June 2016, Dr Rebecca Lilley of the University of Otago referred to the continued difficulty of gathering evidence.

If all workplace injury deaths were recorded....the [New Zealand] death toll would be about 200 a year... Some deaths, such as those involving professional truck drivers [are] not always being recorded as workplace fatalities, and other related road deaths were also not always being picked up... After the Pike River Mine disaster, the reasons for New Zealand's 'poor performance' in workplace safety had been 'highly debated' but in-depth analysis was 'limited by a dearth of detailed work-related fatal injury data'. (55) 
Despite the implementation of many of the recommendations of the Royal Commission and all the work that went into the new Health and Safety legislation which came as a direct result of Pike in April 2016, there are continued difficulties:

'Sweeping changes to health and safety laws have so far done little to curb the country's high workplace death toll,' said senior political reporter, Ms Demelza Leslie, in November 2016 'In the year to date, 43 people have died at work - the same number for all of 2015.' (56)

When also interviewed by Ms Demelza Leslie, in November 2016, Mr Gordon MacDonald, CEO of NZ Worksafe stated that [better workplace practice] 'involved a widespread change in behaviour, systems and culture. We're talking about all of that coming from a particularly low base, where New Zealand was in some respects, twice as bad as Australia in terms of its stats and three times as bad as the UK.' (57)

'A controversial aspect of the new regulations is, they do not classify agriculture as a high risk sector, meaning farm workers are not entitled to health and safety representatives', which Ms Leslie stated, at the time of writing her article, 15 of the 43 fatalities so far that year (2016) had been in that industry. It is also disturbing that deaths related to agriculture became the highest that year. (58)

There have been some brave, encouraging developments in the face of this, though. Things can and are changing. There are researchers here in New Zealand working to understand the work related injuries and fatalities, and contribute to creating safer workplaces and practice. Dr Rebbecca Lilley of the Injury Prevention Unit, at the Department of Preventative medicine of the University of Otago emailed me news of a major piece of work she and a colleague will have published by the end of 2018 .

'We have a study currently funded by the Health Research Council examining patterns of Work-related Fatal Injury in New Zealand using Coronial case files. All sudden and unexpected deaths are referred to a Coroner to examine the cause and circumstances of the fatality event in order to prevent further similar fatalities. We are applying our own definition of work-relatedness (much broader than the legislative definition) to all the injury-related deaths 
for the last 40 years and will be able to look at trends in work deaths over this period. It will be the most comprehensive data on work-related fatal injuries in NZ and the most complete dataset internationally. We plan to have the data ready by the end of this year (2018) as it takes quite some time to review over 1,000 annual injury deaths'. (59)

Similarly, in a determined effort for progress, Andrew Little, Minister of Justice, for Courts, Treaty of Waitangi negotiations, and leader of the opposition (Nov 2014 Aug 2017) fought for a charge of corporate manslaughter for the deaths at Pike River Mine, by introducing a bill to parliament in 2012 to amend the NZ Crimes Act 1961.

Andrew Little's proposed Crimes (Corporate Manslaughter) Amendment Bill 2012 was written to deter and respond to events like Pike River Mine. The amendment would have allowed companies to be charged with corporate manslaughter in cases of workplace deaths caused by failures at board and senior management level.

Under this amendment bill a company or organisation would also have been fined up to $\$ 10$ million, with directors or senior managers receiving a prison term for up to ten years for corporate failure and there would have been a requirement for the conviction to be publicised in the annual report of that company or organisation.

Although Andrew Little's Crimes (Corporate Manslaughter) Amendment Bill 2012 was not passed, the Health and Safety in Employment Amendment Act 2013, the Mines Rescue Act 2013, and the Worksafe New Zealand Act 2013, all soon followed. They were direct responses to safety in the workplace after the Pike Mine tragedy. They all began as the Health and Safety (Pike Mine Implementation) Bill with some of Mr Little's proposals later implemented in the Health and Safety at Work Act 2015.

Looking to Health and Safety (Pike River Implementation) Bill there were, for example, developments that would be relevant to specialists in mining and energy law and to all working in health and safety with the development of the Crown entity Worksafe New Zealand. It was from this that the Ministry of Business, Innovation 
and Employment (MBIE) developed its aim to 'promote and contribute to the prevention of harm to all people at work and in the vicinity of the workplace'. (60)

This (2013) Act also included the possible introduction of the crime of corporate manslaughter and reflected some of the recommendations of the government's Independent Taskforce on Workplace Health and Safety which found that New Zealand's (then) current health and safety system 'was not fit for purpose' (61)

The bill was initially presented in three parts. There was the proposed development of Worksafe NZ. Part 2 made some much needed mining-related amendments to the Health and Safety in Employment Act 1992 (HSEA); Part 3 created the Mines Rescue Act 2013; which was to 'provide for the Mines Rescue Trust Board and its role in responding to, and ensuring capacity, readiness to respond to emergencies and certain mining operations' while 'provid[ing] for an effective and co-ordinated response in the even of an emergency at an underground operation.' (62)

The main objective of WorkSafe New Zealand was to be one of 'promoting and contributing to a balanced framework for securing the health and safety of workers and workplace'. The Act of 2013 also states that 'When performing its functions under the relevant health and safety legislation, WorkSafe New Zealand must act in a way that furthers any relevant objectives or purposes stated in that legislation'. (63) Among its functions Worksafe NZ must develop codes of practice, monitor and enforce compliance with relevant health and safety legislation; promote and support research, education, and training in work health and safety, and collect, analyse, and publish statistics and other information relating to work health and safety.

The Mines Rescue Act 2013 which repealed the earlier Mines Recuse Trust Act 1992 also stated 'The Mines Rescue Act 2012 will better elaborate the functions of the Mines Rescue Trust in relation to its emergency activities and will extend the reach of the Mines Rescue Service. It will enable the funding levy to be set by regulation and hence be changed as the need arises'. (64) 
The 2013 regulations included a swathe of stricter certification requirements. In the past, usually only a mine manager, and perhaps their deputy, would need a certificate of competence. Now these are compulsory down to supervisory level. Applicants need to pass unit standards and go before a board of examiners to get accredited. (65)

These acts and amendments were designed to encourage and strengthen employee participation with regard to health and safety in the New Zealand workplace. It was also hoped that these changes would encourage inspectors to take preventative action 'if they have a reasonable belief that a mine operator is likely to fail to comply with the act or regulations via the issuing of improvement and prohibition notices' (66) Once again, the amendments followed Andrew Little's initial bill in a push for proactive management vs. reactive responses after something has gone wrong.

When the Health and Safety at Work Act was passed in 2015, there was also an increase in penalties companies and organisations would be fined if they did not maintain standards. This legislation replaced the Health and Safety in Employment Act 1992 (HSE Act) and the law imposed a maximum fine of \$3 million and a term of up to five years imprisonment if they fail to comply with individual obligations.

There are, however, a number of unresolved issues to be identified and confronted.

When the select committee reported back to parliament on the Health and Safety Reform Bill in 2015, it identified the increased penalties available under the new law as sufficient to ensure employers would meet their duty of care and that a corporate manslaughter offence was, therefore, unnecessary. Hence, there is still no serious criminal sanction for workrelated death at the hands of corporations. (67)

There was a lack of accountability regarding the case of Pike River Mine and there remains a risk of this being a recurrent theme in Aotearoa/ New Zealand context. This is disturbing in any context, for what really happened at Pike Mine reflects structurally embedded conditions within industry that are still being ignored and as 
such, another disaster like that of Pike could happen again, despite all the good legislation that has since passed. Indeed, it could be argued it is happening already in the multiplicity of single workplace fatalities in other New Zealand industries. Not only was no one held accountable for the fatalities at Pike River Mine but the 29 men remain entombed together with any latent evidence that might assist further Inquiry. Although a number of mining experts, including Mines Search and Rescue argued for sealing of the mine in the days and weeks following the deaths, they were ignored and the mine went on to explode another three times before it was sealed.

There definitely has been improvement to health and safety in the New Zealand workplace since the passing of the Health and Safety Act 2015 but no one has been prosecuted (so far) for any of the workplace fatalities that have followed in the eight years since Pike and with the 'highest fine to date [being] $\$ 504,000$. It is arguable that current penalties provide a sufficient incentive for good behaviour'. (68) Below is the draft for consultation which was debated in parliament, but never passed.

DRAFT FOR CONSULTATION

\section{Crimes (Corporate Manslaughter) Amendment Bill}

Member's Bill

Explanatory note

\section{General policy statement}

The purpose of this Bill is to add the offence of corporate manslaughter to the Crimes Act 1961. Corporate manslaughter is culpable homicide when committed by a body corporate. It will be a charge that is appropriate to situations where the actions or omissions of the directors or senior managers of a body corporate cause a person's death when those actions or omissions amount to a gross breach of a relevant duty of care owed by the organisation to the deceased. The introduction of this charge remedies a gap that currently exists in New Zealand law, as demonstrated by the Pike River Mine tragedy. 


\section{Clause by clause analysis}

Clause 1 is the Title clause.

Clause 2 is the commencement clause. It provides that the Bill comes into force 1 year after the date on which it receives the Royal assent.

Clause 3 provides that the Bill amends the Crimes Act 1961 (the principal Act).

Clause 4 is the purpose clause.

Clause 5 inserts new sections 177A to 177C.

Andrew Little

\section{Crimes (Corporate Manslaughter)}

\section{Amendment Bill}

Member's Bill

\section{Contents}

1 Title 1

2 Commencement 1

3 Principal Act 2

4 Purpose 2

5 New sections 177A to 177C inserted 2

177A Corporate manslaughter 2

177B Public policy decisions, exclusively public

functions, and statutory inspections $\quad 4$

177C Inclusions 4 
The Parliament of New Zealand enacts as follows:

1 Title

This Act is the Crimes (Corporate Manslaughter) Amendment Act 2012.

\section{Commencement}

This Act comes into force 1 year after the date on which it receives the Royal assent.

\section{Principal Act}

This Act amends the Crimes Act1961 (the principal Act).

4 Purpose The purpose of this Act is to create a new offence of corporate manslaughter, which is culpable homicide committed by a body corporate.

\section{New sections 177A to $177 \mathrm{C}$ inserted}

After section 177, insert:

\section{“177A Corporate manslaughter}

“(1) An organisation to which this section applies is guilty of an offence if the way in which any of its activities are managed or organised by its senior managers-

“(a) causes a person's death; and

“(b) amounts to a gross breach of a relevant duty of care owed by the organisation to the deceased.

“(2) The organisations to which this section applies are-

“(a) a company, including a State-owned enterprise; and

"(b) a firm, partnership, or body corporate carrying out functions intended to return revenue to the body corporate or to its partners or members; and

“(c) a public authority, including-

“(i) a department of the Public Service listed in 
Schedule 1 of the State Sector Act 1988:

“(ii) a Crown entity listed in Schedule 1 or 2 of the Crown Entities Act 2004:

"(iii) the New Zealand Defence Force:

"(iv) the New Zealand Police:

"(v) the New Zealand Security Intelligence Service:

"(vi) the Government Communications Security Bureau:

"(vii) the Parliamentary Counsel Office:

"(viii) the Office of the Clerk of the House of Representatives:

“(ix) the Parliamentary Service:

“( $x)$ the Reserve Bank of New Zealand:

“(xi) any Office of Parliament:

“(xii) any local authority, council organisation, or council-controlled organisation within the meaning of the Local Government Act 2002

“(3) For the purposes of this section,-

“(a) a person is a senior manager of an organisation if he or she is a director or a committee member of a body corporate or plays a significant role in-

“(i) the making of decisions about how the whole or a substantial part of its activities are to be managed or organised; or

“(ii) the actual managing or organising of the whole or a substantial part of those activities; and

"(b) relevant duty of care means any duty of care which, but for the accident compensation system, may be said to exist as a matter of law whether the law of negligence or any other law; and 
“(c) a breach of a duty of care by an organisation is a gross breach if the conduct alleged to amount to a breach of that duty falls far below what can reasonably be expected of the organisation in the circumstances

“(4) An organisation that is guilty of corporate manslaughter is liable on conviction on indictment to a fine not exceeding $\$ 10$ million.

“(5) Any senior manager whose acts or omissions contributed materially to the elements of an offence leading to the conviction under this section of a organisation is liable to a sentence of imprisonment not exceeding 10 years

“(6) Without limiting subsections (4) or (5), an order, to be known as a publicity order may be made on the conviction under this section of an organisation requiring the organisation to publicise in a specified manner-

“(a) the fact that it has been convicted of the offence; and

“(b) specified particulars of the offence, including the names and position descriptions of any senior managers convicted under subsection (5);

“(c) and the amount of any fine imposed on the organisation and any term of imprisonment imposed on any individual; and

“(d) any other matter that the court considers just in the circumstances.

“(7) A publicity order made under subsection (6)-

“(a) must specify a period within which the order must be complied with;

“(b) and may specify the manner and form of publication, including whether publication should be in the organisation's statutory or other annual report.

Andrew Little_Consultation draft 
"177B Public policy decisions, exclusively public functions, and statutory inspections

“(1) Any duty of care owed by a public authority in respect of a decision as to matters of public policy (including, in particular, the allocation of public resources or the weighing of competing public interests) is not a relevant duty of care. '

“(2) Any duty of care owed in respect of things done in the exercise of an exclusively public function is not a relevant duty of care unless the duty of care arises through the public authority being an owner of premises or other property, or an occupier of premises.

“(3) In this section,-

"exclusively public function means a function that falls within the prerogative of the Crown or is, by its nature, exercisable only with authority conferred-

“(a) by the exercise of that prerogative; or

"(b) by or under a statutory provision

"statutory function means a function conferred by or under a statutory provision.

\section{"177C Inclusions}

“(1) For the avoidance of doubt, a person and a body corporate can both be guilty of appropriate applicable offences in respect of the same acts or omissions and the guilt or innocence of one does not affect, and is irrelevant to, the guilt or innocence of the other.

"(2) A person cannot be guilty of aiding and abetting an offence under section 177A." 


\section{Revisiting the Model of Workplace Fatality Causation}

It is time to reinterpret and develop the original model of accident causation. All the findings indicate that there were a multitude of actions behind the archers of primary arrows (dysfunctional decisions) which were driven out on trajectories via a culture that normalised them in the drive to meet production and financial targets and which struck the original model so repetitively (with little or no diversion) that in the end, there was little or nothing left to any line of defence to protect the workers

We have not yet got the question right. It appears we have left the framework askew when it comes to problematisation (Bacchi, 2009). Perhaps it is a matter of examining our own interrogation processes first. We can not, afterall, fix something with the same thinking that put us there in the first place. There is an urgent need to look at our own behaviours around power and risk to make a difference, and we certainly need to look at our behaviours around investigating it. We must challenge our own silences also with regard to workplace fatalities at Pike River Mine and those that continue in other industries developing and operating in this country.

In discussing what Pike River Mine was really a case of, I hope to open up a whole new conversation to spur others into collectively creating dialogue and actionreflection praxis (69) around health and safety, using the language and experience of many cultures in the workplace for visible and authentic change. I make a beginning on this by breaking down my own findings and those of the Royal Commission so that we can look anew at problematisation, problem questioning, problem solving and building authentic cultural and systemic models that really do provide enduring solutions in an Aotearoa/New Zealand context. This may initially seem to be a small start, but it could by the 'hundredth monkey' (70) that creates a very significant one; begun in the hope that others will come forward to add to it, their own experience, strength and hope to a more relevant and constructive model of new beginnings.

So in referring back to the heuristic problem-questioning device presented by Bacchi in her own work (71) I will continue to ask questions, re: the problematisation of Pike 
River Mine as follows: 'What is left unproblematic in this problem representation? Where are the silences? Can the problem be thought about differently? (72)

We need to start the process by realising the James Reason Model of causation is a structural model and as such illustrates well, accident causation as a failure of organizational systems but it cannot possibly model cultural logics/power dynamics driving decision-makers within the systems. This is a very significant silence.

There has also been a failure to make connections between systems of power in the face of risk, production, and the pressure to make profit in the workplace with regard to neoliberalism and recreancy. What happened at Pike River Mine occurred because there was agency in the culture of the mine, and in the systems which allowed it. Connection needs to be made between what was said by presenting the original model and the gaps or silences it could not speak to. This is particularly difficult, as already cited, when there has been a one hundred year embargo placed on many of the transcripts of its own investigation. (73) It was not within the scope of the Royal Commission to examine 'accountability' but this does not mean it should end there. The commission did a thorough job of looking to risk, but left undefined and unexamined, issues of power. This deserves further analysis because it is the issue of power which still circulates beneath risk in the hazardous workplace today.

Language and context also matter in defining this. The way we describe things is significant in seeking constructive solutions to problems and given all that we have learned now from the findings of the Royal Commission it seems a little incongruous to still be referring to a model of 'accident causation' when what we really have here is 'model of workplace fatality'. British in origin, there is also no place on the original model for indicating voice from Te Reo/ Pasifica perspectives and this is a huge silence in an Aotearoa/New Zealand context. We need to go back to asking 'Who had the power?' 'Where is the power?' 'Who still holds the power?' There is a need to understand language, context and to investigate multiple lines of stories. We need to ask the right questions if we are to construct the right solutions. 
There is also a need to refer to the Bacchi's (WPR) (74) method and to be sure to ask the last of her six questions which I continually use in relation my own investigation and they are: 'What effects are produced by this representation of the problem? How/where has this representation of the problem been produced, disseminated and defended? How could it be questioned, disrupted and replaced?' (75)

In looking to these gaps, these silences, we also begin to get a clearer visual picture of 'what the problem has been represented to be' right up to the present point and realise that with the tendency to look at complex strategies we have sometimes missed the very simplicity of potential solutions. One of the major silences is around just how complicated whole government systems have made, for example, the actual representation of the problem of Pike River Mine in the first place; almost to the point of it now slipping to yet another 'diversion strategy' of positive asymmetry.

Recently, for example, I heard someone refer to the whole process of resolving issues pertaining to that of the Pike River Mine tragedy as being much like those around resolving issues in the aftermath of the (February 2011) Christchurch Earthquake. (76) The governance process of resolving the ongoing structural problems in aftermath of that disaster has now gone on for so long that some feel it may never be sorted out at all because everyone has been totally exhausted by the process.

I would argue that a similar complexity occurred in the aftermath of the Cave Creek Tragedy of 1995 (77) and it certainly occurred with regard to the Erebus Tragedy of November, 1979; (78) with an acknowledgement of the wrongs regarding that case finally being made thirty years after the event, in a thirty second apology on the 6pm Friday night news. (79) The recasting practices and tendency in this country to make such processes far more complex than they really need to be is an example of clouding practice and a culture of socially organised denial. (Norgaard, 2011).

In such a climate a whole variety of eclipsing and clouding practices (Cerulo, 2006) occur over time which simply wear people down, silencing them into an exhausted sense of powerlessness and resignation, where once again individuals begin to collectively distance themselves and fail to act (and sometimes even react at all) to 
the worst case scenario, which is now no longer an impending one, but one which has engulfed and overwhelmed them. (Norgaard, 2011). This collective distancing is not now the result of an 'information deficit' model, via which the public fails to respond due to lack of information. It is rather, the result of the 'social organisation of denial' via which individuals collectively resist the available information. (80)

This culture makes it particularly difficult for families, post-tragedy who do have voice enough to continue their protest or investigation into findings. The implication is that after a certain protracted length of time everyone should somehow just step back and accept in silence, the complex volumes of findings by the same culture that created the tragedy in the first place; until the disaster itself inadvertently becomes so distant that it is almost recast as an 'unfortunate' event of some bygone era.

In relation to the Pike River Mine disaster the West Coast of New Zealand begged to differ on this and has continued to lead an ongoing fight for the re-entry of the (2.3 $\mathrm{km}$ drift) to the mine; to be allowed one attempt to 'bring the bodies of their 29 men home' along with any latent evidence that might be in this entrance, as the workers would have been coming out that way on a Friday at the time of the explosion. (81)

'With Pike, they're not buried_All of them aren't buried under rock,' said a family member in July 2012 'They're just sitting there waiting .... They're sitting there waiting to be got out.' (82)

'I had three children in my [last] school who lost relatives to Pike,' said a another head teacher who had worked in two West Coast Schools. 'And I had the children here, who had lost their father [pause] And I didn't know where I needed to be... And that was, that was probably the hardest part; not knowing. So that was tricky. Cos you said, your first question was How did it affect you? Well, that was really tough. And then you have to understand that when they cry for no reason_ when they get angry for no reason. Or they [pause] flick out, for no reason; it's never for no reason.' (83) 
'Look, we are the cross roads as a nation,' said the Mayor of Greymouth in July 2011. 'Do we value our people? Or have we put the mighty dollar above them? And I'm saying that should've even come into it. You tag both...You bring our bodies out too.' (84)

A certain silencing of populations also still occurs regarding the multiplicity of single work place fatalities in other industries in this country which can, at times, appear to almost follow the path of an actuarial model. As time passes, the efforts of families, concerned parties and those in administration and management are eventually defeated with complex costly processes which collapse their search for answers. An example of this were the efforts Green MP, Kevin Hague who tried to prosecute with regard to the Pike Mine fatalities, only to eventually fail due to the costs. (85)

'Our community started through coal mining,' a school principal told me in 2012. 'And as community they've gone through the Strongman Mine disaster [1967] And many other mining tragedies where families have been affected. Then we had a [pause] death that happened about four, five years ago....And a mine thing broke and the water came through [pause] So he was washed away and drowned ... So we have been very much affected by mining disasters before. But nothing prepared us for Pike. (86)

We have already made a start on developing a new model. But we can no longer afford to just look to incidents and processes that 'accidentally' overlay each other on the trajectory to production deadlines and expect transparency. We need to demand and interrogate that transparency. We need to ask probing questions of systems and the agents within those systems and say 'What part did/do they play?' 'How can we change that?' And expect an answer. It really is not as complicated as it sounds. We can even start at the very beginning by refusing to call this new model, one of 'accident causation' when it was clearly all along, one of 'workplace fatalities'. 
'So when we came back to school on Monday [the third day after the explosion] we didn't know whether the miners were dead or alive,' said the another school principal. 'But by Monday they were starting to give quite a bit of hope that there could've been miners alive... On the Wednesday, when the second explosion happened, we were actually at a school meeting in town. And I got a text to say they were all dead. And the people who were running the meeting actually knew that; but didn't want to tell us till they had run the meeting. But by that stage everybody was getting texts. And so then they made the announcement that it had happened.' (87)

In an Aotearoa/New Zealand context, we could also use a little more compassion, vision and anticipatory governance. (88) It is time to stand together to demand more transparency, so that we can all find and follow the lines of problematisation which might lead to one consistent line of responsibility and accountability. Some might suggest this is an impossible task, given even the Royal Commission could not come up with the answers to that. But the commission was not asking that question. And it is not too late. There is a need to come out of isolation and any sense of personal and political powerlessness to find our voice to at least begin to name things, because 'naming the problem' is the beginning of regaining power in the face of it.

This might simply begin with acknowledgement that powerful deregulated worlds do exist, morph and shift beneath our feet, like a series of quakes which have stolen over time, our sense of agency. We need to name them. If everything is still moving to the point we feel powerless in the face of predetermined risk which continues to kill our loved ones in the workplace only to slip away again from the face of accountability, then we need to stand up, find voice and altogether name that too.

We are told to look to risk and we are told to see our part in risk [as in the James Reason Model of Causation] when in fact, our whole system is predicated on risk. If we want to make any in-roads to finding one consistent thread through all these lines of fatality, the fundamental question has to be, where does that power intersect with that risk? How, for example, is power demonstrated and distributed through our workplace culture and its systems? How is it accessible to us in our daily 
quest to make a living wage? Are we even getting a living wage? Who has the power to change that? Acceptance is definitely not the answer to all our problems. Sometimes courage is. We need to wake up out of this culture of silence, positive asymmetry (Cerulo, 2006) and socially organised denial [Norgaard, 2011] to thoroughly look to issues of power while analysing how systems are tied together and failures interact. [Perrow, 1999]. Only then, do we have a chance of creating an action-reflection praxis that works in the long term to confront the normalisation of technical deviance and the social organisation of mistake. [Vaughan, 1989].

We need to all come back to the table and realise that what has so far transpired, both pre and post-Pike River Mine tragedy was a politically motivated decision. It was not a policy driven decision. If it had been policy driven to find real answers, then those in power would have been asking all along 'What is the problem. Let's find a solution.' We need to be vigilant as to recreancy [Freudenburg 2013] and to the many processes of power driving production in the workplace. It all comes back to the power set beneath the acceptance of risk-taking. It is time to switch the tables around and ask with one collective voice the question often hidden within the structural secrecy of actuarial models 'Just how many more lives is all this worth?'

'And on Wednesday, [five days after the first explosion] I had to go to a meeting with the Ministry,' said another principal in July 2011. '[It was] all the principals in the Grey area, our Board Chairs and I took my deputy principal. The Ministry from Wellington, in their suits proceeded to tell us what they had in place. That was fine. Like, what they could do to support schools if it did go pear shaped [with the potential 'rescue']. We were all sitting there.

...Anyway, halfway through this talk, I got a text. My secretary's son is one of the head's of Red Cross. And he's at the Red Cross Centre. And my secretary had text me through 'It's over. There's been another explosion. They're all gone'. So in the middle of this talk I'm reading this text, listening to this woman from the Ministry of Education who has no connection with the Coast... And all I wanted to do was get up... We need to get out of here... 
And I couldn't actually speak. I wanted to interrupt her. But I just couldn't. So anyway, my deputy principal obviously saw the look on my face and she grabbed my phone. She read it. She just looked at me. We just looked at each other. Then my Chair, she read it. Then another principal who'd got a similar text stood up and said 'There's been another explosion. We need to leave'. (89)

The case of Pike River Mine did not end with the deaths of 29 men. The tragedy of Pike Mine is a mirror of an entire system predicated on power weaving beneath risk which is still killing people in the New Zealand workplace. Where is the genuine agency? It has been taken away. But we can find voice, name, and take it back again.

The transcripts gathered up for the Royal Commission may have an embargo on them for 100 years (90) but there was a start to voices being heard just recently. Seven years to the day of the fateful news in that Greymouth community hall, a group of long struggling Pike River Mine family members won a Supreme Court ruling that a Pike River Deal was indeed unlawful.

'Pike River victims Sonya Rockhouse and Anna Osborne have won an important moral victory in the Supreme Court, with today's ruling that the dismissal of charges against former Pike River Mine boss Peter Whittall was unlawful,' reported author and investigative journalist, Rebecca Macfie.

The court found Worksafe entered into an unlawful bargain in 2013 when it agreed to a deal in which insurers for Whittall would pay the Pike victims \$3.41 million if the prosecution was dropped.

The 12 charges against Whittall accused him of acquiescing in or participating in breaches of the Health and Safety in Employment Act. He pleaded not guilty on all counts. A trial was to have been held in 2014 but, instead, negotiations starting in mid-2013 led to the payment of $\$ 3.41$ million to the families of the 29 who died and the two workers who survived, on condition that WorkSafe offered no evidence to the court to support the prosecution. 
The money was already owed to the victims after the prosecution of the defunct mine company Pike River Coal. Because the company had gone into receivership shortly after the November 2010 disaster, it was unable to pay the $\$ 3.41$ million in reparations ordered by the District Court. Under the arrangement brokered between Whittall's lawyer, Stuart Grieve, and thenCrown Prosecutor Brent Stanaway, the money was paid by insurers for the company's officers and directors as part of the arrangement to allow Whittall to walk away.

'It is contrary to the public interest and unlawful for an arrangement to be made that a prosecution will not be brought or maintained on the condition that a sum of money is paid,' the Supreme Court judges wrote...'We need to know, all of New Zealand needs to know, that justice will be done,' said Sonya Rockhouse. (91)

It is important we take the tireless example of the Pike Families to rediscover our own sense of agency and along with this, our individual and collective voice as New Zealanders. It is no longer enough to accept that to make a living wage we must 'keep our heads down' in the workplace in the quiet hope that if we are patient enough, a living wage might finally appear before us in a signed contract; or if we just 'work to impossible and dangerous deadlines for the sake of our kids until Christmas, we can sort it all out in the New Year'.

We can no longer wait for that magic bullet of someone finally 'hearing us'; or hope that a leader will somehow emerge in the next election on our behalf on some white charger to lead us out through this maze of clouding, eclipsing and recasting practices to some much safer, saner place. We are that leader. We need to find our voice and lead ourselves out from every tier of the system, to actively and constructively challenge every tier of that system. We are also the 'watch dogs' sitting on our own forgotten heritage of peaceful and constructive resistance. It is not only multinational corporates we need to be aware of, but ourselves. In a growing number of New Zealand industries, many of us are simply selling out our own people and resources to unchecked corporations all by ourselves. 
The case of Pike River Mine (2010) is a case of deliberate risk and hibernating underneath that risk was (and still can be) a base of unchecked power. It follows that any 'error-tolerant' systems we now design, will only ever work insofar as there is an 'error-intolerant culture' inside the industry. Pike River Mine was not an isolated incident. And therein lies the double helix of terrible tragedy. The culture of 'production before safety' that was once Pike continues to exist to varying extents in a number of other industries across Aotearoa/New Zealand.

The good news is that much of that culture is now within the perceptual porthole (Cerulo 2006) of all those dedicated to working for new health and safety legislation in this country. The problem is, we will continue to despair the high rate of fatalities in these industries - (and note, that they can no longer be called 'accidents' with this knowledge, but 'fatalities') - until we individually, corporately and as a nation, recognise and call out the culture of power for what it is, that still exists around production and risk. We urgently need to look to where power and risk intersect with the culture of positive asymmetry, (92) It is that simple: Look to junction of power, risk and positive asymmetry and therein lies the triple helix of a perfect storm conditions for future tragedy in whichever industry chooses to practice it.

Right now, no one is talking about this. We seem to be still focussed on traditional risk prevention models; the very ones that were so willingly violated at Pike River Mine. The conversation must change from risk to power. If we don't address this now, we are on a timeline for more Pikes to come. 'And they never saw it coming?' Yes they did. They just looked the other way. These are not accidents but fatalities.

'One of the guys was giving evidence,' said a mother who lost her son to Pike River disaster 'One of the experts from DoL, he commented that he thought Spaghetti Junction was just a nick name that had developed [for a part of the mine] But that was the official name for that area. He said he could understand why [that was] when he realised all the activity going on there and all the crossover of pipes... We'll you immediately think about what's 
happening at that minute,' she said. 'And that hour, and the hours that are going on for all the people. You know what they are going through.' (93)

'It will never be over until they come home,' said another grieving family member later in 2012 'They're in a damp, dark hole. None of them deserve to be there. They went to work in good faith.' (94)

\section{Endnotes: Chapter 6}

(1) Perrow, Charles (1999) Normal Accidents: Living with High-Risk Technologies, New Jersey: Princeton University Press, p.12.

(2) Mulholland Interviews, January 2015, HB (31.1.15) 6:15; 5:45. See also the Wishart email in Royal Commission of Inquiry (2012) Vol.2, 9:62-64.

(3) Ibid., February 2012, JO (7.2.12) 32:48.

(4) bid., February 2012, JB (10.2.12) 11:43; 10:40-43; 6:50.

(5) Ibid., July 2011, MO (14.7.11) 8:28.

(6) Ibid., July 2011, JO (15.7.11) 33:20.

Note: Another teacher described in 2011, the tensions that continued in the weeks that following the deaths at Pike Mine 'There was huge tension. The kids whose parents were in the Rescue Team were getting huge crap.... 'Why aren't your freegen parents getting in there and rescuing them!' And we had to go in and deal with it... At the beginning of this year, for the first six weeks, we had a ton of punching going on; punch ups, you know? We'd never had that before, like that. And that was the post delay stress coming through, if you like. Like the Christchurch [earthquake 2011]. It's later on things start to come out.' Mulholland Interviews, July 2011, JL 15.7.11, 10:36-11:46.

(7) Ibid, July 2011, AM (17.11.11) 23:04.

(8) Royal Commission of Inquiry on the Pike River Mine Tragedy NZ, Te Komihana a te Karauna mo te Parekura Ana Waro te Awa O Pike (2012), Vol.2, 2:20, fig 2.1. 
(9) Ibid., Vol.2, 2:1-23. See also, Dr Kathleen Callaghan, (April 2013) ‘Pike River: Lessons for Directors and Senior Business Leaders Conference Health \& Safety Forum www.zeroharm.org.nz/leadership/case-studies/pike- river

(10) Royal Commission of Inquiry, op. cit., (2012).

(11) A culture of positive asymmetry is one in which there is a failure to acknowledge a looming worst case scenario in the drive to meet intended targets. See, Cerulo, Karen (2006) Never Saw it Coming: Cultural Challenges to Envisioning the Worst, Chicago: University of Chicago Press.

(12) Royal Commission (2012) op. cit. Vol.2, 5:3. 'Gordon Ward, an executive director and chief executive, refused to provide written or oral evidence to the commission but had provided evidence to the joint investigation. [Gordon Ward, Police/DOL interview, 29 September 2011, INV.03.28891]. Mr Ward had been on the board since July 2006 and resigned in September 2010. He moved to Australia where he was effectively beyond the commission's reach.

(13) Mulholland Interviews, February 2012, BM (14.2.13) 9:04.

(14) Dr Felicity Lamm, Pike River Mine: Bring Them Home, (May 2017) para. 4.

Briefing Papers: http://briefingpapers.co.nz/pike-river-mine-bring-them-home/

(15) Bacchi, Carol. (2009) Analysing Policy: What's the Problem Represented to be? Australia: Pearson.

(16) Ibid., (xxi).

(17) Ibid., p. 1.

(18) Ibid., p. 20.

(19) Royal Commission of Inquiry (2012), op. cit., Vol.1, p. 19, para. 2.

(20) Dr. Lamm has been teaching and researching in the area of occupational health and safety (OHS) for over 25 years. She has written for New Zealand and overseas public and private sector organisations in areas such as regulating and complying with employment and OHS law in the small business sector and OHS issues in the 
agricultural, construction, forestry, mining, fishing and service sectors. Dr. Lamm has also been involved in a number of governmental inquiries into OHS, most recently the 2012 New Zealand Independent Taskforce on Workplace Health and Safety and the 2014 Worksafe Advisory Group of OHS Compliance and Worker Participation.

(21) Dr Felicity Lamm, (May 2017) Briefing Papers: http://briefingpapers.co.nz/pikeriver-mine-bring-them-home

(22) John Gibb, Otago Daily Times, https://www.odt.co.nz/news/dunedin/nzworkplace-death-rate-appalling NZ workplace death rate 'appalling, ' 16 June 2016.

See also: Demelza Leslie, Safety law fails to curb workplace death rate, 23 November 2016. https://www.radionz.co.nz/news/national/318693/safety-law-fails-to-curb$\underline{\text { workplace-death-rate; }}$

Paloma Migone, Wellington Bureau Chief, Seven workplace deaths in a fortnight, 24 April 2017. http://www.radionz.co.nz/news/national/329339/seven-workplacedeaths-in-a-fortnight

(23) Te Aniwa Hurihanganui, Five forestry deaths this year spurs new safety call, 28 August 2017. https://www.radionz.co.nz/news/national/338149/five-forestrydeaths-this-year-spurs-new-safety-call

(24) Norgaard, Kari .M. (2011) Living in Denial: Climate Change, Emotions and Everyday Life, Cambridge, Massachusetts: The MIT Press, p.9.

(25) Dr Kathleen Callaghan (April 2013) 'Pike River: Lessons for Directors and Senior Business Leaders Conference Health \& Safety Forum'. www.zeroharm.org.nz/leadership/case-studies/pike- river See also, Callaghan, K., Accident Analysis: Some Concepts; Commission of Inquiry, Vol.2. Ch. 2. Note also Mark Parcell, Pike River NZ Workplace Safety Seminar, Wellington, NZ, Oct 2014 and his Pike River: A Failure to Learn 2014 www.PikeRiver DVD.com.

(26) Kelsey, Jane (1990) A question of honour? Labour and the Treaty, 1984-1989. Wellington, N.Z.: Allen \& Unwin; Kelsey, Jane. (1995) The New Zealand Experiment: $a$ world model for structural adjustment? Auckland, N.Z.: Auckland University Press; 
Bridget Williams Books; Kelsey, Jane and O'Brien, M. (1995) Setting the record straight: social development in Aotearoa/New Zealand. Wellington, N.Z.: Association of Non Government Organisations of Aotearoa; Kelsey, Jane. (1999) Reclaiming the future: New Zealand and the global economy Wellington, N.Z.: Bridget Williams Books; Kelsey, Jane. (2015)The Fire Economy: New Zealand's Reckoning. Wellington, New Zealand : Bridget Williams Books with the New Zealand Law Foundation.

(27) Bacchi, Carol, op. cit., (2009).

(28) Smol, David (2013). See also, Shanks, D; Meares, Jane. (2013) Pike River Tragedy: Report of the Independent Investigation to the Chief Executive of the Ministry of Business, Innovation and Employment, 14 March 2013. such functions were 'handled in a light-handed and perfunctionary way'. http://www.business.govt.nz/worksafe/news/releases/2013/independent$\underline{\text { investigation-report-released }}$

(29) Royal Commission of Inquiry (2012); op. cit., Vol.2, 7:55.

(30) Freudenburg, William R. (2013). A Life in Social Research: 21; Research in Social Problems and Public Policy ed. Susan Maret, UK: Emerald Group Publishing.

(31) Cerulo, Karen. (2006) Never Saw it Coming: Cultural Challenges to Envisioning the Worst, Chicago: The University of Chicago Press.

(32) Norgaard, Kari .M. (2011) op. cit., p.9-12

(33) Perrow, Charles, op. cit., (1999).

(34) Vaughan, Diane. (1996) The Challenger Launch Decision: Risky Technology, Culture and Deviance at NASA, USA: The University of Chicago Press.

(35) 'The Ford Pinto Case': The Valuation of life as it applies to the negligence efficiency argument, Christopher Leggett, Law \& Valuation, Professor Palmiter, 1999. https://users.wfu.edu/palmitar/Law\&Valuation/Papers/1999/Leggett-pinto.html (36) See also, Diane Vaughan (1996) op. cit., 34-35, 408; also (FR) Review William Freudenburg, WR, 400, full disclosure principle, 369. 
(37) Beck, Ulrich, Giddens, Anthony (1992) Risk Society: Towards a New Modernity

(Theory Culture and Society) first ed. SAGE Publications. See also: Eugene Rosa, Ortwin Renn, and Aaron McCright, A., eds. (2014) The Risk Society Revisited: Social Theory and Governance, USA: Temple University Press. See, Volume 34, Issue 12, December, 2014: An Official Publication of the Society of Risk Analysis.

(38) The Royal Commission of Inquiry (2012) op. cit., Vol. 1 \& Vol.2.

(39) Ibid., Vol.2, 12:27, 12:29.

(40) Ibid., Vol. 2 fig 14.2, fig 14.3, pp. 183-84; chapter 3:60; 7:62; 8:116-19; 8:121;

8:127; 8:129; Pike River Coal Ltd, Incident/ Accident Form, 29 October 2010, Panel 1 Goaf Fall 29/10/10, DAO.001.00436/23.

(41)This point was brought to my attention by Dr Daina Harvey, associate professor of sociology and anthropology (from Rutgers University, US) on reading this thesis. (42) Dr Rebbecca Lilley, (16 June 2016) https://www.odt.co.nz/news/dunedin/nzworkplace-death-rate-appalling .

(43) Paloma Migone, Seven workplace deaths in a fortnight (24 April 2017) http://www.radionz.co.nz/news/national/329339/seven-workplace-deaths-in-afortnight;

(44) Mulholland Interviews, February 2012 HL (8.2.12) Pt2, (13:30).

(45) Mulholland Interviews, July 2012, BM (5.7.12) 27:22.

(46) Ibid., February 2013, BM (14.2.13) Pt.2, 12:48- 13:30.

(47) 'On 18 November, the day before the explosion, the company was on the brink of raising a further $\$ 70$ million capital involving a share placement to ordinary share holders of $\$ 25$ million and to institutional investors of $\$ 45$ million, fully underwritten by a major international investment bank, the chair of the board, considered that this $\$ 70$ million would have carried the company through the third quarter of 2011 when 'we expected to be in fully steady hydro mining.' 
(48) Ibid., Vol.2, 4:26. 'A new technical services manager had been recruited, but was not due to start at Pike until December 2010. In the meantime, technical services coordinator, Gregory Borichevsky, an experienced mining engineer was the most senior member of the technical services department. '

(49) 'The main fan failed in the explosion. It was not explosion protected. A back-up fan at the top of the ventilation shaft was damaged in the explosion and did not automatically start as planned. The ventilation system shut down'. Royal Commission of Inquiry (2012) op. cit., Vol. 1, p. 19. See also:

http://www.nzherald.co.nz/nz/news/article.cfm?c id=1\&objectid=10831669 Reopening of Pike River Inquiry Pointless, Court told. NZ Herald, 5 September, 2012. Royal Commission of Inquiry, op. cit., Vol.2, 8:83. 'Mr Borichevsky, an electrician, examined the damage to the surface fan on 22 November 2010, before the second explosion on 24 November damaged it further. The airlock doors in the fan housing and the louvres installed on the evase had been blown open and damaged. The fan was intact but three of the fan blades were damaged. The control panel had been blown over by the force of the blast coming out of the airlock doors and had fallen onto the emergency stop button of one of the generators. The DoL investigation report concluded the surface fan did not start at all, but it appeared that at least one of the diesel generators had started, since some fuel had been used.'

See Vol.2, 8:84 'Mr Borichevsky believed the surface fan could and should have been restarted. Although damaged, his 22 November examination found the fan was intact, the second generator was running, the airlock doors could have been secured, the main cabling to the control panel appeared to be intact and could have been made safe to restart, the fan cowling, shutters and belts were slightly damaged but repairable, and the drive belts and motor on the fan appeared to be undamaged. He says he told the production manager, Stephen Ellis, of his inspection and his view that the fan could be repaired and restarted to ventilate the mine, but that did not occur. Mr Ellis does not recall this, but comments that effecting repairs would have been too dangerous and restarting the surface fan was a decision for the mine manager Mr White...' 
(50) The Strongman Mine disaster referred to here, occurred in Runanga, $7 \mathrm{~km}$ north of Greymouth in January 1967, resulting in the deaths of 19 men.

(51) Chapter 4, Note (7); See also Cave Creek, re: the deaths of 13 students and their guide north of Greymouth at Paparoa National Park in April 1995. Cave Creek was mentioned several times in my Pike River Mine Interviews, particularly (2011-2012) with participants referring to association with past tragedy via sounds of helicopters and sirens. Mulholland Interviews, February 2012, (8.2.12) Pt.2, 3:13-3:28.

(52) Mulholland Interviews, February 2012, MT (8.2.12) 15:24.

There are many poignant references, particularly in the earlier Pike Mine interviews (2011-2012) to how stunned the community of Greymouth and was that such tragedy could strike their town again.

'Like, what are we going to do, you know? And the picture -If I'd a camera - It wasn't a picture that you'd hang up on your wall,' said one head teacher in 2011, whose husband was a tunneller further up the West Coast. 'But everyone was in that pub,' she said on that Friday after work, suddenly hearing the explosion had happened. And they'd locked the [mine] gates. Everyone just walked in off the street. It was just silent. They were just having a drink. And we did the same... 'What are we going to do now?' Mulholland Interviews, July 2011, NK (18.7.11).

There are also many accounts of first hearing the news of Pike, 19 November 2010 in my own interviews (2011-2016):

'When I got up there [to Pike]' said Tony Kokshoorn, the mayor of Greymouth 'They've got major security there....And that's seven kilometres at the bottom of the mountain. They wouldn't let anyone past there. And I said 'I wanna get up there!' I was lucky [to get in]. So, when I got up there, there were ambulances. It was like a Lockdown. They didn't even know there was 29 at this point because...of the tags. I went to a major meeting room with about 15 people. But everyone was just looking at each other because they didn't know what to do. They were trying to assess information.... I just said to one of them, I says 'Look, have you notified the families?' And he says 'Yeah, we're doing it.' Well it turned out later, they didn't. 
And we had a major argument over that. We made some statements.

When I got up to the security gates_one wife, Anne Osborne_She actually got through security as well. She was down at those bottom bins. And when we got down there, there was a bit of a problem.

The HR man said 'Ah, you can't be here! No one's allowed past security'.

And she said 'I'm not moving!' She hung onto the table. And she hung onto the table and she says 'I'm not moving without my husband!' she says 'I'm not going!'

There's probably about six workers there. I says 'Listen this is not fair. She's ok here. Leave her. She's in now. These six people here, they will look after her'.

Mulholland Interviews, July 2011, TK (14.7.11) 8:16-11:40.

(53) See Note (41).

(54) See Note (52) and chapter 4, Note (7).

(55) Dr. Rebbecca Lilley, op. cit., NZ workplace death rate 'appalling' Otago Daily Times, 16 June 2016. https://www.odt.co.nz/news/dunedin/nz-workplace-deathrate-appalling See also: Dr Rebbecca Lilley, Independent Taskforce on Heath and Safety, 2013) http://www.hstaskforce.govt.nz/documents/comparison-of-ilopublished-occupational-fatal-injury-rates.pdf

(56) Demelza Leslie, Senior Political Reporter, Safety law fails to curb workplace death rate, 23 Nov 2016 https://www.radionz.co.nz/news/national/318693/safetylaw-fails-to-curb-workplace-death-rate

(57) Ibid., Demelza Leslie, interviewing Gordon MacDonald, chief executive of NZ Worksafe, 2016.

(58) Ibid., para. 18, 19, 14.

(59) Email from Dr. Rebbecca Lilley to Catriana Mulholland 15 Jan 2018.

(60) Garth Gallaway, Health and safety law an area to watch, New Zealand Law Society, 5 Aug 2013 'Worksafe' http://www.lawsociety.org.nz/lawtalk/lawtalkarchives/issue-824/health-and-safety-law-an-area-to-watch 
(61) Garth Gallaway, New Zealand Law Society, op. cit., 'Directors' Guidelines' http://www.lawsociety.org.nz/lawtalk/lawtalk-archives/issue-824/health-andsafety-law-an-area-to-watch

(62) Mines Rescue Act 2013, (3) Purpose (1-2); Parliamentary Counsel Office, Wellington, NZ: Te Tari Tohutohu Paremata, http://legislation.govt.nz/act/public/2013/0096/latest/DLM5709323.html?src=qs

(63) WorkSafe New Zealand Act 2013 (9) objectives (10) functions; Parliamentary Counsel Office, Wellington, NZ: Te Tari Tohutohu Paremata, http://legislation.govt.nz/act/public/2013/0094/latest/DLM5302055.html

(64) New Zealand Law Society, op. cit., Mines Rescue Act 2013

http://www.lawsociety.org.nz/lawtalk/lawtalk-archives/issue-824/health-andsafety-law-an-area-to-watch

(65) Michael Wright, Pre-Pike mine safety rules 'clearly deficient' 18 November, 2015 https://www.stuff.co.nz/national/74109213/prepike-mine-safety-rules-clearlydeficient

(66) New Zealand Law Society, op. cit., 'Changes to HSEA' http://www.lawsociety.org.nz/lawtalk/lawtalk-archives/issue-824/health-andsafety-law-an-area-to-watch

(67) Grant Nicholson, Back from the dead? Corporate manslaughter is back on the table 17 July 2018 https://www.hrmonline.co.nz/news/back-from-the-dead-corporatemanslaughter-is-back-on-the-table-252422.aspx

(68) Grant Nicholson, op. cit., (2018).

\section{Revisiting the Model of Workplace Fatality Causation}

(69) Freire, Paulo. (1972) Pedagogy of the Oppressed, UK: Penguin Books, 1972; See also his: Cultural Action for Freedom, UK: Penguin Books. 
(70) The 'hundredth monkey' effect is a hypothetical phenomenon in which a new behaviour or idea is claimed to spread from one group to all related groups once a critical number of members of one group exhibit the new behaviour or acknowledge the new idea. I use it here, as a metaphor for hope.

(71) Bacchi, Carol. op. cit., (2009).

(72) Bacchi, Carol. Ibid., p. 2. Here, I refer to fourth of the six questions Bacchi lists re: the process of problematisation. The full six questions are listed under Ontology, Epistemology and Methodology, Chapter 2 of this dissertation.

(73) 'It is difficult, if not impossible to gain access to the thousands of documents gathered by the Royal Commission of Inquiry into the Tragedy. The reason for the one hundred year embargo is outlined in an email from the Department of Internal Affairs Te Tari Taiwhenua.... See Dr Felicity Lamm, op. cit., (May 2017) Pike River Mine: Bring Them Home, May 2017; See also Briefing Papers: http://briefingpapers.co.nz/pike-river-mine-bring-them-home (74) Bacchi, Carol. (2009), op. cit., p. 7, p. 12.

As referred to in (Chapter 2) of this thesis, Carole Bacchi's (2009) framework for social policy (WPR) encourages the use of the following six questions:

1. What is the problem represented to be in a specific policy? (WPR)

2. What presuppositions or assumptions underlie this representation of the problem? 3. How has this representation of the problem come about? Analysing policy: What is the problem represented to be?

4. What is left unproblematic in this problem representation? Where are the silences? Can the problem be thought about differently?

5.What effects are produced by this representation of the problem?

6. How/Where has this representation of the problem been produced, disseminated and defended? How could it be questioned, disrupted, replaced? 
$(Q n 1)$ identifies what the problem is represented to be (WPR)

(Qn 2) analyses the cultural underpinnings

(Qn 3) examines the origins, history and mechanisms

(Qn 4) reflects on gaps and silences in designated represented problems

(75) Bacchi op. cit., (2009), Question (6).

(76) At 12:51pm on Tuesday 22 Feb 2011, a magnitude 6.3 earthquake caused severe damage in Christchurch, NZ killing 185 people and injuring several thousand.

(77) The Cave Creek Tragedy of 28 April 1995; See Note (51).

(78) On the Wednesday 28 November 1979, Air New Zealand flight 901, a DC-10 registered ZK-NZP, crashed into Mt Erebus on Ross Island, Antarctica, killing all 257 people on board.

(79) NZ Herald (NZPA) 2009Air NZ Erebus apology 'proper thing to do' October 15, 2009. http://www.nzherald.co.nz/nz/news/article.cfm?c id=1\&objectid=10603332 'The man who apologised over the Cave Creek disaster says Air NZ should have apologised for the Erebus air crash years ago...'

See also: Roeland van den Bergh, Air NZ to apologise to Erebus families Oct 22, 2009 www.stuff.co.nz/national/2964833/Air-NZ-to-apologise-to-Erebus-families

'30 years later Air NZ apologises to Erebus families for the way they were treated'.

(80) Norgaard, Kari .M. (2011) op. cit., p. 12.

(81) Dr Bryce Edwards, Vital Progress in Dealing with the Pike River Mine Tragedy, Thursday, 23 November 2017. https://www.nbr.co.nz/opinion/vital-progressdealing-pike-river-mine-tragedy

(82) Mulholland Interviews, July 2012, BM (5.7.12) Pt.3, 2:06.

(83) Ibid., February 2012, DR (10.2.12) 4:56-5:18; 1:25. 
The trauma of children comes through a number of the earlier interviews; something we as teachers were able to relate to and identify with when, for example, referring to it in passing re: knowing my own experience of being a teacher near Kings Cross on the day of 7 July bombings 2005.

'During [the days of the Pike tragedy],' one principal of a Greymouth School told me in July 2011 'What was really amazing [strange] before_ and even after_ the second explosion was the kids in our playground_We had 178 kids at that stage_played silently.' [pause]

Catriana: Silently?

NK: Silently. Have you ever seen kids play [in the playground] silently?

Catriana: No.

NK: The whole playground: No noise.

Catriana: What?

NK: They just played.

Catriana: During this time - So, this just one particular playtime?

NK: No. For the whole time, there was no noise.

Catriana: No shouting or anything?

NK: No. They played silently.

Catriana: That's shock.

See, Mulholland Interviews, July 2011, NK (18.7.11) 24:33-24:52.

(84) Ibid., July 2011, TK (14.7. 11) 59:29.

(85) Green Party MP Kevin Hague, who tried to prosecute the Department of Labour, for example, in 2011 over Pike River Mine, but found it became too difficult and too expensive to pursue. Mulholland Interviews, op. cit., 24.3.16, pt.2, (1:03-124). 
See Also: RNZ_MPs first step to prosecute department over Pike disaster 25

November 2011. http://www.radionz.co.nz/news/pike-river-2010/92019/mp\%27s-

first-step-to-prosecute-department-over-pike-disaster

(86) Mulholland Interviews, February 20120 JB (10.2.12) 1:33- 3:59.

(87) Ibid., February 2012, MP (9.2.12) 3:27; 4:18.

(88) Boston, Jonathan. (2017) Safeguarding the Future: Governing in an Uncertain World, Wellington, NZ: Bridget Williams Books Limited.

(89) Mulholland Interviews, July 2011, NK (18.7.11) 5:00-6:40.

(90) See Note (73).

(91) Rebecca Macfie, Supreme Court rules Pike River deal unlawful, The Listener, 23 Nov, 2017. Supreme Court rules Pike River deal unlawful.

https://www.noted.co.nz/currently/social-issues/supreme-court-rules-pike-riverdeal-unlawful/

(92) As previously defined, 'positive asymmetry' is the failure to acknowledge a looming worst case scenario in the drive to meet intended outcomes. (Cerulo 2006)/ (93) Mulholland Interviews, February 2012, KM (12.2.12) Pt.2, 3:39; 22:22.

(94) Ibid., July 2012, NR (8.7.12) 39:21. 


\section{Chapter 7 Summary of Findings and Recommendations}

The case of Pike River Mine (2010) is one of deliberate risk and hibernating underneath that risk was (and still can be) a base of unchecked power. It follows that any 'error-tolerant' systems we design will only ever work insofar as there is an 'error-intolerant culture' inside the industry. Pike River Mine was not an isolated incident. There is a triple helix of this tragedy. In practising vigilance, we need to look to the junction of power, risk and cultures of positive asymmetry* for therein lies the perfect storm of future workplace tragedy in whichever industry practices it.

One day, while looking out my window over all these voices of interviews and loss, I asked myself one last time 'What was Pike River Mine really a case of?' It was an unusually hot day for Wellington as I wandered out to the veranda to look into the sun but instead, my eyes fell down to the tiny Buddha and the 29 stones I had gathered all those years back at a Memorial on the West Coast. And suddenly I had the words for it, though I had no idea until much later that there were actually 29 of them: The tragedy of Pike River Mine (2010) is actually a case of deliberate risk and hibernating underneath that risk was (and still can be) a base of unchecked power. There exists a triple helix to guide us out of socially organised denial into better forecasting and action in our workplaces. But we have to see it. We need to look for the intersection of that perfect storm of conditions; that triple helix of power, risk, and positive asymmetry. If we do not recognise and name this, there will be more Pikes to come, as is already evident in the multiplicity of single workplace deaths in agriculture, forestry and construction. (1) It is even more disturbing that many industries such as fishing are not even included in many representations of annual workplace fatalities; nor are many deaths caused while driving work vehicles and the list goes on and on, indicating an ongoing culture of eclipsing, clouding and recasting practices which continue to operate in the Aotearoa/New Zealand workplace.

\footnotetext{
* A culture of positive asymmetry is one in which there was a failure to acknowledge a looming worst case scenario in the drive to meet intended targets. Cerulo, Karen (2006) Never Saw it Coming: Cultural Challenges to Envisioning the Worst, Chicago: University of Chicago Press.
} 
We do have dedicated staff working throughout New Zealand on improving workplace safety and some particularly talented educators too, who argue that we need to exercise greater vigilance at all tiers of systems; but until we recognise our own culture of socially organised denial [Norgaard 2011] we will only ever see our workplace deaths temporarily stabilise, at best, under the deregulated systems' drive to meet production targets in a culture of risk power and positive asymmetry.

For workplace safety to improve in the long term, our industries and the many unnamed powerful systems which encourage and support them must be more accountable. We need to look at decision making process within whole systems from the inception of a project and be vigilant for patterns of dysfunction that lead to the 'normalisation of imperfect standards' (and production over safety) in the drive for profit. We need to prevent the 'normalisation of technical deviance' [Vaughan 1996].

These early decisions [are] precedent setting, in the full literal meaning of the term. The decision making-sequence...the normalisation of technical deviation... and the belief [in] acceptable risk was to be repeated many times. The first decision establishes a precedent that becomes a normative standard for future decisions in similar cases, pacing the way for development of a pattern... When you get acceptance of the configuration and its known lack of perfection by the highest level... That also tends to be a little bit of an umbrella for subsequent decisions. (2)

This very pattern ended in the deaths of 29 mean at Pike River Mine and there has also been a tendency post-Pike, to reframe the high rate of workplace fatalities in other New Zealand industries as somehow 'separate' single sets of 'unfortunate' workplace 'accidents'; when they are in fact workplace 'fatalities' and there are a number of inter-related links to be made between these repetitive incidents still intact and un-investigated. We need to unravel what's the problem represented to be (WPR) (3) and ask probing questions. It is a bit like engineering. In looking to the construction of a problem we unpack it first in an effort to construct a solution. But if we keep constructing the problem incorrectly then we will continue to get the wrong solution. Any model or policy then based on that will be incomplete, if not flawed. 
Then of course there is the 100 year embargo placed on so many of the witness transcripts gathered up by the Royal Commission in relation to the Pike disaster; a fact recently revisited in May 2017 by Dr Felicity Lamm, associate professor and codirector of the Centre for Occupational Health and Safety Research (AUT). (4)

The Royal Commission concludes there was a 'culture of production before safety' at Pike River Mine; (5) but what I find even more disturbing is that nobody in New Zealand stopped it. Contradictory statistics also continue to be a concern and make it difficult to know how bad things really are in order to measure and confront trends.

One of the goals of anticipatory governance must be to minimise the frequency with which we are surprised by events and outcomes which should have come as no surprise. Another goal must be to enhance the capacity of our governmental institutions to cope with surprises. (6)

So, where is our voice as New Zealanders? For, where the Royal Commission (2012) rightly focused on risk and what happened at Pike River Mine, there is still a need to interrogate issues of power which lay behind that risk. I ask not just what happened at Pike River Mine, but why it was possible for it to happen in the first place and why this continues to occur in the multiplicity of single workplace fatalities in other industries in New Zealand. We must ask the right questions if we are ever to find the right solutions and the way we use language to frame the problem really matters.

I argue, for example, that with all the findings and the knowledge we now have in an Aotearoa/New Zealand context, we can not now continue to refer to our repetitive workplace deaths as 'accidents', when they are in fact 'workplace fatalities'; any more than we can continue to refer to a model of 'accident' causation and expect it to fully describe what happened at Pike when what we really have is a model of 'fatality causation'. Language matters and so does the way we reframe the argument [Lakoff 2014] if we are ever to implement cognitive symmetry into our industries and create safer systems and work place environments for everyone in the long term. (7) 
George Lakoff (2014), was of course, the cognitive linguist and philosopher I referred to earlier in this thesis who asks us to consider the power of language in the framing of debate. He states, for example that 'frames are mental structures that shape the way we see the world. As a result they shape the goals we seek, the plans we make, the way we act and what counts as a good or bad outcome of our actions. In politics our frames shape our social policies and the institutions we form to carry our policies. To change our frames, is to change all of this. Reframing is social change'. (8)

In her own research, Bacchi (2009) also reminds us her (WPR) approach to policy making is important because 'the way in which the 'problem' is represented carries all sorts of implications for how the issue is thought about and for how people involved are treated, and are evoked to think about themselves.' (9) This also matters in the creation of viable solutions at the three levels of systems, industry and worker. It is in the interests of all to have a safe workplace. So we need a particular type of vigilance for any strand of the Triple Helix intersecting with any other tier of systems.

In the case of Pike, the Royal Commission of Inquiry (2012) discovered, for example, that an under manager was appointed to a specialist hydro mining position. This was a position in new technology he felt unqualified for (a fact he stated at the interview) but for which he felt he had been promised training. He did not get the training he expected and found himself struggling to such a point that he later admitted to the commission that he would gain his information by googling 'hydro mining'. There had been other applicants on the West Coast more experienced for the position, which might suggest we need to look to aspects of croynism and nepotism in our own systems of organised denial that have potential to lead to workplace harm. (10)

When all systems are encouraged however, to realise that it is both 'positive' and 'profitable' to 'look out' for a 'worst case scenario' then potential for perfect storm conditions at the juncture of risk, power and positive asymmetry, could be averted. The associated thinking of 'either/or' must also be brought to the fore, named and confronted for what it is. It should not ever have to be a case of 'either' profitable production 'or' workplace safety. We need to un-tag this cognitive slip and add in a conjunction. It is very possible to run a profitable business 'and' have a safe work 
practice. It is in everyone's interest to run a safe business, so it is important to catch this cognitive dissonance wherever it might appear in systems as well as at the coalface. Neither can it be 'acceptable' to excuse hazardous risk in industry simply because there was 'no law to say otherwise' as was evidenced in my own findings:

'New Zealand legislation at the time, didn't specifically not allow it,' said a senior executive in 2014, reflecting on what may have been the logic behind the Pike. 'It doesn't say we can't do it. So that must mean we can do it.' (11)

We need to be vigilant at all levels of this and have thorough policy and systems in place to confront it. We also need to counteract our long held belief that 'She'll be right' when it so obviously is not; because the ingenuity that built us as a pioneering nation is morphing into systems of tragedy. It is time to change the narrative; to come out of silence and be part of a newly developing and very present conversation on health and safety in the New Zealand workplace; to hear other voices as we all emerge from the different tiers of this culture of silence and positive asymmetry.

In the findings of the Royal Commission of Inquiry (2012) there are references to how Pike River Mine was once considered an important 'show case development' (12) There is also reference to the fact that so many known and uncorrected faults in the mine were not considered 'show stoppers'; (13) while those in power considered the 'show must go on' despite many fundamental requirements still not having been attended to before the explosion of 19 November 2010. It is as if all involved became actors on a stage. The outer representation was that of 'All is well at Pike River Mine' when clearly there was plenty of evidence available at the time to suggest otherwise.

This consistent refusal to see an impending worst case scenario is a classic hallmark of positive asymmetry (Cerulo 2006) and socially organised denial (Norgaard 2011). At Pike River Mine, something was rotten in the state of... something almost Shakespearian, and yet 'the show must go on'. At tiers of the system, people could see all was not well, but they chose to turn a blind eye; others occasionally toyed with 'to be or not to be' scenario, then placed their bets on a bonus system and that 'it might just work out for everyone quite well in the end'. Many others just stood by 
immobilised as if before a modern day rendition of the Emperor's New Clothes. 'All is not well. But I am told it is all well. What would I know? So it must be so.' The show must go on. And so it did, right down to its tragic last act, and with no accountability.

What people are still not speaking to at present, is that in the workplace this perfect storm of conditions is still not dealt with and set for another tragedy wherever there is an intersection of this proposed triple helix of power, risk and positive asymmetry. We need to start practising a new vigilance from the top down. We have to move from a certain two dimensional view of the world which tends to 'normalise' tragedy through the perspective of our lap tops and our iphones, isolating us even further in our increasingly small cultures of socially organised denial which can also, in turn, have us still believing we are powerless to change anything at all. We are not.

We must look to how this tragedy is still problematised. It does not help that that attitude of some of those operating Pike considered it to be some kind of 'show' in the first place. But we can stop the continued play in our own workplace cultures right now, by finding voice. There needs to be further investigation, to look to the power of narration that underlies risk in order to find the other junctions of cognitive and internalised belief that keep people blinded in socially organised denial. Investigation into the use of language along the lines of Lakoff's (2014) concept of the 'elephant in the sitting room' would be a good starting point. (14) This might help us tag and forecast dysfunction in systems leading to potential workplace tragedy.

In this thesis I have also often referred to Karen Cerulo (2006) and her concept of positive asymmetry which, as earlier defined, involves habitual ways of both thinking and behaving which increase the propensity to ignore an approaching worst case scenario in the drive to meet outcomes. (15) Such a culture might inadvertently (or otherwise) encourage certain eclipsing, clouding and recasting practices in the drive to meet financial and production deadlines and might include any of the following:

Eclipsing Practices (acts of banishing, physical seclusion, shunning)

Clouding Practices (acts of impressionism, shadowing)

Recasting Practices (rhetorical, prescriptive behaviours) 


\section{For the Future}

I have used examples of Cerulo's theorising throughout my analysis alongside that of the Royal Commission as I see it pertaining to the case of Pike Mine disaster. (16) As referred to earlier in the thesis, Cerulo (2006) also theorised around concepts of negative asymmetry which is of course, the opposite of positive asymmetry and as such, could foster improved safety via the implementation of cognitive symmetry into industries (with policy to support it) in an Aotearoa/ New Zealand context.

It is important to reiterate that I have written this thesis, knowing readers might only refer to certain chapters or an aspect of my analysis regarding their own enquiry (whether that be as a family member, researcher or other interested party) and so I return here to an earlier discussion to be sure the foundation of this is well defined.

I looked at how, in her own work, Karen Cerulo (2006) cites computer operators, programmers, systems analysts (COPS) and medical practitioners (MPs) as examples of groups who actively practise positive asymmetry in reverse that is, (negative asymmetry). Cerulo found these industries tend to be dynamic, flexible and willing to communicate on multi-dimensional levels. She also suggests that each tend to work via structural webs which encourage 'thinking outside the box'; often breaking with cultural conventions to find not only satisfactory, but innovative solutions. (17)

Cerulo found certain commonalities, for example, existing within the approaches of both the medical and ICT industries in relation to the efficient aversion of both Y2K and SARS threats. She noted the approaches of these industries tended to be autonomous, service oriented, dominated by 'formal knowledge' and often exhibiting porous community boundaries. These industries also often held explicit beliefs from highly articulated script for action and despite affiliation with organisations, maintained considerable ability to monitor and control themselves (18)

I looked at how Cerulo further emphasises that when these characteristics 'occur in combination, they create a distinct type of social structure; an 'emancipating 
structure'... [one that] can free groups, communities from constraints of perceptual conventions...Thus, beyond MPs, beyond COPS, any group or community structured in this way can leave positive asymmetry behind' (19) That is, those industries attuned to being as consistently on the lookout for a 'worst case scenario' also tend to be more likely to locate threatening scenarios and act ahead of time, averting disaster.

So in looking to the practices of our own industries and to positive outcomes in the creating profitable and safe business, I suggest we look to the incorporation of - (as ironic as this might initially sound) - certain aspects of negative asymmetry into our health and safety culture. We need to implement policy that encourages cognitive symmetry and thinking 'outside of the box' in the development of both safer and profitable workplaces. This will of course be challenging, given that Aotearoa has been swept up by over three decades of deregulation and associated webs of risk and consequence that made us the 'New Zealand experiment' of neoliberalism. (20)

As much as we might still like to pride ourselves on our ingenuity, determination and our 'she'll be right, mate' independence, many of our industries are obviously not autonomous, service oriented, dominated by formal knowledge; nor do they always hold to explicit beliefs from highly articulated script for action, and often no longer maintain the independence to monitor and control themselves. To think otherwise, when noting the death rate in some of our other industries would be to further confirm we are indeed living in our own culture of socially organised denial. (21)

In drawing from the analysis of Norgaard (2011) to disentangle the layers of links between risk, emotion and power, we must look to problematisation and our own often unidentified assumptions (Bacchi 2009) and also to the research of Kathleen Tierney (2014) who, in confronting ways of thinking with regard to disaster and risk, states 'Looking at disaster as social productions requires a shift in thinking away from the notion that the forces of nature - or in the case of financial catastrophes, human nature - produce disasters toward a fuller understanding of the role that social, political, economic, and cultural factors play in making events disastrous.' (22) 
This is no easy task. Tierney also looks to systems of power and recreancy around disasters such as in Hurricane Katrina (2005), the Haiti Earthquake (2010) the Deepwater Horizon BP Oil Spill off the Gulf of Mexico (2010) and the financial meltdown of 2008 only to find that in each case the disaster was not inevitable. Tierney states that to prevent future disasters we must 'understand the social forces that produce them, and then take action to address these forces'. She admits that 'applying this knowledge is difficult because of institutional inertia and especially because of the benefits those in power obtain through activities that increase risk.' (23)

I would also suggest that in further utilising the analysis of Vaughan $(1996,1998)$ regarding structural secrecy, the normalisation of technical deviance and the social organisation of mistake (24) we must also incorporate the concepts of Perrow (1999); whose analysis of socio-technical systems is invaluable when looking to practices and the drive behind industries as they blend human organisational and technical systems with the potential to interact in complex and often in disastrous ways. (25)

If our industries were to practise cognitive symmetry (Cerulo 2006) with the aim of creating both safer and more efficient work environments it would profit everyone. We could be trained from the top down in our own fields with specific skills and practise vigilance as to the interactive complexity of systems and tight couplings; noting 'the extent to which a problem or failure in one element of a system straightforwardly triggers problems in one or more additional elements (Perrow 1999) and be more able to identify and divert a developing worst case scenario.

An industry which is alert to its own potential interactive failures would be a happier and more profitable one in the long term as there would be better outcomes and less stalling around production as a result of more vigilant solutions to problems that are more effectively resolved. Policy implemented to assist with the identification and resolving of issues around often mundane tightly coupled failures, for example, that subtly interact as one component or process in the system dominoes or 'cascades' into another, could be more easily identified in dealing with eclipsing, clouding and recasting practices (Cerulo 2006) that might prevent the identification 
of a worst case scenario in the drive to meet production targets. This could also successfully divert the terrible coupling of both grief and false economy when an unexpected interaction in a feedback loop of runaway processes destabilises an entire system to inevitably cause injury or - as in the case of Pike River Mine multiple fatalities and catastrophic failure for everyone at all levels of the system.

Tierney (2014) emphasises that it really is possible for more positive outcomes in predicting and averting a worst case scenario if we look to the social production of disasters. She also includes earlier concepts of Perrow in her analysis when she states 'Complexly interactive systems can be contrasted with linear ones in which a problem (a component failure) that develops in one component or phase of system operation remains independent of and isolated from others' (26)

In looking to the case of Pike River Mine I also think back to a comment of Tierney (2014) in referring to Charles Perrow (2010) and how she says he disagrees that his own 'normal accidents theory' should never be fully used for example, to account for the likes of the disaster that was the (2008) 'melt down' or financial crash.

[Perrow] argues that while the requisite system characteristics were indeed present, the (2008) financial melt down was the consequence of the behaviour of financial elites who were aware of the risks inherent in their activities but who acted in disregard of their own institutions, their clients and the public. (27)

In many respects the case of Pike River Mine (28) was also one of power, drive and financial 'melt down' in which 'many requisite system characteristics were indeed present' and ignored. The findings of the commission show a mine beleaguered with financial concerns right up to the day of the fatal explosion (29) Yet despite all the information available, the warnings (many of which are cited in this thesis) were disregarded in the drive for targets and, I argue, distanced by the norms of emotion, conversation and attention in a culture of socially organised denial. [Norgaard 2011]. 
This brings to the fore, the fact (once again) that often hidden beneath the more obvious fallout of positive asymmetry and risk, are the issue of recreancy and power. There are, of course, tightly coupled characteristics to financial markets that have a melt down effect right down to operations of health and safety at the coal face. It could be equally said the tight couplings of financial pressure, the drive for targets and the regulatory failure of institutions has a cascading effect, with the drive for ever larger profits and the ignoring of ever larger risk (Freudenburg, 1993) until no matter what occurred at Pike River Mine, it was never going to be a 'showstopper' but a production of disaster embedded in the social order itself (30) This, I argue, created a gap for a capitalist endeavour to walk in and right back out with no accountability for the production of disaster once the inevitable but 'cognitively unforeseeable' occurred. This was not just a case of risk but of power and recreancy.

As previously cited, Freudenburg (1993) defines recreancy as 'the risk that socially consequential actors will fail to carry out their duties with the full degree of competence and responsibility their fellow citizens need to expect...' But '[It] is more than a particular violation of trust, it is a condition of dependency on shaky social scaffolding prone to such violations... The common thread is, duties are not carried out properly; whether the 'fault' is on of individual actors or of a broader system in which important responsibilities may fall through the institutional cracks. (31)

Freudenburg (2000) further states recreancy is to be found 'where collusion between parties with common interests overcomes fiduciary responsibilities; where people undertake tasks absent the requisite competence to carry them out; where corners are cut, favours are offered and palms are greased'. (32) He also points out 'recreant behaviour in regulatory or management structures has become the norm' and that 'victimisation is often an outcome of recreancy' (33). All of which brings me right back to the work of Cerulo (2006) and how important it is to not only identify clouding, eclipsing and recasting practices in industry but to turn this symmetry around to create effective solutions for both safety and production in the workplace.

Following on from the concept of Cerulo's (2006) positive asymmetry (which as earlier defined) involves habitual ways of both thinking and behaving which increase 
our propensity to ignore an approaching worst case scenario in the drive to meet outcomes, I also argue that negative asymmetry might be useful to our own industries should it be incorporated into our own improved efforts to avert disaster.

As previously cited, Cerulo found that negative asymmetry exists in the approaches of the medical and ICT industries; that they used positive asymmetry in reverse (negative asymmetry) in averting the potential disaster of the Y2K and SARS threats. She cited the commonalities in these industries as them both being autonomous, service oriented, dynamic, flexible and willing to communicate on multi-dimensional levels, operating via structural webs which encourage 'thinking outside the box' and often breaking with cultural conventions to find innovative solutions. (34) Given the success here, it is vital to start the process of incorporating cognitive symmetry into our own industries, but where do we begin when the drive for production exists?

Cerulo speaks to a complete re-education of symmetrical vision (35) where there is equal presence for naming, and envisioning both the 'best' and 'worst' case scenarios so that we find ways to act upon these in timely ways to prevent tragedies. This might involve exploring ways 'of seeing' and require the development of new cultural and systemic practices. Cerulo starts us off on a journey of three steps:

\section{Step 1: Acknowledgement: Consciousness Raising (36)}

This involves the use of information to state the facts, to raise consciousness about workplace fatalities. Acknowledgement leads to empowerment to act vs. react in the creation of better systems and safer workplace culture. This is happening already with the seminars for business leaders run by Dr Kathleen Callaghan (37) throughout the country and by the work of Mr Mark Parcell (38), the teaching and advocacy of Ms Hazel Armstrong (39) but it must not end there. No matter how small, we all have a part to play in developing and encouraging action reflection praxis across cultures. There also seems to be a lack of voice from Te Reo and Pasifica perspectives and that is a huge silence in a New Zealand context which needs to be urgently addressed. 


\section{Step 2: Develop a New Evaluative Practice (40)}

In having acknowledged Step One and come out of silence of isolation to meet others to voice a variety of independent experience and expertise from all levels of community and systems we might begin to construct new evaluative practices. Cerulo would, for example say: 'The 'worst' may not be the 'opposite' of the 'best'. The two may represent two distinct categories. And if we continue to restrict quality assessment to uni-dimensional continua, we will lose the opportunity to the broadest meaning of quality...' Cerulo advocates a 'separate-but-equal strategy'; that would allow us to consider a variety of quality dimensions simultaneously' (41)

So perhaps, mining, forestry, fishing and agriculture (and other less recognised fatality industries in Aotearoa) could begin by examining some of the autonomous, service oriented practices of other industries that utilise emancipating structural webs of active dialogue, problem solving and 'thinking outside the box' for solutions. We could look to those industries and the structural webs that encourage dialogue, problem solving and flexibility to communicate on multi-dimensional levels. Cognitive symmetry has all the potential to forward us all into a win/win culture where workers are not only happy and safe, but where financial targets are reached, while welcoming action reflection praxis around averting the worst case scenario.

We need to join our individual and collective experience to re-examine perceptions of 'best' and 'worst' and bring to the table our 'dialectic deliberations'; our reasoning that allows the contradictions and distinctions of any, to be considered fully by all. Once again, there also seems to be a marked absence of Maori and Pasifica perspectives whose participation would contribute enormously in any such process.

\section{Step 3: Amendments to structure. (42)}

Cerulo suggests we must 'consider settings in which cognitive and cultural change is best implemented.' She suggests 'separate-but-equal- strategies' to groups but the evaluative practices requires: 
(1) willingness to wander from some of the established strategies and practices that support them

(2) action to adopt and institutionalise more variable ways of seeing emancipating structures, for example, structural webs and 'dialectic deliberations'; a form of reasoning that allows the contradictions and distinctions of any to be considered fully and carefully (43)

For those who enquire 'But HOW do we even start this?' I reply, find voice, keep it simple, and never forget the acronym; HOW: Honest, Open-minded and Willing to change. And for those of us who have become part of this process already (because our life journeys brought us here professionally and/or through tragedy), there are some pertinent, visible patterns to watch out for, according to Vaughan (1996), in sequences of decision making which can lead to tragedy which must be addressed:

Adaptive behaviour, hardwired into human cognition, is complimented and reinforced by cultural practices, which return institutionalised in the rules and structures of formal organisations. (44)

The initial step to change is acknowledgement; the naming of the problem and the dialogue and reflection our own individual and collective experience. The tragedy of Pike River Mine was a case of deliberate risk and hibernating underneath that risk was (and still can be) a case of unchecked power. In finding voice to emerge from silence and often from prolonged isolation we get the chance to voice our doubts, our hopes, our expertise. It provides an opportunity for cognitive and social change. It is a courageous act of 'taking back the power'. It is a practice of empowerment.

So in using the heuristic tool of Bacchi (45) we could continue here with her poststructural (WPR) approach to analysis and go right back to basics to ask 'What was (and is) the problem represented to be?' It is important in this phase to shift the focus initially from 'problem solving' to some very direct 'problem questioning' (46) We gather the voice and encourage dialogue to revisit 'problematisation'; looking to the ways we think and represent a problem in order to solve it more effectively. (47) 
That is, by positing an issue as a particular sort of issue, a range of factors must be simplified. Only part of the story is being told. As a result it is crucially important to interrogate the problem representations that lodge within public policies to see what they include and what they leave out. (48)

We need to speak to some of those silences. We must problematise and investigate in more depth not only 'what the problem is represented to be' with regard to what happened at Pike River Mine, but to also find the common line of threads that exist in the multiplicity of single workplace fatalities of other industries in this country. (49) There are gaps and silences which need voice, and we have to ask the right questions if we are ever to find the right solutions. The findings of the Royal Commission into the Pike Mine tragedy (50) were an important declaration to that time and space. What is not clear is the unchallenged power that underlay all that documented risk.

I argue there are other industries in New Zealand immersed in this culture of risk, power and positive asymmetry and it needs to be made clear, that even when 'errortolerant' systems are designed, these will only ever work insofar as there is an 'errorintolerant culture' inside industry. At Pike River Mine, there was no intervention and if we only analyse what happened at Pike in terms of risk and never look at the dynamics of power that setoff all primary arrows (not once, but repetitively) into the model of fatality causation in the first place, then there will be more 'Pikes' to come. Cultures of positive asymmetry too often tend to normalise dysfunction to meet financial targets and can create a sense of powerlessness which can also reinforce a certain silence. It is time to challenge this_whatever our background, experience and expertise in order to avert future workplace tragedies in this country_ Together

\section{Cognitive Symmetry and those Directly Affected by Workplace Fatality}

Individual behaviours cannot be understood without taking into account the organisational environmental context of that behaviour... Although we focus on the microcosmic world of routine decisions to show the process of culture production and how the work group normalised technical deviation, the very 
obvious influences from the external environment...sensitize us to why the normalization of deviance occurred. (51)

In conducting this research, I discovered that many of those bereaved of loved ones at Pike River Mine on 19 November 2010 also used some of practices of positive asymmetry that Cerulo (2010) describes, as a means to cope. There were a number of occasions when the families were directly encouraged to 'hope for the best' when in reality the eclipsed and clouded facts of certain situations were far from hopeful.

A case in point would be that of the many issues surrounding the aftermath of 19 November 2010. The families had been, for example, encouraged to believe that their men were still alive even five days after the first explosion. Here, issues of power not only continued to cloud the facts around risk but served to recast them.

'We thought we were going to be like the Chilean Miners,' said some interviewees, with reference to televised rescue of the televised rescue (just three months prior to the Pike tragedy) of the 33 men trapped 2,300 feet underground for 69 days in the San Jose gold mine near Copiago, Chile on 5 August 2010.

'No one knew what was going on. And we still had that hope. So it wasn't [pause] so much - It was shock. But at that stage, tragedy hadn't set in. You know, it was that hope: We're gonna be like the Chilean Miners [They will all get out] - And that's what people were lead to believe... [But] they were completely different mines, as we know now.' Mulholland Interviews, July 2011, K (18.7.11) 3:34.

Other interviews refer to similar hopes that clearly indicate positive asymmetry: 'We were told there was this pipe going to be put down so they could breathe'.

'They told us that our men would be down there playing cards, joking, impatient to get out for the Game [televised sport]'.

'We thought they were saying that they were going to finally get them out...'

'We were told they were waiting for rescue down there, probably in the [FAB]'. (52) 
The end-result of all this positive asymmetry is to be seen with the announcement to gathered families on 23 November 2010 that their 29 men were, in fact, all dead.

'People dropped to the ground, mate,' a father told me in July 2011; speaking of the way families were informed of the deaths of their men, five days after the initial explosion. 'And they [had been] clapping. People [had been] clapping. They thought they were going in to get [the men out] you know. Everyone was clapping. And then they says No. No. There's been another explosion.'

Mulholland Interviews, July 2011, BM (14.7.11) 20:16-19.

'Why would they even build everyone up like that?' asked a man who lost his brother at Pike. 'Then, just go in there and shoot them all down?'

Mulholland Interviews July 2011 AM (14.7.11) 20:26.

'It was the [CEO] who broke it [the news five days after the first explosion] to the crowd; the families...' the mayor of Greymouth told me in July 2011. [We had gathered in the hall, on 24 November 2010]. And I'll never forget it as long as I live... We sat in anticipation [pause] And he [the CEO] says 'Ah,' he says 'We just been up the mine and when we got up there, we helicopter-ed up.' He says, the Search \& Rescue were all decked out; had all their gear on. They were going in_'

'Well, when he said that, we all started going_You bloody beauties!_This is the families. Could you imagine the scene?' said the mayor to me in July 2011, recalling it. 'And we said-That's fantastic, right? And my wife actually said to me. She said 'Tony_ Look at his face!' she says. 'He's_ This is wrong_'

And [the CEO motions down with hands]... And I thought we were playing the 'glad game'. And everyone quietened down. And [the CEO] he says 'Look sorry,' he says 'No. No,' he says 'They [the rescuers] were decked out to go in. But_we looked at a gas monitor because the gas levels had dropped right down in the mine,' he says 'And ah, let's run it back and have look at the film,' he says. 
See, it was a film thing too. That was that close circuit telly they could see outside. 'When we run it back,' [the CEO] says 'Sorry. We now realise that there's been a massive explosion. And there was no survivors...'

'Well, shit. At that point, we went from jubilation to the opposite, you know. Like, there's people collapsing. And they started wailing. And screaming and running out. Mulholland Interviews, July 2011 TK (14.7.11) 21:30-23:15.

'And that was a terrible moment which you wouldn't wish on anyone,' said the mayor of Greymouth 'It was just terrible. I mean, I still think of it. In the hall_the screams that came.' Mulholland Interviews, July 2011, TK (14.7.11).

'It's been very badly handled,' a grieving father told me in 2011 'We've been treated like bloody dirt, mate,' Mulholland Interviews July 2011 BM (17.7.11) 7:33; 15:59.

Matters were not going to improve for the families much either, in the months and years to follow, with their continued struggle to have just one government attempt to bring out the bodies of their men. This was denied them, even when international experts provided proof it would be safe to enter the drift to the mine (53) for an attempt to bring out the bodies of their men or any latent evidence; as they would have been coming out of the mine at the time of the explosion that Friday afternoon.

The families continued to fight on for this cause despite the added grief of betrayal they also experienced in relation to a system of broken promises. This is reflected in many of my earlier interviews with many of the deeply affected... We've been swept under the carpet; They're walking away from us, BM (5.7.12) 3:37; They sold, sealed, walked away (20.10.11 Pt2) 8:39; We'll be forgotten (20.10.11) Pt.4, 11:05; We've been written off the Books, BM (12.2.12 Pt2) 7:46; It's a huge impact, MP (9.2.12) 2:27; JO (15.7.11) 33:20; MO (14.7.11) 1:16; JL (15.7.11) 1:03; JB (10.2.12) 3:10; 3:59. Indeed, until very recently, every attempt to re-enter the drift of Pike River Mine was eclipsed, clouded and recast even though the Royal Commission had even said in its final report (54) that it was 'limited in its analysis' due to the lack of entry (Vol.2, 11:3) 'Because it has not been possible to access the underground parts of the mine in 
which significant electrical equipment is located, its installation and functioning, and its potential contribution to the explosion, cannot be determined.... the commission is compelled to limit its analysis'; (Vol.2, 14:59) 'Mr Reczek acknowledged that...the non-availability of information following the forensic analysis of the failed resistors in the United States all limited the weight that should be placed upon his opinions. Indeed, in another answer, Mr Reczek described his report as 'incomplete' because it involved 'drawing conclusions or inferences, based on information which is available [but] which isn't conclusive'.... 'Both inspectors gave candid evidence... DoL also commissioned an internal operational review of its inspectors' interactions with Pike River Coal Ltd. Conclusions from the Gunningham and Neal review are sometimes referred to in the chapter. In assessing these, and any different views expressed by the commission, it should be borne in mind that the review was based on departmental files (excluding health and safety investigations) and written without access to Pike managers or any post-tragedy documents'. (Vol.2, 15:2).

I reiterate here that the Royal Commission of Inquiry into the Pike River Mine did an excellent analysis of risk in the time that was allocated it. But again, what was not made clear was the unchallenged power that underlay all that documented risk.

With regard to cognitive asymmetry, I have (as with other researchers of positive asymmetry, power and disaster) often heard families of such tragedy mention in their interviews that they never expected it to happen (i.e. never saw it coming); only for them to then reference similar disasters and sometimes later conclude they were not surprised the tragedy had happened at all. I found this almost undulating cognitive asymmetry seemed to occur with the unravelling of shock, as participants attempted to make sense of what is too traumatising to even initially comprehend and I would argue that it is a different type of cognitive symmetry than that practised by the power of deregulated industry in the deliberate drive for profit.

An example of this would be the constant references of participants to other local disasters such as that of Strongman, Brunner and Davey Mines, and to the loss of 13 students and their guide at Cave Creek at a West Coast National Park in April 1995. In my own interviews, this 'making sense' of repetitive local tragedy and trauma was 
relayed often through references to associated sights and sound. There was for example, constant reference to helicopters overhead in relation to the Pike disaster, bringing back sudden memories of similar tragedies as in 'Oh no, I've had this feeling before', and to the point of people feeling often physically sick when they heard the whirring, thump of the wings or the sight and sound of the sirens of rescue services. There was also the later sight of ribbon and balloons that tied memories like kites to long lines of fatalities. I would say again that positive asymmetry, when practiced by families and survivors, is a certain form of coping and of surviving initial trauma.

The community of the West Coast was unique too, in that they knew from past experience of disaster that it was important to engage in indepth dialogue with each other in closed families meetings, on a regular basis at least once a week, for many months following the disaster; which had them reflecting on all their experience of tragedy and provided for a united front to face the powers that confronted them.

In this respect, the families of Pike River Mine were possibly using a form of cognitive symmetry the industry of Pike River Mine never had. These families showed how, despite all their trauma and grief, a whole placement of people can flip the cognitive symmetry right back around to being something that challenges the status quo via being dynamic, able to communicate at multi-dimensional levels, while working via structural webs which encouraged 'thinking outside the box' and often breaking with cultural conventions to find not only satisfactory, but innovative solutions.

If this sounds familiar then these are, of course, the very qualities that (Cerulo 2006) attributes to the running of successful industry and in forecasting the potential of a worst case scenario in time enough to divert it. Yet, those most affected by the loss of their 29 men, showed the very characteristics that could have saved their men had the business of Pike possessed and utilised any of these qualities from the start; i.e had those in power actually used the 'flip side' of positive asymmetry in their own enterprise to forecast the worst case scenario in the first place, to save them.

The cognitively liberating theme for the rest of us to consider, however, is that despite being basically betrayed and blind-sided by all the power, risk and positive 
asymmetry of the newly planted business of a deregulated industry, the people of the West Coast did not fade into their grief. They stood back up and gathered to themselves all their own past experience of being 'autonomous, service oriented, dominated by 'formal knowledge'; holding to their own explicit beliefs from highly articulated script for action' and despite affiliation with organisations, maintained considerable ability to monitor and control their own path in the struggle ahead. They had, even in trauma, managed to stand apart as they had once done so well historically (Chapter 1 ) in their struggle with the power of politics to say to the rest of the country 'We've had enough. If we have to fight this on our own again, we will'.

In so doing, the families of the West Coast have, at great cost to themselves, once again potentially provided the rest of New Zealand inadvertently with a template (if we are willing to see it) to constructively confront some fallout of the risk society (Beck, Giddens 1992) with a potential map of resilience, that we could all learn from.

Like risk, resilience arises from social order. It is not an accident that some families, communities, and societies are more resistant to, and better able to cope with disastrous events than are others. Disaster resilience... is rooted in a range of sociological, structural, economic, and cultural preconditions. (55)

I have sometimes been asked what we can do to keep families of workplace fatality from being blind sided in the future from the worst case scenario. We can of course attune ourselves to strategies of disaster resilience, (which is vital at the other end of the cliff). But we can no longer just wait there, in a state of socially organised denial. Neither can we afford to be silent, crushed by systems of power as fatalities roll in.

We can all learn to use the problematisation tools of (Bacchi 2009) to constantly ask probing and inciteful questions, and act. We can encourage the development of characteristics that (Cerulo 2006) and (Norgaard, 2011) promote in developing cognitive symmetry to find our way out of socially organised denial and confront the social organisation of mistake, technical deviance and structural secrecy. (Vaughan 1996). We need to examine culture of production and the production of culture, in 
order to solve this so that we might have healthy, profitable workplaces which actively forecast a worst case scenario for the well being of industry and all in it.

With the drive for production being what it is, however, it is imperative to have policy to implement this. The James Reason Model of Causation has always been a great model for indicating the need for exercising personal responsibility in the workplace. We have had plenty of training in that. This same model fails to look at the collective power of industry, however, with all its supporting systems and ask of them to do the same. So something has to change. This will require vigilance around the power and the drive of deregulated industry and the participation of whole communities asking active questioning around our fatalities. This might require a cognitive shift after decades of deregulation and neoliberalism but we do still have voice to stand and say we will no longer be part of a New Zealand experiment. (56)

We could also encourage whole communities existing around hazardous industries to learn from the cognitive resistance of the Pike River Mine Families to examine more thoroughly too, issues of power around industry and the need for more transparency with regard to national/international business practice in New Zealand, in the first place. Even well run industries with a low probability/ high consequence potential for disaster (Beck, Giddens 1992) should have the integrity to have a fundamental format as to how families are to be informed and dealt with in the event of fatalities. Some of the families of the Pike River Mine disaster have not (as of 2018) ever been officially notified of the deaths of their loved ones, all of whom remain entombed in the mine. And none in the company ever made an apology.

Finally, in following the analysis of [Norgaard 2011] and her own Norwegian study (57) although the families of Pike River Mine may have been 'blind-sided' to the disaster that killed their men, this was never just a case of a 'failure to learn' (although that is part of it); nor the preliminary result of any attention deficit model but rather, Pike River Mine was a case of risk, power and socially organised denial, supported by structural secrecy, technical deviation and the social organisation of mistake. (58) So any enactment of policy must speak to these findings to resist future fatality. 


\section{An introduction to Recommendations}

In conducting this research it is has been challenging to evaluate the work of the Royal Commission when, as I mentioned (Chapter 2) all the first-person evidence gathered by the commission has been embargoed for the next 100 years. I also mentioned in that chapter, that in a perfect world I would have been able to gather primary evidence from the Royal Commission itself to analyse this data from a cultural and sociological (rather than a structural risk management) perspective; but the data is not publically available for a century. So I attempted to do the next best thing and to use my own interviews (2011-2016) and place them alongside the findings of the commission's report. This is a beginning, but it is by no means ideal.

Having said this, the whole research experience, provided me with the unique chance as a teacher, journalist and academic to interview a wider sample of people across a traumatised community in the search for answers to risk, power and death in the New Zealand workplace and to issues of cognitive denial in related systems.

I must further reiterate this was not intended to be a comparative analysis but an introduction into what happened at Pike River Mine using the theorising of Cerulo (2006) on positive/negative asymmetry and that of others around issues of the social construction of risk (Beck, Giddens 1992, 2002); risk, and power in the workplace (Perrow 1999, Freudenburg 2013), the production of disaster (Tierney 2014) and that of socially organised denial (Norgaard, 2011) technical deviation, and the social organisation of mistake. (Vaughan, 1996). With this foundation in place, I now highly recommend a comparative study of the fatalities in the logging, farming, fishing and trucking industries in an Aotearoa/New Zealand context. (Curiously, the latter two are not yet part of the cohort of Worksafe NZ analysis) and they urgently need to be.

We also need to look to the work of Dr Rebbecca Lilley of the Injury Prevention Unit, at the Department of Preventative medicine of the University of Otago who tells me a major piece of work she and her colleagues will have published by the end of 2018 . 
'We are applying our own definition of work-relatedness (much broader than the legislative definition) to all the injury-related deaths for the last 40 years and will be able to look at trends in work deaths over this period.

It will be the most comprehensive data on work-related fatal injuries in New Zealand and the most complete dataset internationally. We plan to have the data ready by the end of this year (2018) as it takes quite some time to review over 1,000 annual injury deaths'. (59)

This data could be used to identify targets for policy and as interventions for prevention. Together we can make long term change but we need our websites to reflect accurately the real numbers of fatalities and injuries as they come through. There also needs to be further investigation, into the work of Norgaard (2011) and norms of conversation, emotion and attention that still have whole communities distancing themselves in a culture of socially organised denial. A further study of language that underlies risk would also be powerful to find the other junctions of cognition and belief that keep people blinded in socially organised denial. I would also suggest further investigation into the use of language and the powerful framing of debate following the research of George Lakoff (2014) in cognitive linguistics and neuroscience would be a very informative and rewarding place to start. (60)

It is also vital to encourage Te Ao Maori, Pasifica and the many cultures of this country to come together with renewed dialogue, experience and action reflection praxis, to collectively construct not just a workplace model of 'accidents' but one of workplace fatalities, calling it out for what it is in an Aotearoa/New Zealand context.

Pike River Mine was never a show case of production. It was a workplace with real living people in it who worked and died in a disaster that could have, and should have been averted. It was not. The deregulated, unaccountable drive for production occurs, to this day, in other New Zealand industries causing fatalities. It has to stop.

He aha te mea nui o te ao? He tāngata, he tāngata, he tāngata. (61) 


\section{Uncomfortable Truth no. 7}

'It is the nature of regulatory proceedings that those who are asked to 'live with' the consequences of the hazard most intimately are of the ones whose interests are least weighed in the decisions'. (62) It is time to change that.

\section{Recommendations}

The Inquiry does not have to end here. It was not within the scope of the Royal Commission to make anyone 'accountable' for what happened at Pike River Mine but this does not mean future enquiry has to end there. In that instance, it was 'risk' that was problematised before the commission, not 'accountability'. It is vital that we now look to issues of power that lay beneath that risk and use 'problematisation' (Bacchi 2009) to investigate and ask probing questions for viable long term solutions.

\section{(1) We must challenge the 100 year Embargo on Transcripts}

One of many silences to have been bypassed in relation to the case of Pike River Mine is there was (and still is) a 100 year embargo placed on many of the witness transcripts gathered up by the Royal Commission. This need to be challenged and was revisited recently by Dr Felicity Lamm of the University of Auckland in 2017.

'It is difficult, if not impossible to gain access to the thousands of documents gathered by the Royal Commission of Inquiry into the tragedy. The reason for the one hundred year embargo is outlined in an email from the Department of Internal Affairs Te Tari Taiwhenua: 'Access restrictions of 100 years have been placed on submissions and evidence to protect personal privacy as well as to maintain implied and existing undertakings in relation to confidentiality'. Families and friends of the deceased have reason to feel thwarted in their attempt to understand what really happened at Pike River Mine,' she said 'The Royal Commission answered a number but not all the questions. The Royal Commission did not determine the 'immediate cause' of the first explosion primarily because they were unable to enter the mine. 
And yet now when the drift to the mine can be accessed, the owners are seeking to seal it.' - Dr Felicity Lamm, Pike River Mine: Bring Them Home, (May 2017) para. 4. (First printed on the Briefing Papers website: http://briefingpapers.co.nz/pike-river-mine-bring-them-home

A case must also be made for transparency and access for use in evidenced research. The commission should reconsider the releasing of that data (redacted if necessary) to assist in future research and to help everyone come to terms with what happened at Pike River Mine. If we do not ask the right questions we will never find long term effective solutions to workplace fatalities. If we do not get the problem definition and theorising right, we will keep writing reports that fail to address issues fully.

\section{(2) The conversation must change from risk to power.}

We are still focussing on traditional risk prevention models; the very ones that were so willingly violated at Pike. The evidence shows we must examine issues around power and I suggest we begin by looking to the triple helix of power, risk and positive asymmetry that I have introduced in this thesis. We must practice greater vigilance and look to the junction of these three, for therein lies the perfect storm of conditions for tragedy for whichever industry practises it. If we fail to address this there will be more Pikes to come. In fact, they are already here in the multiplicity of single workplace fatalities still occurring in a number of New Zealand industries. We cannot continue to insist 'that we never saw that coming' when in fact, we did.

\section{(3) We should activate systems of protection and new legislation where needed.}

It can no longer be acceptable for anyone to create a business in this country believing that, as was articulated in my own findings, 'Well, New Zealand legislation at the time, didn't specifically not allow it. So that must mean we can do it.' (63) This would not be acceptable in Australia or the UK and it can not be acceptable here. We should have active policies and laws in place to protect everyone in the workplace, and prosecutions in cases of, for example, negligent homicide. There must also be a 'stand down' period for those under investigation from continuing to 
work in the same industry; their trade and industry tickets temporarily removed while under examination, and a record made accessible for both internal and international employees to refer to. Those involved in fatality should know they could be subpoenaed for further investigation should they try to leave the country.

(4) It is essential we revisit Andrew Little's draft legislation for Consultation of the Crimes (Corporate Manslaughter Act) Amendment Bill (pp. 229-234). As of May (2018) Dr Stephen Blumenfeld, director of the Centre for Labour, Employment and Work at Victoria University of Wellington, also referenced that negligence is indeed missing in the Crimes Act Repeal and that 'an offence of corporate manslaughter is needed to hold organisation and executives at the highest level accountable for deaths resulting from management findings'. In referencing this, he speaks to the deaths of 115 people in the collapse of the CTV building as a result of the 2011 Christchurch earthquake and to a number of other workplace disasters. https://www.victoria.ac.nz/news/2018/05/negligence-missing-in-crimes-act-repeal

(5) We need transparent and publically accessible comparisons made between groups in New Zealand, Australia, the UK and OCED countries

Contradictory statistics are a concern. This makes it very difficult to know the extent of workplace fatalities and injuries in New Zealand, and to measure trends. As of January 2018 the public really has to hunt for those 'workplace accident' statistics hidden away in the fabulous tabs of Worksafe NZ website and it is hard to tell why there appear to be inconsistencies. For example, the cohort of six 'focus' industries seems to differ markedly from that of the 'ten year strategy and national action agenda identified focus' on 'high-risk sectors' suggested by the Royal Commission. (64) Having made several polite phone calls, I am no clearer as to why certain industries are missing from the evaluations of Worksafe NZ. Their annual fatality statistics do not, for example, include the fishing and trucking industries which I am told are now 'defined as belonging' to some 'other' section of statistics, 'a bit like aviation'. That is all very well, but the omission of these statistics alone definitely skews the 'official' NZ workplace fatalities on an official site; although it might serve 
to reassure overseas applicants of the 'safety' of their industry before deciding to invest their experience in traveling halfway across the world to live and work here.

We urgently need to ask some probing questions around the use of statistics and how they are used to publically represent (or not) in a 'safe and improved New Zealand workplace'. The way statistics are reported can be affected by recasting practices when there is a culture of socially organised denial. This same website has a tab for ' 2010 ', for example, with no workplace fatality statistics for that year at all and this was the year 29 men died at Pike River Mine. The men of Pike have already been clouded from the memory by not being included on the NZ Worksafe website.

As New Zealanders, we also need to be more than the proverbial 'watch dogs' of any public website advertising itself as representing improved informative praxis; but it seems equally difficult in this country to get the required representation of reliable comparative statistics relating to our workplace fatality in other spheres as well.

Dr Rebbecca Lilley, SeniorResearch Fellow at the Injury Prevention Research Unit, Department of Preventive and Social Medicine of the University of Otago speaks to this problem in an interview I cited earlier with journalist, John Gibb in June 2016.

'Efforts to reduce New Zealand's 'appalling' death toll from workplace injuries are being handicapped by inadequate statistics, University of Otago researcher Dr Rebbecca Lilley said, adding that 'shortcomings in current information on work-related fatal injuries were a 'significant barrier to reducing workplace death'.... If all workplace injury deaths were recorded, she believed the death toll would be about 200 a year. Some deaths, such as those involving professional truck drivers, were not always being recorded as workplace fatalities, and other related road deaths were not always being picked up... After Pike River Mine... the reasons for New Zealand's 'poor performance' in workplace safety had been 'highly debated' but in-depth analysis was 'limited by a dearth of detailed work-related fatal injury data'. Statistics showed New Zealand workplaces were 'unsafe when compared to workplaces in UK, Australia and many other OECD nations", she said.' (65) 
Things can change and are changing. There are researchers in New Zealand working to understand our work related injuries and fatalities, contributing to creating safer workplaces and practice. In January 2018, Dr Rebbecca Lilley of the Injury Prevention Unit, at the Department of Preventative medicine of the University of Otago tells me that a major piece of work she and her colleague will publish by the end of 2018. (66)

This data could be used to identify targets for policy and as interventions for prevention. Together we can make long term change but we need our websites to reflect accurately the real numbers of fatalities and injuries as they come through.

\section{(6) We must confront issues of 'production before Safety' in the workplace.}

As has been noted in this thesis, the case of Pike River Mine was one of deliberate risk, and hibernating beneath that risk was (and still can be) a base of unchecked power. The culture of 'production before safety' continues to exist in a number of other industries in New Zealand. The good news is, much of that culture is now discussed and made visible by of all those dedicated to working for new health and safety legislation in this country. The problem is, although we may stabilise risk we will always have difficulty lowering the rate of workplace fatalities, long term, in our industries until we choose as individuals, as industries and as a nation to recognise and confront cultures of power that still exist beneath production and risk. (67)

\section{(7) We must identify and challenge issues around power, risk and recreancy}

In looking to identifying and resolving issues around power, risk and recreancy, further analysis of Freudenburg (1986-2009) we must incorporate his findings into any future health and safety praxis. In his own research Youn (2013) writes 'Freudenburg argued that future research should focus on the examination of institutional behaviours that provide reason to believe that some portion of our increasingly complex and interdependent societal system can no longer be counted on... There is a need for more work to examine the kinds of institutionalised arrangements that are most, or least, likely to foster recreant behaviour and about the factors that can foster the efforts of recreant officials and organisations to evade the responsibility for their failing. (68)... 'Perhaps the next level of questions as 
Freudenburg advocated should focus on the societal impact of these recreant behaviours. Do institutional failures affect social structure and social relations of organisations and institutions in society? Freudenburg [wanted] a more institutional analysis of policy-making organisations. How are visible structures and routines of policy making organisations affected by wider organisational environments?' (69)

\section{(8) We must include Te Ao Maori \& Pasifica perspectives in creating new models}

There is an urgent need to look at the framing of language, context and the lack of voice from Te Ao and Pasifica perspectives. Other than the empowering voice of pioneers in health perspectives like those of Mason Durie, Sione Tu'itahi, Leti Lima and Mihi Ratima (70) there seems to be a striking absence of analysis of voice in relation to workplace fatalities from Kaupapa and Pasifica perspectives. This is a huge silence in an Aotearoa/New Zealand context. It is vital that Matauranga Maori and Pasifica voice be central to the development of any new model or praxis.

How much, of the former culture of Pike Mine is still occurring, for example, in other industries with repetitive workplace fatalities, affecting the lives of Maori, Pasifica and many other iwi of this land? What are the interwoven threads of this tragic kete we are still not seeing? How and where is it occurring? Why are we still allowing it?

In discussing what Pike River Mine was a case of, we must start a new conversation to spur us all into collectively creating dialogue and action-reflection praxis around health and safety, using the language and experience of many cultures in the workplace to create visible and authentic change. We must look anew at problemquestioning, problem-solving and building authentic cultural and systemic models that really do provide enduring solutions in and Aotearoa/New Zealand context. This is begun in the hope that others will come forward to add to it their own experience, strength and hope to create a relevant and constructive model of new beginnings. 


\section{(9) We must challenge language i.e 'Accidents' vs. 'Fatalities' in the workplace}

Language and context matter. How the problem is constituted really matters too. 'This is because the way in which the 'problem' is represented carries all sorts of implications for how the issue is thought about and for how the people involved are treated, and are evoked to think about themselves.' (71) We need to realise the power of language and stop referring to 'workplace accidents' in this country when they are in fact 'workplace fatalities'. We also do not now so much need to address a model of workplace 'accident causation' as one of 'fatality causation' in context. We must constantly challenge how workplace 'injuries' are represented (or not) in data.

We must also challenge for example, language around 'mine re-entry' when we are in fact seeking the re-entry of the drift. Words like that matter, or they can alienate support from those who do not understand the difference; not only to bring the men home, but for closure and any latent evidence the Commission said was missing. (72)

\section{(10) We need to be vigilant for Arrows of Causation and the Triple Helix of tragedy}

In presenting arrows of causation, there is a need to realise any 'error-tolerant' systems we are now designing, will only ever work insofar as there is an 'errorintolerant culture' inside the industry. We must include in any new model of causation reference to the Helix of Workplace Tragedy (HWT) as the issues of power, risk and positive asymmetry intersect to create the perfect storm conditions for workplace tragedy. We need to incorporate understanding of eclipsing, clouding and recasting (Cerulo 2009) into our analytical models. We must use practical indicators for cognitive symmetry and socially organised denial to guide us both individually and collectively to forecast worst case scenarios in time to face up and divert them.

\section{(11) We must look to the incorporation of cognitive symmetry into safety culture}

This will require an understanding of both positive and negative asymmetry and policy to implement training that encourages the dynamic, flexible characteristics in praxis to which both Cerulo (2006) and Norgaard (2001)refer. This means working to communicate at multi-dimensional levels via structural webs that encourage thinking 
'outside the box' to find not only satisfactory, but innovative solutions for industries that while affiliated with organisations, still maintain considerable ability to monitor and control themselves. (73) This will, of course, be challenging, given that Aotearoa has been swept up by over three decades of deregulation and associated webs of power and risk but it is possible to move away from the 'New Zealand experiment' of neoliberalism. (74) It is possible to have both safe and profitable work environments.

\section{(12) We must decipher links between cognition and socially organised denial}

In implementing strategies that create effective long term solutions we must look to links between cognition and emotion. What happened at Pike River Mine was not the result of an attention deficit model. There was plenty of information. It was not acted upon. There were some safety systems. They were not utilised. We need to incorporate the analysis of [Norgaard 2011] and challenge how people collectively distance themselves from disaster not just due to the norms of attention but to those of conversation and emotion. To combat socially organised denial (Norgaard 2011) dialogue must be encouraged across all levels of the system with reflective praxis. This was clearly not happening at Pike River Mine and needs to be actively challenged in a deregulated system with reference to other industries as well.

\section{(13) We should look to structural secrecy, technical deviance and the social organisation of mistake in our analysis and development of a new model}

In developing a model of causation for finding solutions to workplace fatality we need to look to the analysis of Vaughan (1996) around issues of structural secrecy, technical deviance and the social organisation of mistake. We can no longer afford (on any level) allow 'technical deviation... [whereby ] predictions [are] redefined as an acceptable risk in official decisions; [where] this sequence [is] repeated until it becomes a pattern.' Or where, each time 'there were anomalies that were signals of potential danger the outcome [was ] to accept the risk...[until] this pattern indicated existence of a work group culture in which [even those] working most closely on problems constructed beliefs and procedural responses that became routinized'. (75) 
(14) We need training to be alert around interactive complexity, the potential of mundane tightly coupled failures, and cascading of failure to worst case scenario

Policy must be implemented to assist with the training, identification and resolving of issues around the interactive complexity and the potential for often mundane tightly coupled failures (Perrow 1999) that subtly affect one component or process in the system, in order prevent them 'cascading' into chain reaction and failure. An industry which is alert to its own potential interactive failures would be a happier and more profitable one in the long term with better outcomes around production as a result of more vigilant solutions to problems that are more effectively resolved.

Further dialogue and analysis must also centre around the analysis of Perrow (2010) who later agreed, for example, that while there were requisite system characteristics present in the (2008) financial melt down, this failure was primarily the consequence of the behaviour of financial elites who were aware of the risks inherent in their activities but who acted in disregard of their own institutions, their clients and the public. (76) I argue that Pike River Mine was also one of power, drive and financial 'melt down' in which 'many requisite system characteristics were indeed present' and ignored. The findings of the Royal Commission show a mine beleaguered with financial concerns right up to the day of the fatal explosion. (77) Issues of recreancy lay beneath the risk with no later accountability. This needs to be addressed.

(15) There must be training around identification of eclipsing, clouding, recasting practices (Cerulo 2006) that fail to recognise an impending worst case scenario in the drive to meet production targets (p. 266); accompanied by improved legislative and administrative changes to actively deal with these wherever they appear at any level of the system; as some disasters are 'built on a series of faulty decision making sequences, which when repeated without much consequence gradually become a trusted paradigm'. (Vaughan 1998). Looking to the Triple Helix of power, risk and positive asymmetry could be a useful heuristic tool here, as would the development of negative asymmetry and symmetrical vision as espoused by Karen Cerulo (2006). 
(16) A comparative study of the fatalities in the logging, farming, fishing and trucking industries in an Aotearoa/New Zealand context must be made once the data from Dr Rebbecca Lilley's data study is published at the end of 2018. The latter industries also need to be included in the cohort of Worksafe NZ analysis with all industries regularly updated with clear citation of statistics on the website.

(17) We must have more inspectors of mines and other hazardous industries. These must be trained in the trade and be given training on a regular basis to be updated and informed in their field in order to directly address issues of concern.

(18) We must bring back apprenticeships in trades where the newly trained can continue to work alongside mentors via 'internship' for a period of time. This could be supported by requiring the applicant to work in their industry for a defined time post-apprenticeship, securing themselves employment and returning their skills to the country, in much the way New Zealand did prior to decades of neo-liberalism.

(19) All workplace must have evidence of the format and the protocol to be followed in dealing with fatalities and the reporting of deaths to families and loved ones. There must be designated personnel who are trained in the gathering and delivering of this information effectively and with compassion which does not add any more to the trauma already being experienced by those directly affected.

\section{(20) Strategies, collaborative dialogue and action reflection praxis must be}

\section{developed and revisited regularly around risk and resilience}

In looking to the power and recreancy that underlies risk in industry and the workplace, we need to also have policy that implements action reflection praxis of cognitive and social developments in risk and resilience in order to confront it.

Tierney (2014) states 'Both risk and resilience are socially produced, pointing out again that since this is the case, societies, communities, institutions, and organisations can reduce risk and achieve higher levels of resilience. However, because risk and vulnerability are outcomes of the exercise of political and economic 
power in their various forms, confronting risk also means confronting power. For this reason risk and resilience-related efforts must go beyond current approaches.' (78)

We need to exercise specific vigilance around 'regulatory capture'; a situation (Tierney 2014) describes as being one in which 'those charged with policing the operations of an industry are incapable of doing so, typically because industry wields overwhelming power'. (79) 'Regulatory capture is a form or rent seeking or activity that aims at influencing government policies and activities in ways that create advantages for groups that are exerting such pressure. (80)So, extra vigilance is vital of low probability/high consequence risk (Beck, Giddens 1998) in all our industries.

\section{(21) We need to re-enter the drift of Pike River Mine and bring the men home.}

We've been swept under the carpet... They're walking away from us.... It's sold, sealed and they're walking away....We'll be forgotten... Written off the Books... It's a huge impact. (81)

The families do not want to enter the mine. They want to re-enter the drift of the mine. There is a difference in engineering terms. Words, context and concepts really do matter in framing this. The media and other commentators must use the correct terminology for the scenario. Misinformation clouds and recasts viable solutions.

The retrieval of remains after any death scene is spiritually and emotionally important to many Maori and Pasifica cultures and equally, to many Celtic iwi. One attempt is all that is asked for; which is the least that could be done for the families, given the way they have been treated through this entire process. There is not one family member who would risk the life of another for the retrieval of their men and that is why they have spent so much time collecting international evidence to assure safety. In entering the drift there is also a chance of bringing back vital evidence which even the Royal Commission referred to the lack of, in coming to its own conclusions and findings. (82) At the very least, families deserve to know if there are remains or evidence left in the entrance to the mine, so they can finally have closure. 
'There was an article in the local paper,' Kath Monk said as we sat before a winter fire in 2011. Her son Michael, aged 23, had been killed at Pike. 'There was once this miner who'd come here... from Italy...' she said. 'There was an accident and he was killed. 70 years later his family from Italy have dug the grave up....So they're taking his remains back to Italy where he belongs.' 'It's important,' I said. 'It is,' she said. 'It never goes away.' (83)

'There's a real feeling of despair for the families around the recovery of the bodies,' said a community leader in 2012 'There's no closure. And everybody knows getting closure for the families would be so important.' (84)

'You get the managers and the official books,' said Harry Bell, former chief inspector of mines who tried to warn, as early as 1990, of another impending mining disaster. 'You get them. And you go through them. And sign them, to say that you've seen them. But you see now,' he told me in March 2016, 'They got all these check lists....And they just tick it [tick, tick, tick] And sign them. And they think everything's alright. And it's not. It's not alright.' (85)

It is time for change. Every worker should be able go to work in trust that they will have as much chance as anyone else, to return home again at the end of the day.

He aha te mea nui o te ao? He tāngata, he tāngata, he tāngata What is the most important thing? It is the people, the people, the people.

\section{Endnotes: Chapter 7}

(1) WorkSafe evidenced that the highest workplace fatalities for New Zealand in (2017) were in agriculture, forestry and construction. https://worksafe.govt.nz/dataand-research/ws-data/fatalities/workplace-fatalities-summary/

(2) Vaughan, Diane. (1996) The Challenger Launch Decision: Risky Technology, Culture and Deviance at NASA, USA: The University of Chicago Press, p. 112. 
'...We see the first occurrence of the five-step decision sequence revealing the initial choices that would become a pattern... [That] decision sequence allows us to follow the negotiation of risk as the first evidence showing that the behaviour of the technical component was deviating from predictions was normalised.' p.11.

(3) Bacchi, Carol. (2009) Analysing Policy: What's the Problem Represented to be? Australia: Pearson.

(4) Dr Lamm, see Chapter Six, Note (20-21) Also, Briefing Papers:

http://briefingpapers.co.nz/pike-river-mine-bring-them-home

(5) The Royal Commission of Inquiry on the Pike River Mine Tragedy NZ, Te Komihana a te Karauna mo te Parekura Ana Waro te Awa O Pike (2012), Vol.2, 3:75, See 'Culture of Production Before Safety'. Vol.1, p. 19; Vol.2, 13:10, 13:20.

(6) Boston, Jonathan. (2017) Safeguarding the Future: Governing in an Uncertain World, Bridget Williams Books (BWB) Texts. Wellington, New Zealand, p. 14-15. Ibid., p.16 Boston defines 'poor anticipatory governance' as including the 'failing to exercise proper foresight...by ignoring 'creeping' problems and those which have a cumulative or snowballing dimension; downplaying certain kinds of risks, including systemic risks; delaying measures to mitigate and manage well-established risks and retaining policies that are demonstrably unsustainable, whether economically, socially or environmentally.'

Ibid, p.11 'Good anticipatory governance...requires a commitment to 'future proofing' public institutions and protecting the long-term public interest. This means taking the long view... It means giving proper attention to issues with long-term consequences, proactively identifying, mitigating and managing significant threats, wrestling with complex intertemporal trade-offs, and recognising the risk that pressing day-to-day demands can readily override more distant, but far more weight concerns...It means taking care of tomorrow today'. 
(7) Lakoff, George. (2014) Don't Think of an Elephant: Know Your Values and Frame your Debate, USA: Chelsea Green Publishing. See also, Lakoff, G., Johnson, M. (1980) Metaphors We Live By, USA: University Chicago Press.

(8) Ibid., (xii); See also (1980) Metaphors We Live By, USA: University Chicago Press.

(9) Bacchi, Carol. (2009) Analysing Policy: What's the Problem Represented to be? Australia: Pearson, p 1.

(10) Royal Commission of Inquiry (2012), op. cit., 2.Vol.2, 6:9; 'On occasion, Pike hired for specialised roles, individuals who required intensive on-the-job learning amid the pressure for coal production.

An example of this includes 'the hydro co-ordinator had no previous hydro mining experience. He had made this clear when interviewed for the position. He was promised training and support and was confident he could up-skill. But he received no formal training and was 'a little out of my depth because of my lack of knowledge of hydro machinery and equipment'. Other applicants with operational hydro mining experience at West Coast mines applied for the role but were unsuccessful." See also www.stuff.co.nz/the-press/news/pike-river-disaster/.../Mine-boss-out-of-his-depth

(11) Mulholland Interviews, October 2014, V (2.10.14) 1/02: 52:25.

(12) 'Show Case Development' Royal Commission of Inquiry (2012), op. cit., Vol.2, 3:67 '...DOC recognised Pike River for 'the environmental consideration it had demonstrated in the establishment of [its] mining facilities...Two months later, on a visit to the mine, Minister of Conservation added it was a 'showcase development which had set a new environmental standard for coal mining'.

Royal Commission of Inquiry (2012), op. cit., Vol.2 13:9, 'Pike had a strong environmental culture. When the company received an award from the Department of Conservation (DOC) in September 2008, the minister of conservation shortly afterwards described the mine as a showcase development'.

(13) 'Show Stoppers' Royal Commission of Inquiry (2012), op. cit., Vol. 2 12:50. 'These actions were not allocated to individuals until 16 September 2010, three days before hydro extraction began. In emailing the list to key personnel, Mr White stated 'None 
of these issues are show stoppers and some will take time to implement'. Many of these requirements had not been attended to before the explosion on 19 Nov 2010.' (14) Lakoff, George. (2014) Don't Think of an Elephant: Know Your Values and Frame your Debate, USA: Chelsea Green Publishing; See also, Lakoff, George. (1996) Moral Politics: How Liberals and Conservatives Think, USA: University of Chicago Press. See also, Lakoff., Johnson. (1980) Metaphors We Live By, University of Chicago Press. https://www.youtube.com/watch?v=n4UfGZOPJjE

(15) Cerulo, Karen. (2006) Never Saw it Coming: Cultural Challenges to Envisioning the Worst, Chicago: University of Chicago Press.

(16) Royal Commission of Inquiry on the Pike River Mine Tragedy NZ, Te Komihana a te Karauna mo te Parekura Ana Waro te Awa O Pike, (2012) Vol.1; Vol.2.

(17) Cerulo., op. cit. p.235.

(18) Cerulo, op. cit., pp. 187-192.

(19) Ibid., p. 193.

(20) For further discussion of this, see, Kelsey, Jane. (1995) The New Zealand Experiment: a world model for structural adjustment? Auckland, N.Z.: Auckland University Press; Bridget Williams Books. See also Kelsey, Jane, (2015) The Fire Economy: New Zealand's Reckoning. Wellington, New Zealand: Bridget Williams Books with the New Zealand Law Foundation.

(21) For further understanding of socially organised denial and the links between risk and cognition, see Norgaard, Kari Marie. (2011) Living in Denial: Climate Change, Emotions and Everyday Life, Cambridge, Massachusetts: The MIT Press.

In her own study of a Norwegian community Norgaard examined, for example, how people experienced disturbing information in their direct environment and then failed to react, even when it deeply affected them physically, culturally and economically. She discovered that this was not the result of an information deficit model. The community had plenty of information. She analysed why they were not acting proactively in defense of the repetition of loss in time to save themselves. 
(22) Tierney, Kathleen. (2014) The Social Roots of Risk, Producing Disasters, Promoting Resilience, Stanford University Press, p.5.

(23) Ibid., p. 6.

(24) Vaughan, Diane, op. cit., (1996). See also Vaughan, D (1998) Abstract, Re:

Rational Choice, Situation in Action and the Social Control of Organisations. Law and Society Review 32, 1 June 1998: 23-61.

(25) Perrow, Charles. (1999) Normal Accidents: Living with High-Risk Technologies, New Jersey: Princeton University Press.

(26) Tierney, Kathleen. (2014) op. cit., p.98. See also her reference to Perrow in her comment on the Three Mile Island (1979) nuclear power plant incident. 'Three Mile Island facility and the Fukushima plant [are] examples of complexly interactive and tightly coupled systems that are subject to runaway processes of destabilisation and degradation often as a consequence of relatively mundane component failures' p.99. (27) Ibid., p.100; Kathleen Tierney's reference to Charles Perrow (2010).

(28) Royal Commission of Inquiry (2012) op. cit., Vol 1. p.17; The Company Situation: '...Development costs escalated over the $\$ 143$ million figure projected in 2007. Pike required capital and during 2010 it raised $\$ 140$ million from shareholders, and was seeking another $\$ 70$ million as at 19 November and also borrowed $\$ 66$ million from NZOG. [New Zealand Oil and Gas].'

See also. Royal Commission of Inquiry (2012) op. cit., Vol.2, 3:70. Note: David Salisbury witness statement, 25 May2011, NZOG0068/24, para, 95, 147, 151. 'In May 2010 NZ Oil and Gas (NZOG) advanced the company US \$28.9 million (NZ\$41 million) upon the security of a convertible bond. This sum was required to pay a debt owed a Goldman Sachs entity (Liberty Harbour) after Pike River breached a production covenant contained in the loan agreement. In September NZOG also granted a short-term loan facility of $\$ 25$ million to meet a projected cash shortfall. In October Pike River drew down \$13 million’.

For more background to this, see Pike River Coal Ltd, Prospectus, DAO.012.02790/7. 
'In its 2007 prospectus Pike River anticipated that coal production would begin in the May 2008 quarter, with production of 243,000 tonnes for that calendar year, which would generate a cash flow of $\$ 38$ million at an average sale price of $\$ 157$ per tonne. The first two first two coal shipments were not until February and September 2010, when 20,000 and 22,000 tonnes respectively, were sold for around $\$ 9$ million. In October the company announced that its production forecast to June 2011 was downgraded from 620,000 to $320,000-360,000$ tonnes.' Vol. 2, 3:68.

Pike River Coal Ltd, Annual Review 2010, 22 September 2010, DAO.0008.05092/12. 'The company therefore had to raise funds to meet operational and capital costs in each of its last three years of operation. In February 2010 Pike River announced a $\$ 90$ million fundraising initiative. It raised $\$ 10$ million from a share placement in April and $\$ 40$ million from a rights issue in May. By October 2010 capital raised over the pervious three years had increased the number of ordinary shares on issue from 200 million on listing in 2007 to over 405 million'. Vol. 2, 3:69.

(29) On 18 November, the day before the explosion, the company was on the brink of raising a further $\$ 70$ million capital involving a share placement to ordinary shareholders of $\$ 25$ million and to institutional investors of $\$ 45$ million, fully underwritten by a major international investment bank. [It was] considered that this $\$ 70$ million would have carried the company through to the third quarter of 2011 when 'we expected to be in fully steady state hydro mining'. Royal Commission of Inquiry (2012) op. cit., Vol.2, 3:71. See also: John Dow, transcript, pp. 3931-32. (30) Tierney (2014) refers to the 'production of disaster embedded in the social order' in her own analysis of Hurricane Katrina (2005), the Haiti Earthquake (2010) the Deepwater Horizon BP Oil Spill off the Gulf of Mexico (2010) and the financial meltdown of 2008 , stating 'disasters and their impacts are socially produced, and the forces driving the production of disaster are embedded in the social order, itself.' (31) Freudenburg, W. R. (2013). A Life in Social Research: 21; Research in Social Problems and Public Policy ed. Susan Maret, UK: Emerald Group Publishing, p. 121. (F, 1993, p. 915, also F, 2000). 
(32) Ibid., p. 121. See also...Freudenburg, W; Gramling, R; Laska S; and Erikson Kai. (2009) Catastrophe in the Making: The Engineering of Katrina and the Disasters of Tomorrow. Washington, D.C.: Island Press.

(33) Ibid., 121-123.

(34) Cerulo, Karen. (2006) op. cit., p. 235.

(35) Ibid., p. 237.

(36) Ibid., p. 238.

(37) Callaghan, Kathleen. (April 2013) www.zeroharm.org.nz/leadership/casestudies/pike- river

(38) Mark Parcell, a mines safety consultant based in Brisbane, often accompanied by former Royal Commissioner, Stewart Bell, ran a series of seminars re: Pike River Mine tragedy in New Zealand and Australia. Pike River NZ Workplace Safety Seminar, Wellington, 2 October 2014. https://www.minesafetyinstitute.com.au See also Pike River: A Failure to Learn [DVD] 2014 www.PikeRiver DVD.com.

(39) Hazel Armstrong, a personal injury attorney in Wellington, New Zealand who specialises in accident compensation (ACC) law, employment law and health and safety law. She is author of 'Blood on the Coal, The origins and future of New Zealand's Accident Compensation Scheme', Trade Union History Project, Wellington, 2007; 'Your Life for the Job, New Zealand Rail Safety 1974-2000', Labour History Project, Wellington, 2013. Hazel is also involved in education around the country, re: Worksafe Reps, Initial Health and Safety Representatives Training, Under the Health and Safety Work Act 2015; See also, Stage 2: Managing Risks (2016).

support@worksafereps.org.nz

(40) Cerulo, Karen op. cit., p. 239.

(41) Ibid., p. 240.

(42) Ibid., p. 242.

(43) Ibid., p. 242-243. 
(44) Ibid., p. 236. See also the work reviewed in Reisberg 2001,

(45) Bacchi, Carol. op. cit., (2009); see also Chapter 6, Note (76) for the six questions.

(46) Ibid., (vii).

(47) Ibid., (xii).

(48) Ibid., (xii-xiii); see Note (45).

(49) Gibb, John. op. cit., https://www.odt.co.nz/news/dunedin/nz-workplace-deathrate-appalling 16 June 2016. See also: Demelza Leslie, Senior Political Reporter, Safety law fails to curb workplace death rate, 23 November 2016.

https://www.radionz.co.nz/news/national/318693/safety-law-fails-to-curbworkplace-death-rate; Paloma Migone, Wellington Bureau Chief, Seven workplace deaths in a fortnight, 24 April 2017.

http://www.radionz.co.nz/news/national/329339/seven-workplace-deaths-in-afortnight; Te Aniwa Hurihanganui, Te Manu Korihi Reporter, Five forestry deaths this year spurs new safety call, 28 August 2017.

https://www.radionz.co.nz/news/national/338149/five-forestry-deaths-this-yearspurs-new-safety-call

(50) Royal Commission of Inquiry op. cit., Vol.1, Vol.2.

(51) Vaughan, Diane. (1996), op. cit., p. 114.

(52) The (FAB) or Fresh Air Base is 'an underground room-like sealed facility to maintain a respirable atmosphere in emergencies.' Royal Commission Inquiry (2012), op. cit., Vol.1, p. 11 See also, Vol.2, 7:16, 7:55, 16:118-123.

In reality however, the drive to produce coal in 2010 at Pike River Mine led to a view that management of some hazards could await the implementation of a long-term solution, when for example, suitable second egress and a usable fresh air base (FAB) should have been high-priority safety requirements. Vol.2, 7:16.

A proper FAB was not completed by the end of June (2010) There was only a pulldown brattice stopping to isolate the slimline shaft stub. This was in interim measure 
while the $F A B$ was designed and ventilation surveys undertaken. Vol.2, 7:46. The interim safeguard of a proper FAB had not eventuated either. A fundamental concern of the workforce remained unaddressed - eight months after it was first raised. Vol.2, 7:49. These details would have been known to Pike Management.

(53) The 'Drift' is the $\mathbf{2 . 3} \mathbf{~ k m}$ stone tunnel leading into the mine. It is not the mine proper. The families have had international evidence for years that it is safe to reenter the $2.3 \mathrm{~km}$ stone drift to make just one attempt to bring back home any remains they can find of their men, given that many would have been coming out that tunnel in a bus on the Friday afternoon in the moments before the $3: 45 \mathrm{pm}$ explosion. There were two survivors who walked out, one of them was only saved because his mate, Daniel Rockhouse found him and dragged him out despite the potential loss of his own life. It is likely there were others coming out the drift. There could also be latent forensic evidence in this tunnel or at the very least the chance for some closure and resolution after a seven year struggle to be heard.

(54) The Royal Commission (2012) op. cit., Vol. 1 \& 2.

(55) Tierney, Kathleen. (2014) op. cit., p. 6.

(56) Kelsey, Jane. (1995) The New Zealand Experiment: a world model for structural adjustment? Auckland, N.Z.: Auckland University Press ; Bridget Williams Books.

(57) Norgaard, Kari Marie, op. cit., (2011).

(58) Vaughan, Diane. (1996) op. cit., p. 11, 61, 75. Also, 'structural secrecy' p. 398. See also: Cerulo, Karen. (2006) op. cit., p. 60.

(59) Email from Dr Rebecca Lilley, University of Otago, to Catriana Mulholland, 15 January 2018.

(60) Lakoff George. (2014) Don't Think of an Elephant: Know Your Values and Frame your Debate, USA: Chelsea Green Publishing.

'All thoughts are physical. Thought is carried out by neural circuits in the brain... $98 \%$ of what our brains are doing is below the level of consciousness.... Yet we act on the basis of those largely unconscious thoughts. Cognitive science... found ways to study 
unconscious, as well as conscious modes of thought... to find out and let the world know what is determining our social and political behaviour... I believe such knowledge can lead to positive and political change. Why? Because what goes on in people's brains matters.' Lakoff, George op. cit., (xi)

'Frames are mental structures that shape the way we see the world. As result they shape the goals we seek, the plans we make, the way we act and what counts as good or bad outcome of our actions. In politics our frames shape our social policies and the institutions we form to carry our policies. To change our frames is to change all of this. Reframing is social change.... Even when you think of a frame, you activate the frame. If I tell you 'don't think of an elephant'. You think of an elephant. Though I first found this out in the study of cognitive linguistics, it has begun to be confirmed in neuroscience'. George Lakoff, op. cit., (x-xiii).

(61) He aha te mea nui o te ao? He tāngata, he tāngata, he tāngata What is the most important thing of all? It is the people, the people, the people. (62) Freudenburg, William. (2013) A Life in Social Research: 21; Research in Social Problems and Public Policy ed. Susan Maret, UK: Emerald Group Publishing, p. 121.

(63) Mulholland Interviews, October 2014, V (2.10.14) 1/02: 52:25.

(64) Ibid., Vol. 2, 24:43 p. 294 , fig. $24: 4$.

(65) Dr Rebbecca Lilley interviewed by John Gibb., op. cit., NZ workplace death rate 'appalling' 16 June 2016.

(66) Email from Dr Rebecca Lilley, University of Otago, to Catriana Mulholland, 15 January 2018. Dr Lilley is a Senior Research Fellow at the Injury Prevention Research Unit, Department of Preventive and Social Medicine, University of Otago, NZ.

'We are applying our own definition of work-relatedness (much broader than the legislative definition) to all the injury-related deaths for the last 40 years and will be able to look at trends in work deaths over this period. It will be the most comprehensive data on work-related fatal injuries in New Zealand and the most complete dataset internationally. We plan to have the data 
ready by the end of this year (2018) as it takes quite some time to review over 1,000 annual injury deaths'.

Note also: Journalist John Gibb, interviews Dr Lilley op. cit., NZ workplace death rate 'appalling' 16 June 2016, "The reported death rate from workplace injuries was 'appalling" and had to be addressed... Every year, one in 10 workers was injured at work in New Zealand. Most recent estimates indicated more than 100,000 workers required time off work, 12,000 were permanently disabled and 105 were killed every year from work-related injuries... Her research focus was on 'creating safer workplaces' and 'understanding our work-related fatalities... This research would address the need for comprehensive and informative fatal injury data by using coronial data, which had been shown to yield 'high-quality, rich information with comprehensive capture of work fatalities. The data would be used to 'identify targets for policy" and for 'interventions for prevention'.

(67) Vaughan, Diane. (1996) op. cit, p. 65.

(68) Youn, Ted, I.K. 'Toward a better understanding of social problems and policy making: Institutionalism of William R. Freudenburg', W. R. (2013), p. 115, in A Life in Social Research: 21; Research in Social Problems and Public Policy ed. Susan Maret, UK: Emerald Group Publishing.

(69) Ibid., pp. 115-116. See also Freudenburg, W; Gramling, R; Laska S; Erikson Kai. (2009) Catastrophe in the Making: The Engineering of Katrina and the Disasters of Tomorrow. Washington, D.C.: Island Press.

(70) Durie, Mason; Ratima, Mihi. And Hond, Ruakere. 'Maori health promotion', Signal, L., Ratima , M. eds. (2015) Promoting Health in Aotearoa/New Zealand, NZ: Otago University Press, Pp. 42-63.

(71) Bacchi, Carol. (2009) op. cit, p. 1.

(72) Royal Commission of Inquiry (2012) op. cit., Vol.2, 11:3; Vo.2, 14:59; Vol.2, 15:2.

(73) Cerulo, Karen. op. cit., pp. 187-192.

(74) Kelsey, Jane. (1995) The New Zealand Experiment: a world model for structural adjustment? Auckland, N.Z.: Auckland University Press; Bridget Williams Books. 
(75) Vaughan, Diane. op. cit., p. 61.

(76) Tierney, Kathleen. op. cit., p.100.

(77) Royal Commission of Inquiry (2012) op. cit., Vol.2, 3:71. See also Note (28-29).

(78) Tierney, Kathleen. op. cit., p. 94.

(79) op. cit., p. 9. See also, Perrow, C (2007) the Next Catastrophe: Reducing our Vulnerabilities to Natural, Industrial and Terrorist Disasters, New Jersey, Princeton University Press.

(80) Ibid., p. 96-97.

(81) See, BM 5.7.12, 3:37; 20.10.11 Pt2, 8:39; 20.10.11, Pt.4, 11:05; BM 12.2.12 Pt2;

7:46; MP 9.2.12, 2:27; JO 15.7.11,33:20; MO 14.7.11, 1:16; JL15.7.11, 1:03; J 10.2.12.

(82) Royal Commission of Inquiry (2012) op. cit., Vol.2, 11:3; 14:59; 15:2.

(83) Mulholland Interviews, July 2011, KM (17.7.11) 70:16.

See also: 'The families have had to fight the whole way for everything.' Ibid., October 2011, BM (20.10.11) Pt.2, 9:08.

(84) Mulholland Interviews, February, 2012 JOS (7.2.12) 6:18.

(85) Mulholland Interviews, March 2016 HBE (28.3.16) 44:40.

My time then became listening; letting people cry, sob, scream, yell; whatever they wanted to do. And I would pick up the pieces. And then when it was time for them to leave - Not on my terms - When they were ready to leave - they'd go. And I'd shut the door. I would have my cry. I'd pull myself together, open the door; go out, and go through the next bit... [That's what we do]. Mulholland Interviews, February 2012, JB (10.2.12) 13:05. 


\section{Bibliography}

Andrews, M., Sclater, S., Squire, C. and Treacher, A. (2004) The Uses of Narrative; Explorations in Sociology, Psychology and Cultural Studies, New Brunswick: Transaction Publishers.

Antze, P and Michael, L. (1996) Tense Past: Cultural Essays in Trauma and Memory, New York: Routledge.

Armitage, S., Hart, P. and Weathermon, K. (2002), Women's Oral History: The Frontiers Reader, Lincoln: University of Nebraska Press.

Armstrong, H. (2007) Blood on the Coal: The origins and future of New Zealand's Accident Compensation Scheme, Traded Union History Project, Wellington, NZ.

Armstrong, H. (2013) Your Life for the Job: New Zealand Rail Safety 1974-2000, Labour History Project, Wellington, NZ.

Attwood, B. and Magowan, F. (2001) Telling Stories: Indigenous History and Memory in Australia and New Zealand, Crows Nest, NZW: Allen \& Unwin.

Bacchi, Carol. (2009) Analysing Policy: What's the Problem Represented to be? Australia: Pearson.

Boal, A. (1993) Theatre of the Oppressed, London: Pluto Press $4^{\text {th }}$ ed.

Boal, A. Playing Boal: Theatre, Therapy, Activism, New York: Routledge.

Becker, D. (2001) 'Dealing with the consequences of organised violence in trauma work', in Berghof Handbook for Conflict Transformation, Berlin, Berghof research Centre for Constructive Conflict Management.

Beck, U. Giddens, A. (1992) Risk Society: Towards a New Modernity (Theory Culture and Society) $1^{\text {st }}$ ed. SAGE Publications.

Bennett, J., Kennedy, R and Wilson, T. (2003) 'Reading testimonies of the stolen generations', World memory: personal trajectories in global time, Macmillan: London.

Binney, J. (2004) 'Bringing the Stories Back Home: Dialogues Over 25 Years,' in Remembering: Writing Oral History ed. Anna Green and Megan Hutchin, Auckland: Auckland University Press.

Borland, K. (1991) 'That's not what I said': Interpretive conflict in oral narrative research. S.B Gluck and D. Patai, (eds). Women's Words: the Feminist Perspective of Oral History, New York and London: Routledge, pp.63-75. 
Bornat, J. (2003) 'A second take: Revisiting interviews with a different purpose', Oral History 2003, vol. 31, no.1, pp. 47-53.

Boston, J., Martin, J., Pallot, J. and Walsh, Pat. (1996) Public Management: The New Zealand Model, Oxford University Press.

Boston, J. (1995) The State Under Contract, Wellington, NZ: Bridget Williams Books Limited.

Boston, J. (2017) Safeguarding the Future: Governing in an Uncertain World, Wellington, NZ: Bridget Williams Books Limited.

Brehaut, L. (1999) 'A terrible responsibility: Editing the spoken word for print', in Hamilton, M. (ed), Tales of the Century: Oral History Association of Australia Journal, 1999, no.21, p.30.

Buchanan, R. (2007) 'Decolonizing the Archives: The Work of New Zealand's Waitangi Tribunal,' Public History Review 14.

Burawoy, M. (2008) 'What is to be Done? Theses on the Degradation of Social Existence in a Globalizing World,' Current Sociology 56, no.3.

Burke, P, ed. (2001) New Perspectives on Historical Writing, University Park: Pennsylvania State University Press.

Bridgman, P. and Davis, G. (2000) The Australian Policy Handbook, (2ed) NSW: Allen and Unwin.

Bush, C. (2006) 'Faith, Power and Conflict: Miner Preachers and the United Mine Workers of America in the Harlan County Mine Wars, 1931-1939,' Ph.D dissertation, University of West Virginia, Morgantown.

Bussey, M. and Bula Wise, J, eds. (2007) Trauma Transformed: An Empowerment Response, New York: Columbia University Press.

Carroll, J. and Dunlop, R.J. (2006) "Coal Dust Suspected in Blast: Mine's operator had three related fines just this month." Louisville Courier-Journal, May 22.

Caruth, C. (1996) Unclaimed Experience: Trauma, Narrative and History, Baltimore: Johns Hopkins University Press.

Casey, E. (2004) “Public Memory in Place and Time," in Framing Public Memory, (ed), Kendall R. Phillips, Tuscaloosa: University of Alabama Press, 2004.

Castles, F, Gerritsen, R and Vowles, J. (1996) The Great Experiment: Labour Parties and Public Policy Transformations in Australia and New Zealand, NZ. : Auckland University Press. 
Cerulo, K. (2002) Culture in Mind: Towards a Sociology of Culture and Cognition. New York, NY: Routledge.

Cerulo, K. (2006) Never Saw it Coming: Cultural Challenges to Envisioning the Worst, Chicago: The University of Chicago Press.

Chamberlain, M. (2006) "Narrative Theory," in Handbook of Oral History, ed. Thomas L, Charlton, Lanham, Md, Alta Mira Press.

Chamberlain, M. and Thompson, P., eds, (2004) Narrative and Genre: Contexts and Types of Communication, New Brunswick, N.J.: Transaction Publishers.

Chamberlayne, P., Bornat, J. and T. Wengraf, eds. (2000) The Turn to Biographical Methods in Social Sciences, London, Routledge.

Cohen, S. (2001) States of Denial: Knowing about Atrocities and Suffering, Cambridge: Polity Press.

Choo, C. and Hollback, S. (2004) History and Native Title, Contemporary Theoretical, Historiographical and Political Perspectives, Perth: University of Western Australia Press.

Clark, M. ed. (2005) For the Record: Lange and the Fourth Labour Government, Wellington, NZ: Dumore Publishing Limited.

Clarke, L (2006) Worst Cases: Terror and Catastrophe in the Popular Imagination, USA: The University of Chicago Press.

Connor, S. (1995) Time, Desire and Horror: Towards a History of the Senses, Cambridge, Mass.: Polity Press.

Cooke, D., Hill, C., Baskett, P., and Irwin, R., eds. (2014) Beyond the free market: rebuilding a just societyin New Zealand. Auckland: Dunmore Publishing.

Corbin, D. (1981) Life, Work and Rebellion in the Coal Fields: The Southern West Virginia Miners, 1880-1922 Urbana: University of Illinois Press.

Cruishank, J. (1990) Life Lived Like a Story, Lincoln: University of Nebraska Press.

Cusack-McVeigh, H. (2008) "The Giant Footprints: A Lived Sense of Story and Place" in Living with Stories, ed. William Schneider, Logan: Utah State University Press.

Dawson, G. ed. (1999) Trauma and Life Stories: International Perspectives, London: Routledge. 
Dawson, G. (2005) 'Trauma, place and the politics of memory: Bloody Sunday, Derry, 1972-2004', History Workshop Journal, 2005, issue 59, pp.151-178.

Dawson, G. (2006) Making Peace with the Past? Cultural Memory, the Irish Troubles and the Peace Process, Manchester: Manchester University Press.

Denis, P. (2008) "The Ethics of Oral History," in Oral History in a Wounded Country: Interactive Interviewing in South Africa, ed Denis and Radikobo Ntseimane, Scottsville: University of KwaZulu-Natal Press, 2008.

Douglas M and Wildavsky, A. (1983) Risk Culture, US: University of California Press.

Douglass, T. and Vogler, A. (2003) Witness and Memory: The Discourse of Trauma, New York: Routledge.

Dublin, T. (1998) When the Mines Closed: Stories of Struggles in Hard Times, Ithaca.

Duffin, P. (1994) 'Turning talking into writing', in J. Bornat (ed.), Reminiscence Reviewed, Buckingham: Open University Press, pp. 116-125.

Duke, D. (2002) Writers and Miners: Activism and Imagery in America, Lexington: University Press of Kentucky.

Dunaway, D. and Baum, W. eds. (1996) Oral History: An Interdisciplinary Anthology, Walnut Creek, Calif.: AltaMira Press.

Durie, M., Ratima, M., Hond, R. in 'Maori Health Promotion', (2015) Signal, L., Ratima, M., eds., Promoting Health in Aotearoa/New Zealand: Otago University Press. pp. 42-62.

Eichbaum, C. and Shaw, R. (2011) Public Policy in New Zealand Institutions, Processes and Outcomes ( $3^{\text {rd }}$ Edition) Auckland: Pearson.

Eichbaum, C. (2016) Two watchdogs better than one, NZ: Dominion, August 24, 2016.

Eller, R. (2008) Uneven Ground: Appalachia since 1945, Lexington: University Press of Kentucky.

Eolas, (2003) Consultation Paper on Truth and Justice: A Discussion Document, Belfast: Relatives for Justice.

Erikson, K.T. (1976) Everything in its Path: Destruction of Community in the Buffalo Creek Flood, NY: Simon \& Schuster. 
Erskine, Barbara. (1995) 'Loss and Grief in Oral History', paper delivered at the Annual Meeting of the Oral History Association, Milwaukee, Wisconsin, October 19, 1995

Ewen, P. (2014) Pike: Death by Parliament, Christchurch: Pony Press.

Fairclough, N. (2010) Critical Discourse Analysis: The Critical Study of Language ( $2^{\text {nd }}$ ed), United Kingdom: Longman Group Limited.

Fairclough, N, and Fairclough, I. (2012) Political Discourse Analysis, NY: Routledge.

Fairclough, N. (2013) Language and Power, $2^{\text {nd }}$ ed. NY: Routledge.

Felman, S. and Laub, D. (1992) Testimony: Crises of Witnessing in Literature, Psychoanalysis, and History, New York: Routledge.

Figley, C. (1995) Compassion Fatigue: Coping with Secondary Traumatic Stress Disorder in those who Treat the Traumatised, New York: Bruner/Mazel.

Field, S. (2006) "Beyond Healing": Trauma, Oral History, and Regeneration," Oral History 34, no.1.

Fishman, S. (2008) Copyright Handbook: What Every Writer Needs to Know. (10 $0^{\text {th }}$ ed). Berkeley, Calif.: Nolo.

Foucault, M. (1961) Madness and Civilisation; published by Routledge, (1989).

Foucault, M. (2001) Power: Essential Works of Foucault, 1954-1984, (ed James D. Faubion) The New Press.

Fosl, C. and Myer, T, eds, (2009) Freedom on the Border: And Oral History of the Civil Rights Movement in Kentucky, Lexington: London University Press of Kentucky.

Franklin, (1987) "The Scandal of Death and Injury in the Mines"; See also, Hume, Death and the Mines, Smith, B., Digging Our Own Graves: Coal Miners and the Struggle over Black Lung Disease, Philadelphia: Temple University Press.

Freese, B. (2003) Coal, A Human History. London: Arrow Books.

Freire, P. (1972) Pedagogy of the Oppressed, UK: Penguin Books.

Freire, P. (1972) Cultural Action for Freedom, UK: Penguin Books.

Freire, P. (1974) Education for Critical Consciousness. USA: Bloomsbury Publishing.

Freire, P. (1985) The Politics of Education. South Hadley, Mass. 
Freudenburg, W; Gramling, R; Laska S; Erikson Kai. (2009) Catastrophe in the Making: The Engineering of Katrina and the Disasters of Tomorrow. Washington, D.C.: Island Press.

Freudenburg, W. R. (2013). A Life in Social Research: 21; Research in Social Problems and Public Policy ed. Susan Maret, UK: Emerald Group Publishing.

Frisch, M. (1990) A Shared Authority: Essays on the Craft and Meaning of Oral and Public History, Albany: State University of New York Press.

Frisch, M. (2003) "Sharing Authority: Oral History and the Collaborative Process," Oral History Review 30, no.1.

Frisch, M. (2006) “Oral History and the Digital Revolution: Toward a PostDocumentary Sensibility," in Perks and Thomson Oral History Reader, London: Routledge.

Frisch, M. (2008) "Three Dimensions and More: Oral History Beyond the Paradoxes of Method." In Handbook of Emergent Methods, ed, Sharlene Nagy Hesse-Biber ad Patricia Leavy, New York: Guilford.

Fyfe, J. (1990) The Matriarchs: A Generation of New Zealand Women Talk to Judith Fyfe, Auckland, Penguin.

Gaventa, J. (1980) Power and Powerlessness: Rebellion and Quiescence in an Appalachian Valley, Urbana: University of Illinois Press.

Gerring, J. (2001) Social Science Methodology: A Criterial Framework, Cambridge University Press.

Gilmore, L. (2001) The Limits of Autobiography: Trauma, Testimony, Theory, Cornell University Press.

Glaser, B. and Strauss, A. (1967) The Discovery of Grounded Theory: Strategies for Qualitative Research, Chicago: Aldnie Publishing.

Glen, J. (1995) The War on Poverty in Appalachia: Oral History from the Top Down and from the Bottom Up," Oral History Review 22, 1.

Gluck, S.B. and Patai, D., eds. (1991) Women's Words: The Feminist Practice of Oral History, New York: Routledge.

Godell, J. (2007). Big Coal: The Dirty Secret Behind America's Energy Future, Boston: Houghton Mifflin.

Godfrey, B. and Richardson, J. (2001) 'In deep water: the ethical use of transcripted oral material, in Oral History Association of Australia Journal, 2001, no.23, pp.74-79 
Godwin-Phelps, T. (2004) Shattered Voices: Language, Violence and the Work of Truth Commissions, Philadelphia: University of Pennsylvania Press.

Goffman, E. (1971) Relations in Public, USA: Basic Books.

Goffman, E. (1974) Frame Analysis: An Essay on the Organisation of Experience, USA: University Press of New England.

Goffman, E, (1981) Forms of Talk, USA: University of Pennsylvania.

Gold, A.G. and Gujar, B.R. (2002) In the Time of Trees and Sorrow: Nature, Power and Memory in Rajasthan, Durham, N.C.: Duke University Press.

Green, A. (2008) Cultural History, London: Palgrave MacMillan, 2008.

Green, A. (2011) "Individual remembering and 'collective memory': Theoretical propositions and contemporary debates," in The Oxford Handbook of Oral History, ed. Donald A Ritchie, Oxford University Press.

Grele, R.J. (2006) "Oral history as evidence," in Handbook of Oral History, ed. Thomas Charlton et al, Lanham/Oxford: Altamira Press.

Hammerton, A.J and Thomson A, (2005) Ten Pound Poms: Australia's Invisible Migrants, Manchester: Manchester University Press.

Harcourt, M. (1990) 'A walk in someone else's shoes', Oral History in New Zealand, 1994, no.6, pp.14-20, Oral History Review, vol.18, no.2.

Hardy, C. and Portelli. A., eds. (1999) 'I can almost see the lights from home, in Journal for Multi-Media History 2, 1:

http://www.albany.edu/jmmh/vol2not/lights.html

Hardy, C. (2001) 'Prodigal sons, trap doors, and painted women: some reflections on urban folklore, life stories and aural history', Oral History, vol. 29, no.1, pp. 98-105.

Hastings, M. 'Hacks and scholars: allies of a kind', in D. Cannadine., ed. (2004) History and the Media, Basingstoke: Palgrave Macmillan, 2004, pp. 103-117.

Hayner, P. (2001) Unspeakable Truths: Facing the Challenge of the Truth Commissions, New York: Routledge.

Herman, J. (1993) Trauma and Recovery: The Aftermath of Violence, from Domestic Abuse to Political Terror, New York: Basic Books.

Hevener, J.S. (2002) Which Side Are You On? The Harlan County Coal Miners, 193139 Urbana: University of Illinois Press. 
Hobsbawn, E. (1997) 'On history from below', in On History, London: Weindenfeld \& Nicolsen, pp.266-286.

Hofmeyer, I. (1993) 'We spend our years as a tale that is told': Oral Historical Narrative in a South African Chiefdom, London: James Currey.

Hopkins, A. (2000) 'A Culture of Denial: Sociological Similarities between Moura and Gretley Mine Disasters: Journal of Occupational Health and Safety_Australia and New Zealand, Vol.16, No. 1 pp. 29-36.

Hornqvist, M. (2010) Risk, Power and State: After Foucault, UK: Abingdon:

Routledge.

HLR, (2002) Healing Through Remembering, The (HLR) Report Project, Belfast: HRT.

House, S. and Howard, J. (2009) Something's Rising: Appalachians Fighting Mountaintop Removal, Lexington: University Press of Kentucky.

Hume, B. (1971) Death and the Mines: Rebellion and Murder in the United Mine Workers, New York: Grossman.

Hutching, M, (2004) 'The distance between voice and transcript', in Green, A. and Hutching, M. eds. Remembering: Writing Oral History: Auckland University Press.

James, D. (2000) Dona Maria's Story: Life History, Memory and Political Identity, Durham, N.C.: Duke University Press.

Jones, D. (1998) 'Distressing Interviews and unhappy interviewing', Oral History, 26, 2, pp.49-56.

Johnston, I. (2001) "Whose History is it Anyway?" Journal of the Society of Archivists 22, no.2, pp.213-229.

Jordan, G. (2003) 'Voices from below: Doing people's history in Cardiff Docklands', in S. Berger, H. Feldner and K. Passmore (eds), Writing History: Theory and Practice, London: Hodder Arnold.

Kahan, Dan M. (1999/2017) and Elizabeth K. Dollard Professor of Law \& Professor of Psychology, 'The Culture and Cognition Project', Yale Law School; See: http://www.culturalcognition.net/kahan/

Kelsey, J. (1989) The principles of the Treaty of Waitangi. Lincoln, N.Z.: Centre for Resource Management. 
Kelsey, J. (1990) A question of honour? Labour and the Treaty, 19841989.Wellington, N.Z.: Allen \& Unwin.

Kelsey, J. (1993) Rolling back the state: Privatisation of power in Aotearoa/New Zealand. Wellington, N.Z.: Bridget Williams Books.

Kelsey, J. (1995) The New Zealand Experiment: a world model for structural adjustment? Auckland, N.Z.: Auckland University Press; Bridget Williams Books.

Kelsey, J. and O'Brien, M. (1995) Setting the record straight: social development in Aotearoa/New Zealand. Wellington, N.Z.: Association of Non Government Organisations of Aotearoa.

Kelsey, J. (1999) Reclaiming the future: New Zealand and the global economy Wellington, N.Z.: Bridget Williams Books.

Kelsey, J. (2002) At the crossroads: three essay/Jane Kelsey. Wellington, N.Z.: Bridget Williams Books.

Kelsey, J. (2003) Serving whose interests? : a guide to NZ commitment under the WTO General Agreement on Trade in Service. Christchurch : Action, Research and Education Network of Aotearoa (ARENA).

Kelsey, Jane. (2015)The Fire Economy: New Zealand's Reckoning. Wellington, New Zealand : Bridget Williams Books with the New Zealand Law Foundation.

Klempner, M. (2000) "Navigating Life Review Interviews with Survivors of Trauma," Oral History Review, 2000, vol.27, no.2, pp67-83 (OHA).

Kozak, E.M. (2004) Every Writer's Guide to Copyright and Publishing Law. $\left(3^{\text {rd }}\right.$ ed), New York: Henry Holt.

Krog, A, Mpolweni, N. and Ratele, K. (2009) 'There was this Goat': Investigating the Truth Commission Testimony of Notrose Nobomvu Konile, South Africa: University of KwaZulu-Natal Press.

Kvale, S. (2007) Interviews: An Introduction to Qualitative Research Interviewing, Thousand Oaks, California: Sage Publications.

LaCapra, D. (2001) Writing Trauma, Writing History, Baltimore, Md: Johns Hopkins University Press.

Lakoff, G., Johnson, M. (1980) Metaphors We Live By, USA: University Chicago Press.

Lakoff, G. (1996) Moral Politics: How Liberals and Conservatives Think, $\left(2^{\text {nd }}\right.$ ed), USA: University of Chicago Press. 
Lakoff, G. (2014) Don't Think of an Elephant: Know Your Values and Frame your Debate, USA: Chelsea Green Publishing.

Lakoff, G., ed. (2017) United we Stand, Divided we Fall: Essays on Protest and Resistance from Writers of Conscience, NY: Garn Press.

Landorf, C (2000) 'A sense of identity and a sense of place: oral history and preserving the past in the mining community of Broken Hill', Oral History, vol.28, no.1, pp.91-102.

Langer, L. (1991) Holocaust Testimonies: The Ruins of Memory, New Haven, Conn.: Yale University Press.

Leaffer, M. (2005) Understanding Copyright Law, Newark, N.J.: LexisNexis.

Lilley R. (2013) Independent Taskforce on Heath and Safety. (http://www.hstaskforce.govt.nz/documents/comparison-of-ilo-publishedoccupational-fatal-injury-rates.pdf)

Luckhardt, R. (2008) The Trauma Question, London: Routledge, 2008.

Luker, K. (2010) Salsa Dancing in the Social Sciences: Research in an Age of Info-Glut, USA: First Harvard University Press.

Lundy, P and McGovern, M. (2001) 'The politics of memory in post-conflict Northern Ireland', Peace Review, 13, 1, pp. 27-34.

Lundy, P and McGovern, M. (2002) Ardoyne: the Untold Truth, Belfast: Ardoyne Commemorative Project, Beyond the Pale Publication.

Lundy, P and McGovern, M. (2004)“'You understand again': Testimony and postconflict transition in the North of Ireland', in Words and Silences: Journal of the International Oral History Association, 2004, new series, vol.2, no.2. pp. 30-35

McGill, D. (1990) The Lion and the Wolfhound: The Irish Rebellion on the New Zealand Goldfields, New Zealand: Grantham House Publishing.

McKitterick, D, ed., (1999). Lost Lives: The Stories of Men, Women and Children who Died as a Result of the Northern Ireland Troubles, Edinburgh: Mainstream Publishing.

Macfie, R. (2013) Tragedy at Pike River Mine: How and why 29 Men died, Wellington, New Zealand: Awa Press.

Maidment, J and Beddoe, L. (2016) Social Policy for Social Work and Human Services in Aotearoa New Zealand: Diverse Perspectives, NZ.: University of Canterbury. 
Marsh, D. and Furlong, P.(2010) A Skin, not a Sweater: Ontology and Epistemology in Political Science, Basingstoke. Palgrave Macmillan.

Matthewman, S and Bell, C eds. (2004) Cultural Studies in Aotearoa, New Zealand: Identity, Space and Place, Melbourne: Oxford University Press.

Matthewman, S. (2011) Technology and Social Theory, Auckland: Palgrave.

Meihy, J.C. (2003) 'The radicalization of oral history', Words and Silences, new series vol.2, no.1, pp. 31-41

Messenger, B. (1980) Picking up the Linen Threads: A Study of Industrial Folklore, Belfast: Blackstaffe.

Miller, R. (2001) New Zealand Government and Politics, Oxford University Press.

Mirvis, K.W (1981) 'An American Portrait: A Phenomenological Analysis of the Appalachian Coal-Producing Counties," Ph.D dissertation, Boston University.

Mitaki, Ra. (2003) Treaty of Waitangi: the gathering storm. Te Kauwhata, N.Z. : Mitaki Ra Publications.

Mitchell, A. (2017) Revenge of the Rich: The NeoLiberal Revolution in Britain and New Zealand, NZ: Christchurch University Press.

MLA, (2004) Listening to the Past, Speaking to the Future, Archives Task Force Report, London: MLA.

Montrie, C. (2003) To Save the Land and People:A History of Opposition to Surface Mining in Appalachia, Chapel Hill: University of North Carolina Press.

Moore, K. (1997) 'Perversion of the word: the role of transcripts in oral history', in Words and Silences, Bulletin of International Oral History Association, vol.1, no.1, pp. 14-25.

Moran, M; Rein, M. and Goodin, R. eds. (2006) The Oxford Handbook of Public Policy, UK: Oxford University Press.

Myerhoff, B. (1978) Number Our Days, New York: Simon and Schuster.

Mythen, G (2004) Ulrich Beck: A Critical Introduction to the Risk Society, UK: Pluto Press.

Neal, A. (2005) National Trauma and Collective Memory: Extraordinary Events in the American Experience, Armonk, N.Y: M. E. Sharpe. 
Ndambuki, B. and Robertson, C. (2000) “We Only Came Here to Struggle”: Stories from Berida's Life, Bloomington: Indiana University Press.

Neuenschwander, J.A. (2002). Oral History and the Law: Carlisle, Pa., Oral History Association.

Neuenschwander, J.A. (2004) 'Native American oral tradition/ history as evidence in American Federal courts', Words and Silences: Journal of the International Oral History Association, 2004, new series, vol.2, no.2, pp.11-17.

Nobles, M. (2008) The Politics of Official Apologies, Cambridge University Press.

Norgaard, K.M. (2011) Living in Denial: Climate Change, Emotions and Everyday Life, Cambridge, Massachusetts: The MIT Press.

Nyden, P. (1972), The Coal Miners' Struggle in Eastern Kentucky Huntington, WV: Appalachian Movement Press.

Norris, R. and Cypres, J.P. (1996) Women of Coal, Lexington: University Press of Kentucky.

Nyden, P. (1972) The Coal Miners' Struggle in Eastern Kentucky Huntington, WV: Appalachian Movement Press.

O'Driscoll, M; Taylor, P and Kalliath T. (2003) Organisational Psychology in Australia and New Zealand, Melbourne, Australia: Oxford University Press.

O'Farrell, P. J. (1955) 'The workers and Grey district politics, 1865-1913'; M.A thesis, University of Canterbury, New Zealand, pp. 183 -216.

Olick, J. (2003) States of Memory: Continuities, Conflicts and Transformations in National Retrospection, Durham, N.C: Duke University Press.

Parcell, M. (2014) Pike River: A Failure to Learn [DVD] www.PikeRiver DVD.com

Parr, A. (2007) "Breaking the Silence: Traumatised War Veterans and Oral History," in Oral History 35, no.1.

Parsons, W. (1995) Public Policy: And Introduction to the Theory and Practice of Policy Analysis, Vermont: Edward Elgar Publishing.

Parsonson, A. (2001) 'Stories for land: oral narration in the Maori land court', in Attwood and Magowan, Telling Stories: Indigenous History in Australia and New Zealand, Allen and Unwin, pp.21-40.

Parry, O. and Mauthner, N. (2004) 'Whose data are they anyway? Practical, legal and ethical issues in archiving qualitative data', Sociology, vol.38, no.1, pp. 139-152. 
Patrick, J. (2003) The Denniston Rose, Auckland, New Zealand: Random House.

Perks, R. (2004) 'Corporations are only there because people allow them to be: The growth of corporate oral history in Britain', paper presented at the Oral History Association annual Meeting, Oregon.

Perks, R., Thomson, A., eds. (2006) The Oral History Reader, London/ NY: Routledge.

Perrow, C. (1999) Normal Accidents: Living with High-Risk Technologies, New Jersey: Princeton University Press.

Perrow, C (2007) the Next Catastrophe: Reducing our Vulnerabilities to Natural, Industrial and Terrorist Disasters, New Jersey, Princeton University Press.

Phillips, K., ed. (2004) Framing Public Memory, Tuscaloosa: University of Alabama Press.

Portelli, A. (1981) “Two Peripheries' Look at Each Other: Italy and Appalachian America," Appalachian Journal 12, 1.

Portelli, A. (1988) 'Unchronic Dreams: working class memory and possible worlds', Oral History, 16, 2, pp.46-56.

Portelli, A. (1992) The Death of Luigi Trastulli and Other Stories: Form and Meaning in Oral History, Albany: State University of New York Press.

Portelli, A. (1997) The Battle of Valle Giulia: Oral History and the Art of Dialogue, Madison: University of Wisconsin Press.

Portelli, A. and Hardy C. (1999) 'I can almost see the lights from home, in Journal for MultiMedia History, 2 http://www.albany.edu/jmmh/vol2not/lights.html

Portelli, A. (2003) The Order Has Been Carried Out: History, Memory and Meaning of a Nazi Massacre in Rome, New York: Palgrave Macmillan.

Portelli, A. (2005) 'History, memory and the work of Alessandro Portelli' in Oral History Review, vol.32, no.1, pp. 1-34.

Portelli, A. (2010) They Say in Harlan County: An Oral History, Oxford University Press.

Reason, J. (1997) Managing Risks of Organizational Accidents, London, NY, Routledge.

Reason, J. (2016) Organizational Accidents Revisited, US: CRC Press. 
Reed, P. (2007) "The Truth Which Will Set Us All Free: National Reconciliation, Oral History and the Conspiracy of Silence," Oral History 35, no.1.

Richardson, L. (1984) 'The Denniston Miners' Union: a Centennial History 1884-1984', DMUC, Westport: NZ, pp. 10-21.

Richardson, L. (1995) Coal, Class and Community: The United Mineworkers of New Zealand, 1880-1960, NZ: Auckland University Press.

Riley, M. (2004) "Ask the fellows who cut the hay": Farm practices, oral history and nature conservation', Oral History, vol. 32, no.2, pp. 45-53.

Riordan, M. (2005) An Unauthorized Biography of the World: Oral History and the Front Line, Toronto, Canada: BTL Books.

Ritchie, D. (2001) “When History Goes Public," Oral History 29, no.1.

Ritchie, D. (2003) Doing Oral History: A Practical Guide, New York: Oxford University Press.

Ritchie, D. (2011) The Oxford Handbook of Oral History, Oxford University Press.

Robertson, B. (2006) The Oral History Handbook (Adelaide: Oral History Association of Australia, South Australian Branch.

Rogers, K.L, Leydesdorff, S. and Dawson, G., eds. (1999) Trauma and Life Stories: International Perspectives, London: Routledge.

Roper, B (2005) Prosperity for All? Economic, Social and Political Change in New Zealand since 1935, NZ.: Dumore Press.

Roseman, M. (2000) The Past in Hiding, Harmondsworth, London, Penguin.

Rosa, E.A. Renn, O. and McCright, A., eds. (2014) The Risk Society Revisited: Social Theory and Governance, USA: Temple University Press. See also Volume 34, Issue 12, December, 2014: An Official Publication of the Society of Risk Analysis.

Ross, F. (2007) "Linguistic Bearings and Testimonial Practices" in Discourse and Human Rights Violations, ed. Christine Anthonissen and Jan Blommaert, Amsterdam: John Benjamins Publishing.

Royal Commission of Inquiry on the Pike River Mine Tragedy NZ, (2012) Te Komihana a te Karauna mo te Parekura Ana Waor o te Awa O Pike/ Vol 1 \& 2.

Ryan, B. and Gill, D., eds. (2011) Future State: Directions for Public Management in New Zealand, Wellington: Victoria University Press. 
Sanders, M. (2008) Ambiguities of Witnessing: Law and Literature in the Time of a Truth Commission, Johannesburg: Witwatersrand University Press.

Samuel, R. and Thompson, P., eds. (1990). The Myths We Live By, London: Routledge.

Scott, M. (2007) Blood Passion: The Ludlow Massacre and Class War in the American West, New Brunswick, NJ: Rutgers University Press.

Scott, S. (1994) Two Sides to Everything: The Cultural Construction of Class Consciousness in Harlan County, Kentucky, Albany: State University of New York Press.

Shanks, D. and Meares, Jane. (2013) Pike River Tragedy: Report of the Independent Investigation to the Chief Executive of the Ministry of Business, Innovation and Employment, 14 March 2013. http://www.mbie.govt.nz/infoservices/employment-skills/workplace-health-and-safety-reform/document-andimage-library/Pike-river-independent-investigation-report-mar-2013.pdf

Sharp. A. (1994) Leap into the Dark: The changing role of the State in New Zealand since 1984, NZ: Auckland University Press.

Shaw, R. and Eichbaum, C. (2011) Public Policy in New Zealand Institutions, Processes and Outcomes ( $3^{\text {rd }}$ Edition) Auckland: Pearson.

Shogan, R. (2004) The Battle of Blair Mountain: The Story of America's Largest Labor Uprising, Boulder, Co: Westview.

Signal, L. and Ratima, M., eds. (2005) Promoting Health in Aotearoa New Zealand, Otago University Press.

Smith, R.C (2001) "Analytical Strategies for Oral History Interviews" in Handbook of Interview Research, ed. Jaber F Gubrium et al., Beverly Hills, Calif.: Sage Publications.

Smyth, M. and Robinson, G., eds. (2001) Researching Violently Divided Societies: Ethical and Methodological Issues, London: Pluto Press.

Spiegel, G. (2005) Practicing History: New Directions in Historical Writing After the Linguistic Turn, New York: Routledge.

Stevens, K. (2003) Stevens Enquiry: Overview of Recommendations, Belfast, Stevens Inquiry.

Stranks, J (2001) Health and Safety Law, Great Britain: Pearson Education Limited.

Street, S (2007) 'Saving the Sounds of History,' BBC: Radio4 Archive Hour Sept 1. 
Sunstein, C.R. (2007) Worst-Cast Scenarios, USA: Harvard University Press.

Swain, E. (2006) 'Oral History in the Archives: Its documentary role in the twentyfirst century' in Perks, R. and Thomson, A. (eds) The Oral History Reader, London/ NY: Routledge.

Szanto, Andras. (2007) What Orwell Didn't Know: USA: Public Affairs.

Taksa, L. (2004) 'Globalization, memory and industrial heritage_Remembering and forgetting the noise, jobs, skills, conflicts and camaraderie of a forgotten era', paper presented to the XIIIth International Oral History Conference, Rome, June 2004.

Taylor, P. F, (1990) Bloody Harlan: The United Mine Workers of America in Harlan County, Kentucky, 1933-1941, New York: University Press of America.

Thesing, W. (2000) Caverns of Night: Coal Mines in Art, Literature and Film, Columbia: University of South Carolina Press.

Thompson K.T. (1993) interviewed by Francis Good in 'Cutting Limestone', in G.Koch (ed.), Kaytetye Country. An Aboriginal History of the Barrow Creek Area, Alice Springs: Institute fore Aboriginal Development.

Tierney, K. (2014) The Social Roots of Risk: Producing Disasters, Promoting Resilience, Stanford University Press.

Tonkin, E. (1992) Narrating Our Pasts: The Social Construction of Oral History, Cambridge: Cambridge University Press.

Vaughan, D. (1996) The Challenger Launch Decision: Risky Technology, Culture and Deviance at NASA, USA: The University of Chicago Press.

Vaughn, D. (1998) Abstract, Re: Rational Choice, Situation in Action and the Social Control of Organisations. Law and Society Review 32, 1 June 1998: 23-61.

Verdooglaege, A. (2008) Reconciliation Discourse: The Case of the Truth and Reconciliation Commissions, Philadelphia: John Benjamins.

Wagner-Pacifici, R. (2000). Theorizing Standoff: Contingency in Action, UK: Cambridge University Press.

Ward Maggard, S. (1999) "Coalfield Women Making History," in Dwight B. Billings, Gurney Norman and Katherine Ledford (eds), Confronting Appalachian Stereotypes: Back Talk from an American Region, Lexington: University Press of Kentucky.

Ward Maggard, S. (1988) Eastern Kentucky Women on Strike: A Study of Gender, Class and Political Action in the 1970's, Ann Arbor MI: University Microfilms International. 
Watson, C. (2000) "'Believe me": Acts of witnessing in Aboriginal women's autobiographical narratives', Journal of Australian Studies 64: pp. 142-152.

Wheeler, W. (2005) 'Reflections on the Social Relations of Indigenous Oral Histories,' in Walking a Tightrope: Aboriginal People and Their Representations, ed. Ute Lische and David T. McNab, Ontario: Wilfrid Laurier University Press.

Wildavsky, A. and Douglas, M. (1983) Risk Culture, US: University of California Press.

Wievorka, A. (2006) The Era of the Witness, Ithacam N,Y: Cornell University Press.

Williams, L. and Banyard. V., eds. (1999) Trauma and Memory, Thousand Oaks: Sage Publications.

Williams, R.H. (2001) "I'm a keeper of information": History-telling and voice', in Oral History Review, vol.28, no.1.

Wilmsen, C. (2001) 'For the record: editing and the production of meaning in oral history', Oral History Review, vol.28, no.1, pp.65-85.

Wilson, W.J. (1997) When Work Disappears: The World of the New Urban Poor, New York: Knopf.

Woolley, B. and Reid, F. (1974) We Be Here When the Morning Comes, Lexington: University Press of Kentucky.

Wright, M. (2014) Coal: The Rise and Fall of King Coal in New Zealand, Auckland, Bateman.

Wright Mills, C. (1959/2000) The Sociological Imagination, NY: Oxford University Press.

Wright Mills, C. (2008) The Politics of Truth, Selected Writings, NY, Oxford University Press.

Worksafe Reps, Initial Health and Safety Representatives Training, Under the Health and Safety Work Act 2015; See also, Stage 2: Managing Risks. (2016) support@worksafereps.org.nz

Yow, R. (2005) Valerie Recording Oral History: A Guide for the Humanities and Social Sciences, Walnut Creek, Calif.: AltaMira Press. 


\section{Appendices}

Appendix (I) $\underline{\text { History \& Maps }}$

(xi) Photos of the Pike 29, Royal Commission of Inquiry on the Pike River Mine Tragedy NZ, Te Komihana a te Karauna mo te Parekura Ana Waro te Awa O Pike (2012), Vol.1 p. 4-5............................................................ 323

(xii) Location of the Mine Ibid, Vol.2, p. 31.................................................. 326

(xiii) Original Map of Pike River Mine (Pike River Coal)................................ 327

(xiv) Map of Pike River Mine op.cit., Vol.1 p. 10 (2012) ................................. 328

(xv) Boundary restricted \& non-restricted zones Ibid, Vol.1 p.20 fig.2 ........ 329

(xvi) Diagrammatic outline of hydro panel, Ibid, Vol.1, p.21, fig.3................ 329

(xvii) Ventilation shaft \& alimak raise, ibid, Vol.2 p. 39, fig 3.7....................... 330

(xviii) Typical elements of main ventilation shaft, ibid, Vol.2, p. 82, fig 8.1.... 331

(xix) Orientation \& operation of underground fan, ibid, Vol.2, p. 93, 8.9.... 331

(xx) Hydro panel \& cross-cut, ibid, Vol.2, p. 103, fig 8.16........................... 332

(xi) Location of the auxiliary fan, ibid, Vol.2, p. 105, fig 8.1...................... 332

(xv) Effects of roof fall on 30 October 2010, ibid, Vol. 2, p. 102, fig 8.15.... 333

(xvi) Last known position of men, Pike River Mine op. cit., Vol.2, p. 20....... 334

(xvii) Photo Map of mountains/portal from Atarau Family Memorial ......... 335 
(i) Photos of the Pike 29, Royal Commission of Inquiry on the Pike River

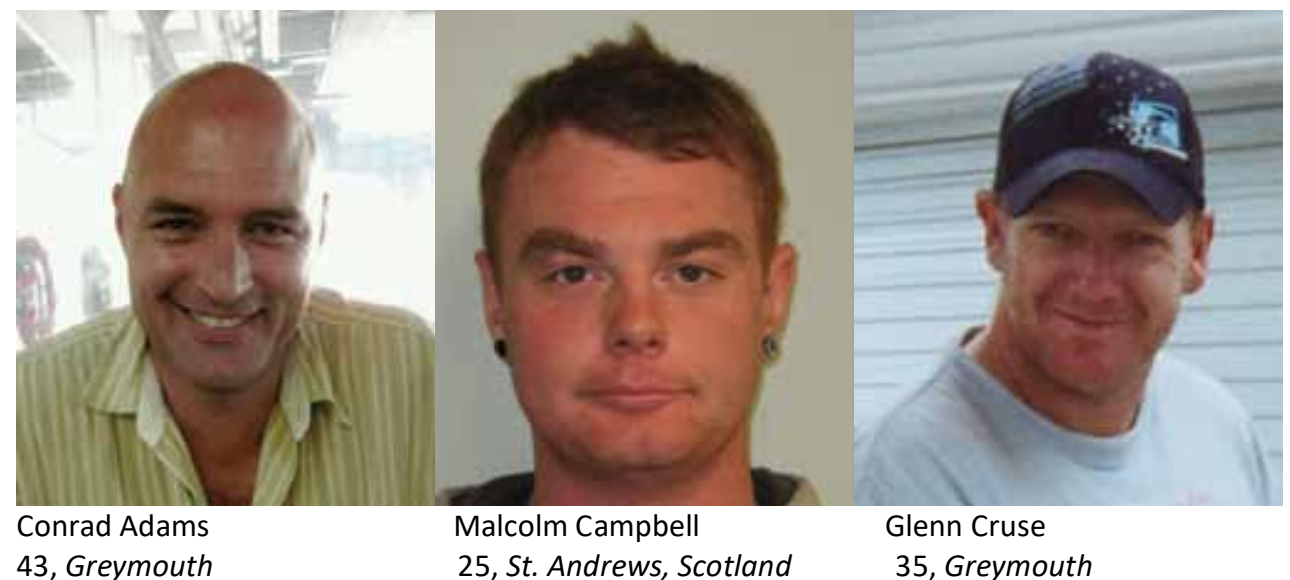

43, Greymouth

25, St. Andrews, Scotland

35, Greymouth

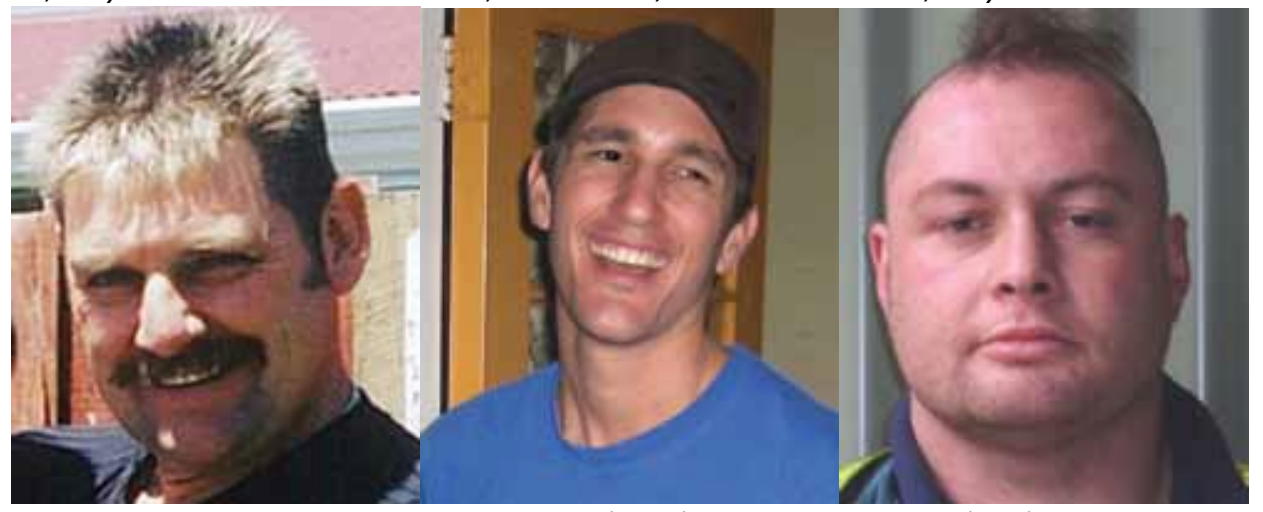

Allan Dixon

Christopher (Chris) Duggan

Daniel (Dan) Herk

59, Runanga

31, Dunollie

36, Runanga

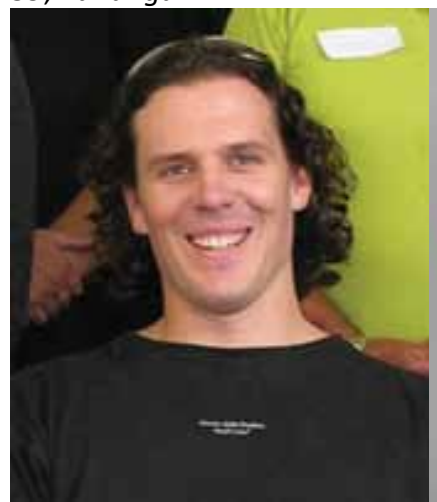

David (Dave) Hoggart

33, Greymouth

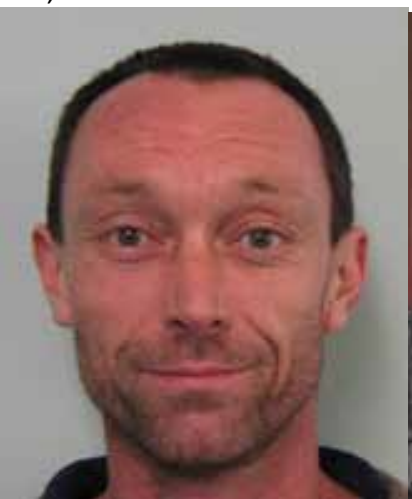

Richard (Rolls) Holling

41, Blackball

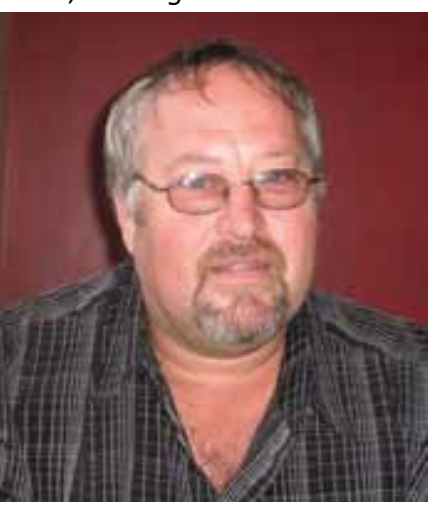

Koos Jonker

47, Limpopo, South Africa 


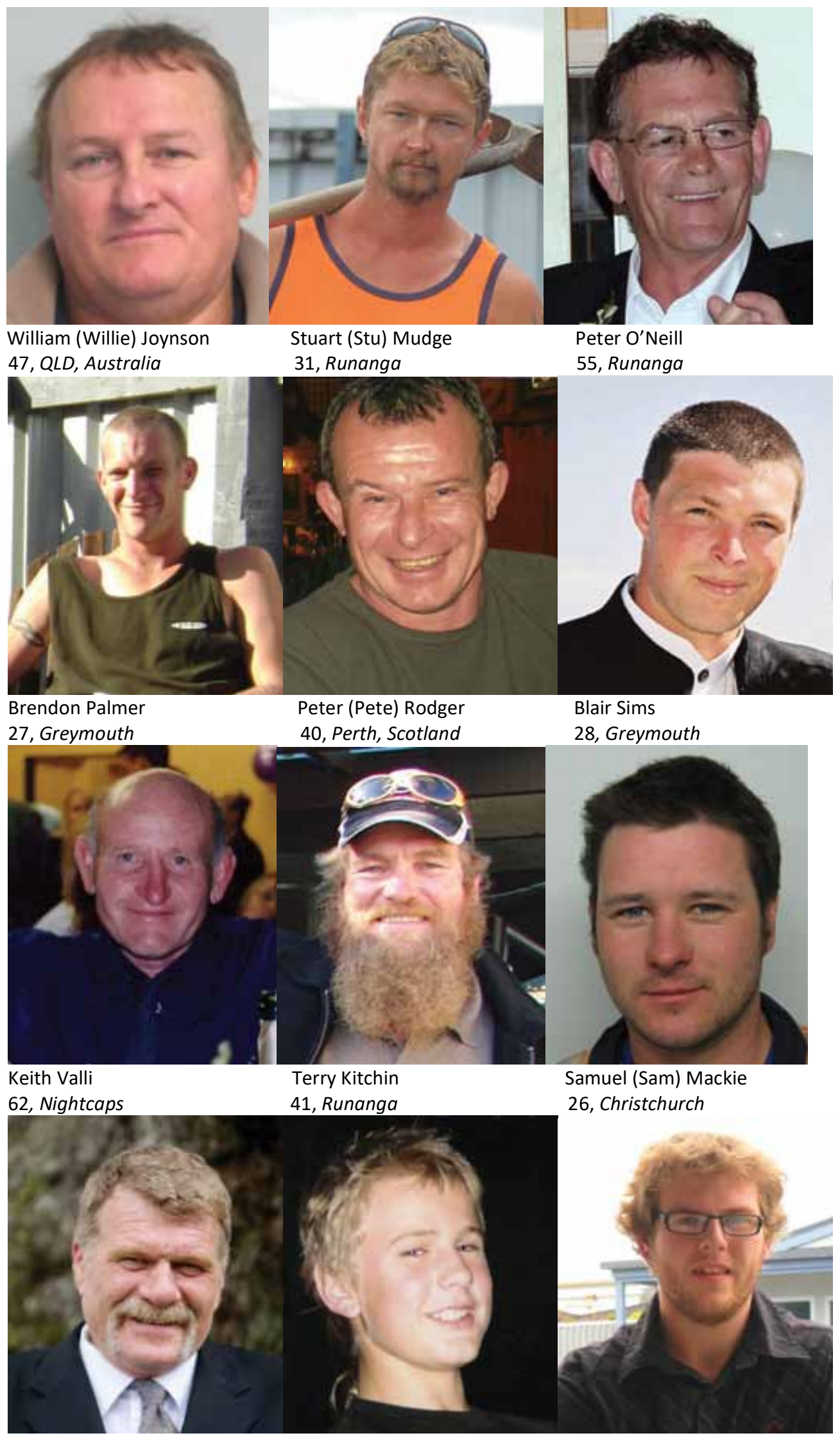

Milton Osborne, 54 Ngahere Joseph Dunbar 17, Christchurch Benjamin (Ben) Rockhouse, NSW 


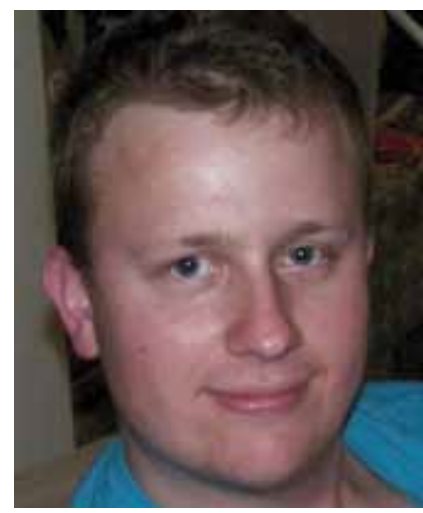

Joshua (Josh) Ufer

25, QLD, Australia

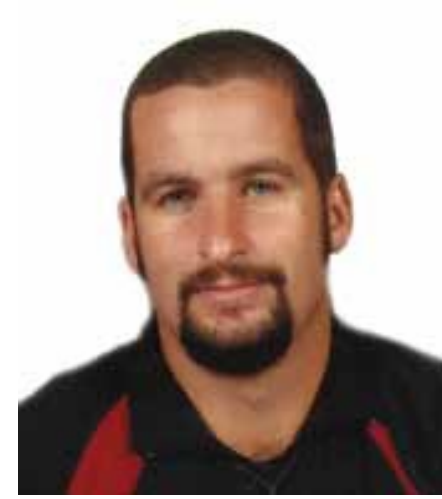

Riki (Rik) Keane

28, Greymouth

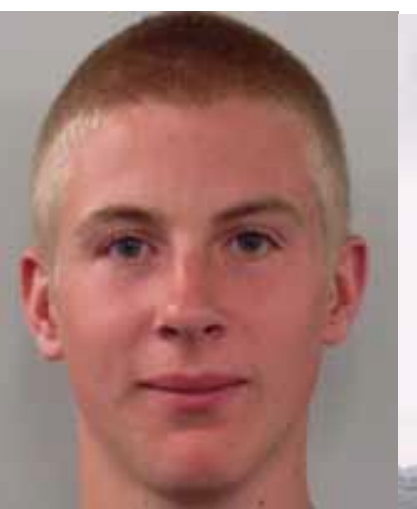

Zen Drew (Verhoeven)

21 Greymouth

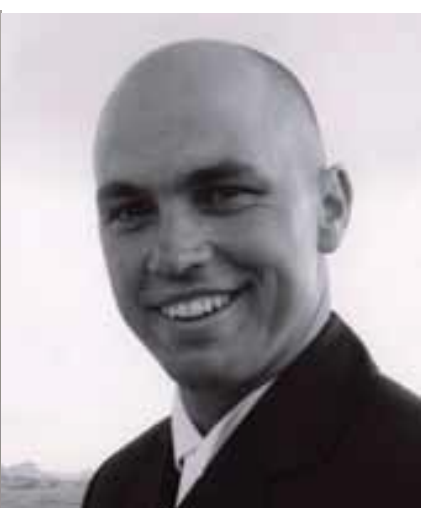

Kane Nieper

33, Greymouth

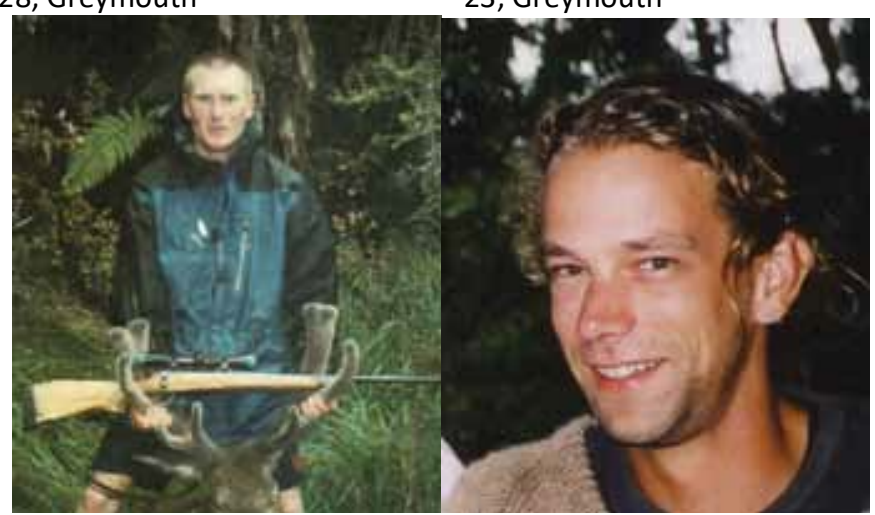

Michael Monk

23, Greymouth

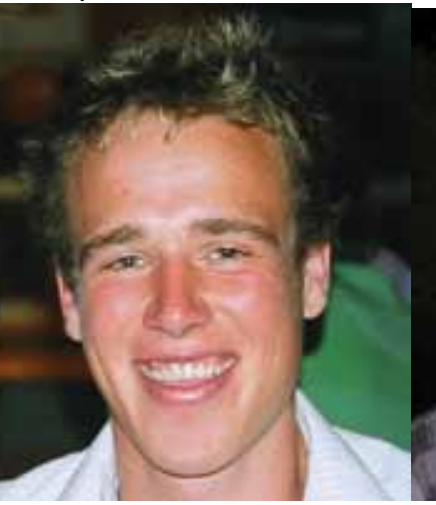

28

John Hale

45, Hokitika

Andrew (Huck) Hurren

32, Hokitika
Francis Marden

41, Barrytown

Note: the men are grouped here according to their profession i.e whether they worked as miners, or in tech services, VLI Drilling, contractors, construction. 
(ii) Location of the Mine Ibid, Vol.2, p. 31

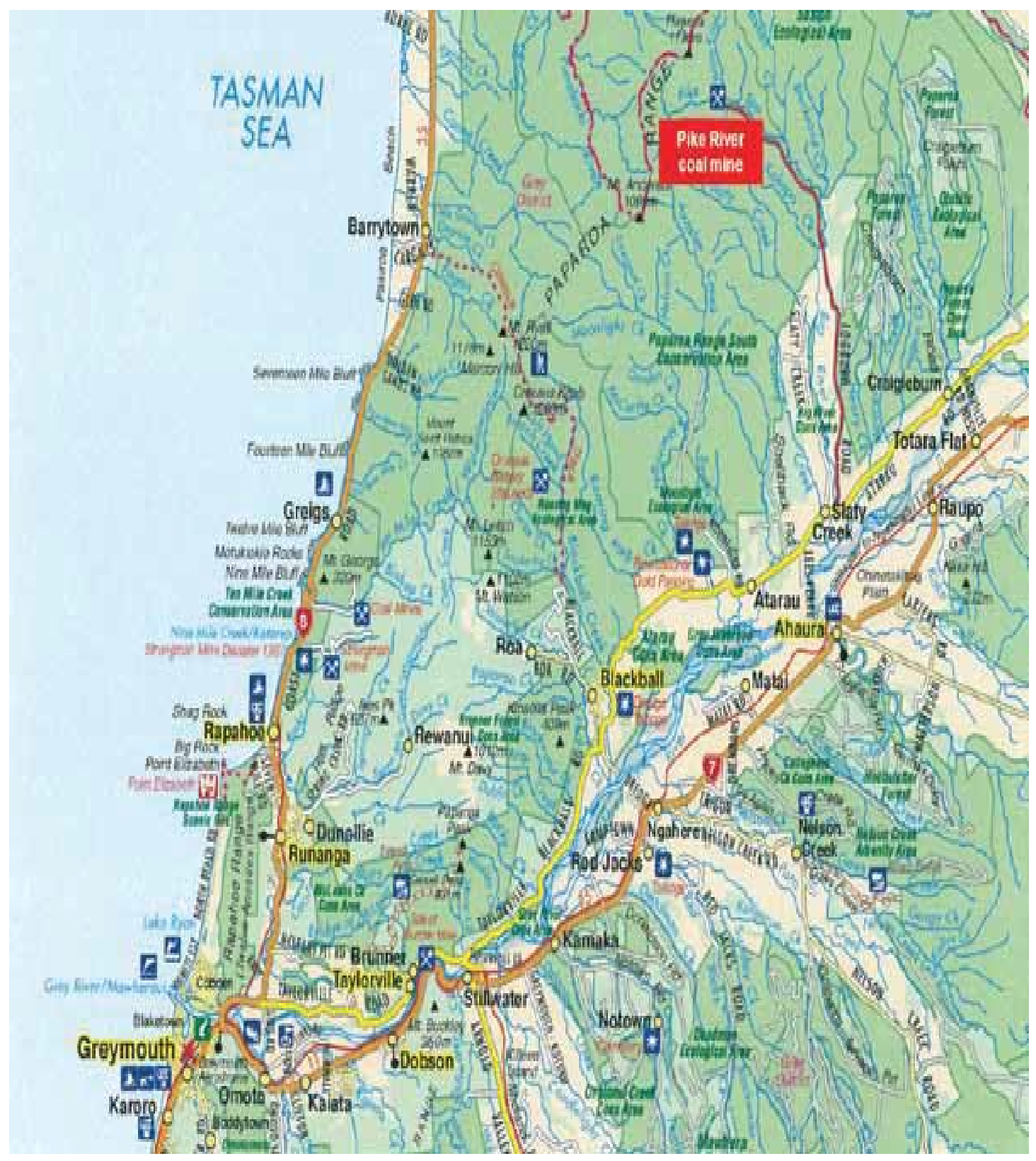


(iii) Original Map of Pike River Mine (Pike River Coal)

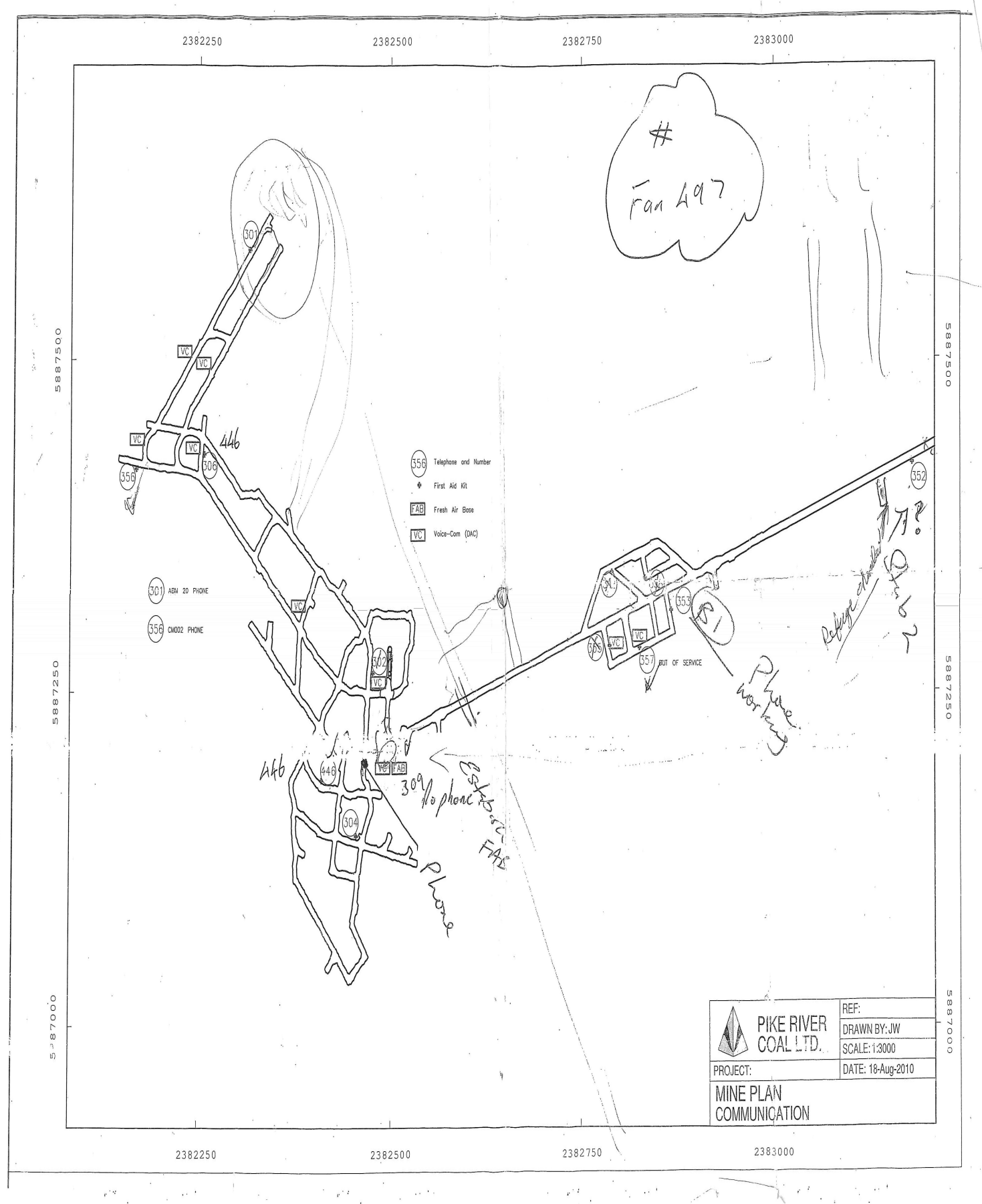


(iv) Map of Pike River Mine, Royal Commission of Inquiry (2012), Vol.1 p. 10.

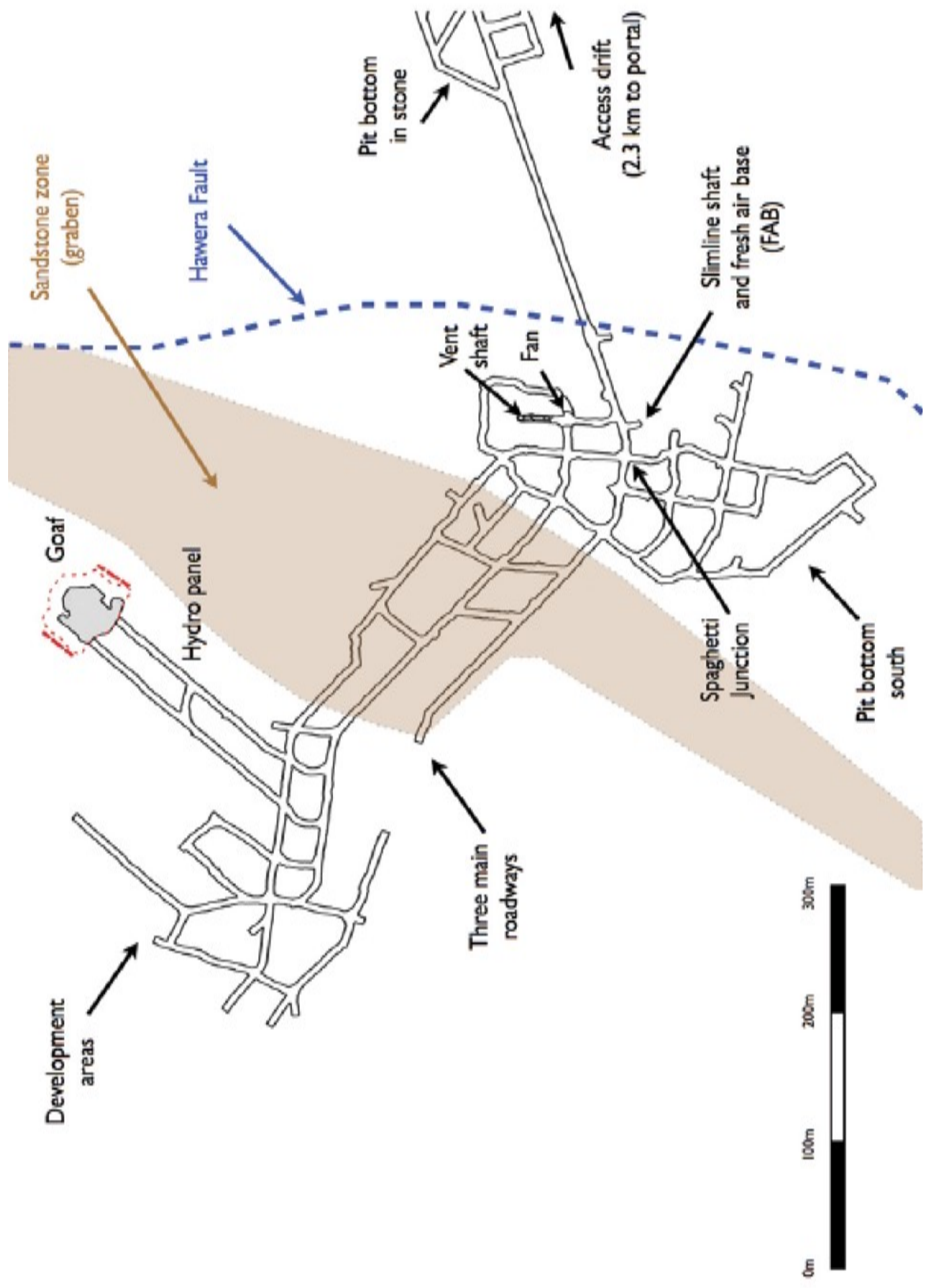


(v) Boundary between restricted \& non-restricted zones Ibid, Vol.1 p.20 fig.2

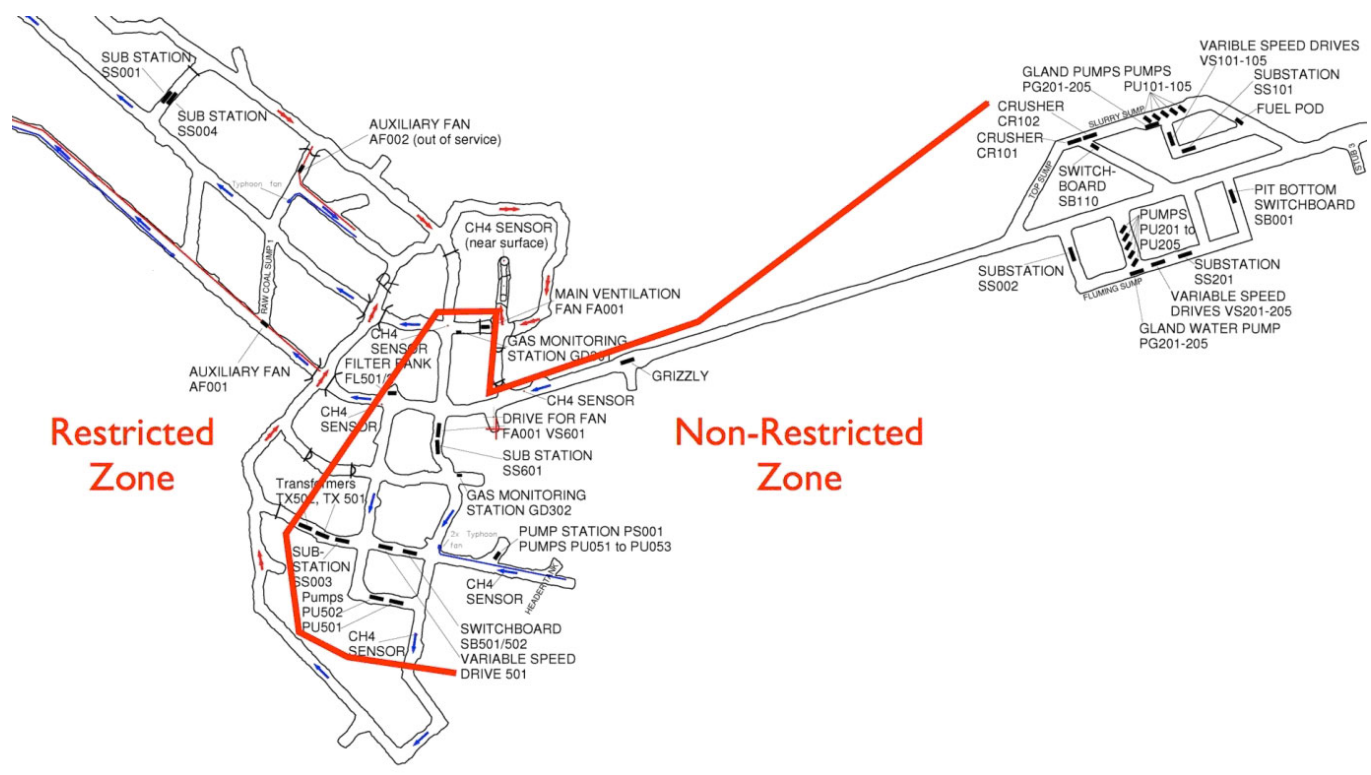

(vi) Diagrammatic outline of hydro panel, Ibid, Vol.1, p.21, fig.3

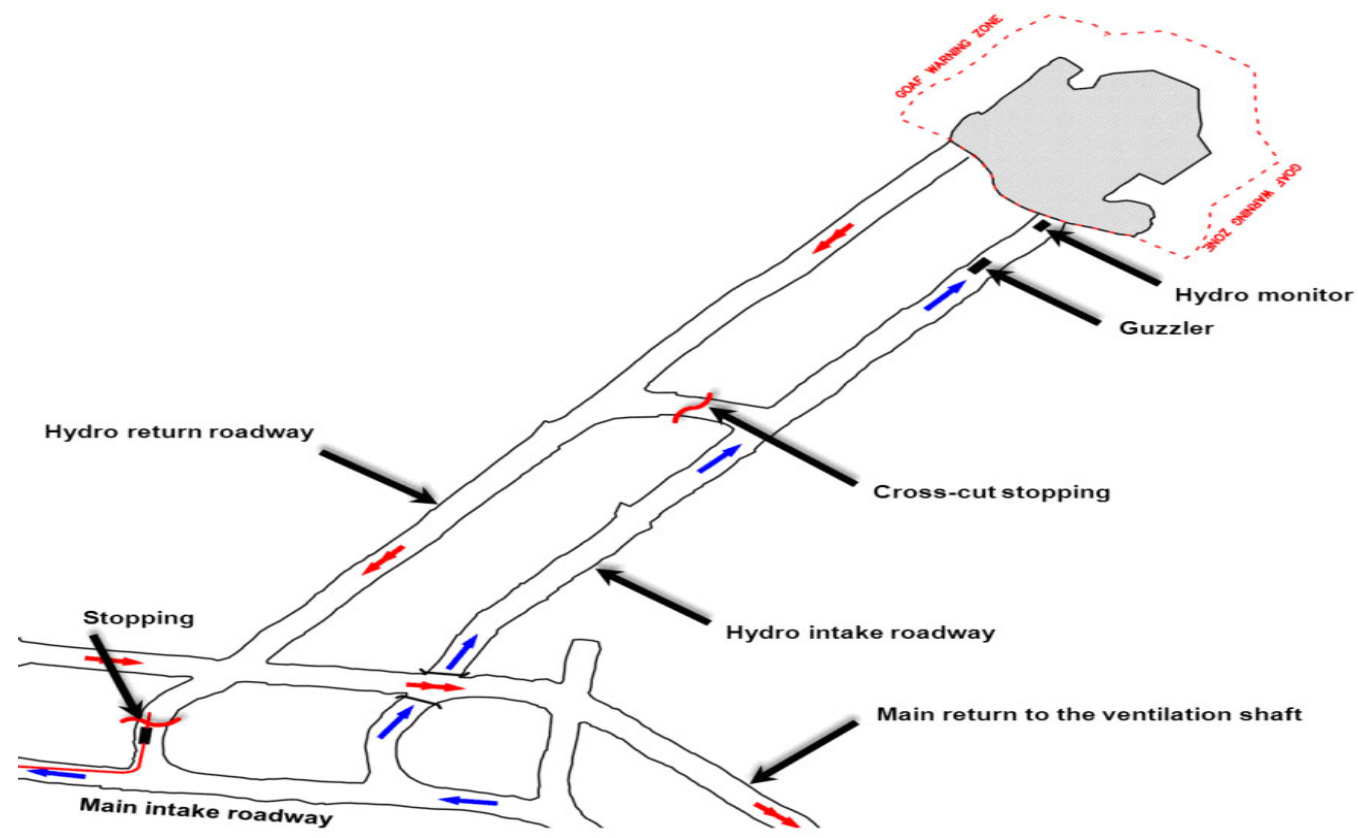


(vii) Ventilation shaft \& alimak raise, ibid, Vol.2 p. 39, fig 3.7.

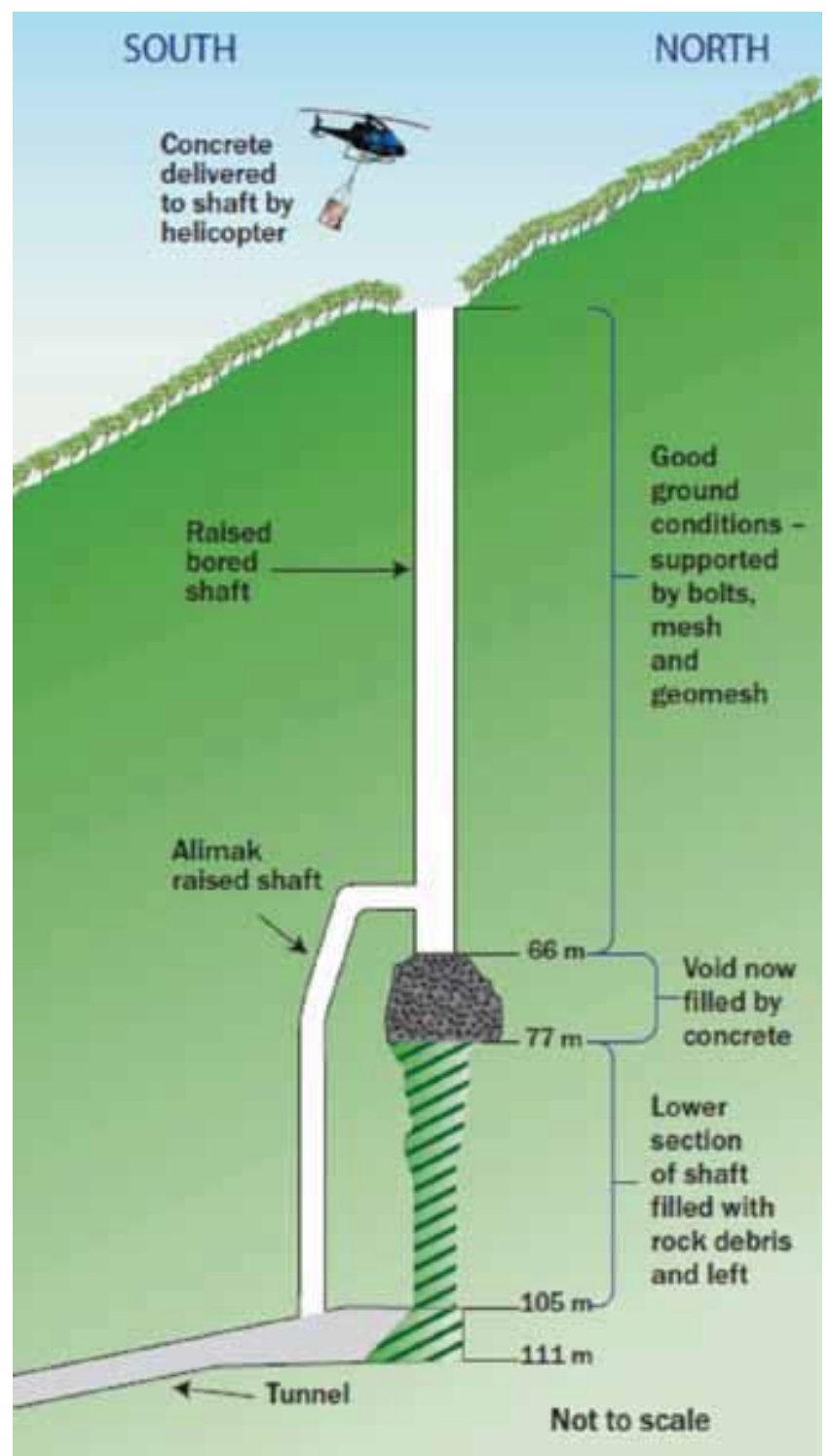


(viii) Typical elements of a main ventilation shaft, ibid, Vol.2, p. 82, fig 8.1.

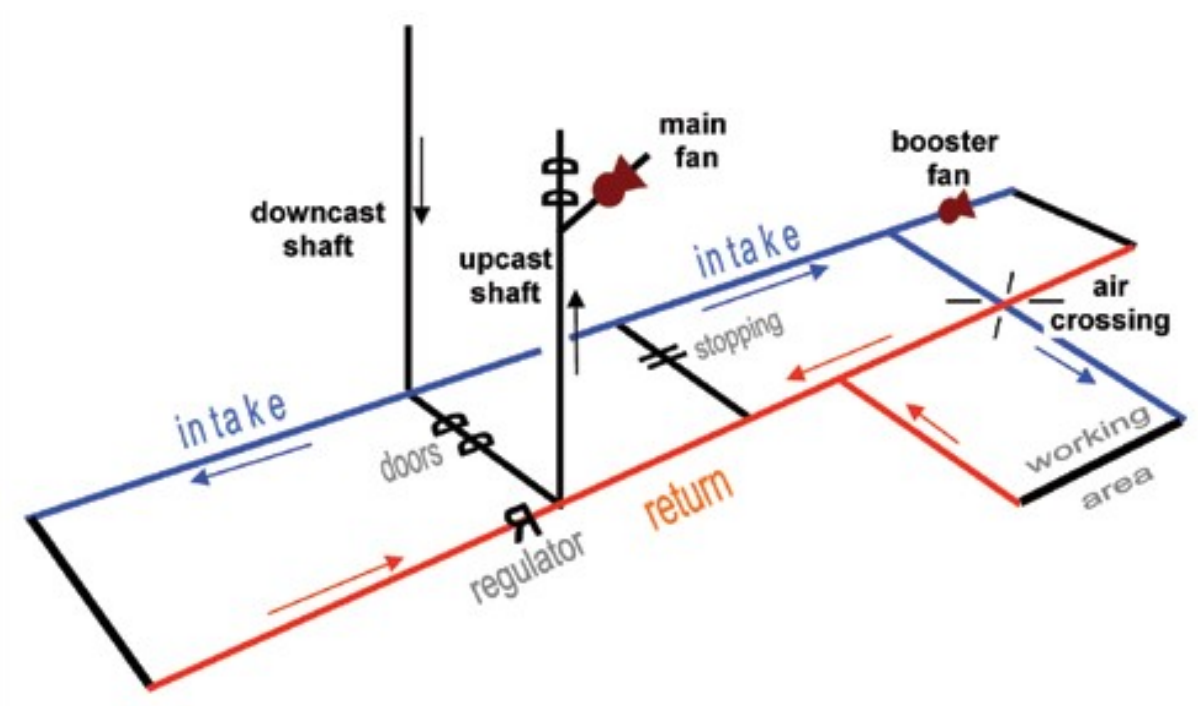

(ix) Orientation \& operation of underground fan, ibid, Vol.2, p. 93, fig 8.9.

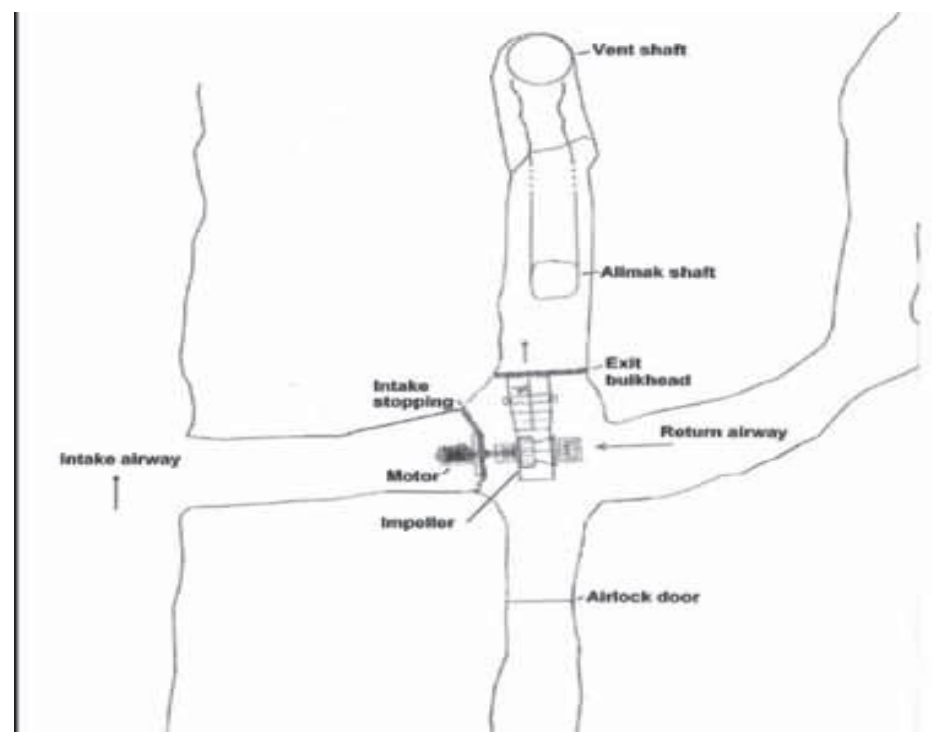


(x) Hydro panel \& cross-cut, ibid, Vol.2, p. 103, fig 8.16.

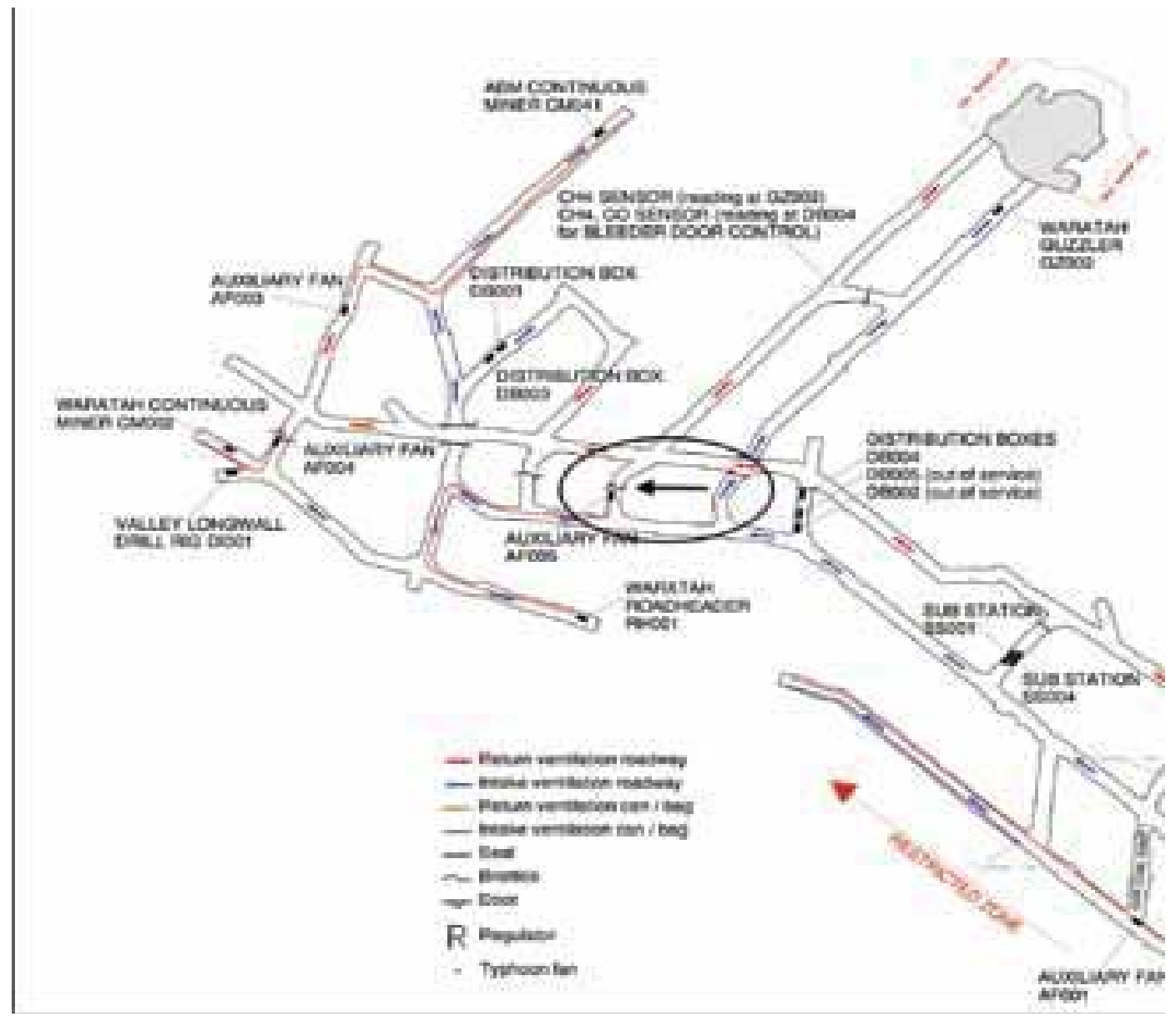

(xi) Location of the auxiliary fan, ibid, Vol.2, p. 105, fig 8.18.

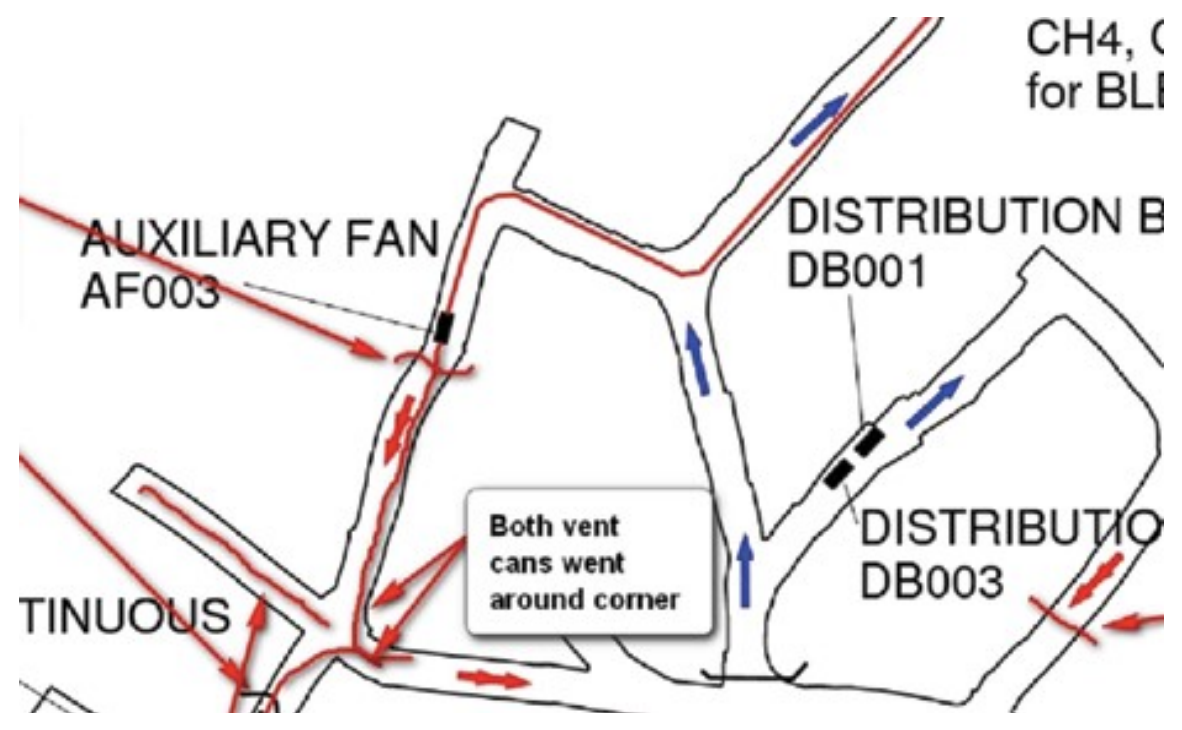


(xii) Effects of roof fall on 30 October 2010, ibid, Vol. 2, p. 102, fig 8.15

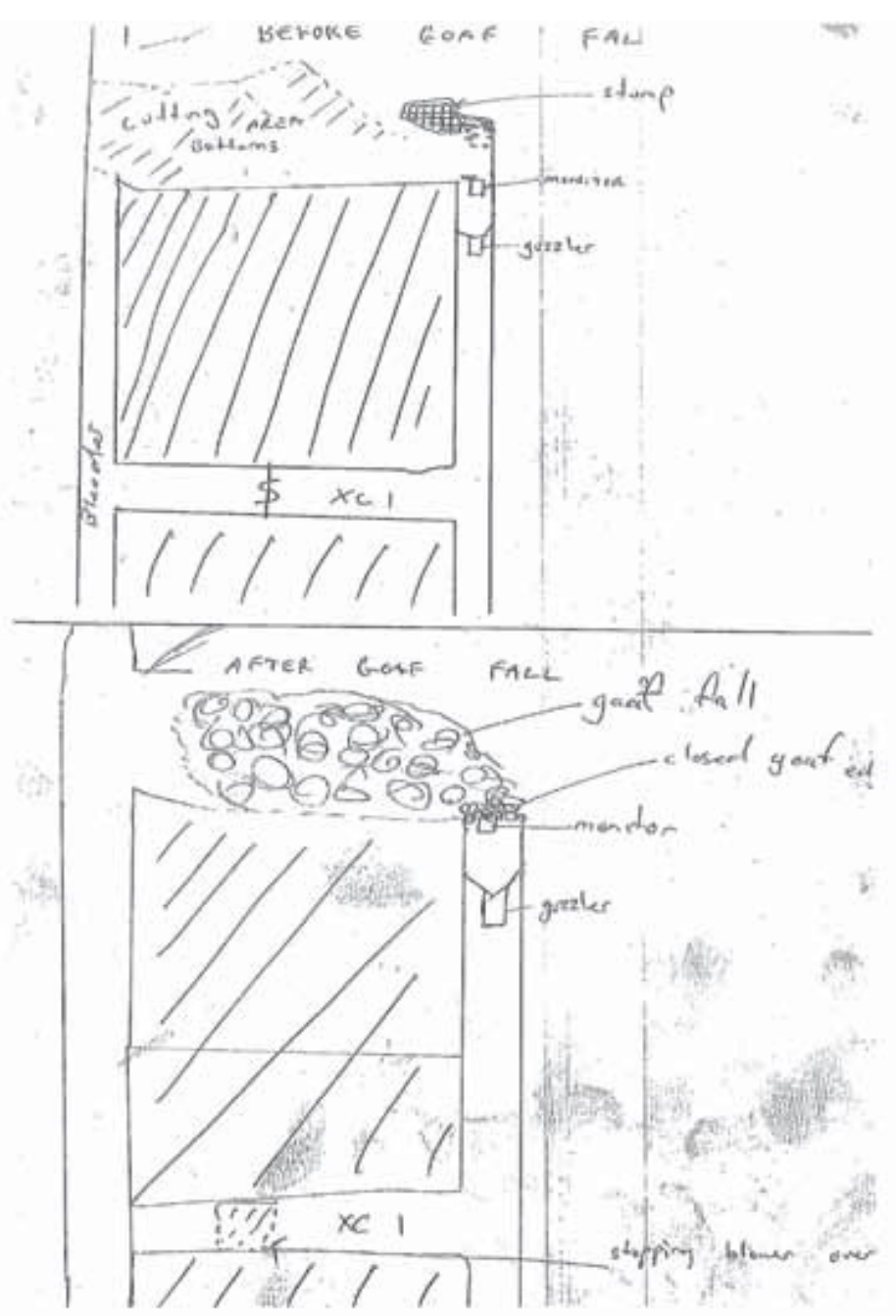

See also: DAO.001.00436/25. 
(xiii) Last known position of the men, Pike River Mine op. cit., Vol.2, p. 20

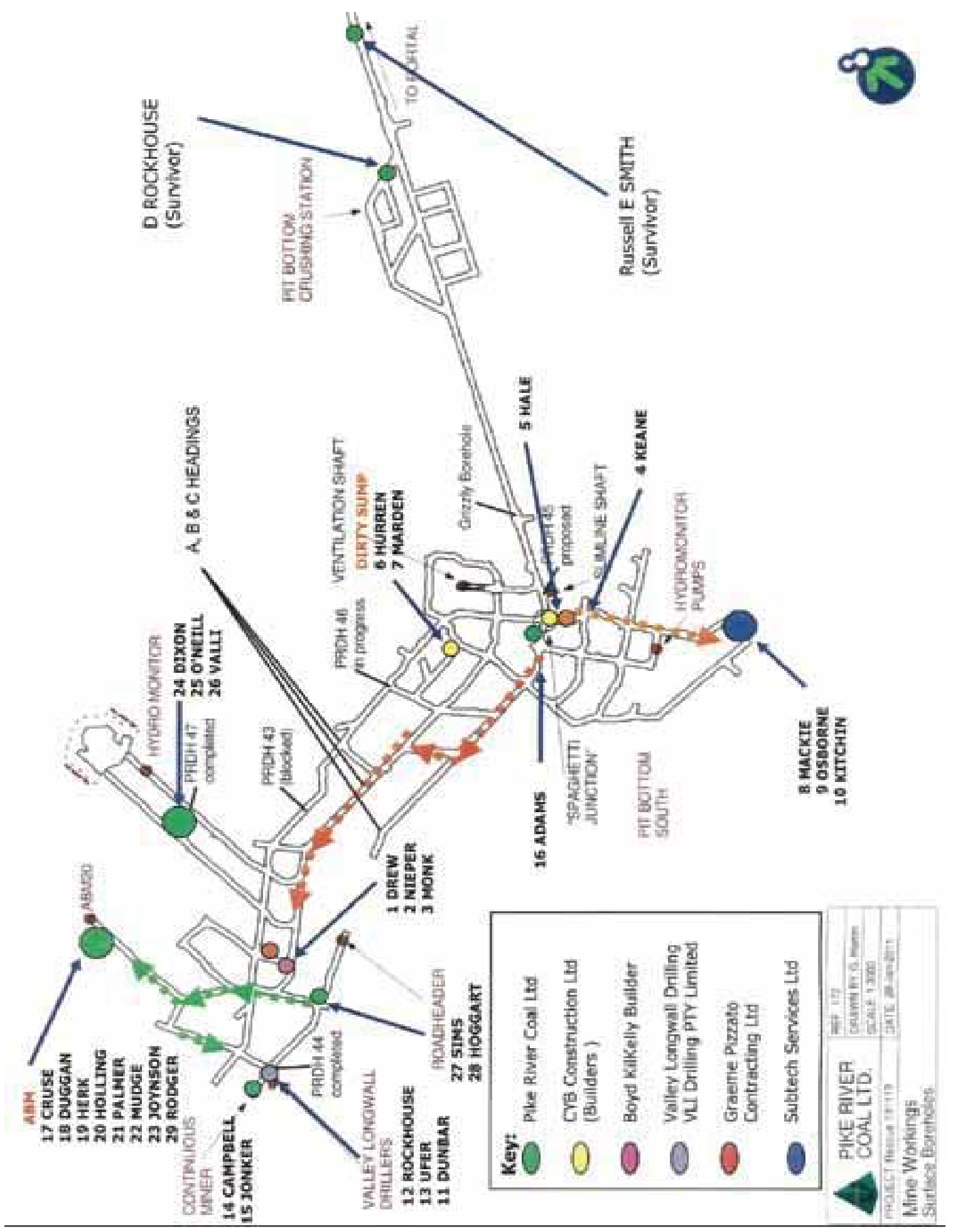


(xiv) Photo Map of mountains/coal processing plant, Atarau

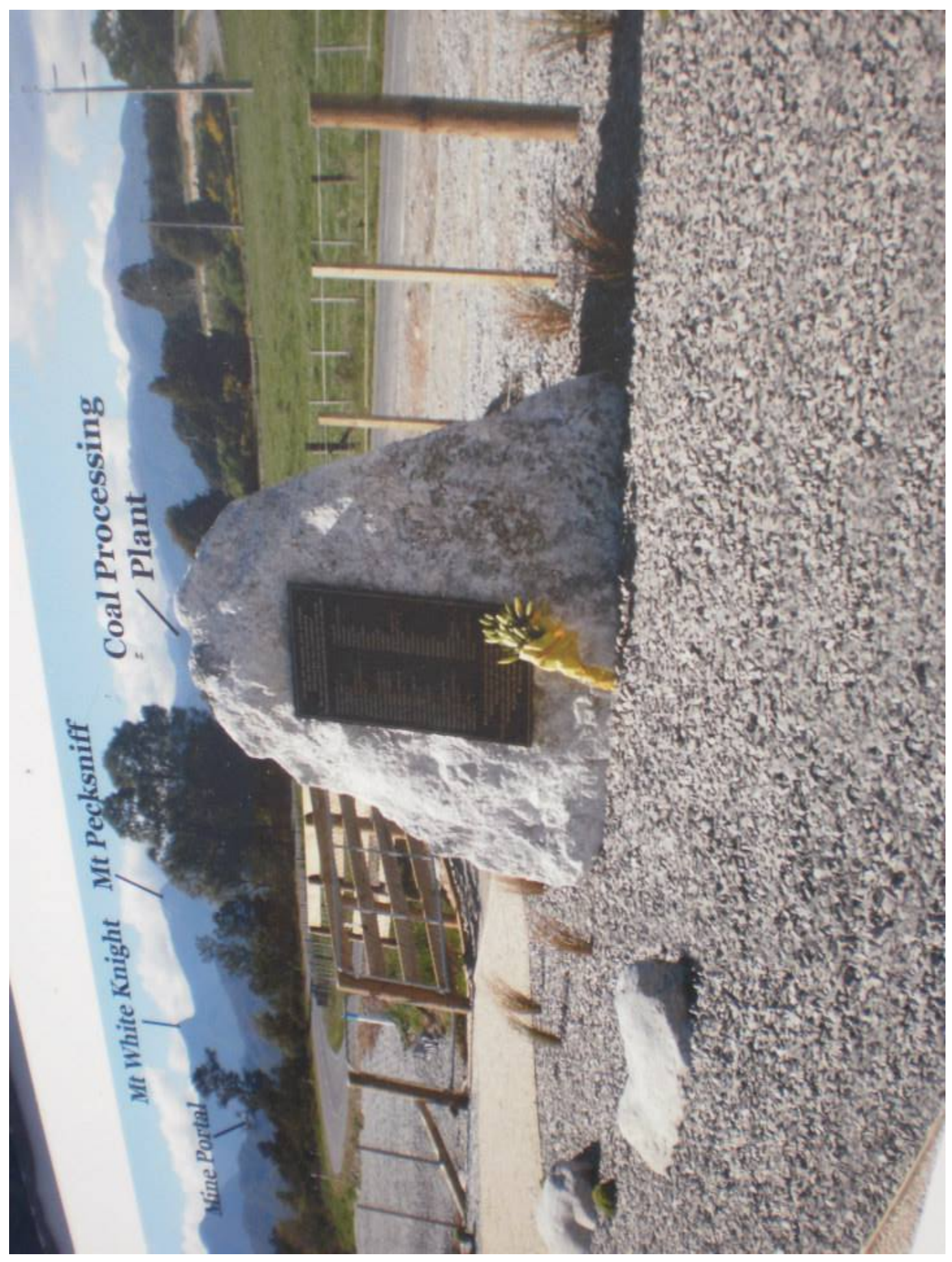




\section{Appendix (II) Guidelines, Questions, Consent Forms}

(i) Ethics: Sample Interview Questions/ Process........................................... 337

(ii) Ethics: New Interview Information Form ................................................ 340

(iii) Ethics: Follow-Up Interview Information Form ........................................ 342

(iv) Ethics: New Interviewee Consent Form .................................................... 344

(v) Ethics: Prior Recorded Consent Form ...................................................... 346

(vi) Ethics: National Library NZ: Oral History Consent Form ............................. 348 
(i) Ethics: Sample Interview Questions/Process

\author{
TE WhaRE WĀNANGA O TE ŪPOKO O TE IKA A MĀUI

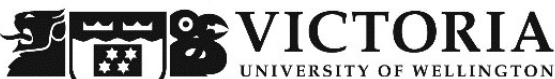 \\ UNIVERSITY OF WELLINGTON \\ Catriana.Mulholland@vuw.ac.nz \\ RESEARCH STUDY
Conversations from the Coalface: Positive Asymmetry and the Culture of Silence that Surrounds the Pike River Mine Tragedy \\ A Doctoral Study by Catriana Mulholland

\section{Interview Questions}

The aim of this study is to discuss events before, during and after the Pike River Mine Tragedy (2010) and to examine any themes which might emerge to help others learn from it and to help avert future work place disaster in this country.

It would be very helpful if you would like to comment on any of the findings and/or recommendations of the (2012) Royal Commission of Inquiry into the Tragedy.

I have added links to the findings and recommendations of the Royal Commission of Inquiry, if you would like to refer to them.

http://pikeriver.royalcommission.govt.nz/Final-Report

I've also added some of the basic recommendations to the end of this document if they are easier to refer to. Or you might just wish to contribute your own experience and knowledge on how to improve safety in the New Zealand workplace.

\title{
The way I Interview
}

The interview is recorded and I bring along a Dictaphone which you can ask to have turned off at any stage. The interview lasts as long as you want it to last. Some 
people have wanted only ten minutes. Most have worked with 30-40 minutes; while others have needed an hour or more. It's completely up to you.

I have questions I can use as prompts, but I usually I start off with:

(1) Could you please describe your experience of the Pike River Mine tragedy?

(2) How did it impact upon you? (if at all)

Quite often, people just talk about their experience from that point, without me (the interviewer) interrupting too much, because I want this process to record your experience and without trying to influence the interview in any particular direction; other than where you_ the interviewee_want it to go.

This is part of Grounded Theory Methodology.... where effective themes of research are generated by the people themselves. It gives you the freedom to say what you want and I later look to the patterns of emerging themes. It is very important that the voices of those affected by this tragedy are the voices that come through in the doctoral work. And it is your voice that needs to be behind the recommendations for improved social policy and safety in the workplace.

Here is a list of possible questions for your interview; but remember they are only prompts. Feel free to reply to them or add your own opinion, knowledge, experience as you go. It's completely over to you. You are in full control of the process and can ask to stop the recording at any time.

\section{Possible Questions/Prompts}

What is your own experience of mining? i.e (as a miner, executive, community or family member/ other....)

What was your experience of the Pike River Mine tragedy?

How did it impact upon you? (if at all)

How do you see yourself now ___ months after the tragedy? 
What have you seen your role as being directly following the tragedy?

Has this changed over the past months?

Do you have any new or changed roles as a result of the tragedy?

How do you see your role in coming weeks?

Do you think that New Zealand has an at-risk culture?

Do you think that New Zealand has a culture that puts production before safety?

Do you think that there has been a failure to learn from past mistakes?

What other struggles have you (or the community) have had to cope with?

When/how?

Would you like to say anything about the Royal Commission of Inquiry into the Pike

River Coal Tragedy? e.g findings or recommendations?

What would you like to happen now?

What can other New Zealanders do to help you in your recovery from this?

What would you like our schools do to support children during traumatic times.

What are your fears for the future?

What are you hopes?

Is there anything else you'd like to add or comment on?

Thank you so much for your time and participation.

Your contribution is much valued and a very important part of this research. 
(ii) Ethics: New Interview: Information Form

\author{
TE WHARE WĀNANGA O TE ŨPOKO O TE IKA A MĀUI

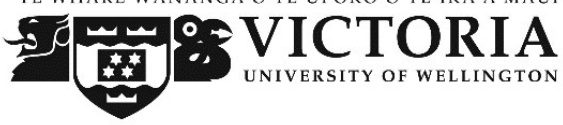 \\ Catriana.Mulholland@,vuw.ac.nz \\ Conversations from the Coalface: Positive Asymmetry and the Culture of Silence \\ that Surrounds the Pike River Mine Tragedy \\ A Doctoral Study by Catriana Mulholland
}

New Interviewee

Participation Sheet

Dear

I am writing to ask you if you would consider being part of my doctoral study of people's experience of the Pike River Mine Tragedy (2010).

The aim is to discuss events before, during and after the tragedy and examine any themes which might emerge to help others learn from it and to help avert future work place disaster in this country.

I will attach an example of the questions and the process this will take. But you would also be free to use the questions only as prompts/ or comment as you see fit.

\title{
The Project
}

My Phd examines, alongside the findings of the Royal Commission of Inquiry how people of the West Coast were affected by the (2010) Pike River Mine Tragedy. The aim is to continue to add to the knowledge of how a community recovers from such an event. It will also look at safety practices in the work place, making links with industries in Aotearoa/NZ with a view to averting future tragedy in this country. 
This project has (VUW) Human Ethics Approval and any recordings will (with your permission) be lodged at the Turnbull Oral History Archives, which is part of the National Library of New Zealand. You can even choose to put a fifty year embargo on your recording after it has been used for the doctoral research if you wish.

So if you are interested, there are some good options here for having your own voice, experience and point of view coming through future work. And I really hope you are. It is very important that the voices of those affected by this tragedy are the voices that come through in the doctoral work. And it is your voice that needs to be behind the recommendations for improved social policy and safety in the workplace. I am also attaching a participant consent form. If you have any other enquiries, feel free to contact me (or my supervisors) at Victoria University of Wellington:

\section{Catriana.Mulholland@vuw.ac.nz Phone}

Dr. Sandra Grey Sandra.Grey@vuw.ac.nz

Dr. Benjamin Snyder Ben.Snyder@vuw.ac.nz.

Thank you for your time and I hope to hear from you in the very near future.

Warm regards,

Catriana (Cat) Mulholland

TE WHARE WĀNANGA O TE ŪPOKO O TE IKA A MĀUI

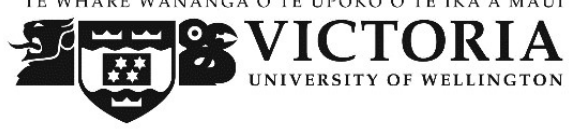

Faculty of Humanities and Social Sciences Victoria University of Wellington PO Box 600, Wellington 6140, New Zealand. 
(iii) Ethics: Follow Up Interview Information Form

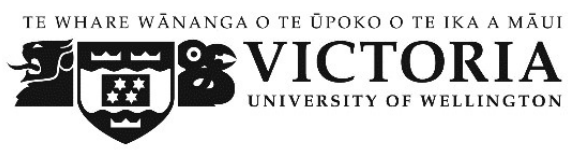

\title{
Catriana.Mulholland@,vuw.ac.nz
}

\section{RESEARCH STUDY}

Conversations from the Coalface: Positive Asymmetry and the Culture of Silence that Surrounds the Pike River Mine (2010) Tragedy

A Doctoral Study by Catriana Mulholland

\author{
Follow-Up
}

Interview Participation Sheet

Dear

In 2011 I interviewed you and members of your community regarding their experience of the Pike River Mine Tragedy (2010). The aim was to discuss events before, during and after the tragedy in order to help others learn from it and to help avert future work place disaster in this country.

I really appreciate your past participation in this project and the agreement to be part of it. If you are able to, I would really appreciate the chance to interview you again for my Phd to see how your opinions may (or may not) have changed since the results of the Royal Commission on the Pike River Coal Mine Tragedy. I will attach the questions and the process this will take. But you would also be free [as with the first interviews] to use these questions only as prompts or simply comment as you see fit.

It is very important that the voices of those affected by this tragedy are the voices that come through in the doctoral work. And it is your voice that needs to be behind the recommendations for improved social policy and safety in the workplace. 


\section{$\underline{\text { The Project }}$}

My Phd will examine, alongside the findings of the Royal Commission of Inquiry (2012) how people of the West Coast were affected by the Pike River Mine Tragedy.

The aim is to continue to add to the knowledge of how a community recovers from such an event. It will also look at safety practices in the work place with a view to averting future tragedy in this country.

This project has (VUW) Human Ethics Approval and any recordings will be (with your permission) lodged at the Turnbull Oral History Archives, which is part of the National Library of New Zealand. You can even choose to put a fifty year embargo on your recording after it has been used for doctoral research if you wish.

Please feel free to contact me any time if you have any questions relating to any of this. You can contact me or either of my supervisors, Dr. Sandra Grey, Senior Lecturer, School of Social and Cultural Studies on Sandra.Grey@vuw.ac.nz 044635371 or Dr. Benjamin Snyder Ben.Snyder@vuw.ac.nz.

Thank you for your time and participation. I look forward to hearing from you. Your contribution was very important to the study and continues to be much valued.

Warm regards,

Catriana (Cat) Mulholland

Catriana.Mulholland@vuw.ac.nz

Phone $* * * * * * * * * *$

TE WHARE WĀNANGA O TE ŨPOKO O TE IKA A MĀUI

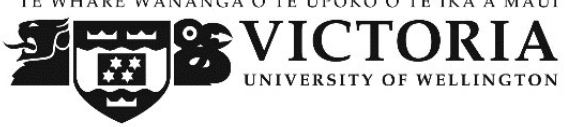

Faculty of Humanities and Social Sciences Victoria University of Wellington PO Box 600, Wellington 6140, New Zealand. 
(iv) Ethics: New Interviewee Consent Form

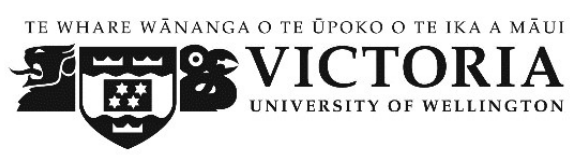

Catriana.Mulholland@vuw.ac.nz

RESEARCH STUDY

Conversations from the Coalface: Positive Asymmetry and the Culture of Silence that Surrounds the Pike River Mine (2010) Tragedy

A Doctoral Study by Catriana Mulholland

\author{
New Interviewee \\ INTERVIEW CONSENT FORM
}

\title{
What is the research?
}

My Phd examines, alongside the findings of the Royal Commission of Inquiry how people of the West Coast were affected by the (2010) Pike River Mine Tragedy. The aim is to continue to add to the knowledge of how a community recovers from such an event. It will also look at safety practices in the work place, making links with other industries in New Zealand with a view to averting future workplace tragedy. This project has (VUW) Human Ethics Approval.

The transcript and recordings of your interview will be (with your permission) lodged at the Turnbull Oral History Archives at the National Library of New Zealand. You can even choose to put a fifty year embargo on your recording after it has been used for the doctoral research, if you wish.

So if you are interested, there are some good options here, for having your own voice, experience and point of view coming through the work. And I really hope you are. It is very important that the voices of those affected by this tragedy are the 
voices that come through in the doctoral work. And it is your voice that needs to be behind the recommendations for improved social policy and safety in the workplace.

\section{The Consent Form}

Full Name:

- I agree to being recorded and my interview with Catriana Mulholland being used in her Phd and other scholarly publications.

- I agree to being named in the research.

- I agree to have the transcripts and recording of my interviews with Catriana Mulholland being kept at the Turnbull Oral History Archives, National Library of New Zealand at the completion of the doctorate. *

Signature

Date 
(v) Ethics: Prior Recorded Consent Form

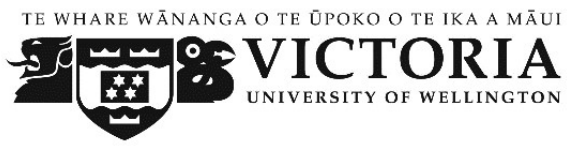

Catriana.Mulholland@,vuw.ac.nz

\author{
RESEARCH STUDY
}

Conversations from the Coalface: Positive Asymmetry and the Culture of Silence that Surrounds the Pike River Mine (2010) Tragedy

A Doctoral Study by Catriana Mulholland

\author{
Prior-Recorded \\ INTERVIEW CONSENT FORM
}

\title{
What is the research?
}

My Phd examines, alongside the findings of the Royal Commission of Inquiry how people of the West Coast were affected by the (2010) Pike River Mine Tragedy. The aim is to continue to add to the knowledge of how a community recovers from such an event. It will also look at safety practices in the work place, making links with other industries in New Zealand with a view to averting future workplace tragedy. This project has (VUW) Human Ethics Approval.

The transcript and recordings of your interview will (with your permission) be lodged at the Turnbull Oral History Archives at the National Library of New Zealand. You can even choose to put a fifty year embargo on your recording after it has been used for the doctoral research, if you wish.

So if you are interested, there are some good options here, for having your own voice, experience and point of view coming through the work. And I really hope you are. It is very important that the voices of those affected by this tragedy are the 
voices that come through in the doctoral work. And it is your voice that needs to be behind the recommendations for improved social policy and safety in the workplace.

Warm regards,

Catriana (Cat) Mulholland

Catriana.Mulholland@vuw.ac.nz

Phone $* * * * * * * * * *$

TE WHARE WĀNANGA O TE ŪPOKO O TE IKA A MĀUI

iq

Faculty of Humanities and Social Sciences Victoria University of Wellington PO Box 600, Wellington 6140, New Zealand.

\section{The Consent Form}

Full Name:

- I agree to my past interview I did with Catriana Mulholland of (date) being used in her Phd and other scholarly publications.

- I agree to being named in the research.

- I agree to have the transcripts and recordings of my interviews with Catriana Mulholland being kept at the Turnbull Oral History Archives, National Library of New Zealand. *

Signature:

Date: 
(vi) Ethics: National Library NZ: Oral History Consent Form

Oral History Recording Agreement

NOTE: ${ }^{*}$ Here is the permission form to be filled in so that your interview can (if you want it to be) lodged at the National Library of New Zealand

\section{Name of Project:}

Conversations from the Coalface: Positive Asymmetry and the Culture of Silence that Surrounds the (2010) Pike River Mine Tragedy; a doctoral study, Catriana Mulholland

Full Name of Person Interviewed:

Date of Interview:

Commissioner: (VUW) Catriana Mulholland

Interviewer: Catriana Mulholland

Copyright Holder: Catriana Mulholland

1. Placement: $I$, the person interviewed, agree that the recording of my interview and accompanying material, prepared for archival purposes, will be deposited in

Alexander Turnbull Library/ National Library of New Zealand

And copies may also be held by

(Any Notes)

2. Access: I agree that the recording of my interview and accompanying material may be made freely available for research at the above location, or a location approved by the commissioner.

YES_ OR NO

(Any Notes) 
If NO: I require that there be NO access to the recording of my interview and accompanying material without my prior written permission until:

Release Date:

OR Review Date: .(select one only)

\section{Any Notes:}

3. Publication: I agree that the recording of my interview and accompanying material maybe quoted or shown in full or in part; this includes broadcast, published work, use in public performances, and electronic publication on the internet.

YES__ OR NO

If NO: I require there be NO publication of the recording of my interview and accompanying material without my prior written permission until:

Release Date: ..................OR Review Date: (select one only)

\section{Any Notes:}

4. Privacy Act: As interviewee I acknowledge that this agreement does not modify my rights and responsibilities under the Privacy Act 1993

\section{Any additional Information:}

\section{Signatures}

Person Interviewed:

Date:

Interviewer:

Date:

For Commissioner:

Date:

\section{Notes:}

1. All signatories to this Oral History Recording Agreement must comply with any restrictions on access/publication. 
2. The terms agreed to in this Oral History Recording Agreement may be amended only with the authority of the person interviewed. Any change must be registered with all holders of the interview and accompanying material.

3. Commissioners,

Approved by the National Oral History Association of New Zealand - Version 1, December 2012 Page 2 of 2

\section{INFORMED CONSENT FORM}

Thank you for agreeing to participate in this study. This form details the purpose of this study, a description of the involvement required and your rights as a participant.

By signing this consent form I certify that I agree to the terms of this agreement.

\section{(Print full name here)}

\section{(Signature)}

\section{(Date)}

In the case you are performing the interview with someone present for support they are required to fill out this section. If you are performing an interview with another individual at the same time they will need to fill out their own consent form.

\section{(Print full name here)}




\section{Once again, thank you for your time and participation.}

It is your voice that needs to be heard in this.

Your participation is much appreciated and is invaluable to this study

Please feel free to contact me any time if you have any questions regarding any of these consent forms. If I have any questions regarding my rights as a research subject, you may contact Dr Sandra Grey, Senior Lecturer, School of Social and Cultural Studies on Sandra.Grey@vuw.ac.nz

\section{I look forward to your much valued contribution.}

Warm regards,

\section{Catriana Mulholland}

\section{Catriana.Mulholland@vuw.ac.net}

Phone $* * * * * * * * * *$

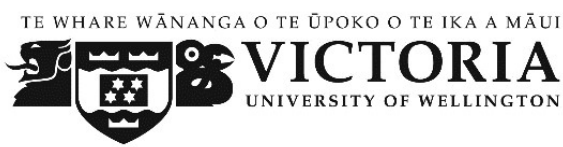

Faculty of Humanities and Social Sciences Victoria University of Wellington, PO Box 600, Wellington 6140, New Zealand. 
Appendix (III) Letters \& Radio Interviews

(i) Harry Bell, (former chief inspector of Mines), Letter to Minister of Energy, Max Bradford, 23 October 1997........................................................................ 353

(ii) M. Bradford, Former Minister of Energy, Reply to H. Bell 4 Nov, 1997......... 355

(iii) See M. Wilson interview Harry Bell, RNZ Checkpoint, 11 April 2013 ........... 356 https://www.radionz.co.nz/audio/player?audio id=2551745 $\left(2^{\text {nd }}\right.$ Item).

(iv) Nicholas Davidson QC, RNZ: K. Ryan Nine To Noon 11 April, 2013 ........... 356 https://www.radionz.co.nz/audio/player?audio id=2551702 
(i) Harry Bell, (former chief inspector of Mines), Letter to Minister of Energy, Max Bradford, 23 October 1997, p. 1.

23 October 1997

Ministry of Energy

The Honorable M Bradford

The Beehive

WELLINGTON

\section{Dear Sir}

I am writing in support of the Mine Inspection Group (M.I.G.) staying with the Ministry of Commerce (M.O.C.) instead of them going to the Labour Department.

Mines Inspectors particularly in the underground situation have had to have at least 5 years experience as a Mine Manager before qualifying for the Inspectorate.

The repealed Acts \& Regulations laid out the practicable experience required for a person before he could even sit for a certificate of competency under that Act. This meant that he had a minimum of 8 years underground experience before he could even consider being appointed as an. Inspector, vastly different from the appointment of Labour Department Inspectors.

At present in M.O.C. we have these experienced inspectors who do not wish to be down graded either in status or financially.

In 1979 I was the Inspector of Coal Mines for West Coast - Canterbury area, I was asked to go before an Appeal Tribunal in Christchurch between the State Services Commissions and the Labour Department.

The Labout Department Representatives were trying to use the Mines Inspectors higher salaries as a lever to gain themselves higher salaries. I had to explain to the Commission what was needed to gain my certificate and in fact had to reach top Management before I was considered fit to be appointed an Inspector. As you can imagine the Appeal was dismissed, as there was no parity between the Mines Division and the Labour Department Inspectorate.

Official information Act. 
Page 2

Mining is an entirely different industry to shops and factories. The coming of the Health and Safety in Employment Act 1992 has not changed this.

In my opinion this situation should never had arisen when the 1992 Health \& Safety in Employment Act was brought into being, the Marine \& Aviation were left out as being too different to come under the Act, the mining industry should also have been left out as they are equally unique in that the pilot of plane or captain of a ship has the same responsibilities as a Mine Manger.

The summing up of the Magistrate in the Inquiry into the Strongman Mine Disaster in 1967 stated quote "the Mine Manager is the Paramount Chief and all responsibilities fall on him".

Because of his background experience the Mines Inspector was always called on to make judgements in certain areas that may have been contrary to the regulations, this dispensation was not given lightly and hard and fast rules were drawn up to safely achieve the solution.

For the smaller mines the Inspector, apart from his regulatory duties also acted to a degree as a consultant giving good advise on improvements as well as safety.

From what I have read in the papers the Labour Department Inspectors thrive on prosecutions and stopping jobs rather than offer advise to solve the problem.

The Mines Inspectorate were created in the previous century due to the atrocities that occurred in Mining and any weakening of this necessary historic Act would not be in the best interest of safety.

It is my understanding that if Mines Inspectors go to Labour they will do so at a reduced salary, I can tell you that that if that happens you will not get the calibre of Inspectors this industry demands.

I therefore ask you to consider these valid points and not be pushed into a decision that can only weaken a system that is working.

Yours sincerely

H. W. Bell

Retired Chief Inspectors of Coal Mines 
(ii) Max Bradford, Former Minister of Energy, Reply to Harry Bell 4 November, 1997.

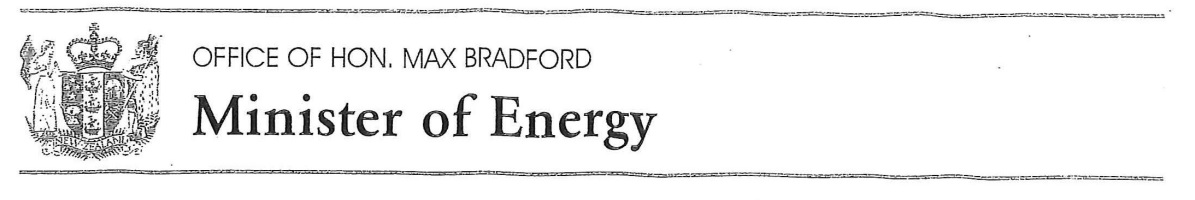

\section{NOV 1997}

Mr Harry W Bell

2/16 Rewi Road

Royal.Oak

AUCKLAND

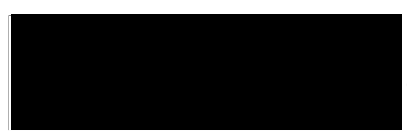

Thank you for your letter dated 23 October 1997 supporting the Mine Inspection Group staying with the Ministry of Commerce. I have noted the points that you have raised.

I appreciate the time you have taken in writing raising your concerns. I will take your submission into consideration along with the other submissions I have received regarding the proposed move of the Mining Inspection Group to the Department of Labour, before any decision is made.

Yours sincerely

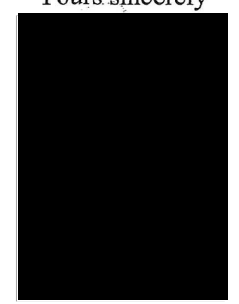

Hon Max Bradford Minister of Energy 
(iii) See Mary Wilson interview Harry Bell, RNZ Checkpoint, 11 April 2013 https://www.radionz.co.nz/audio/player?audio id=2551745 $\left(2^{\text {nd }}\right.$ Item $)$.

Note: Harry Bell was later made a member of the NZ Order of Merit for his services to the mining industry in 2015.

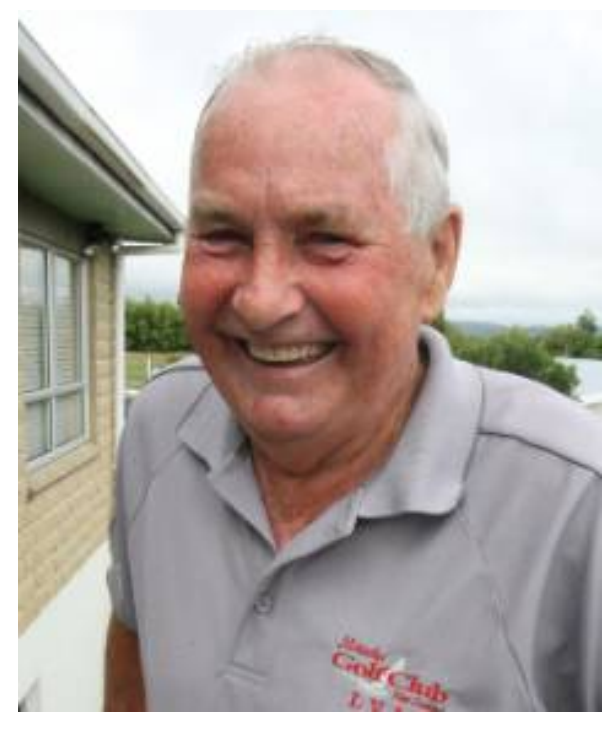

(iv) Nicholas Davidson QC, RNZ: Kathryn Ryan Nine To Noon 11 April 2013 https://www.radionz.co.nz/audio/player?audio id $=2551702$

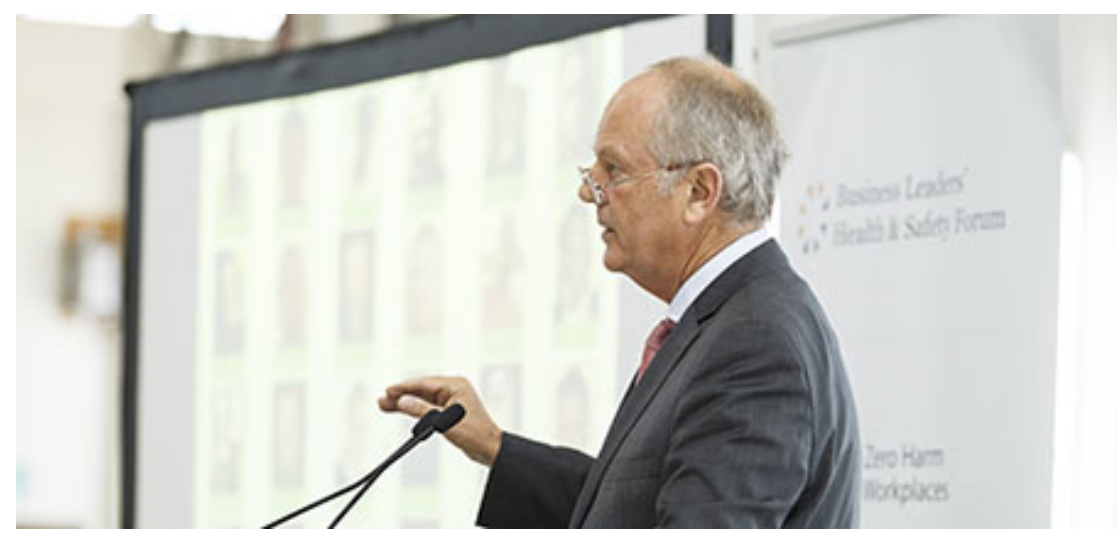

Note: Nicholas Davidson was appointed to be a High Court Judge in June 2015 


\section{Appendix (IV)}

See, Mulholland Interviews: Paul Berry (3 July 2012) farmer and Grey District Councillor who donated some of his farmland for the Family Memorial at Atarau.

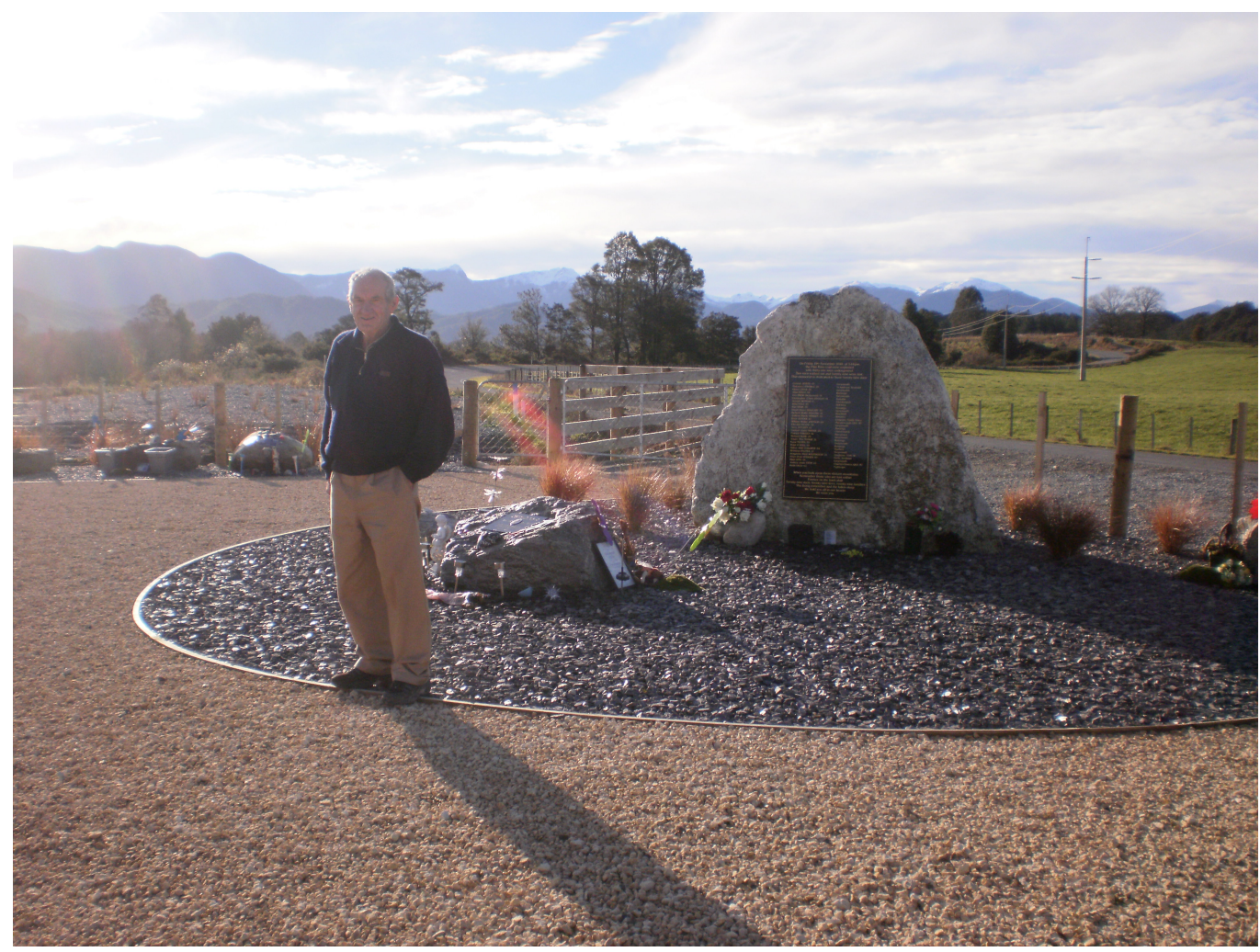

Paul Berry (July 2012) Standing at Atarau Family Memorial,

Grey District Council and farmer Paul Berry denoted his own land to the memorial and brought in the 29 boulders himself while waiting for open heart surgery 


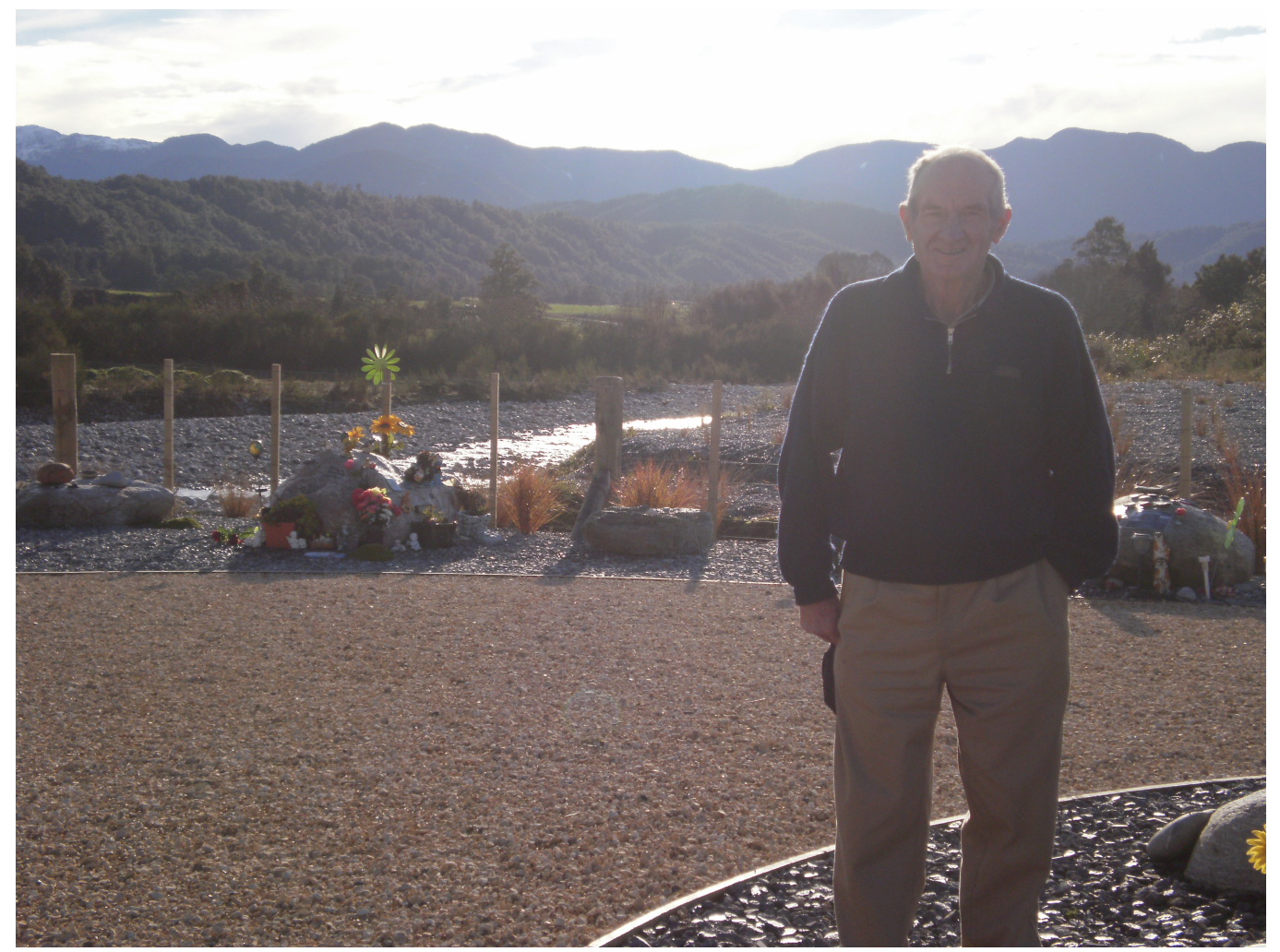

\section{River running behind Paul comes down from Pike and the Mountains}

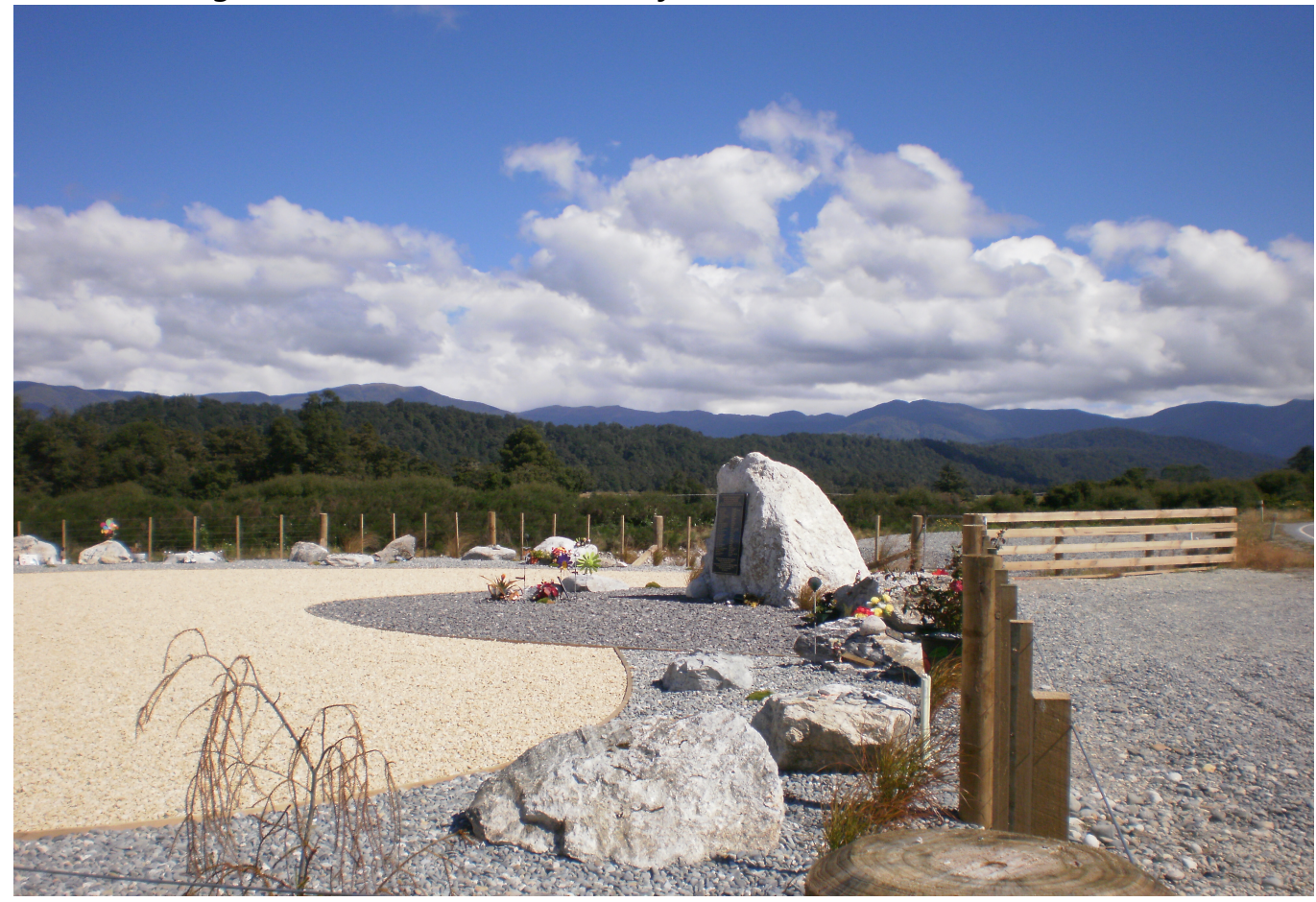




\section{Appendix (V) A Scattering of Pike River Mine Photos 2011-2016}

(1) Don't worry, you will be out soon, Stone-Texts, Grey Main School, 2010-2011.

(2) All our thoughts are with you, Stone-Texts, Grey Main School, 2010-2011.

(3) Atarau Memorial, 2011. Land donated by Grey District Cr. and farmer, Paul Berry.

(4) Atarau Family Memorial, granity centre stone looking out to mountains' portal.

(5) Child's first school writing to loved one, Atarau Family Memorial 2012.

(6) River running down from Pike past Atarau Family Memorial 2013.

(7) Grey District Council and farmer Paul Berry who not only generously denoted his own land to the memorial but who also brought in the 29 boulders for the memorial.

(8) The Tags of 29 Men and Photos in sun/rain shelter, Atarau Family Memorial 2013.

(9) Eerie strip of mist slowly travelling across a winter paddock, Greymouth 2012.

(10) Hope you are safe, Stone-Texts Grey Main School, 2010.

(11) From Pike to the Homes of the 29 men.

(12) From Pike to the Homes of the 29 men (II).

(13) Cobden Beach Greymouth, Winter Inquiry, 2011.

(14) River coming down from Pike and mountains from Atarau Family Memorial.

(15) Shadow of a cross falls from the school fence across kids Stone-Texts, Feb 2011.

(16) Road sign to Pike River Mine.

(17) Moon \& time over Greymouth, 2012.

(18) Angel or Taniwha? The first day of Royal Commission Inquiry 2011.

(19) Sorry, Stone-Texts, Grey Main School.

(20) Bernie Monk, representative of families, July 2012.

(21) Cobden Beach, after one of the memorials, 2011.

(22) I hold my candle high_but mine is blown out. Stone-Text, Grey Main School. 
(23) Stalactites on the Road to Atarau, July 2012.

(24) Mayor, Tony Kokshoorn, before an artist's depiction of the men, July 2011.

(25) Memorial Stone, 2010-2011.

(26) Yellow Ribbon Memorial, July 2011. (The Pike for Truth \& Justice Symbol)

(27) '29' traced in sand, Cobden Beach 2011.

(28) Workers' Memorial Wheel, Blackball township, Grey District.

(29) 'On the rim of this wheel are the miners killed on the Coast since 1990: This wheel is dedicated to workers killed in the workplace and to the ongoing struggle for workplace health and safety'.

(30) Memorial, Floodwall Greymouth with names of all miners killed in 100 years.

(31) Memorial '29 Links' 2010.

(32) Memorial carved by Richie Cornell of Levin, Kapiti 2011.

(33) Cobden Beach after one of the last Memorials, Oct 2011.

(34) Memorial over Cobden Beach for Glen Cruse and Kane Nieper who were both keen surfers.

(35) Anna Osborne and Sonya Rockhouse, Wellington High Court, May 2015.

(36) Parliament, December 2016, Dean Dunbar, father of Joseph who died the day after his 17th birthday, on his first day at work at Pike 19 November, 2010.

(37) Sonya Rockhouse, Anna Osborne at Parliament, December 2016.

(38 Wellington High Court, May 2015, Rebecca MacFie, Helen Kelly, Kath Monk, Bernie Monk, Catriana Mulholland and lawyers.

(39) Pike Mine_Work Safe_Play Safe_Home Safe. Yeah, Right.

(40) Poem on ground inside wires of locked gates to Pike. (W.H Auden) 
(1) Don't Worry, you will be out soon, Stone Texts, Grey Main School

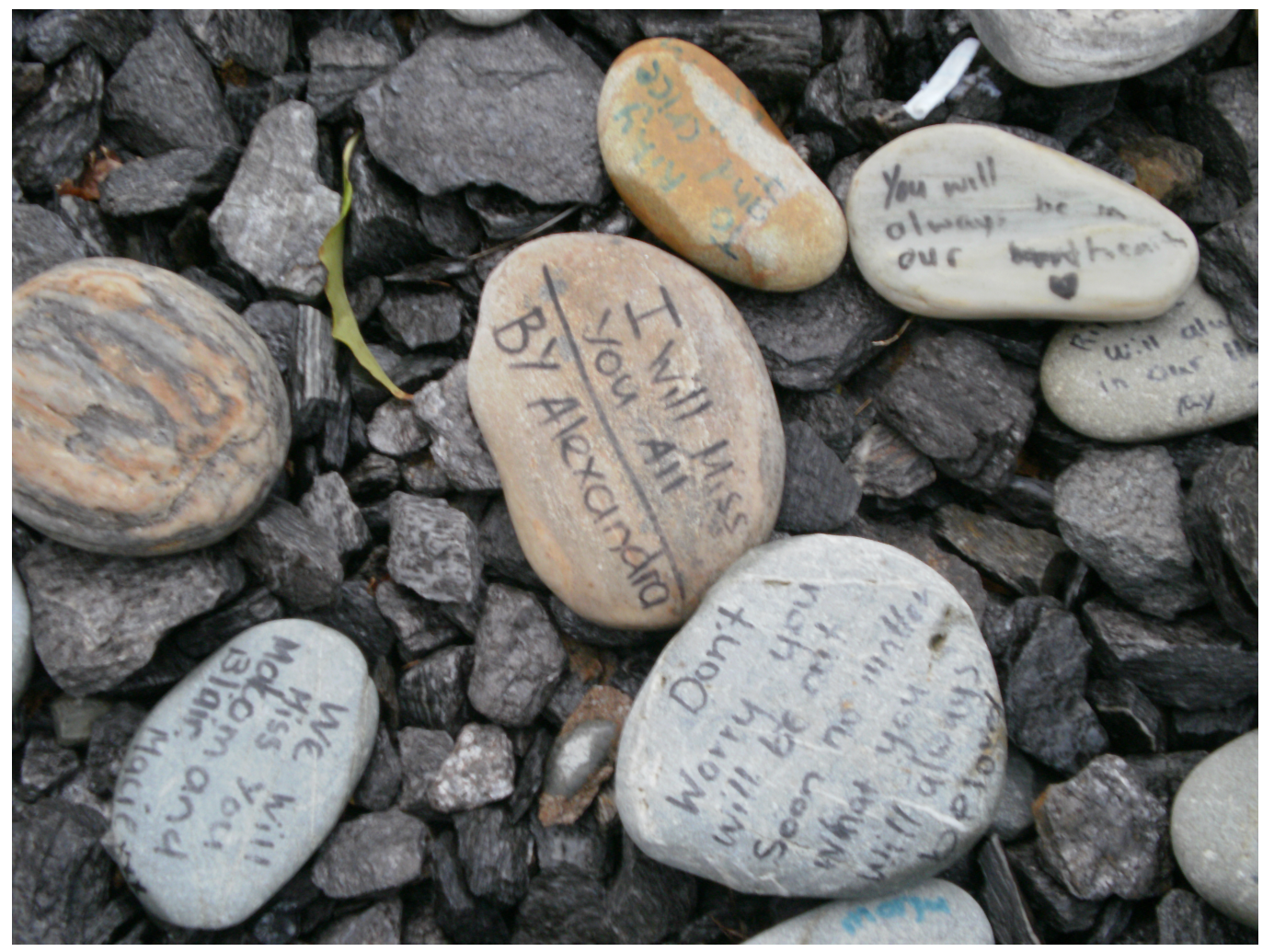

(2) All our thoughts are with you, Stone Texts, Grey Main School

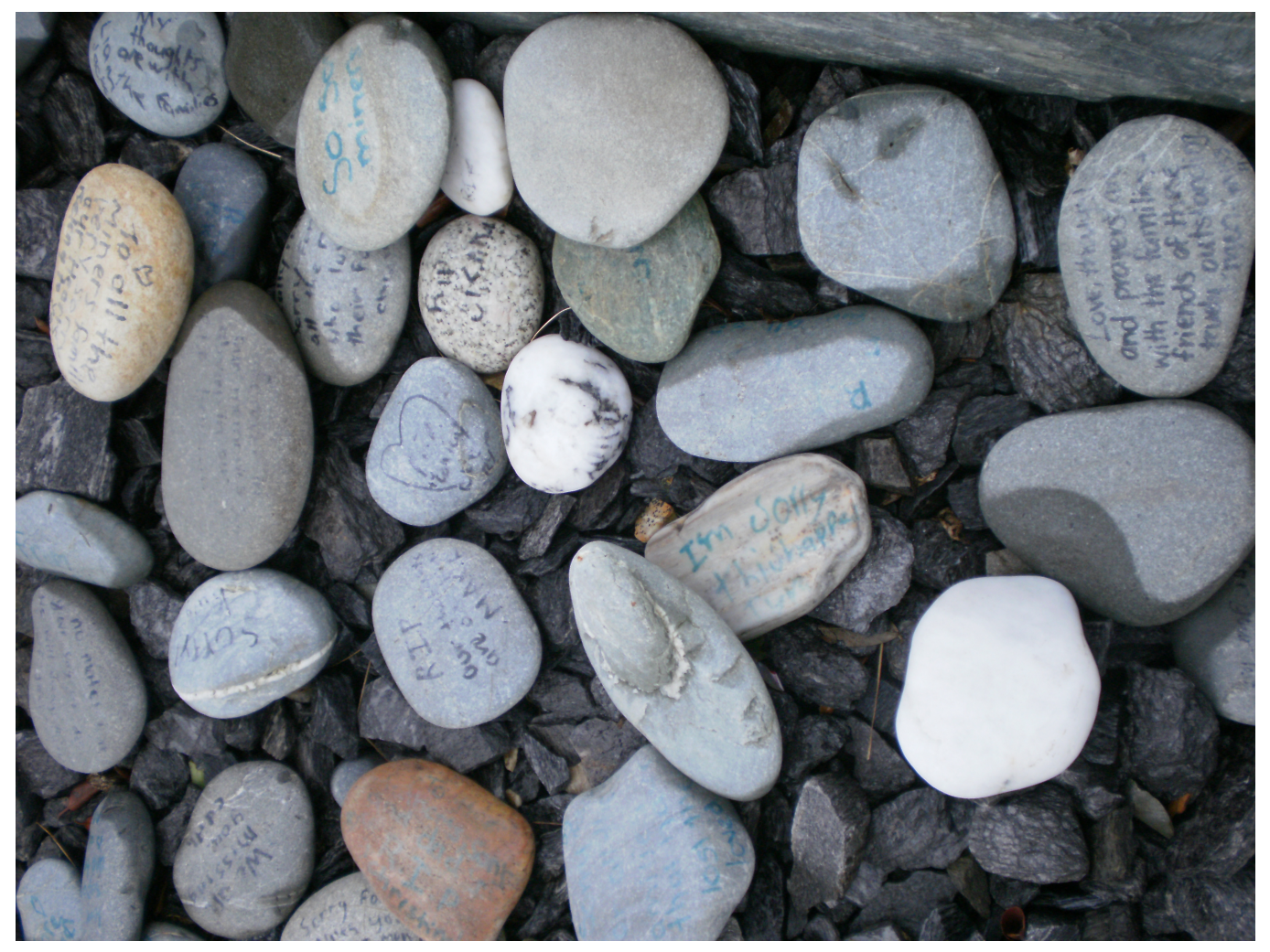


(3) Atarau Memorial, 2011. Land donated by Grey District Cr. and farmer, Paul Berry

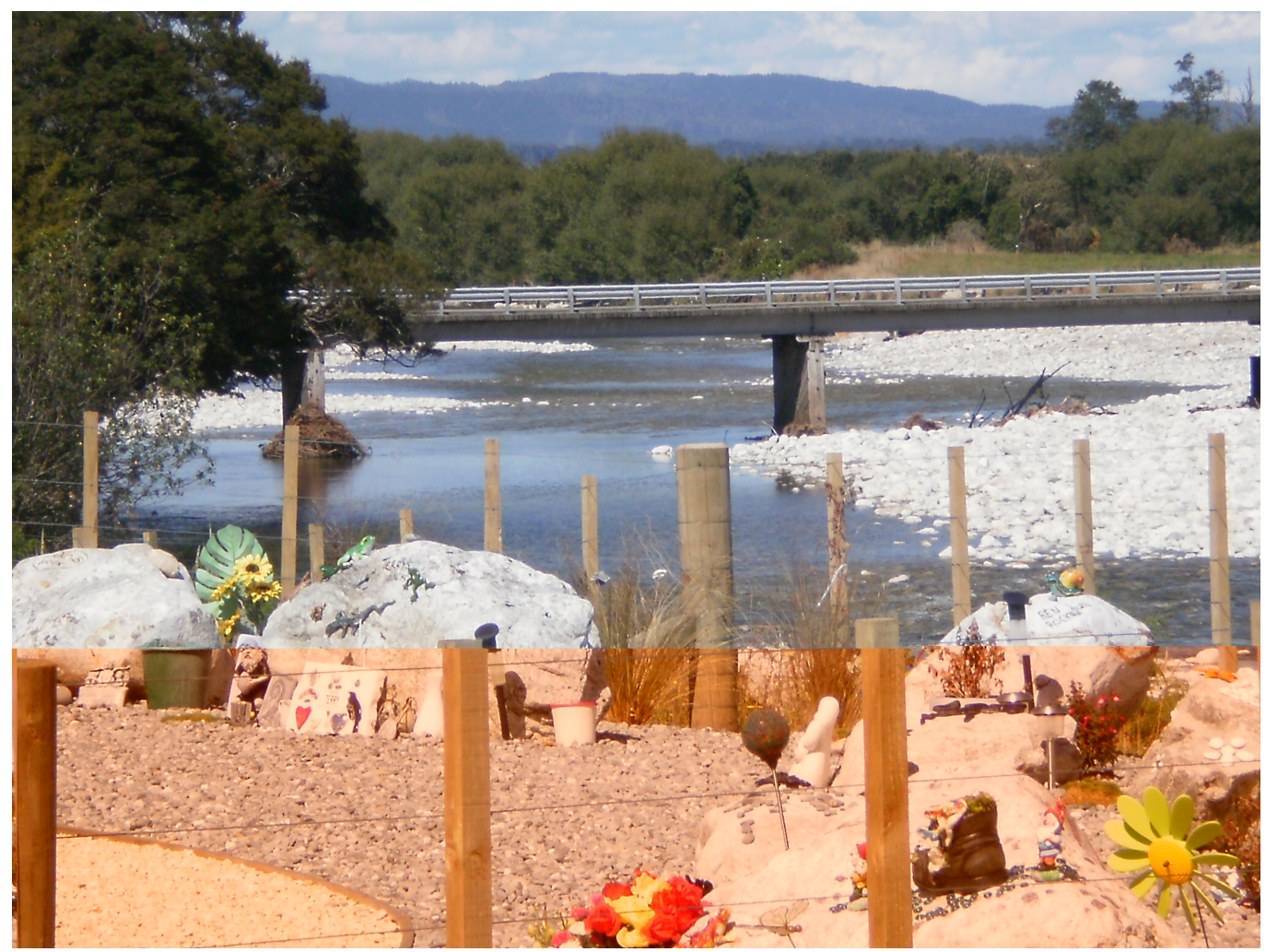

(4) Atarau Family Memorial, granity stone looking out to Pike

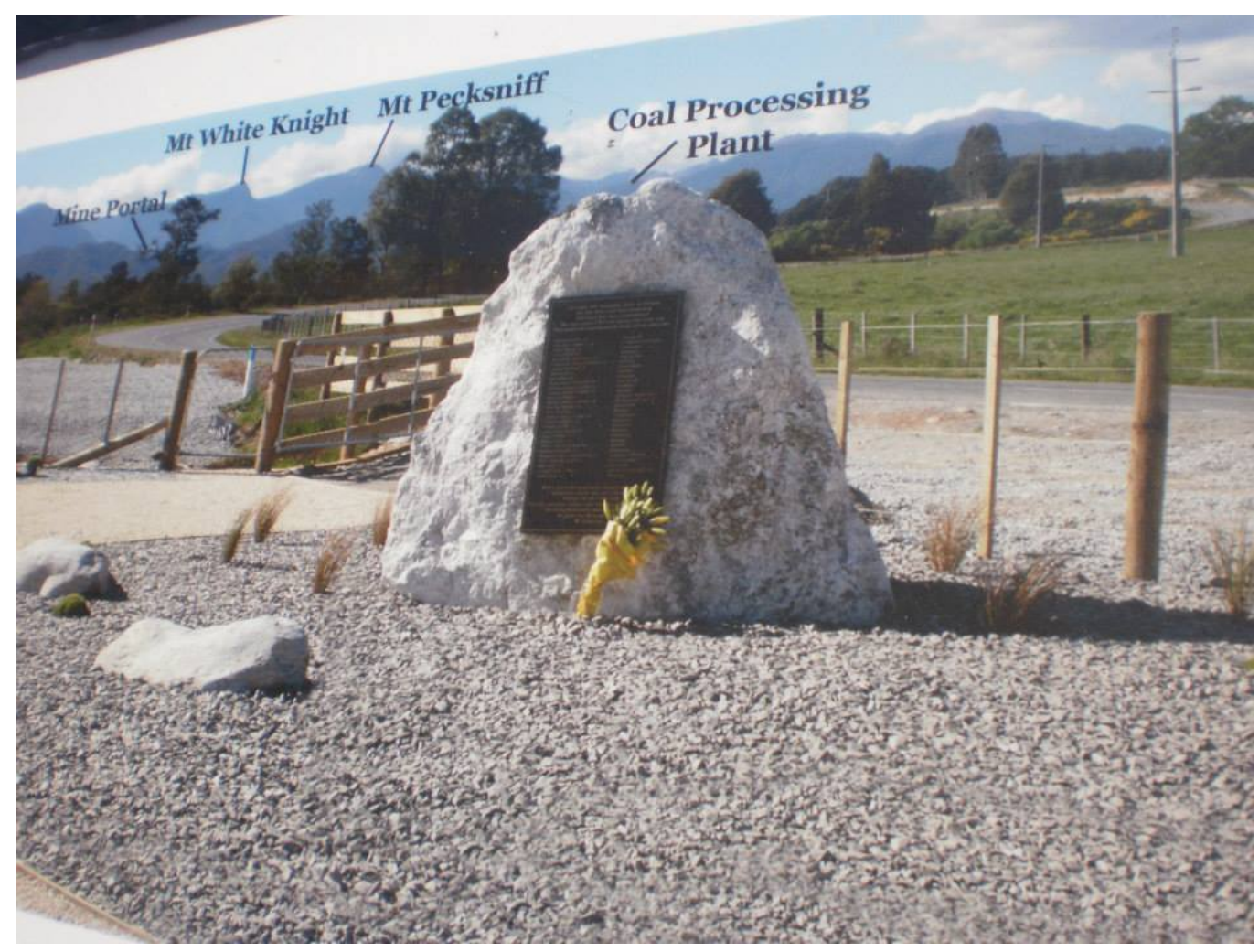


(5) Child's first school writing to loved one, Atarau Family Memorial 2012

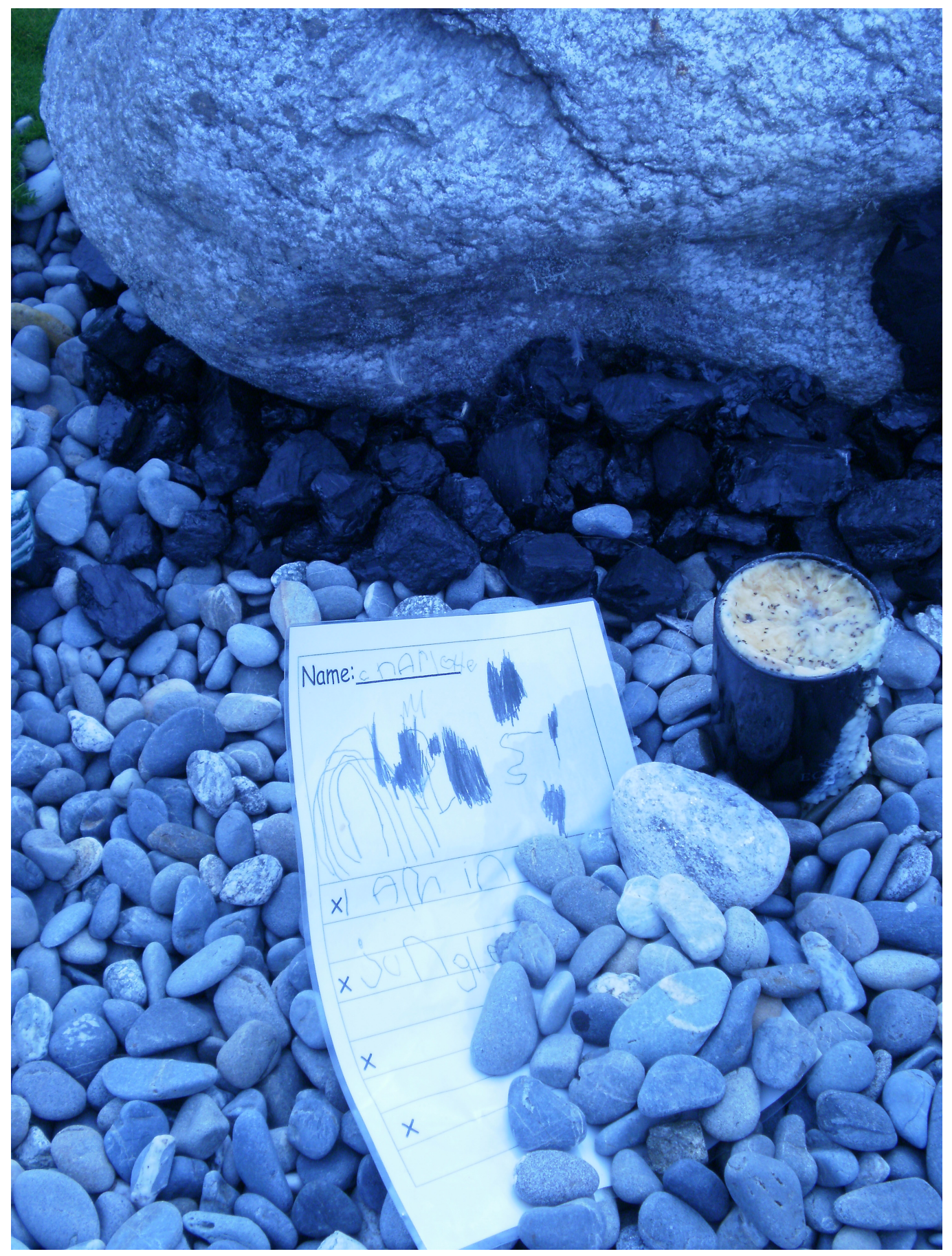


(6) River running down from Pike past Atarau Family Memorial 2013

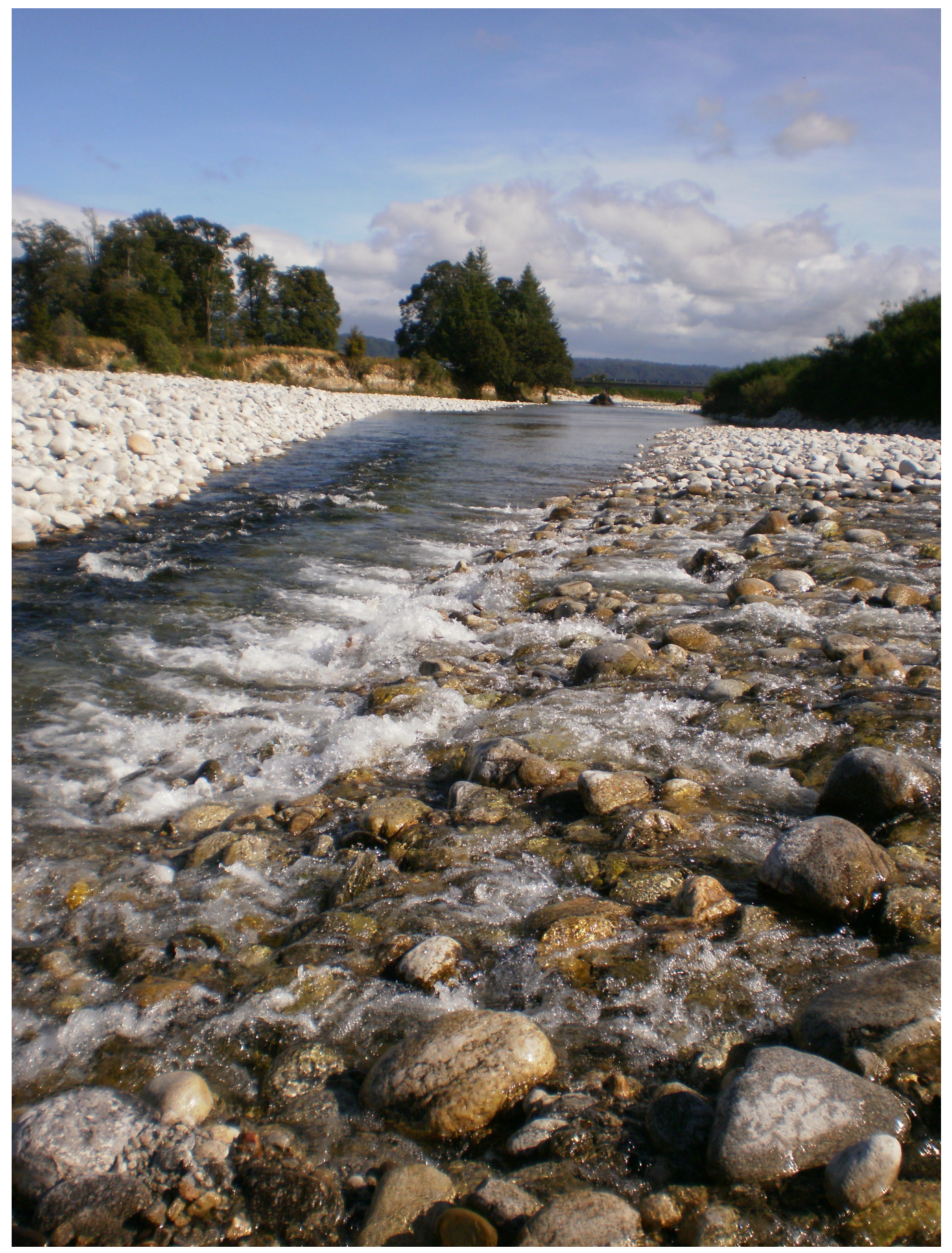




\section{(7) Paul Berry Grey District Council who denoted his land to the Memorial}

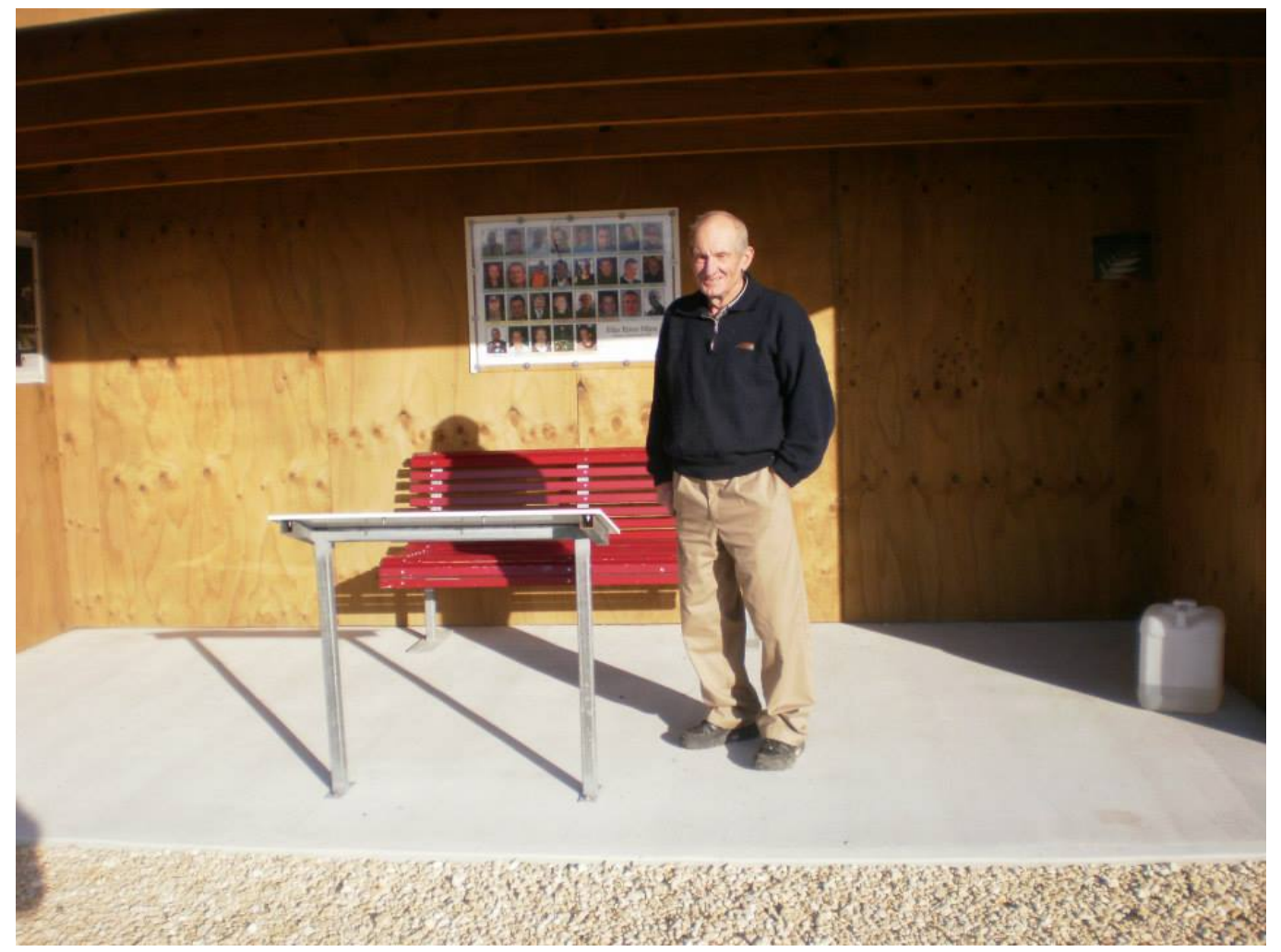

(8) The Tags of 29 Men and Photos in sun/rain shelter, Atarau Family Memorial 2013

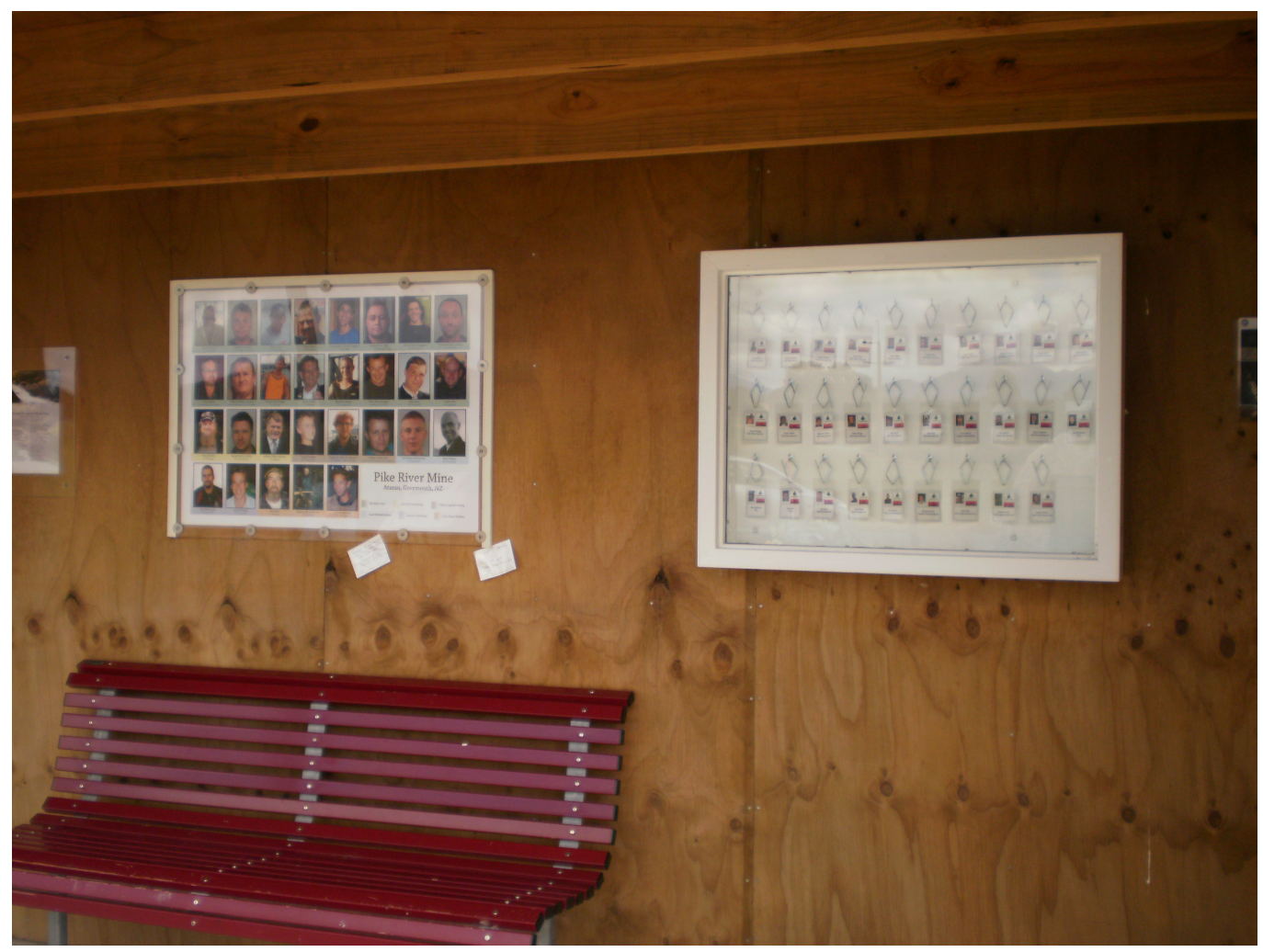


(9) Eerie strip of mist slowly travelling across a winter paddock, Greymouth 2012

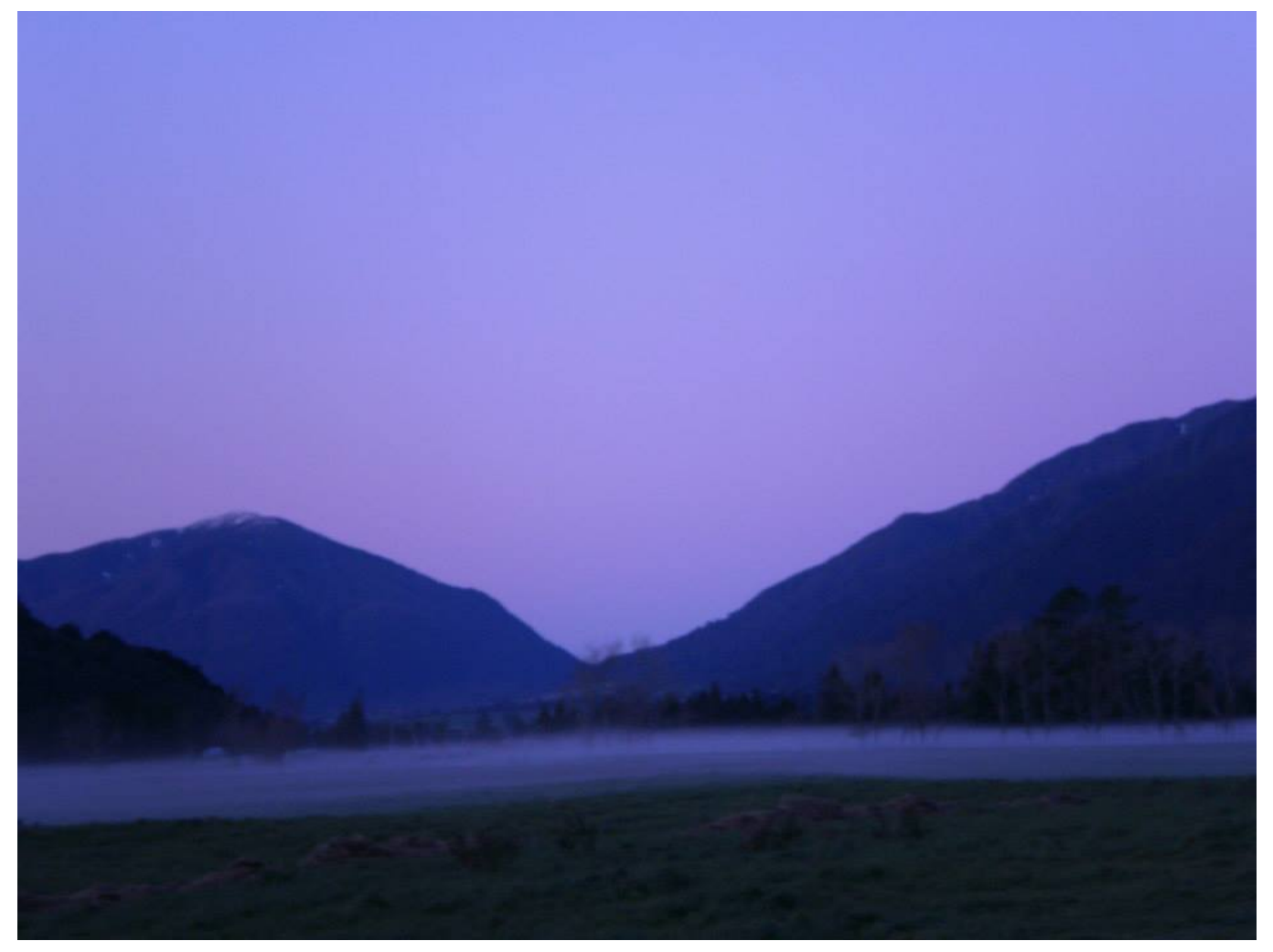

(10) Hope you are safe, Stone-Texts Grey Main School

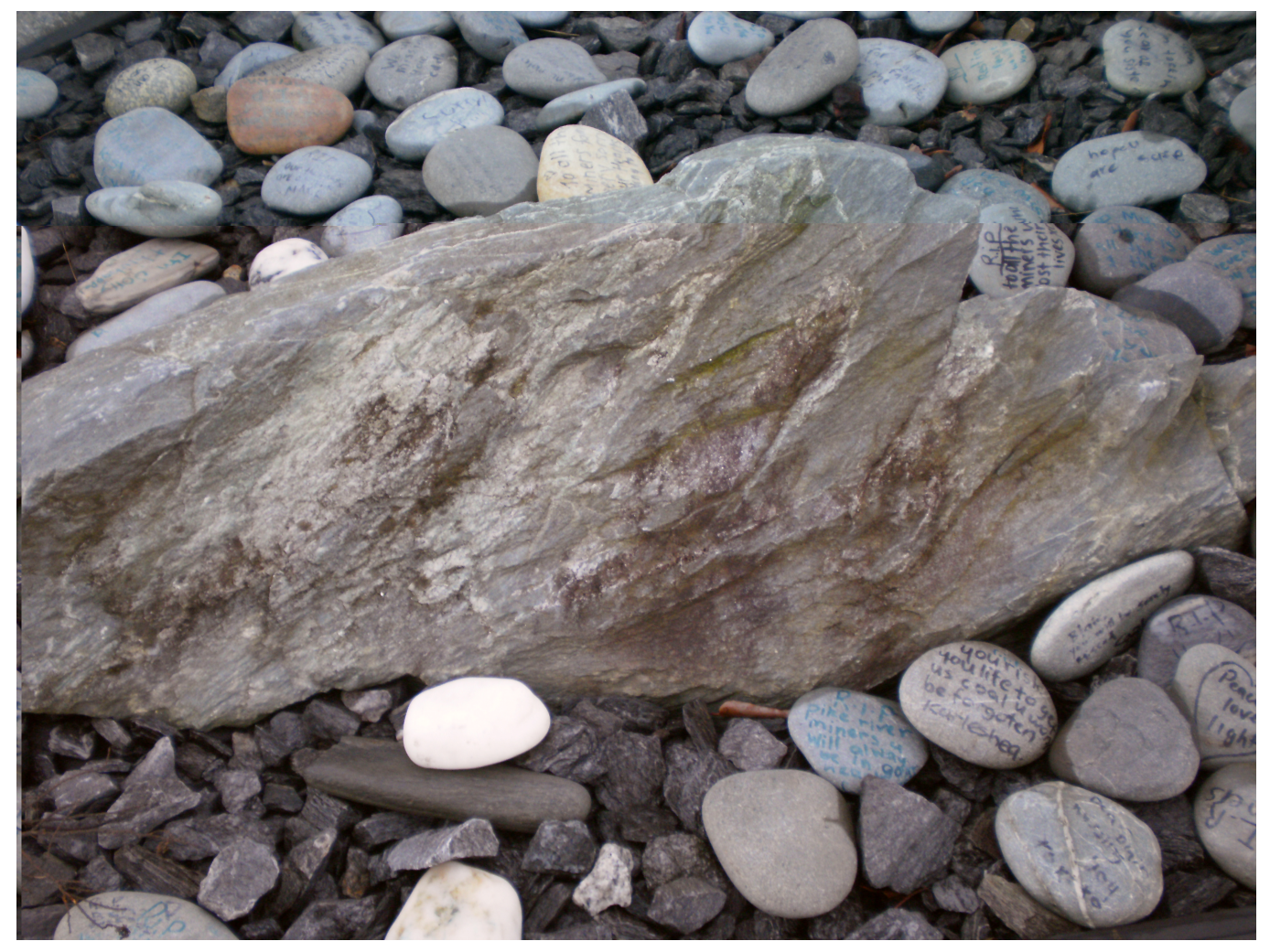


(11) Kilometre Road Signs: From Pike to the Homes of the 29 men

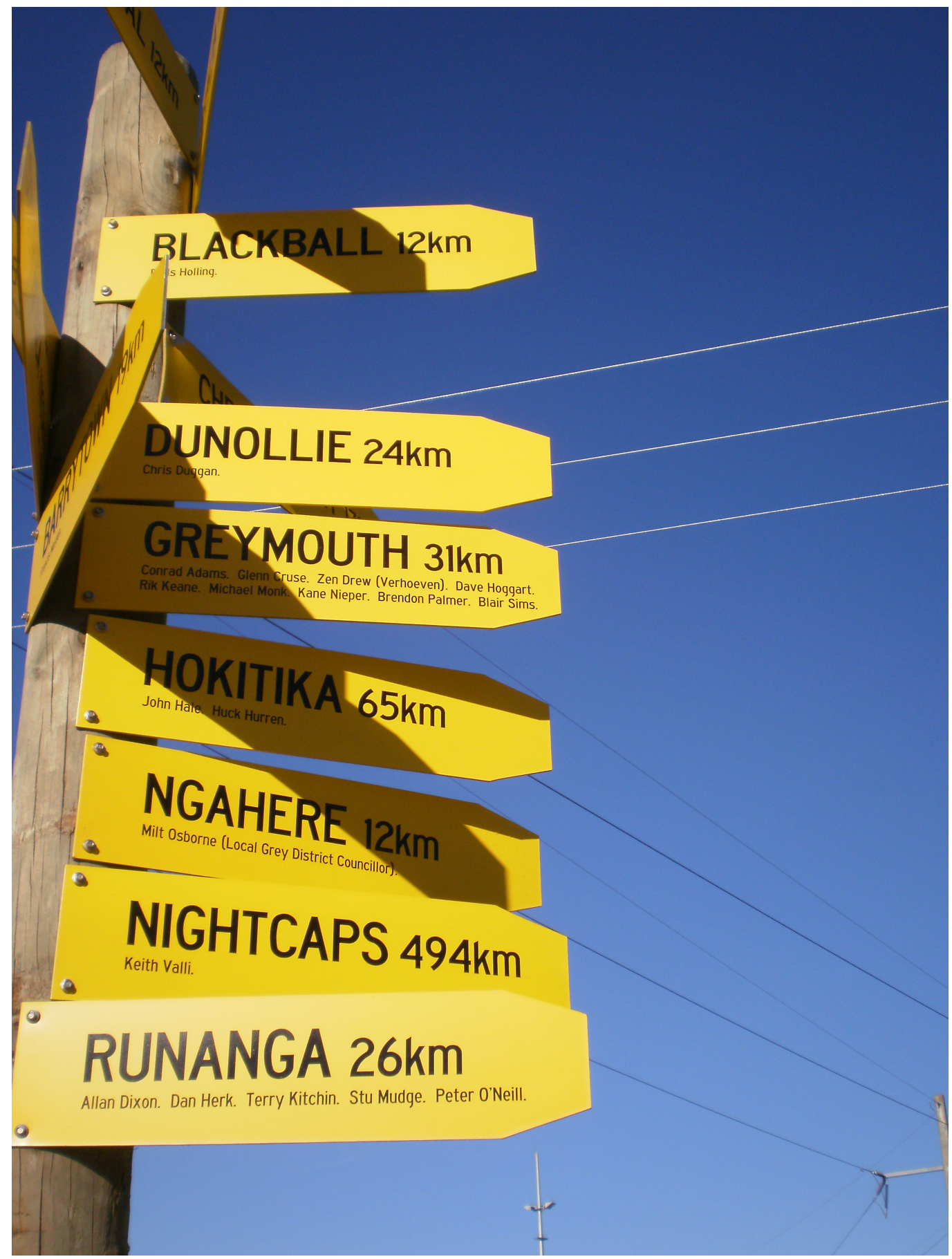


(12) Kilometre Road Signs: From Pike to the Homes of the 29 men (II)

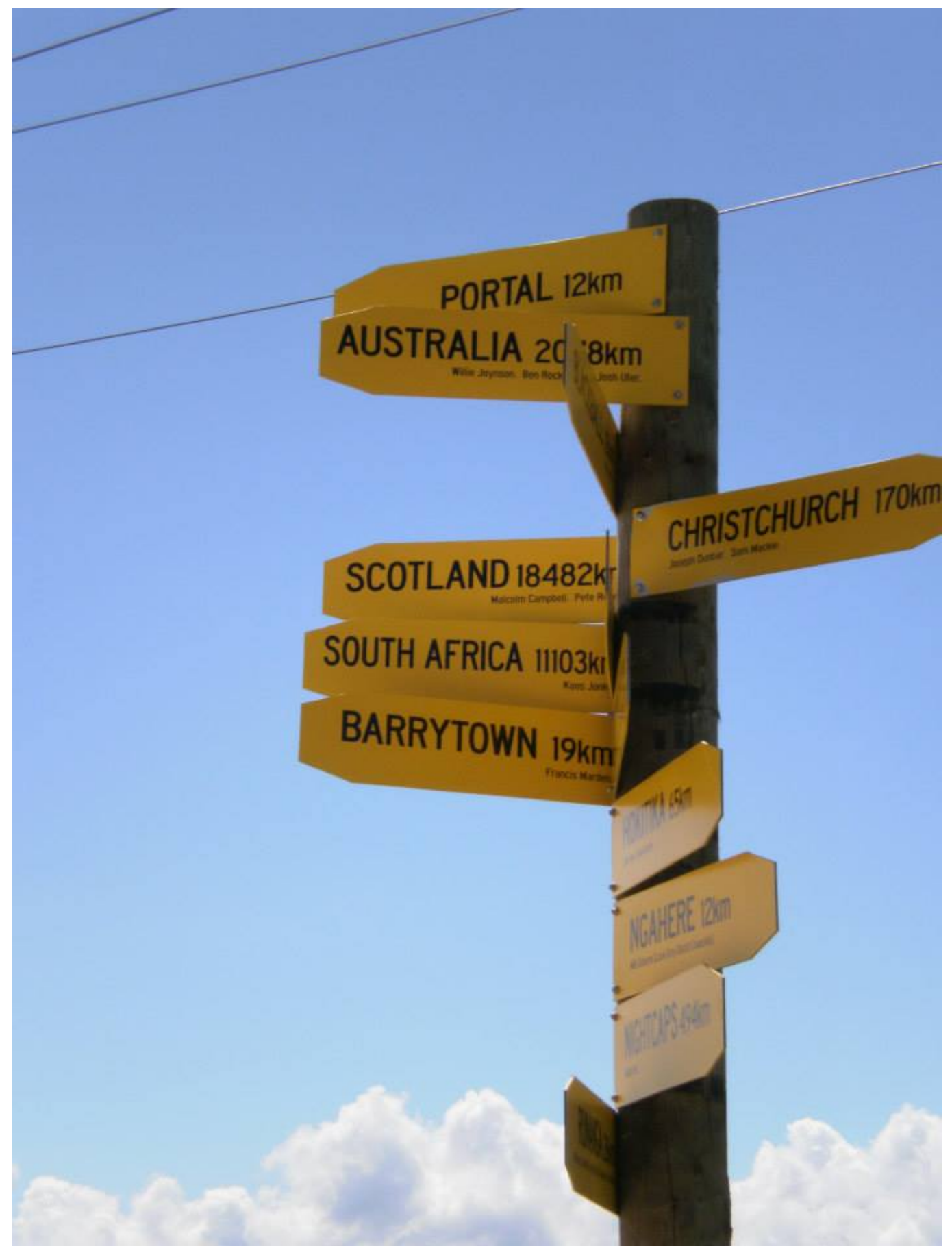


(13) Cobden Beach Greymouth, Winter Inquiry, 2011

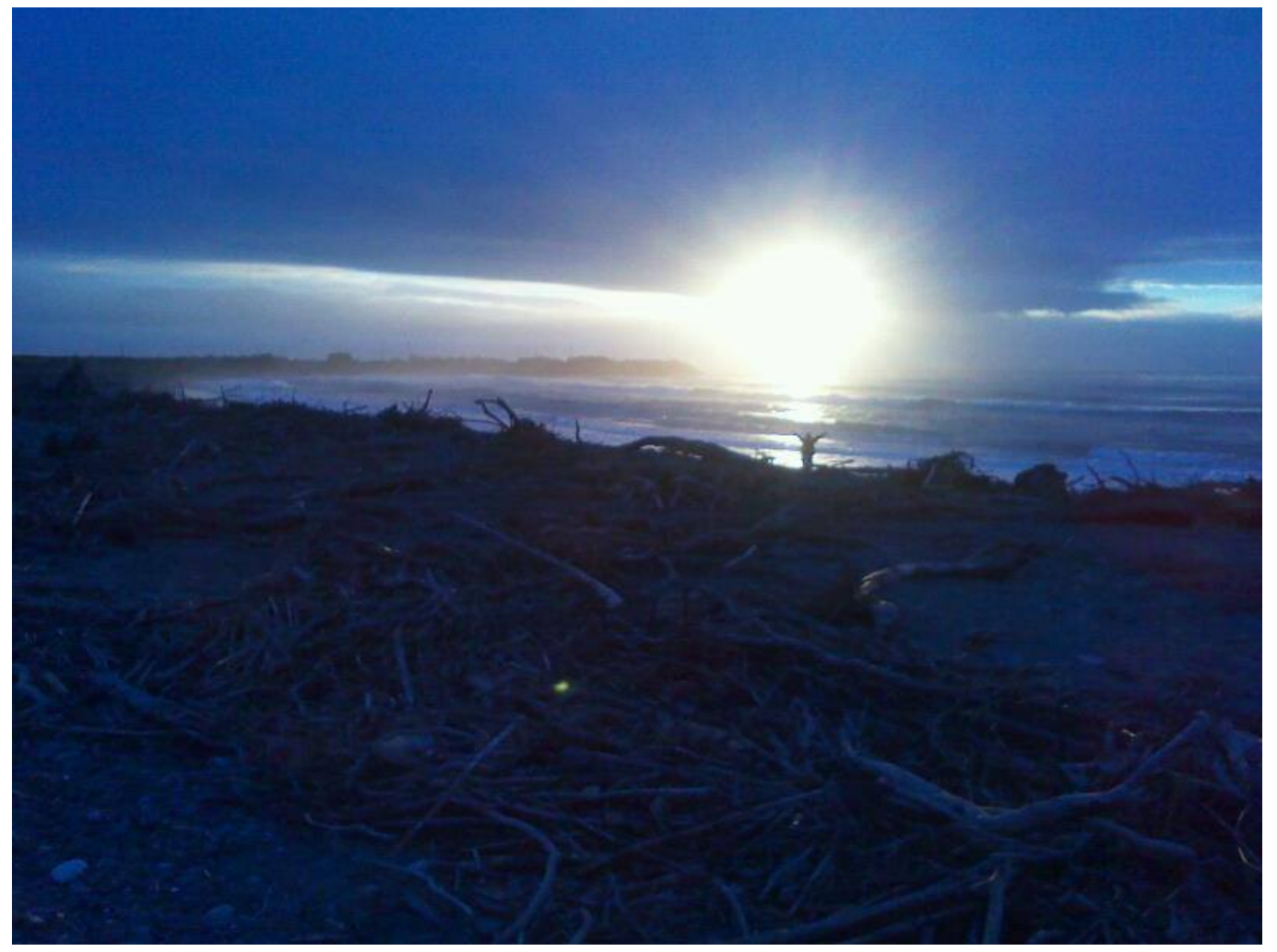

(14) River coming down from Pike and mountains from Atarau Family Memorial

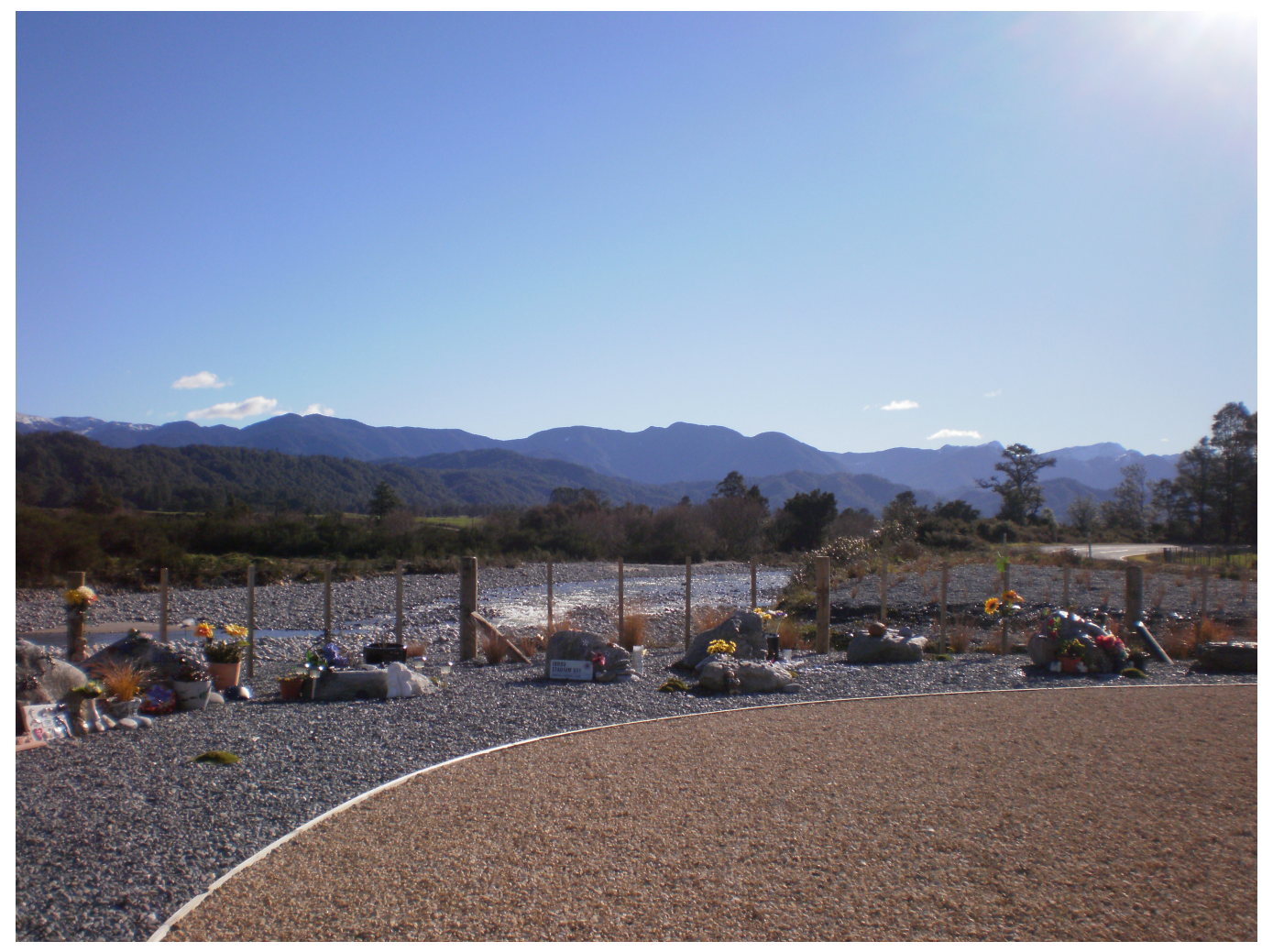


(15) Shadow of a cross falls from the school fence across kids Stone Texts

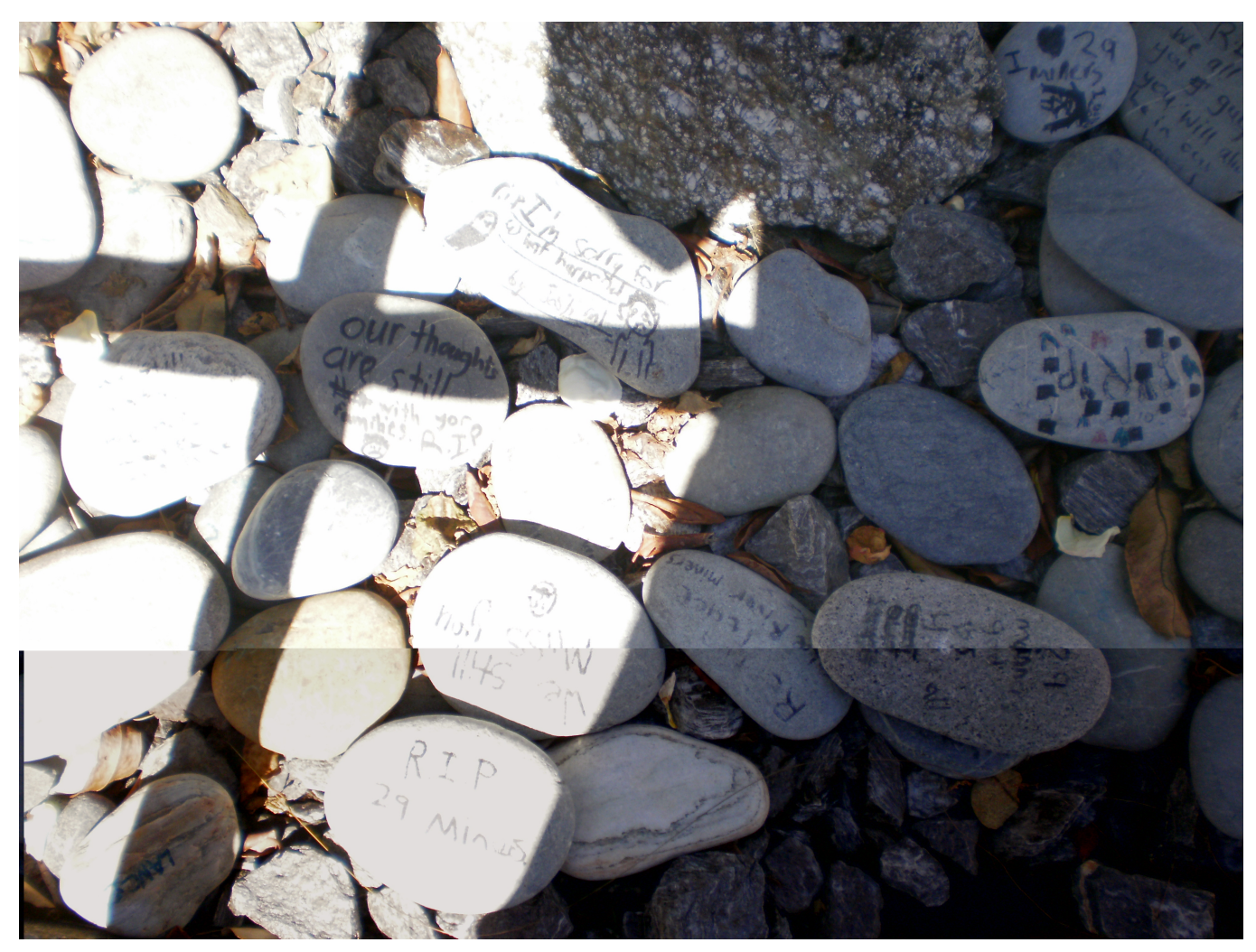

(16) Road sign to Pike River Mine

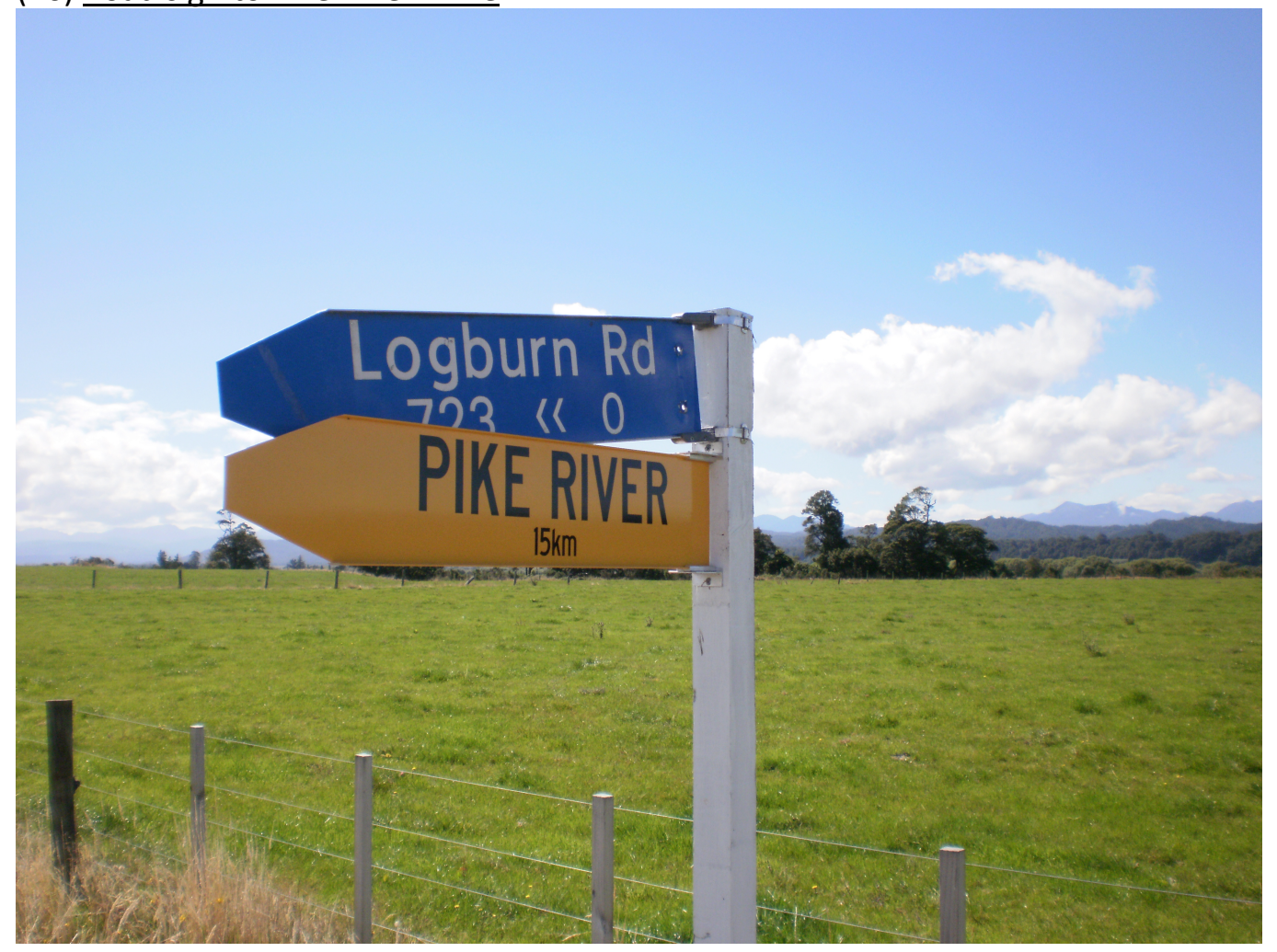


(17) Moon \& Time over Greymouth 2012

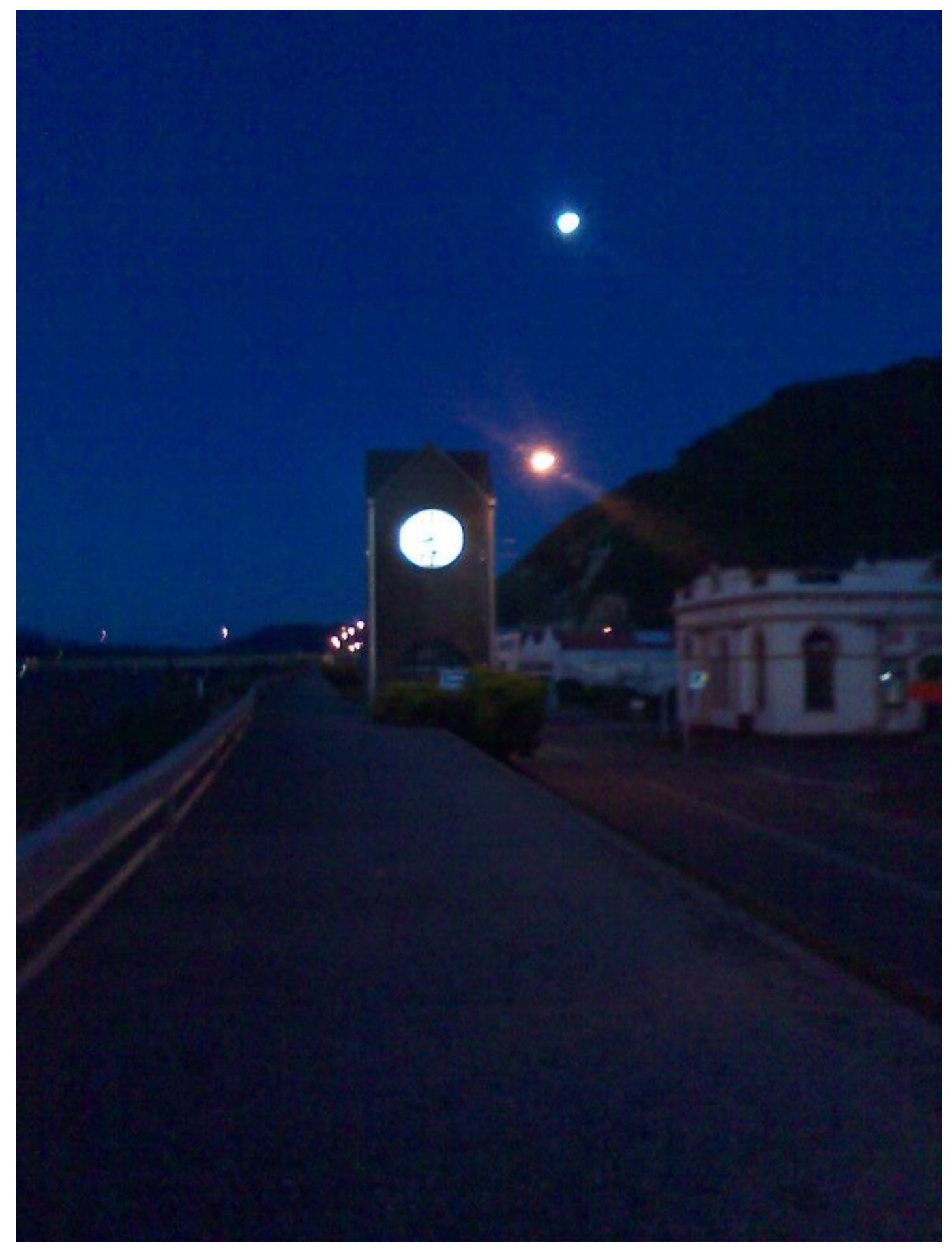


(18) Angel or Taniwha? First day of Royal Commission Inquiry 2011

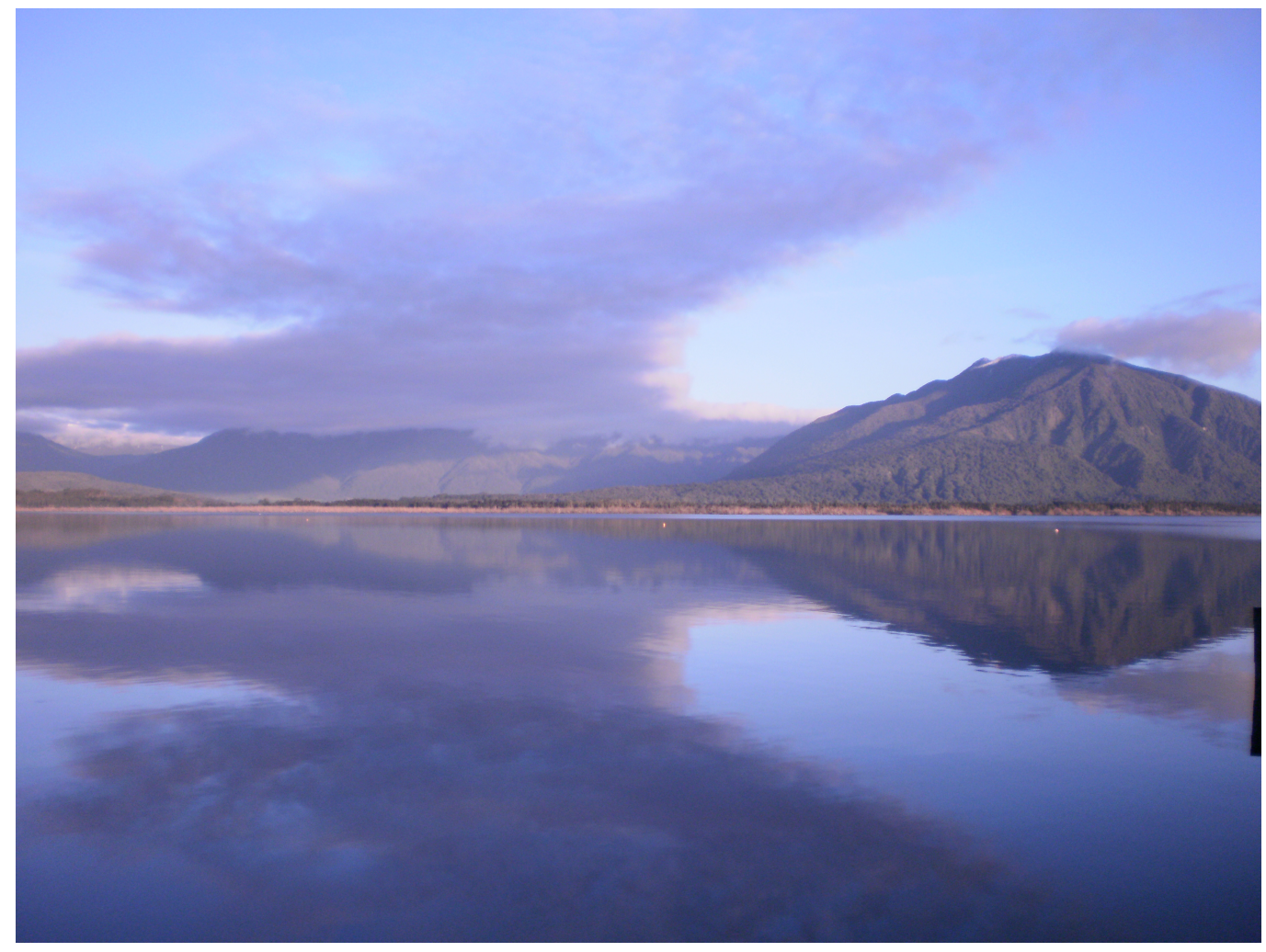

(19) Sorry, Stone Text Grey Main School

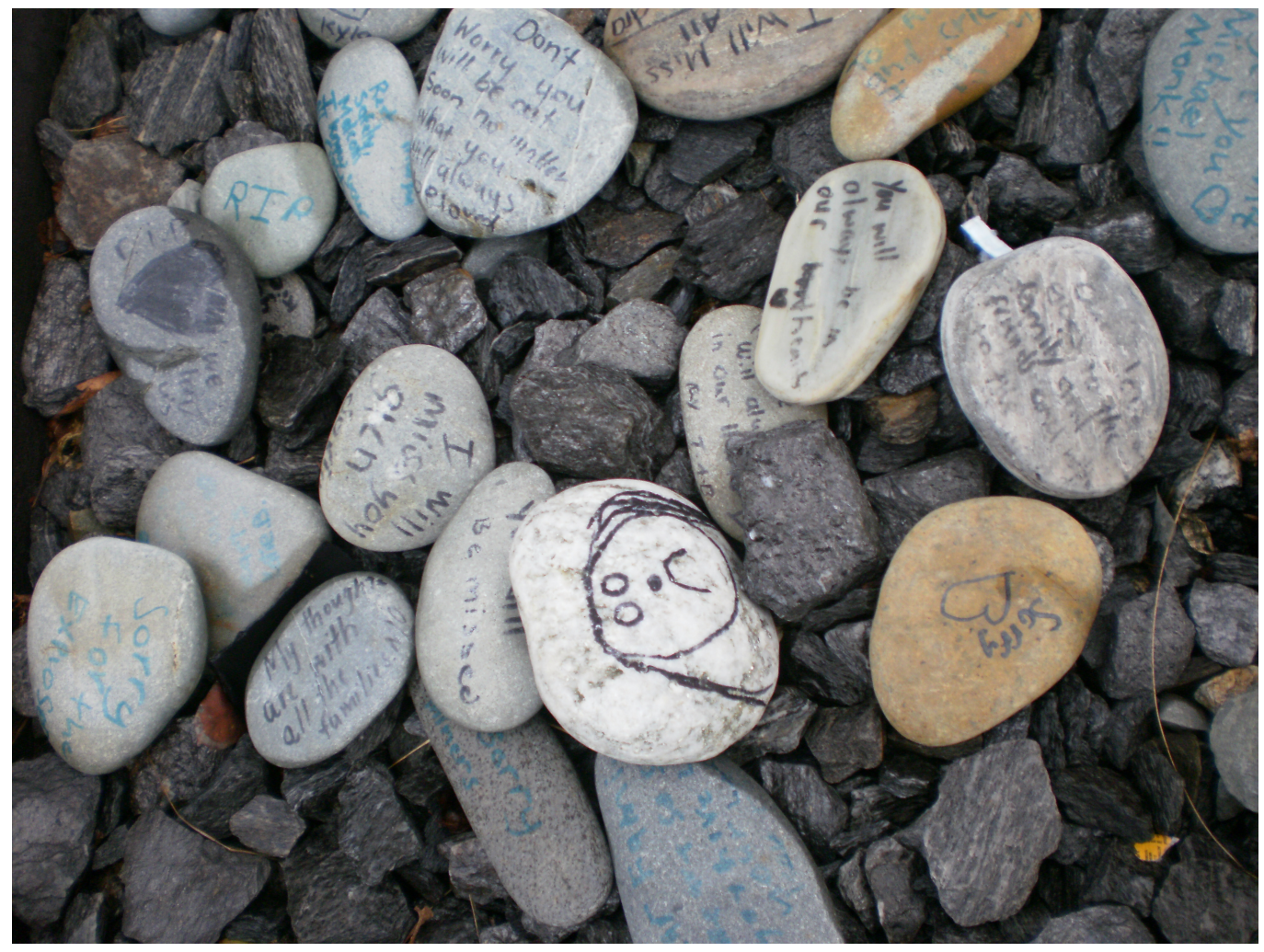


(20) Representative of Families, Bernie Monk July 2012

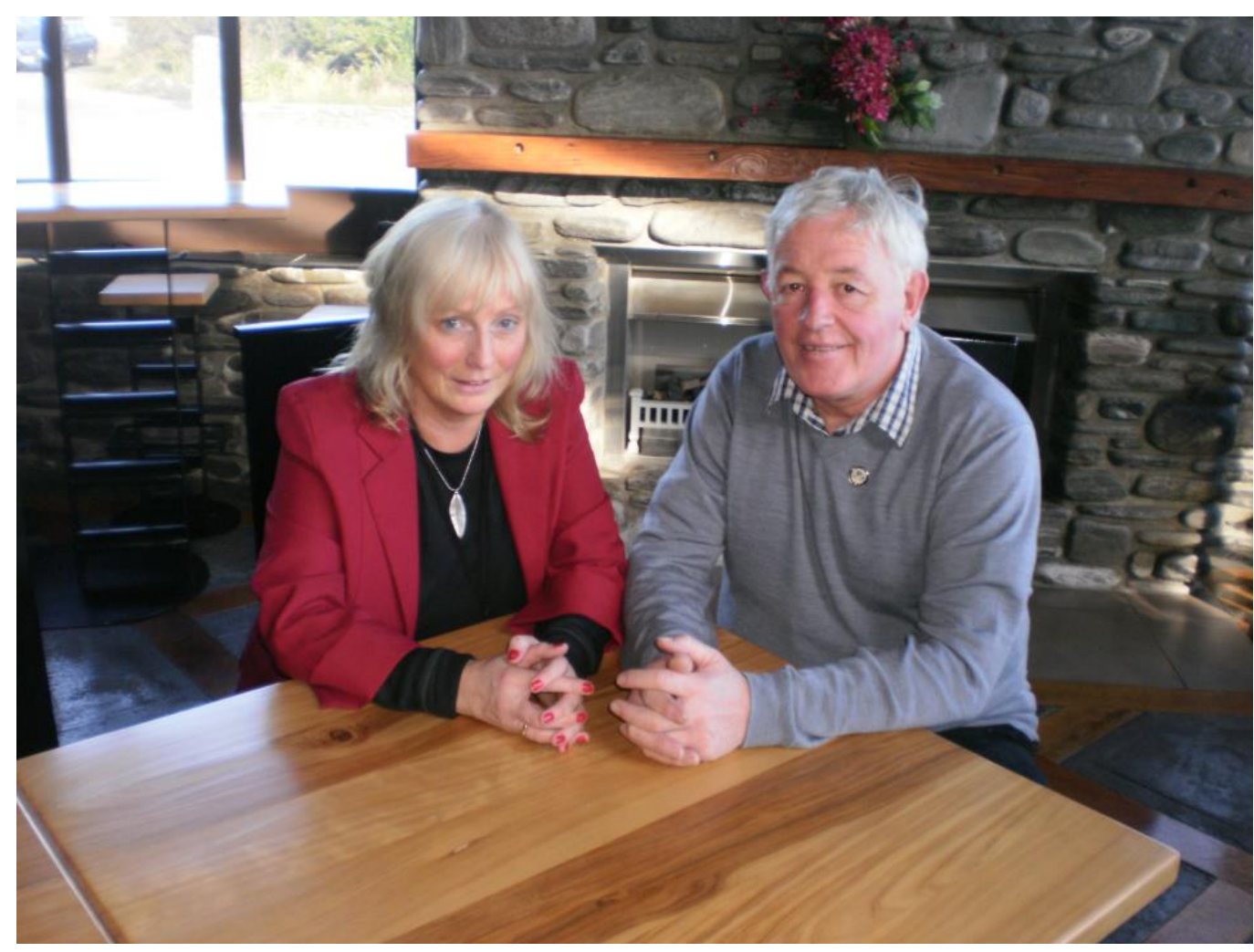

(21) Cobden Beach, after one of the last memorials, 2011

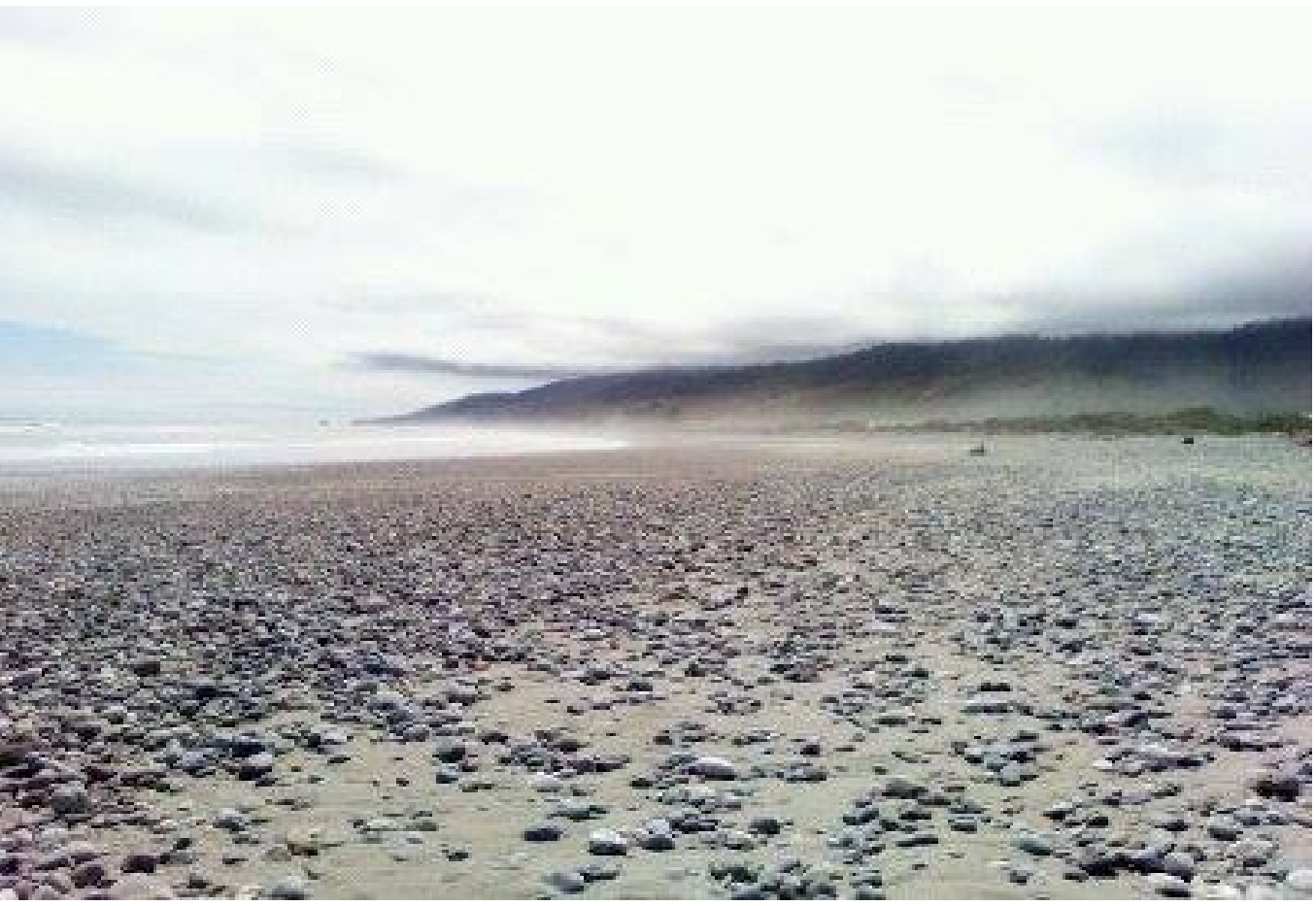


(22) I hold my candle high But mine is blown out. Stone Texts, Grey Main School

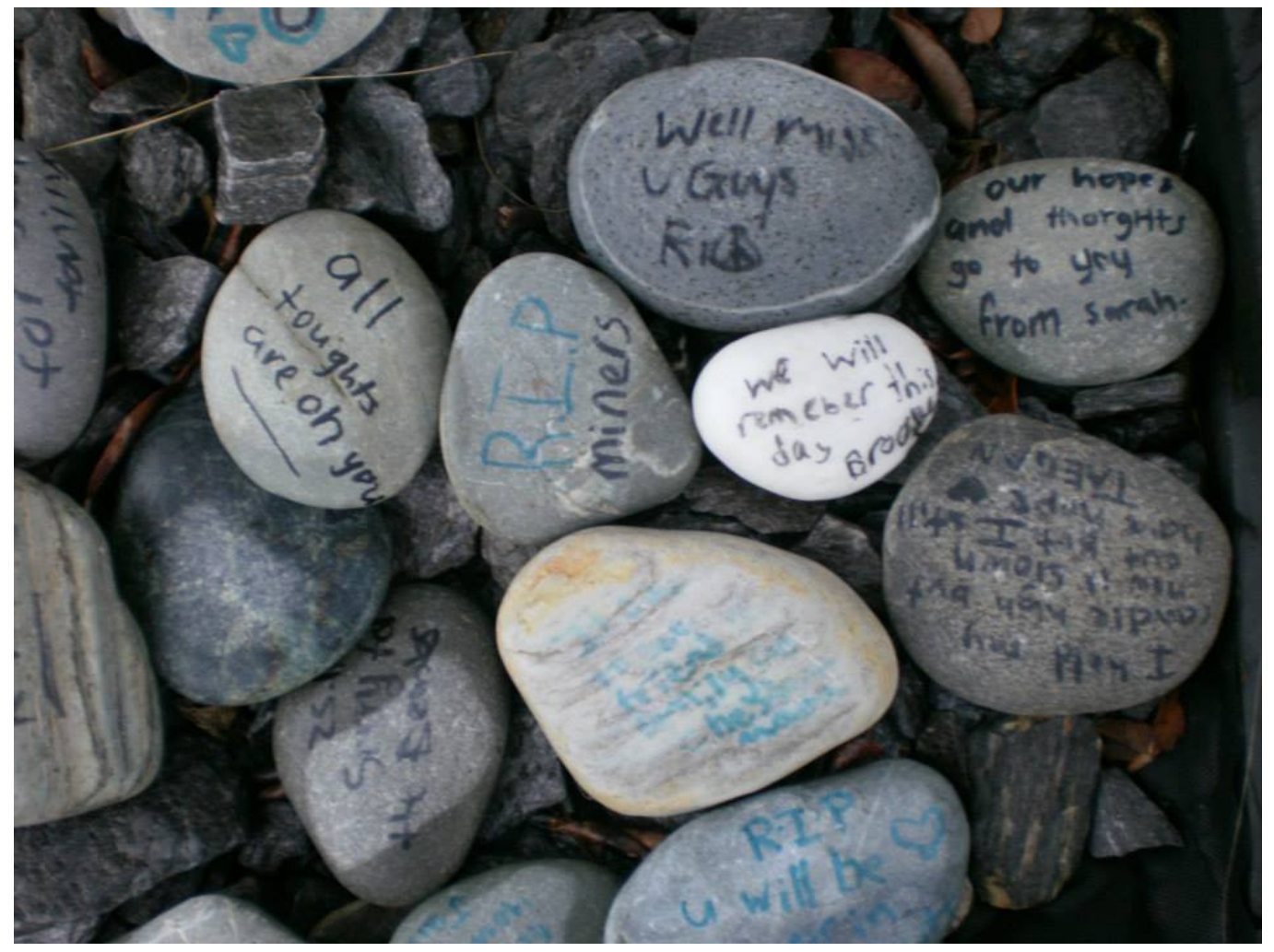

(23) Stalactites on the Road to Atarau, July 2012

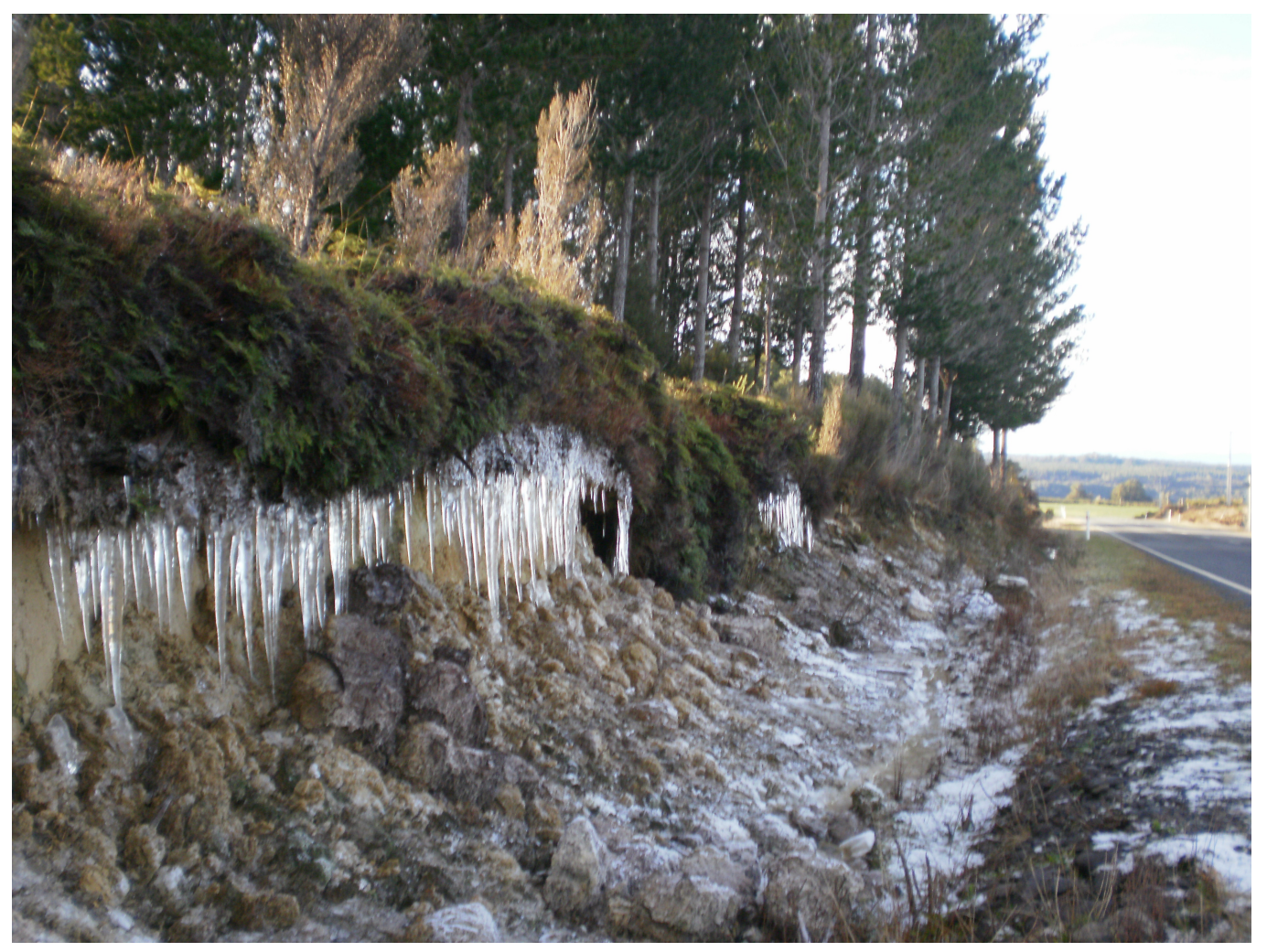


(24) Mayor, Tony Kokshoorn, July 2011

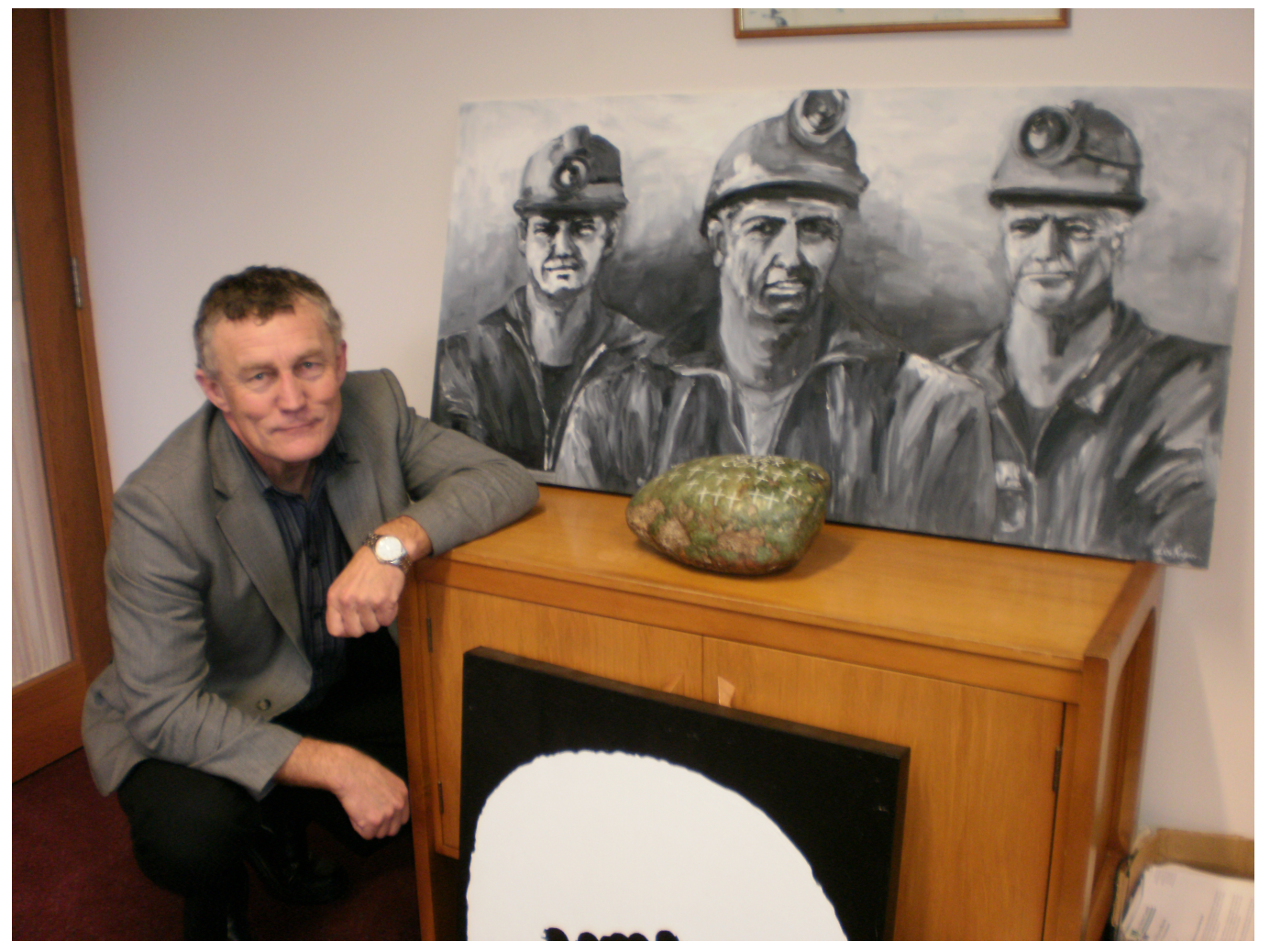

(25) Memorial Stone, 2010-2011

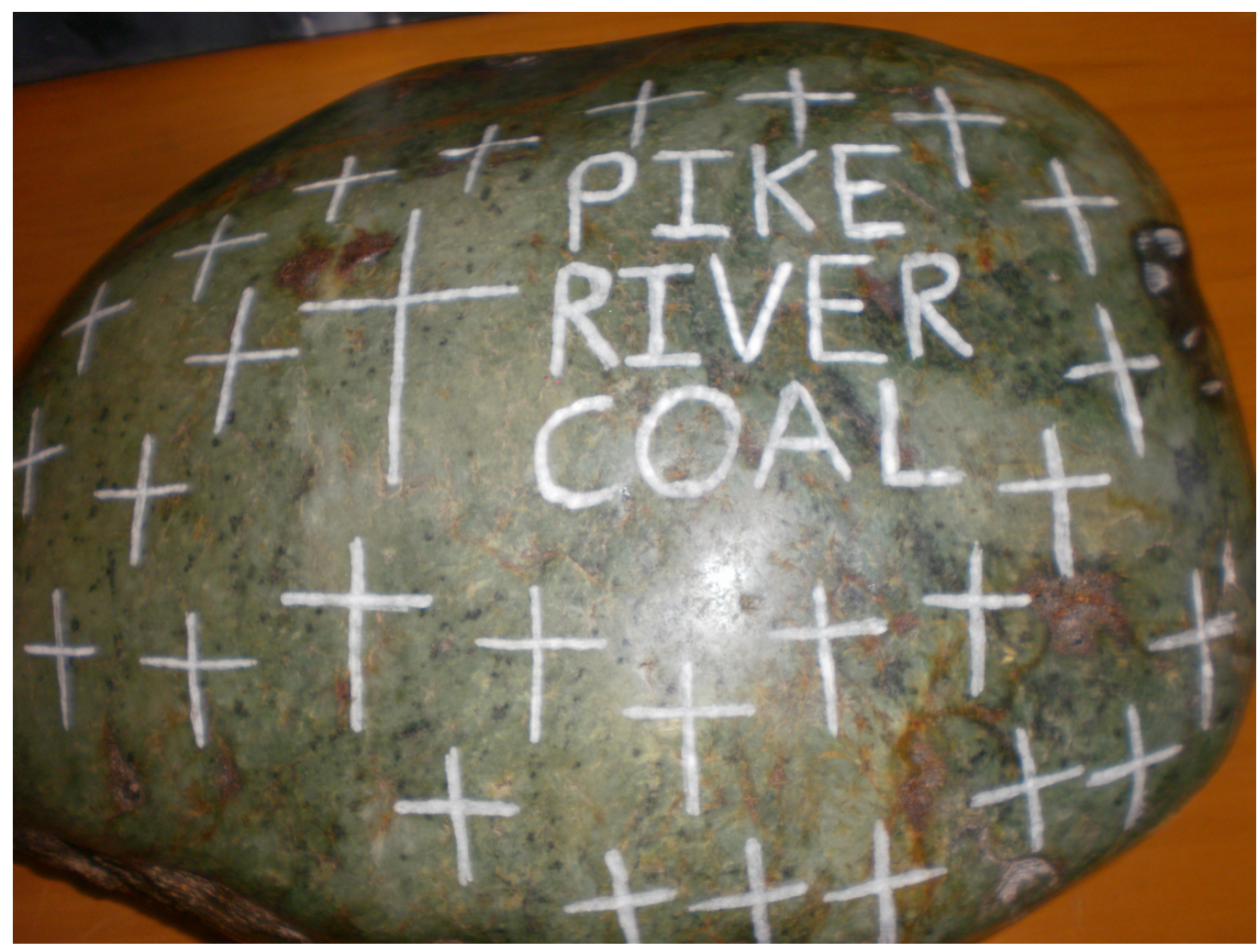


(26) Yellow Ribbon Memorial, July 2011

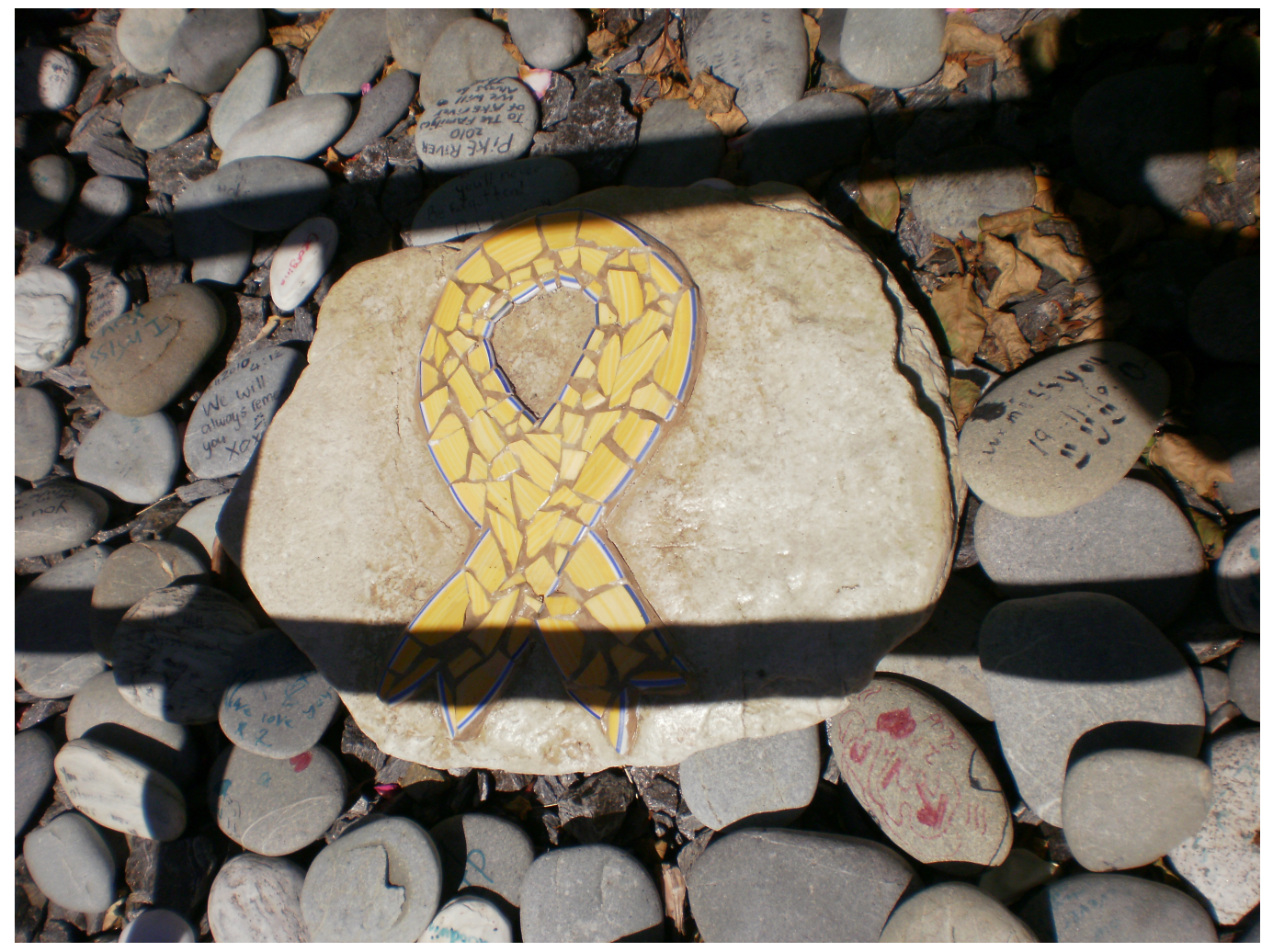

(27) Cobden Beach '29' in sand, 2011

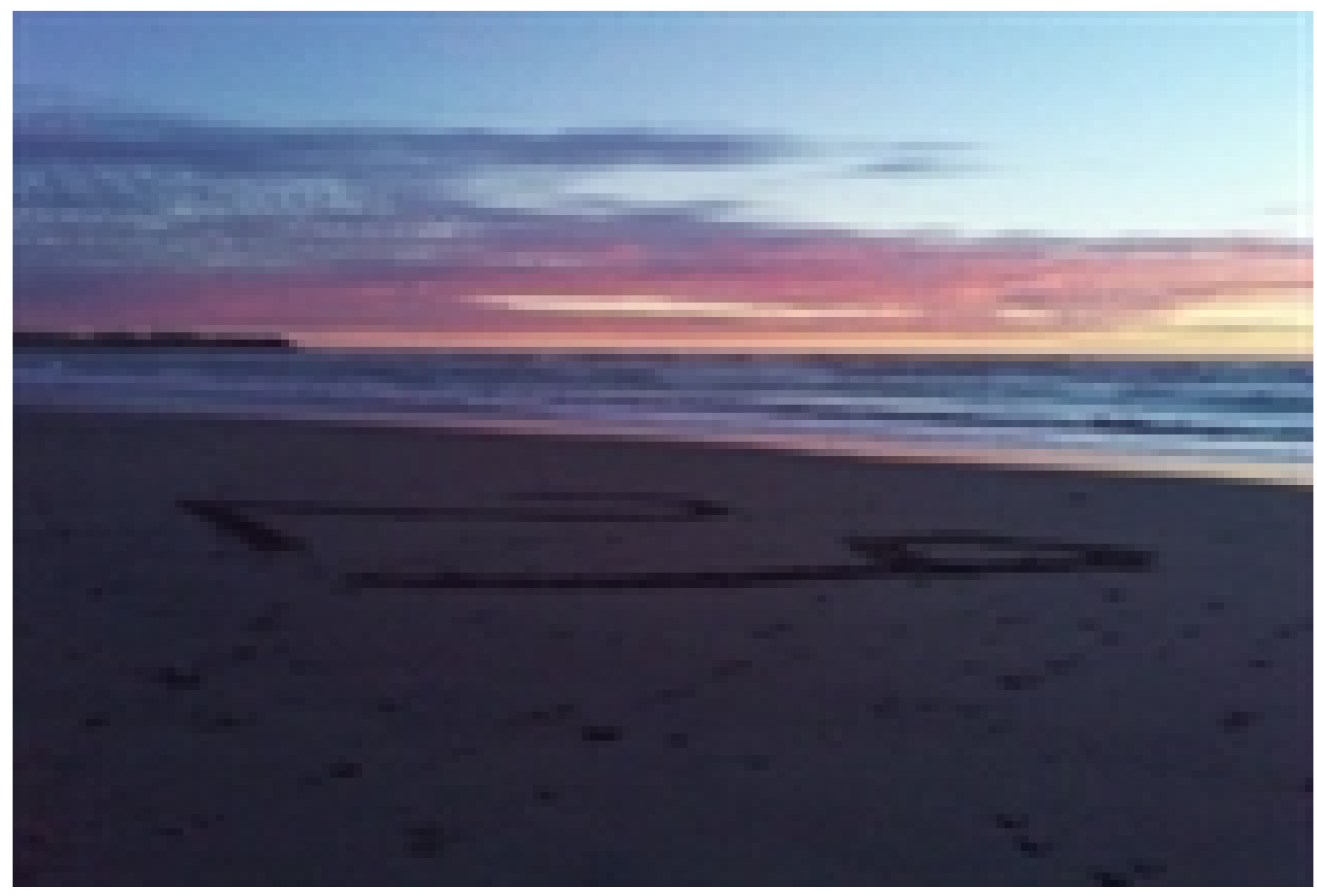


(28) Workers' Memorial Wheel, Blackball, West Coast

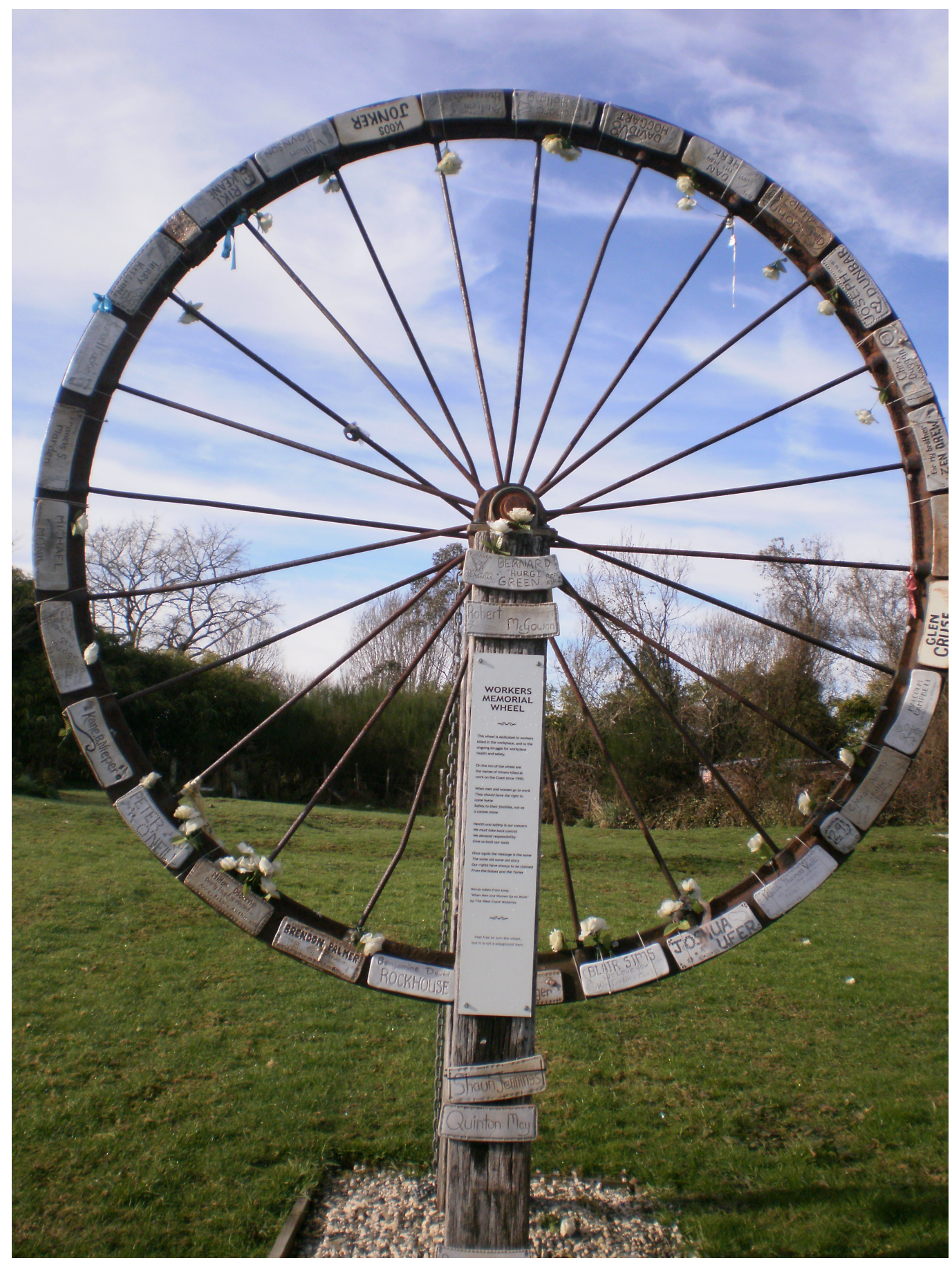


(29) 'On the rim of this wheel are the miners killed on the Coast since 1990.

This wheel is dedicated to workers killed in the workplace and to the ongoing struggle for workplace health and safety.

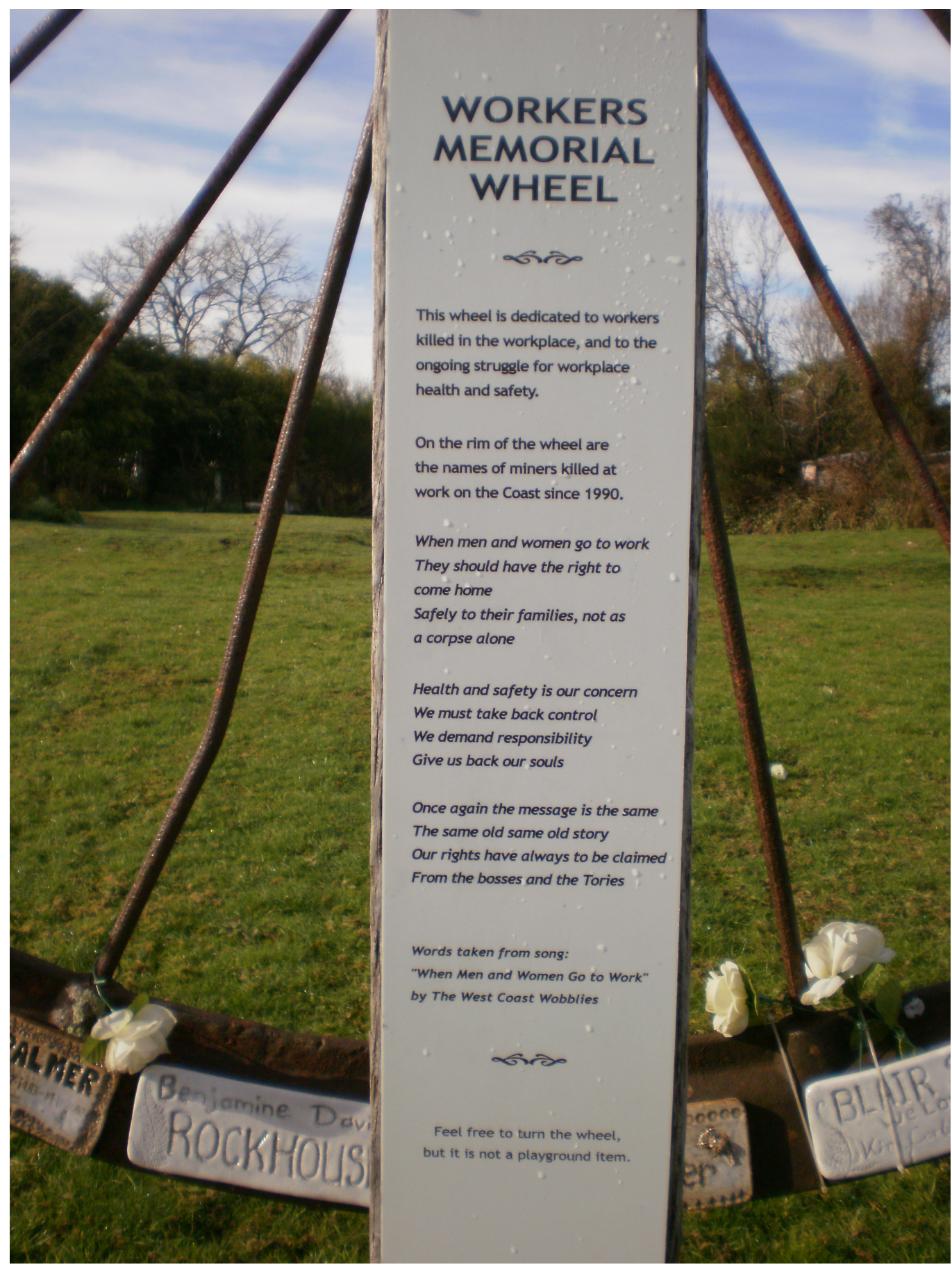


(30) Pike Memorial, Floodwall Greymouth and Names miners killed, past 100 years

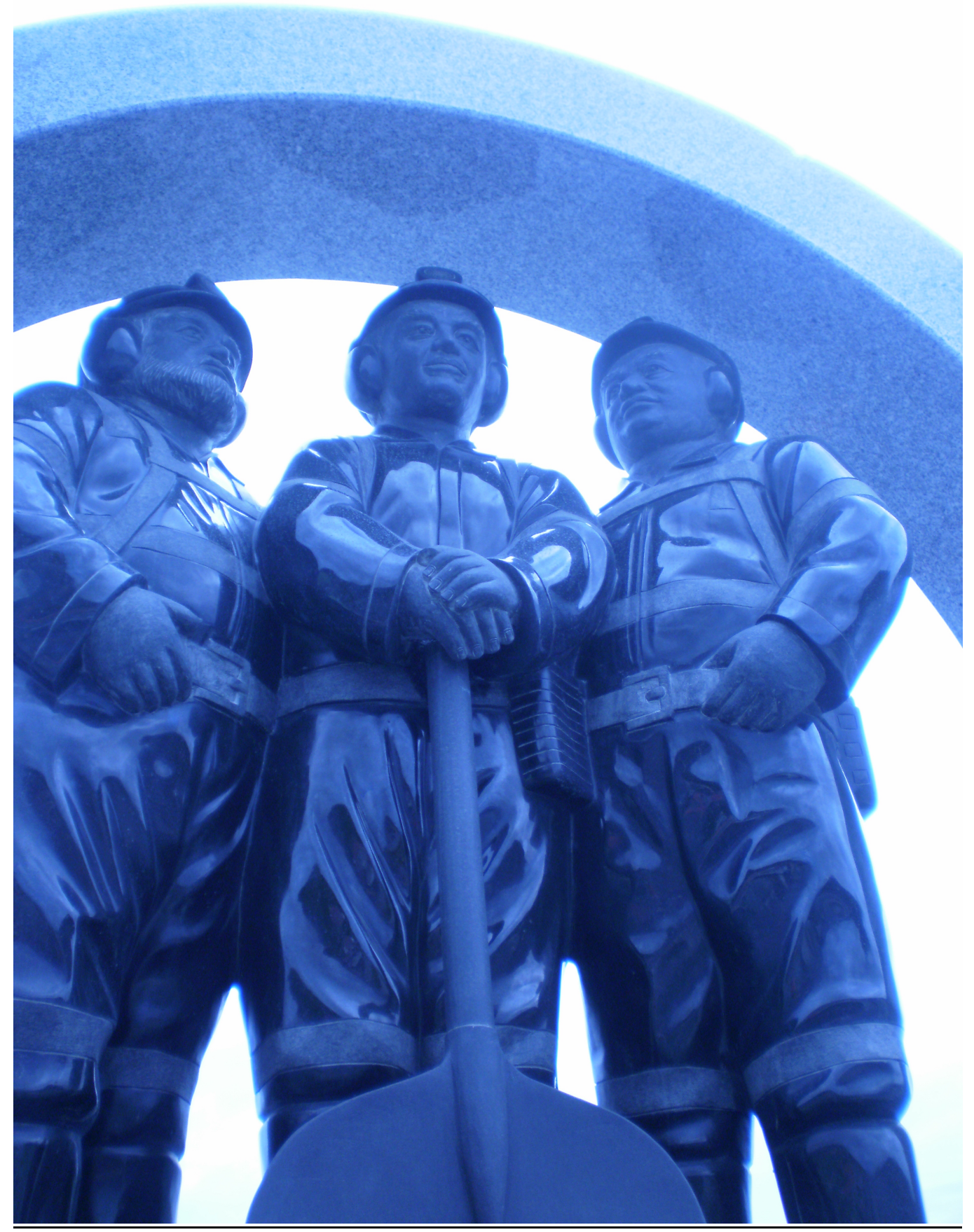


(31) Memorial '29 Links' 2010

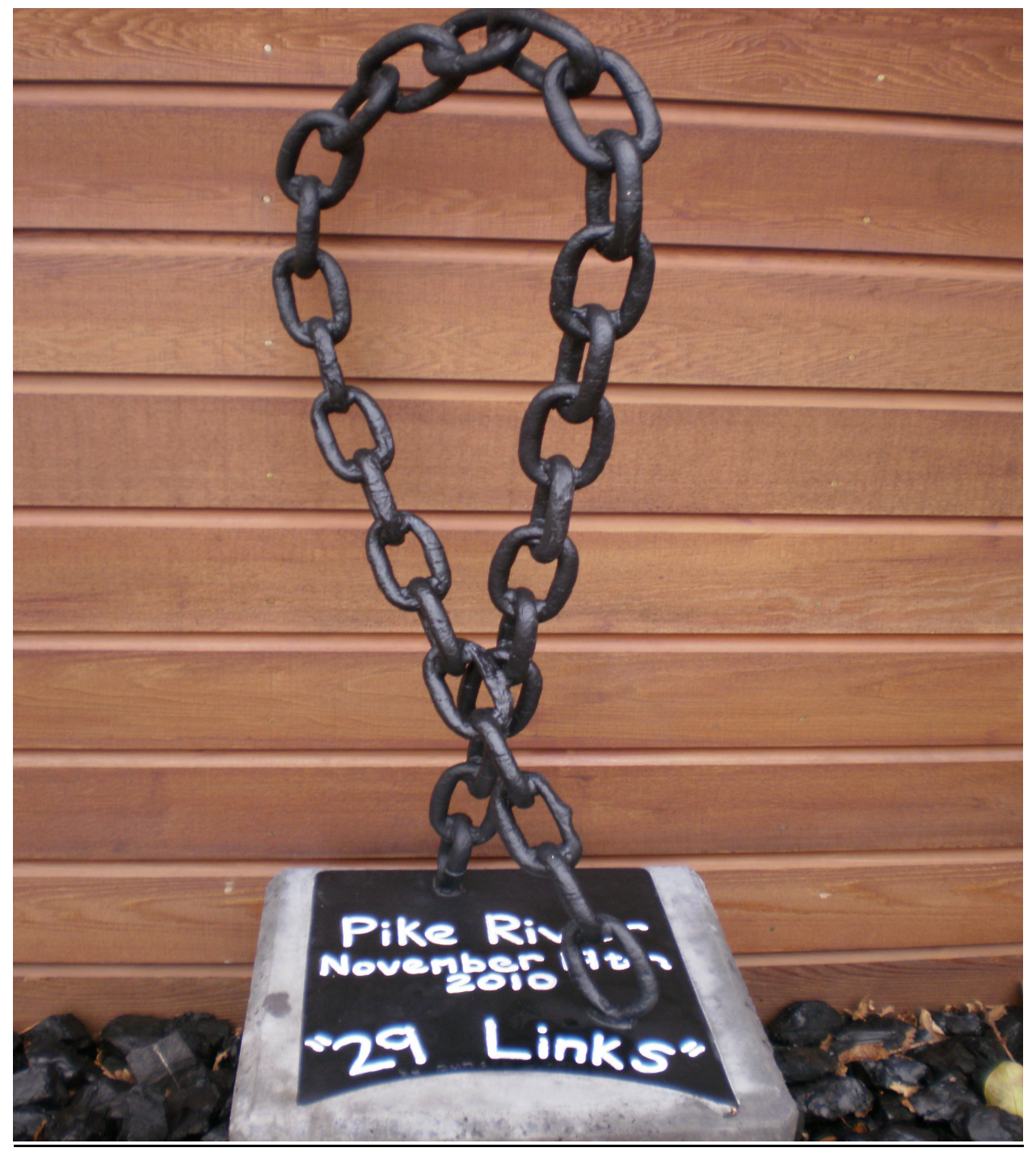

(32) Memorial carved by Richie Cornell of Levin, Kapiti 2011

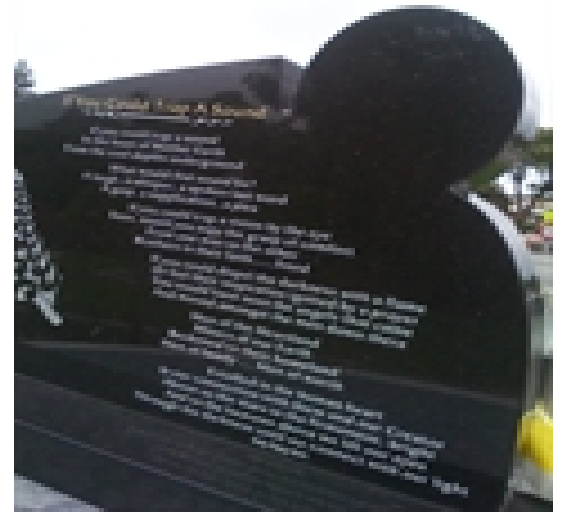


(33) Cobden Beach after one of the last Memorials, Oct 2011

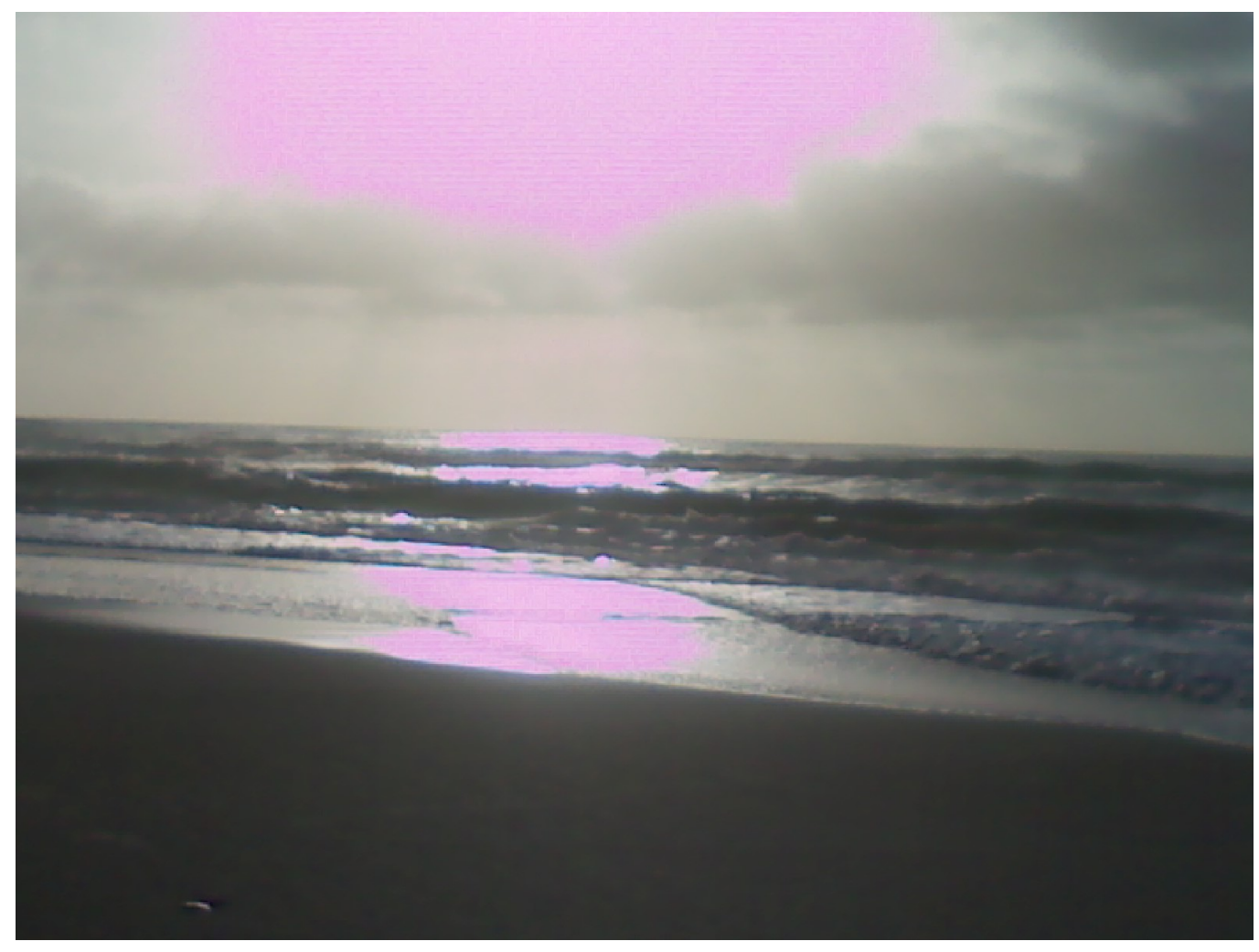

(34) Memorial over Cobden Beach for Glen Cruse and Kane Nieper who were surfers

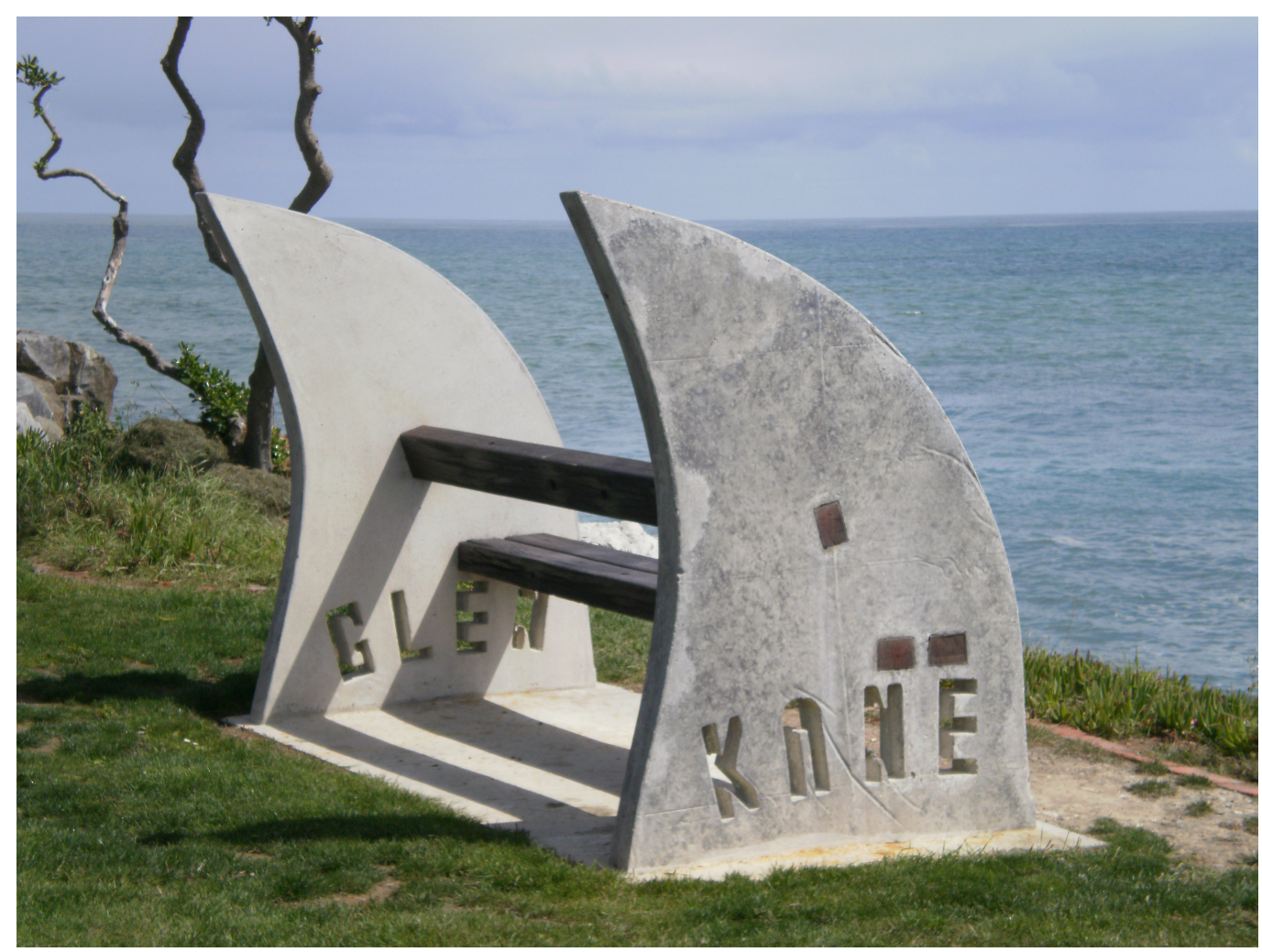


(35) Anna Osborne and Sonya Rockhouse, Wellington High Court, May 2015

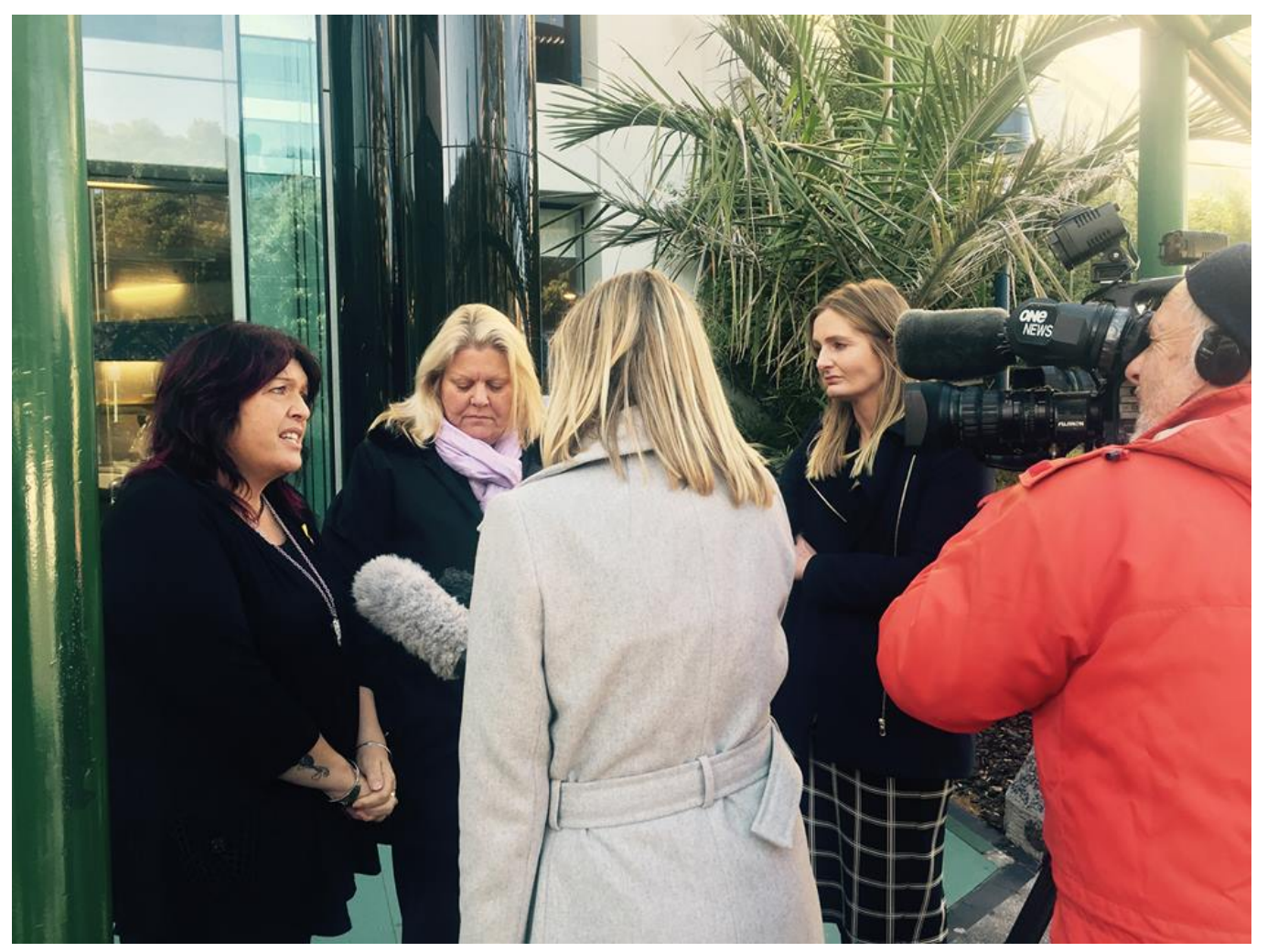

(36) Dean Dunbar at Parliament, December 2016; father of Joseph who died at Pike the day after his 17th birthday, on his first day at work at the mine

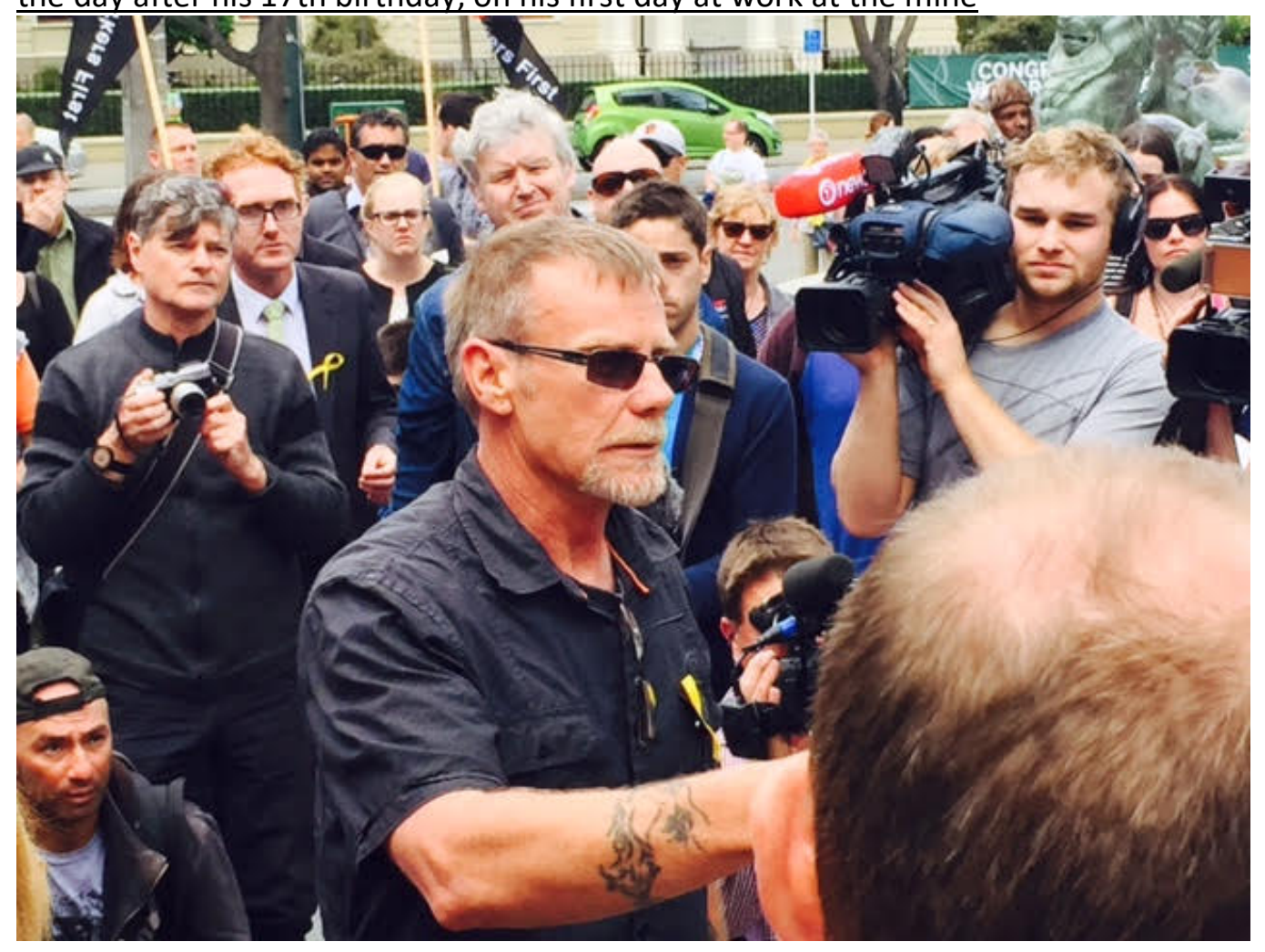


(37) Sonya Rockhouse, Anna Osborne at Parliament, December 2016

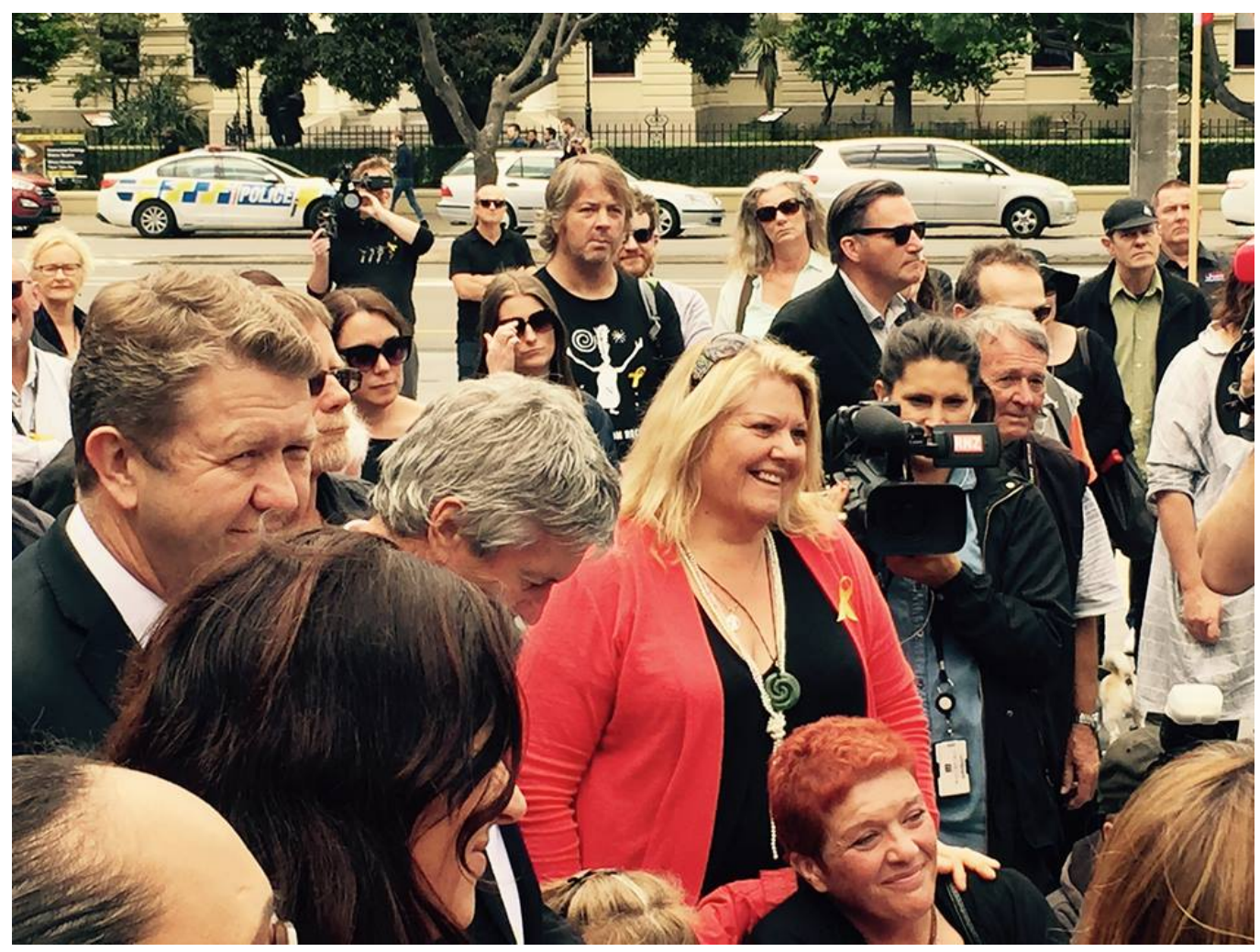

(38) Wellington High Court, May 2015, Rebecca MacFie, Helen Kelly, Kath Monk, Bernie Monk, Catriana Mulholland and lawyers

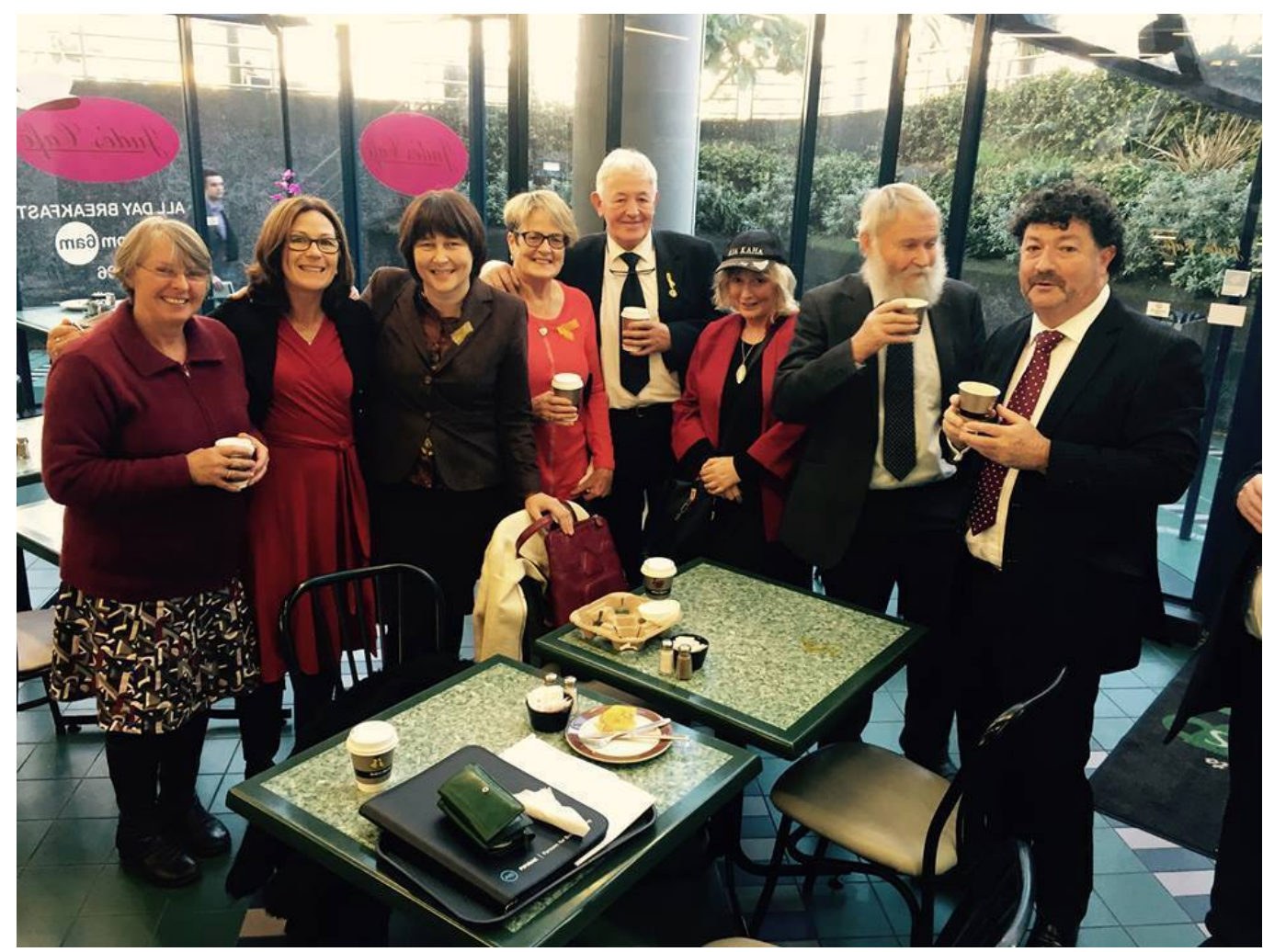


(39) Pike Mine Work Safe Play Safe Home Safe. 'Yeah Right' scrawled on far side

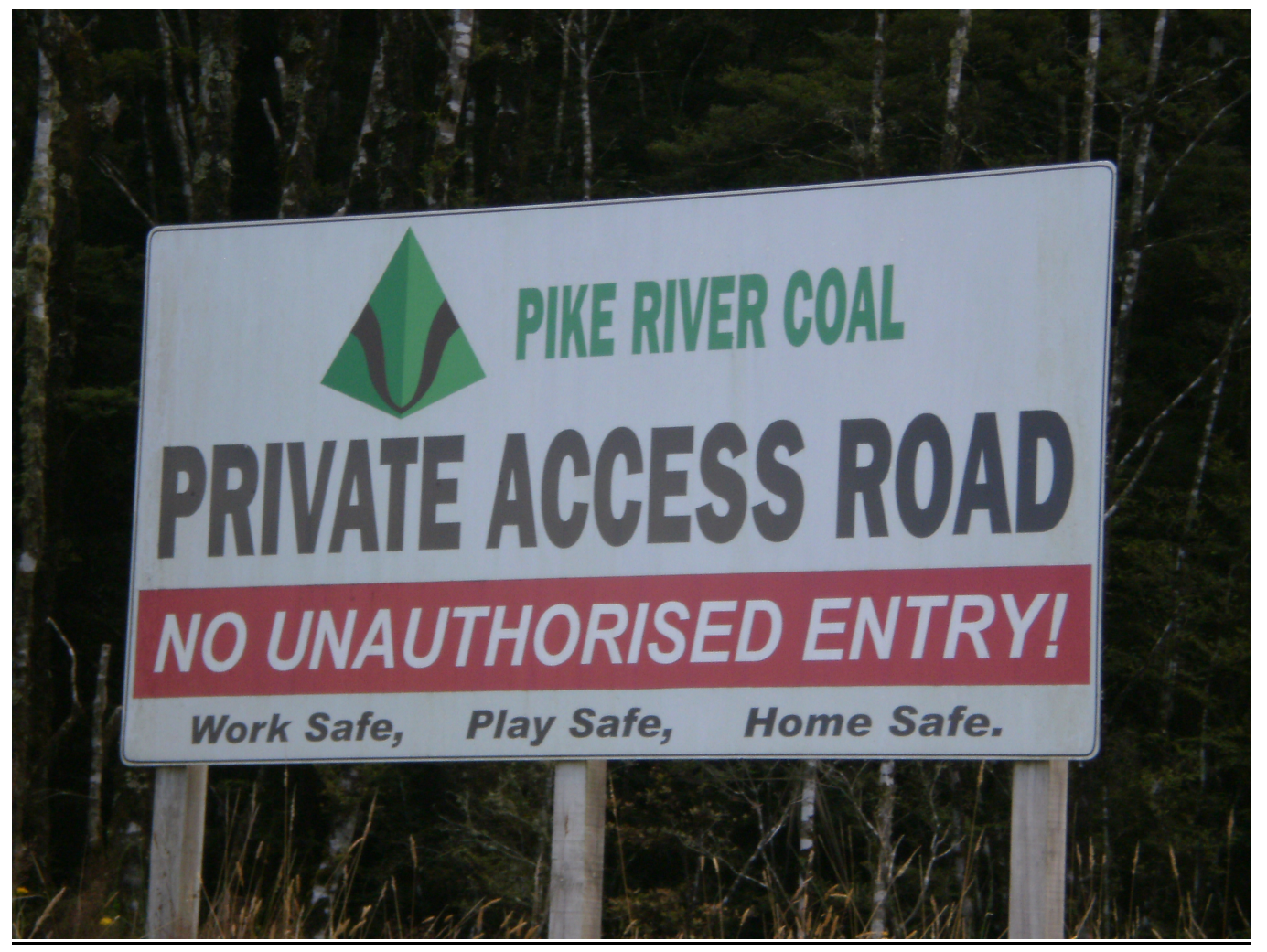

(40) Poem inside fence wire of Pike's Locked Gates. (W.H Auden)

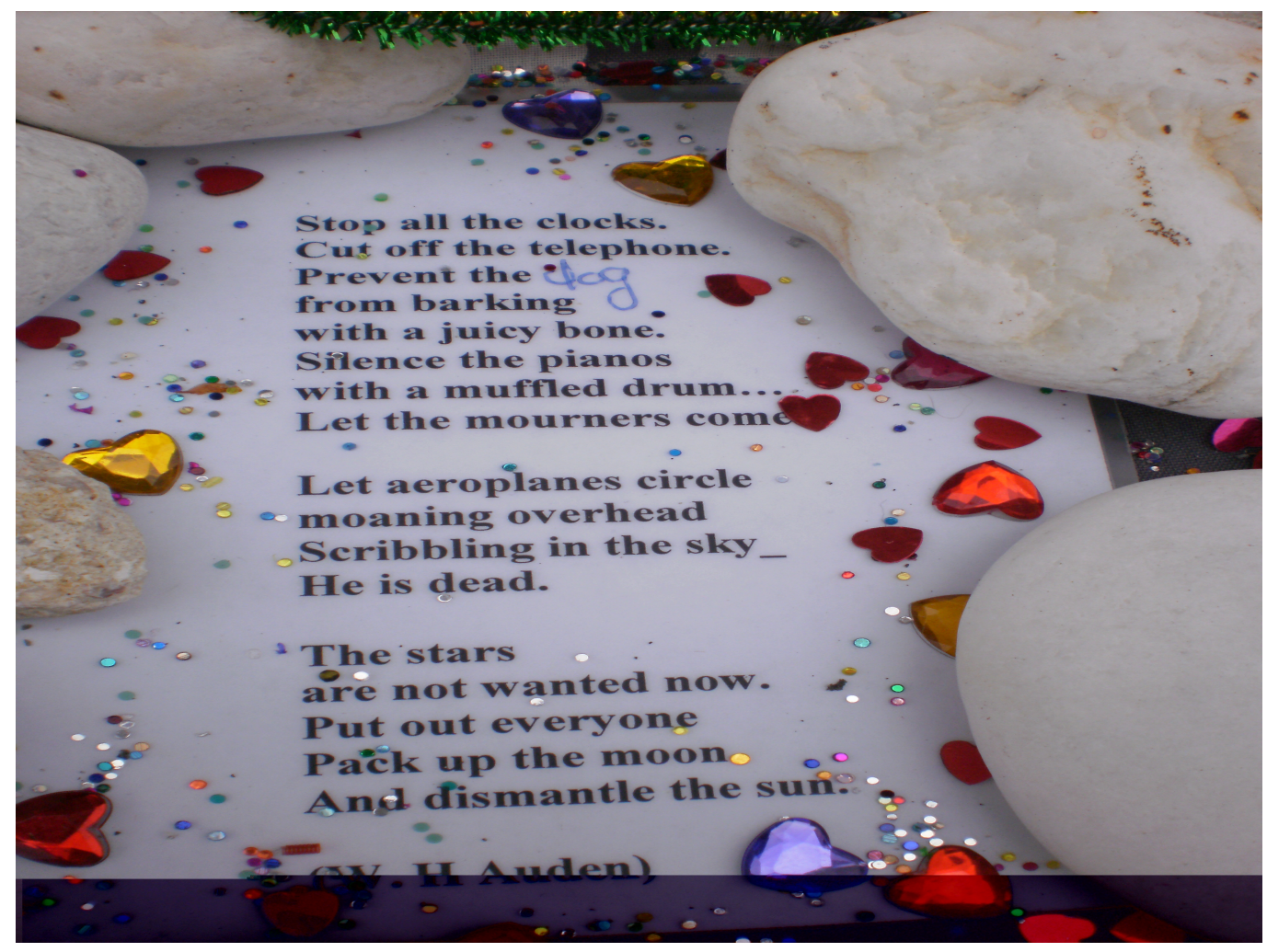




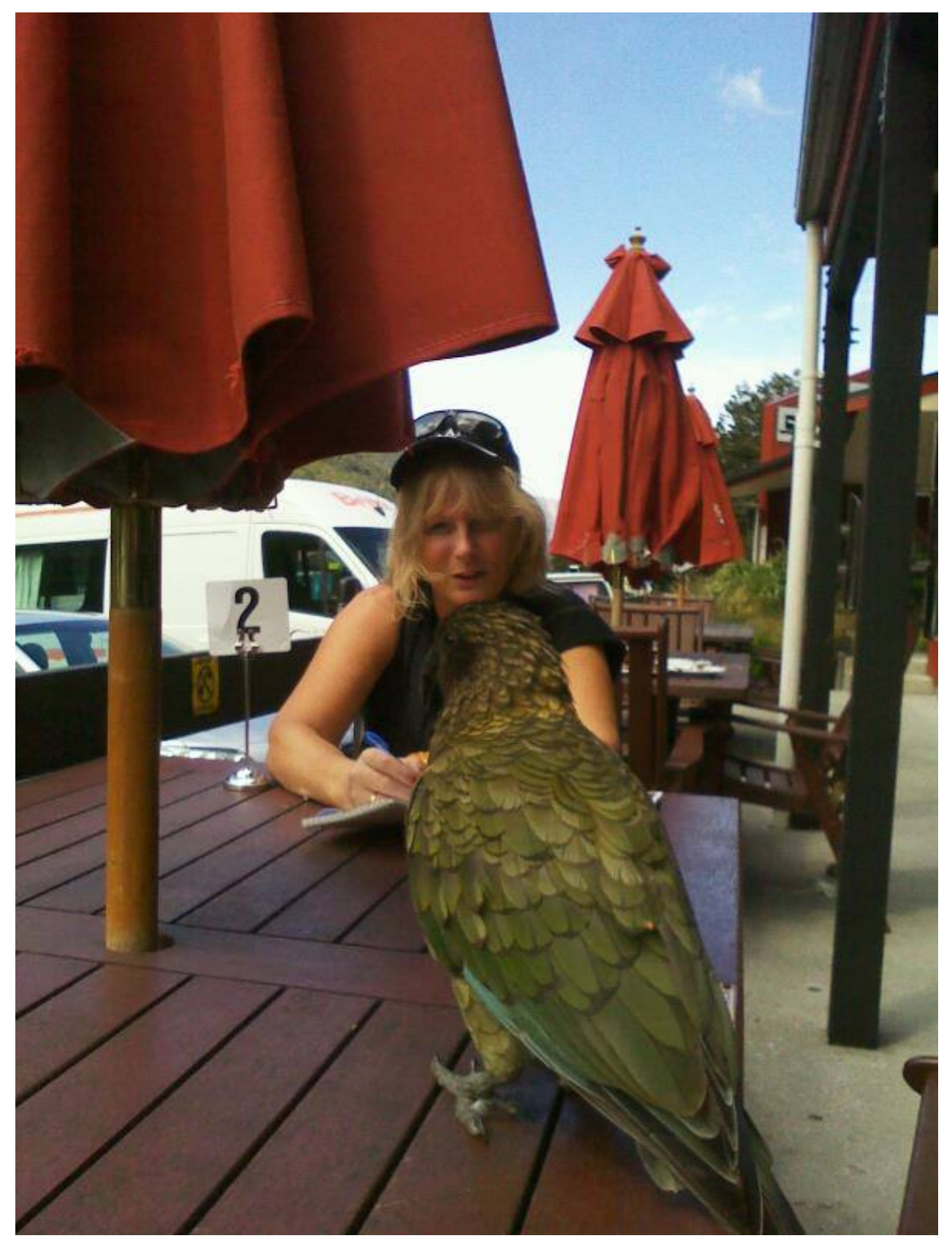

I still insist it will never be ok in New Zealand for 29 men go to work one day in November 2010, never to return home and to be left entombed in their workplace eight years later. That is not ok anywhere. I continued this work in hope that others might contribute their own voice and expertise in both challenging this and the high rate of workplace fatality in an Aotearoa context. I continue in memory of all of those who have died (and are still) dying in other NZ industries driven by deregulated production that favors profit ahead of safety.

$\mathcal{N} a k u$ te rourou nau te rourou ka ora ai te iwi 